CENTRO UNIVERSITÁRIO DA FEI

MAICON CAVALCANTE DE OLIVEIRA

IMPLEMENTAÇ̃̃O DO MODELO UNIFICADO DE COMPORTAMENTO MECÂNICO PARA A SIMULAÇÃO DO CREEP AGE FORMING.

São Bernardo do Campo 
MAICON CAVALCANTE DE OLIVEIRA

\section{IMPREMENTAÇÃO DO MODELO UNIFICADO DE COMPORTAMENTO MECÂNICO PARA A SIMULAÇÃO DO CREEP AGE FORMING}

Dissertação de Mestrado apresentada ao Centro Universitário FEI, como parte dos requisitos necessários para obtenção do título de Mestre em Engenharia Mecânica, orientado pelo Prof. Dr. Roberto Bortolussi.

São Bernardo do Campo 
Oliveira, Maicon Cavalcante de.

Implementação do modelo unificado de comportamento mecânico para a simulação do creep age forming / Maicon Cavalcante de Oliveira. São Bernardo do Campo, 2016.

129 f. : il.

Dissertação - Centro Universitário FEI.

Orientador: Prof. Dr. Roberto Bortolussi.

1. Conformação por fluência com envelhecimento. 2. Elementos finitos. 3. AA2124. 4. Retorno elástico. 5. Sub-rotina CRPLAW. I. Bortolussi, Roberto, orient. II. Título.

Elaborada pelo sistema de geração automática de ficha catalográfica da FEI com os dados fornecidos pelo(a) autor(a). 
Título do Trabalho: Implementação do modelo unificado de comportamento mecânico para a simulação do creep age forming.

Área de Concentração: Materiais e Processos

Orientador: Prof. Dr. Roberto Bortolussi

Data da realização da defesa: 22/04/2016

\section{MEMBROS DA BANCA EXAMINADORA}

Prof. Dr. Roberto Bortolussi

Prof. Dr. Sergio Delijaicov

Prof. Dr. Gilmar Ferreira Batalha
Ass. :

Ass.

Ass.:

A Banca Julgadora acima-assinada atribuiu ao aluno o seguinte resultado:
APROVADO $\bigotimes$
REPROVADO

\section{VERSÃO FINAL DA DISSERTAČ̃̃O}

APROVO A VERSÃO FINAL DA DISSERTAÇÃO EM QUE FORAM INCLUÍDAS AS RECOMENDAÇÕES DA BANCA

EXAMINADORA
Aprovação do Coordenador do Programa de Pós-graduação

Prof. Dr. Rodrigo Magnabosco 
Dedico a todos que me apoiaram no desenvolvimento deste trabalho. 


\section{AGRADECIMENTOS}

Agradeço ao apoio e compreensão dos meus pais em meus estudos.

Ao meu orientador Prof. Dr. Roberto Bortolussi pela oportunidade concedida e pelo incentivo para entrar no programa de Mestrado, que me proporcionou novos conhecimentos durante o desenvolvimento da dissertação e também durante as aulas disponibilizadas no programa. 
"Se deres um peixe a um homem faminto, vais alimentá-lo por um dia. Se o ensinares a pescar, vais alimentá-lo toda a vida."

Lao-Tsé 


\section{RESUMO}

A conformação por fluência com envelhecimento (CFE) foi desenvolvida para atender as novas demandas do mercado aeronáutico, tornando o produto mais competitivo por causar redução nos custos de fabricação e principalmente por gerar um componente com baixa tensão residual. O processo ocorre em ligas de alumínio com a combinação dos processos de conformação e tratamento térmico, em que o tempo da conformação por fluência com envelhecimento é determinado para o material atingir as propriedades mecânicas desejadas. No início da conformação é imposta uma deformação de caráter elástica, que é reduzida durante o processo devido ao aumento da deformação por fluência e ao relaxamento de tensão. No final do processo ao retirar a carga aplicada no componente acontece o retorno elástico devido à parcela de deformação elástica remanescente. $\mathrm{O}$ método dos elementos finitos tem sido aplicado no estudo da conformação por fluência com envelhecimento, principalmente para prever o retorno elástico. Contudo para realizar a simulação é necessário definir no programa de elementos finitos o modelo de comportamento mecânico do material durante a conformação. Sendo assim, este trabalho visa implementar um modelo de comportamento mecânico da conformação por fluência com envelhecimento, através de uma sub-rotina inserida no programa MSC. Marc ${ }^{\circledR}$. As simulações foram realizadas em matrizes com uma curvatura e de dupla curvatura, e o material do blank foi a liga AA2124. Nas simulações observou-se a relaxação de tensão, deformação por fluência, tensões principais e o retorno elástico. Comparando os resultados experimentais da deformação por fluência publicados por Zhang et al. (2013) e os resultados computacionais, foi observado que o modelo da conformação por fluência com envelhecimento não apresentou um bom ajuste. $\mathrm{O}$ retorno elástico determinado para as duas geometrias foi elevado e teve influência dos dados de entrada do modelo da CFE na sub-rotina. A partir dos resultados, conclui-se que a subrotina realizou corretamente a simulação da conformação por fluência com envelhecimento e pode ser aplicada no estudo da conformação.

Palavras-chave: Conformação por fluência com envelhecimento. Elementos finitos. AA2124. Retorno elástico. Sub-rotina CRPLAW. 


\begin{abstract}
The creep age forming (CAF) was developed to meet the new aerospace market demands in order to make the product more competitive, with reducing manufacturing costs and mainly by producing a component with low residual stress. The process takes place with the combination of forming and heat treatment, in which the time of creep age forming is determined for the material to achieve the mechanical properties required. The first stage of forming is established an elastic deformation which is reduced during the process due to creep and stress relaxation. At the end of the process, when the load is released, the springback takes place due to remaining elastic deformation. The finite element method has been applied to study the creep age forming and mainly to predict the springback. However, to accomplish the simulation it is necessary to set the material mechanical behavior model in the finite element software. This work aims to implement a creep age forming model, through the subroutine introduced into the MSC. Marc ${ }^{\circledR}$ software. The simulations were accomplished in dies with single and double curvature and the blank's material was the alloy AA2124. In the simulations were observed the stress relaxation, creep and the springback. Comparing the creep experimental results published by Zhang et al. (2013) and the computational results from the creep age forming model, it was observed that the model did not show a good fit. The two sheets had high levels of springback and these results had influence of the input data from the CAF model in the subroutine. Based on the results, it was concluded that the subroutine accomplished correctly the creep age forming simulation and the subroutine can be used in the study of the creep age forming.
\end{abstract}

Keywords: Creep age forming. Finite elements. AA2124. Springback. CRPLAW subroutine. 


\section{LISTA DE SÍMBOLOS}

\begin{tabular}{|c|c|c|}
\hline$A_{1}$ & $\begin{array}{l}\text { Constante do material relacionada à taxa da deformação por } \\
\text { fluência }\end{array}$ & $\mathrm{h}^{-1}$ \\
\hline $\mathrm{A}_{2}$ & Constante do material relacionada à taxa de encruamento & $\mathrm{MPa}$ \\
\hline $\mathrm{A}_{3}$ & $\begin{array}{l}\text { Constante do material relacionada à taxa da densidade de } \\
\text { discordâncias }\end{array}$ & \\
\hline $\mathrm{A}_{\mathrm{mp}}$ & Constante do material & \\
\hline A & Constante do material relacionada à taxa de deformação & $h^{-1}$ \\
\hline $\mathrm{B}$ & Constante do material relacionada à taxa de deformação & \\
\hline $\mathrm{B}_{1}$ & $\begin{array}{l}\text { Constante do material relacionada à taxa da deformação por } \\
\text { fluência }\end{array}$ & $\mathrm{MPa}^{-1}$ \\
\hline $\mathrm{B}_{\mathrm{mp}}$ & Constante do material & \\
\hline $\mathrm{C}_{\text {ss }}^{\prime}$ & Constante do material relacionada à solução sólida & $\mathrm{MPa}$ \\
\hline $\mathrm{C}_{\mathrm{A}}$ & Constante do material relacionada ao envelhecimento & $\mathrm{MPa}$ \\
\hline $\mathrm{C}_{\mathrm{dis}}$ & $\begin{array}{l}\text { Constantes do material relacionadas à tensão referente ao } \\
\text { encruamento }\end{array}$ & $\mathrm{MPa}$ \\
\hline $\mathrm{C}_{\mathrm{p}}$ & $\begin{array}{l}\text { Constante do material relacionada à taxa da densidade de } \\
\text { discordâncias }\end{array}$ & $\mathrm{h}^{-1}$ \\
\hline $\mathrm{C}_{\mathrm{r}}$ & Constante do material relacionada ao crescimento do precipitado & $\mathrm{h}^{-1}$ \\
\hline $\mathrm{C} 1, \mathrm{n} 1, \mathrm{~m} 1$ & $\begin{array}{l}\text { Constantes do material relacionadas à taxa de fração volumétrica } \\
\text { de precipitados normalizada }\end{array}$ & \\
\hline C3 e Q3 & $\begin{array}{l}\text { Constantes do material relacionadas à taxa de densidade de } \\
\text { discordâncias móveis normalizada }\end{array}$ & \\
\hline $\mathrm{C} 4$ & Constantes do material relacionadas a relação de aspecto & \\
\hline Cppt, n4 e n5 & $\begin{array}{l}\text { Constantes do material relacionadas à tensão referente à } \\
\text { precipitação }\end{array}$ & \\
\hline Css & Constantes do material relacionadas à solução sólida & $\mathrm{MPa}$ \\
\hline $\mathrm{E}$ & Módulo de elasticidade & $\mathrm{GPa}$ \\
\hline$\overline{\mathrm{f}}_{\mathrm{v}}$ & Fração volumétrica de precipitados normalizada & \\
\hline$\dot{\overline{\mathrm{f}}}_{\mathrm{v}}$ & Taxa de fração volumétrica de precipitados normalizada & \\
\hline $\mathrm{h}$ & Passo de integração & $\mathrm{h}$ \\
\hline $\mathrm{K}$ & Constante do material & $\mathrm{h}^{-1}$ \\
\hline
\end{tabular}




\begin{tabular}{|c|c|c|}
\hline $\mathrm{k}_{0}$ & $\begin{array}{l}\text { Constante do material relacionada à taxa da deformação por } \\
\text { fluência }\end{array}$ & \\
\hline $\mathrm{k}_{\mathrm{mp}}$ & Constante do material & $\mathrm{h}^{-1}$ \\
\hline $\mathrm{k} 2$ & Constantes do material relacionadas a relação de aspecto & $\mathrm{K}^{-2}$ \\
\hline $\mathrm{k} 3$ & Constantes do material relacionadas a relação de aspecto & $\mathrm{h}^{-2}$ \\
\hline $\mathrm{k} 1$ e n3 & $\begin{array}{l}\text { Constantes do material controlando o aumento da densidade de } \\
\text { discordâncias devido à fluência }\end{array}$ & \\
\hline 1 & Tamanho característico do precipitado & $\mathrm{nm}$ \\
\hline i & Taxa de crescimento do tamanho característico do precipitado & $\mathrm{nm} \cdot \mathrm{h}^{-1}$ \\
\hline $\mathrm{m}_{1}^{\prime}$ & Constante do material relacionada ao envelhecimento & \\
\hline $\mathrm{m}^{\prime}{ }_{2}$ & Constante do material relacionada à solução sólida & \\
\hline $\mathrm{m}_{3}^{\prime}$ & $\begin{array}{l}\text { Constante do material relacionada a taxa de crescimento do } \\
\text { precipitado }\end{array}$ & \\
\hline $\mathrm{m} 3$ & Constante do material relacionada à solução sólida & \\
\hline $\mathrm{m}_{4}$ & $\begin{array}{l}\text { Constante do material controlando o efeito da densidade de } \\
\text { discordâncias na nucleação e no crescimento do precipitado }\end{array}$ & \\
\hline $\mathrm{m}_{5}$ & $\begin{array}{l}\text { Constante do material relacionada à taxa da densidade de } \\
\text { discordâncias }\end{array}$ & \\
\hline $\mathrm{m} 2$ e $\mathrm{C} 2$ & $\begin{array}{l}\text { Constantes do material relacionadas à taxa de crescimento do } \\
\text { tamanho característico do precipitado }\end{array}$ & \\
\hline $\mathrm{n}$ & Constante do material relacionada à taxa de deformação & \\
\hline $\mathrm{n}_{\text {norton }}$ & Expoente de tensão para fluência & \\
\hline $\mathrm{n}^{\prime}$ & Constante do material relacionada à taxa de encruamento & \\
\hline $\mathrm{n} 2$ & Parâmetro relacionado com a forma do precipitado & \\
\hline $\mathrm{N}_{1}, \mathrm{~N}_{2}, \mathrm{~N}_{3}$ & Constantes do material & \\
\hline q & Relação de aspecto & \\
\hline Q & Energia de ativação relacionada à taxa de deformação & $\mathrm{kJ} \cdot \mathrm{mol}^{-}$ \\
\hline$Q^{\prime}$ & $\begin{array}{l}\text { Constante do material representando o limite de saturação para a } \\
\text { depleção de soluto dentro da matriz }\end{array}$ & \\
\hline Q1 & $\begin{array}{l}\text { Constante do material relacionada à taxa de crescimento do } \\
\text { tamanho característico do precipitado }\end{array}$ & $\mathrm{nm}$ \\
\hline Q2 & Energia de ativação relacionada ao crescimento dos precipitados & $\mathrm{kJ} \cdot \mathrm{mol}^{-}$ \\
\hline & Registrado & \\
\hline
\end{tabular}


Raio do precipitado normalizado

Taxa de crescimento do raio do precipitado normalizado

Tempo

Temperatura

K

Temperatura na máxima relação de aspecto

K

Tempo na máxima relação de aspecto

Variável dependente da microestrutura

Vetor de carregamentos

Vetor de deslocamentos

$\mathrm{mm}$

Vetor dos deslocamentos incrementais

$\mathrm{mm}$

\section{Letras Gregas}

[B]

$\alpha_{1}$

$\alpha_{2}$

$\alpha_{3}$

$\dot{\varepsilon}_{\mathrm{c}}$

$\varepsilon_{\mathrm{c}}$

$\dot{\varepsilon}_{\mathrm{e}}^{\mathrm{c}}$

$\dot{\varepsilon}_{\mathrm{ij}}^{\mathrm{c}}$

$\Delta \varepsilon$

$\Delta \varepsilon^{\mathrm{c}}$

$\Delta \sigma$

$\sigma$

$\sigma_{\mathrm{A}}$

$\dot{\sigma}_{\mathrm{A}}$

$\dot{\sigma}_{\text {SS }}$

$\dot{\sigma}_{\text {dis }}$
Matriz de transformação de deslocamentos para deformação

Constantes do material

Constantes do material

Constantes do material

Taxa de deformação por fluência

Deformação por fluência

Taxa de deformação por fluência efetiva

Tensor da taxa de deformação por fluência

Deformação total incremental

Deformação por fluência incremental

Tensão incremental

Tensão aplicada

Tensão referente à precipitação

Taxa da tensão referente à precipitação

Taxa da tensão referente à solução sólida

Taxa da tensão referente ao encruamento
$\mathrm{MPa}$

$\mathrm{MPa}$

$\mathrm{MPa}$

MPa.h ${ }^{-1}$

$\mathrm{mm}^{-1}$

$\mathrm{MPa}^{-\mathrm{N} 1}$

$\mathrm{MPa}^{-\mathrm{N} 2} \cdot \mathrm{h}^{-1}$

$\mathrm{MPa}^{-\mathrm{N} 3} \cdot \mathrm{h}^{-1}$

$\mathrm{h}^{-1}$

$\mathrm{h}^{-1}$

$\mathrm{h}^{-1}$

MPa.h ${ }^{-1}$

$\mathrm{MPa}^{-1}$ 


$\begin{array}{llc}\sigma_{\mathrm{y}} & \text { Tensão de escoamento } & \mathrm{MPa} \\ \sigma_{0} & \text { Tensão referente ao endurecimento da matriz de alumínio } & \mathrm{MPa} \\ \sigma_{\mathrm{ss}} & \text { Tensão referente à solução sólida } & \mathrm{MPa} \\ \sigma_{\mathrm{ppt}} & \text { Tensão referente à precipitação } & \mathrm{MPa} \\ \sigma_{\mathrm{dis}} & \text { Tensão referente ao encruamento } & \mathrm{MPa} \\ \sigma_{\mathrm{ij}} & \text { Tensor da tensão desvio } & \mathrm{MPa} \\ \sigma_{\mathrm{e}} & \text { Tensão efetiva } & \mathrm{MPa} \\ \sigma_{\mathrm{inicial}} & \text { Tensão aplicada } & \mathrm{MPa} \\ \bar{\rho} & \text { Densidade de discordâncias normalizada } & \\ \dot{\bar{\rho}} & \text { Taxa da densidade de discordâncias normalizada } & \mathrm{h}^{-1} \\ \dot{\bar{\rho}}_{\mathrm{m}} & \text { Taxa de densidade de discordâncias móveis normalizada } & \mathrm{h}^{-1} \\ \bar{\rho}_{\mathrm{m}} & \text { Densidade de discordâncias móveis normalizada } & \\ \gamma_{0} & \text { Constante do material controlando o efeito da densidade de } & \\ v & \text { discordâncias na nucleação e no crescimento do precipitado } & \end{array}$




\section{LISTA DE FIGURAS}

Figura 1 - Tensão residual trativa em função dos processos de fabricação .............................20

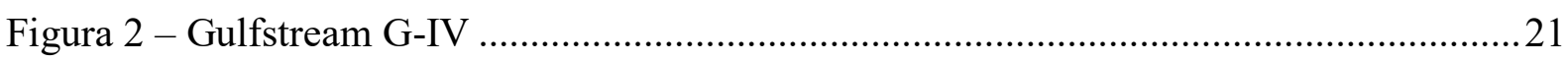

Figura 3 - Painel de revestimento da asa da aeronave A380 ...........................................22

Figura 4 - Perfis extrudados e conformados por fluência com envelhecimento......................22

Figura 5 - Mecanismos de deformação durante a fluência por difusão ...................................26

Figura 6 - Escalagem de discordância: vacância migrando para a discordância .....................27

Figura 7 - Curva típica de fluência. Curva A, ensaio de carregamento constante. Curva B,

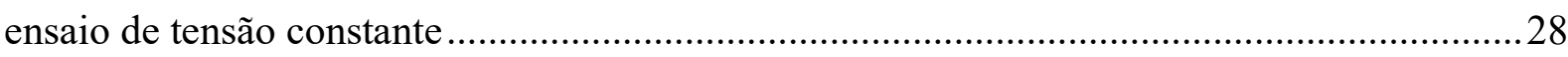

Figura 8- Variação da tensão de escoamento em função do tempo de envelhecimento de uma liga AA 2024

Figura 9 - Alongamento percentual em função do tempo de envelhecimento para a liga AA7050, depois da CFE e do envelhecimento artificial, ambos a $160^{\circ} \mathrm{C}$

Figura 10 - Diagrama das tensões que influenciam a tensão de escoamento durante a CFE ...32

Figura 11 - Representação do tratamento térmico T7 em função da temperatura e do tempo 34 Figura 12 - Representação do tratamento térmico T851 em função da temperatura e do tempo

Figura 13 - Representação do processo de conformação por fluência com envelhecimento ..35

Figura 14 - Autoclave .36

Figura 15 - Curva de relaxação de tensão, $\sigma_{1}$ tensão inicial e $\sigma_{2}$ tensão após a relaxação .......36

Figura 16 - Relaxação de tensão no processo da CFE

Figura 17 - Retorno elástico em função da espessura para superfícies de dupla curvatura (curvaturas $\mathrm{K}_{11}$ e $\mathrm{K}_{22}$ ).

Figura 18 - Representação do gradiente de tensão entre dois componentes com a mesma relação de raio de curvatura-espessura $\left(\mathrm{R}_{1} / \mathrm{H}_{1}=\mathrm{R}_{2} / \mathrm{H}_{2}\right)$.

Figura 19 - (a) Comparação entre o modelo (linhas sólidas) e o experimental (símbolos) para a liga AA7010 em $150^{\circ} \mathrm{C}$; (b) Contribuição do endurecimento por precipitação $\left(\sigma_{\mathrm{A}}\right)$ e do endurecimento por solução sólida $\left(\sigma_{\mathrm{SS}}\right)$ a tensão de escoamento $\left(\sigma_{\mathrm{y}}\right)$

Figura 20 - (a) Raio do precipitado normalizado em função do tempo para a liga AA7055 em $120^{\circ} \mathrm{C}$; (b) Tensão de escoamento em função do tempo e as suas parcelas $\left(\sigma_{\mathrm{ss}}, \sigma_{\mathrm{A}}\right.$ e $\left.\sigma_{\text {dis }}\right)$. As linhas vermelhas (sólidas) indicam o ponto que ocorre o pico de envelhecimento e a tracejada indica a transição da fluência primária para a secundária 
Figura 21 - (A) Densidade de discordâncias normalizada em função do tempo; (B) Deformação por fluência em função do tempo. Ambas as figuras são para a liga AA 7055 em $120^{\circ} \mathrm{C}$. As linhas tracejadas indicam a transição da fluência primária para a secundária ..45 Figura 22 - Comparação entre modelo simplificado e curva de fluência 48 Figura 23 - Parâmetros da geometria do precipitado e morfologias dos precipitados: (a) Disco/Placa; (b) Bastão/Agulha.

Figura 24 - Micrografia eletrônica de transmissão da liga da série AA7000 na têmpera T6,

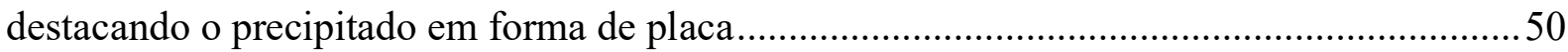

Figura 25 - Micrografia eletrônica de transmissão da liga da série AA 6000 .50

Figura 26 - Fração volumétrica relativa em função do tempo simulada por Zhang et al. (2013)

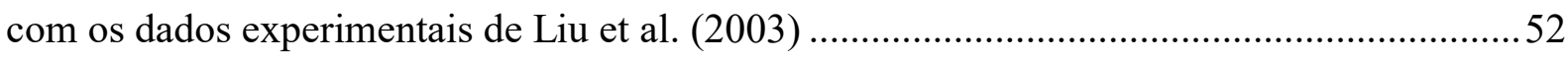

Figura 27 - Representação da relação de aspecto do precipitado em função do tempo...........53 Figura 28 - Comparação entre a deformação por fluência prevista no modelo e a experimental, para a liga de alumínio AA2124 .55

Figura 29 - Deformação por fluência em função do tempo para a liga AA2524 em $180^{\circ} \mathrm{C}$ (a) e $190^{\circ} \mathrm{C}(\mathrm{b})$ .56

Figura 30 - Fluxograma de um algoritmo evolucionário 58

Figura 31 - Esquema demonstrando a instabilidade que pode ser gerada durante a integração numérica 59

Figura 32 - Exemplos de elementos aplicados na análise numérica por elementos finitos .....60

Figura 33 - Fluxograma demonstrando o processo para obter uma solução iterativa .62

Figura 34 - Método de Newton-Raphson modificado

Figura 35 - Deformação por fluência em função do tempo para a liga de alumínio AA2124 (Experimental) 68

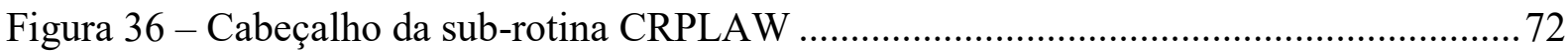

Figura 37 - Programa para testar a sub-rotina CRPLAW …............................................... 73

Figura 38 - Fluxograma das principais etapas da sub-rotina ............................................. 75

Figura 39 - Geometria simulada com carregamento uniaxial............................................. 77

Figura 40 - Painel de seleção dos elementos bidimensionais .................................................. 78

Figura 41 - Painel do caso de carregamento (Loadcase) para simulação de fluência .............79

Figura 42 - Geometria simulada com uma curvatura e a geometria de um ferramental real...80

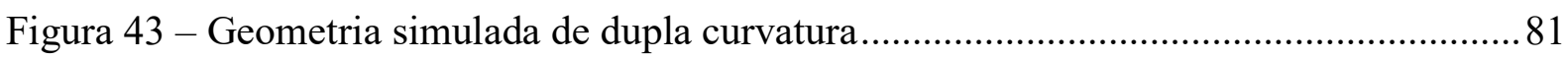

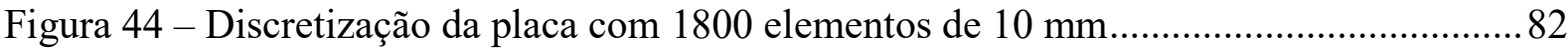


Figura 45 - Deformação por fluência em função do tempo para tensão de $265 \mathrm{MPa}$, utilizando diferentes passos de integração no método de Euler

Figura 46 - Deformação por fluência em função do tempo para tensão de $265 \mathrm{MPa}$, utilizando diferentes passos de integração no método de Runge-Kutta de quarta ordem .84

Figura 47 - Deformação por fluência em $t=6$ horas para tensão de $265 \mathrm{MPa}$, utilizando diferentes passos de integração no método de Runge-Kutta de quarta ordem 85 Figura 48 - Comparação dos dados experimentais de Zhang et al. (2013) com os dados simulados da deformação por fluência, para diferentes níveis de tensão 86 Figura 49 - Variação do erro percentual em função do tempo

Figura 50 - Comparação entre os dados simulados no Matlab ${ }^{\circledR}$ e os dados simulados no Fortran da deformação por fluência, para a tensão de $265 \mathrm{MPa}$, utilizando um passo de integração de 0,1

Figura 51 - A figura a esquerda mostra o resultado da tensão equivalente de von Mises para o último incremento da simulação exibido no MSC. Mentat ${ }^{\circledR}$; A figura a direita demonstra graficamente a evolução da tensão equivalente durante a simulação 88

Figura 52 - Resultados das deformações por fluência simuladas no MSC. Marc ${ }^{\circledR}$ e no Fortran, para tensão de $265 \mathrm{MPa}$. 88

Figura 53 - Comparação entre os dados simulados no Fortran e os dados simulados no MSC. Marc ${ }^{\circledR}$ da deformação por fluência, para as tensões de $241 \mathrm{MPa}$ e $192 \mathrm{MPa}$ 89

Figura 54 - Curva da relaxação de tensão para a geometria com uma curvatura na temperatura de $190^{\circ} \mathrm{C}$ (Dados coletados do nó central da placa)

Figura 55 - Simulação da deformação por fluência em função do tempo para a geometria com uma curvatura na temperatura de $190^{\circ} \mathrm{C}$ (Dados coletados do nó central da placa). As linhas tracejadas dividem as regiões em que os passos foram utilizados. $(0 \mathrm{~h}$ a $0,1 \mathrm{~h}-$ passo $=0,01 \mathrm{~h}$; $0,1 \mathrm{~h}$ a $4 \mathrm{~h}-$ passo $=0,1 \mathrm{~h} ; 4 \mathrm{~h}$ a $12 \mathrm{~h}-$ passo $=2 \mathrm{~h})$

Figura 56 - Distribuição da tensão equivalente de von Mises em MPa para a geometria com uma curvatura

Figura 57 - Distribuição da tensão equivalente de von Mises em MPa para a geometria com uma curvatura em 12 horas de simulação.

Figura 58 - Nós selecionados para coletar os dados da tensão equivalente de von Mises

Figura 59 - Tensão equivalente de von Mises ao longo do comprimento da placa para a geometria com uma curvatura

Figura 60 - Distribuição da tensão equivalente de von Mises em MPa para a geometria de dupla curvatura 
Figura 61 - Distribuição da tensão equivalente de von Mises em MPa para a geometria de dupla curvatura em 12 horas de simulação.

Figura 62 - Tensão equivalente de von Mises ao longo do comprimento da placa para a geometria de dupla curvatura

Figura 63 - Gradiente de tensões na direção do comprimento da placa, para a geometria com uma curvatura

Figura 64 - Gradiente de tensões na direção do comprimento da placa, para a geometria com dupla curvatura

Figura 65 - Gradiente de tensões na direção do comprimento da placa, para a geometria com dupla curvatura .97

Figura 66 - Dureza medida após a CFE em diferentes temperaturas e tensões 98 Figura 67 - Tensões máximas principais em MPa na superfície superior da placa com uma curvatura 99

Figura 68 - Tensões mínimas principais em MPa na superfície superior da placa com uma curvatura

Figura 69 - Tensões máximas principais em MPa na superfície superior da placa com dupla curvatura

Figura 70 - Tensões mínimas principais em MPa na superfície superior da placa com dupla curvatura 100

Figura 71 - Distribuição da deformação por fluência na superfície inferior da geometria com uma curvatura em 12 horas de simulação 101

Figura 72 - Distribuição da deformação por fluência na superfície inferior da geometria de dupla curvatura em 12 horas de simulação 101

Figura 73 - Deformação por fluência em função do tempo 104

Figura 74 - Exemplo das rotinas necessárias para realizar o ajuste do modelo e o fluxo de cálculos realizados no Matlab ${ }^{\circledR}$. 120

Figura 75 - Menu da ferramenta de otimização (Optimization Tool) 121 


\section{LISTA DE TABELAS}

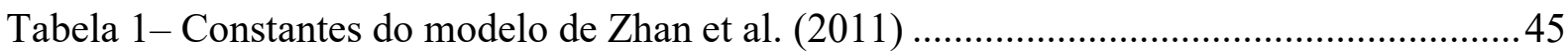

Tabela 2 - Composição química dos principais elementos da liga AA7055 (\% peso) ............46

Tabela 3 - Composição química da liga AA2219 (\% peso)....................................................46

Tabela 4 - Composição química da liga AA7B04 (\% peso) ...................................................46

Tabela 5 - Medidas experimentais e previstas do retorno elástico .......................................46

Tabela 6 - Constantes do modelo de Zhang et al. (2013) para a liga AA2124 ......................54

Tabela 7 - Composição química da liga AA2124 (fração em massa \%) .................................68

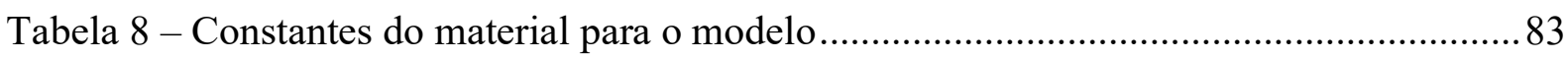

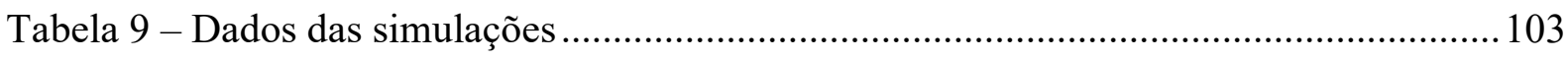

Tabela 10 - Dados das simulações realizadas por Brandão (2013) ..................................... 103

Tabela 11 - Dados das simulações realizadas por Zhan, Lin e Huang (2011) ........................ 103 


\section{LISTA DE ABREVIATURAS}

$\begin{array}{ll}\text { CFE } & \text { Conformação por fluência com envelhecimento } \\ \text { CAF } & \text { Creep age forming } \\ \text { TAF } & \text { Temper for age forming } \\ \text { AA } & \text { Aluminum Association } \\ \text { FORTRAN } & \text { Formula Translation }\end{array}$




\section{SUMÁRIO}

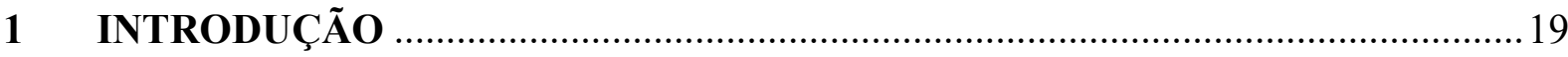

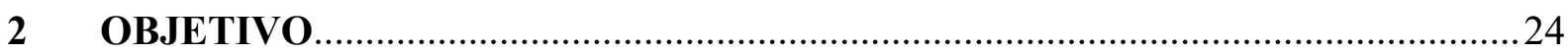

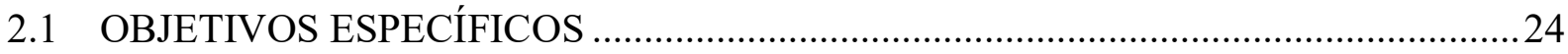

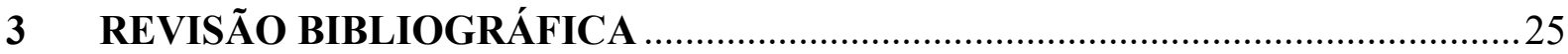

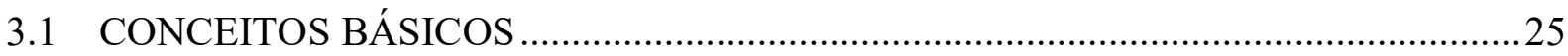

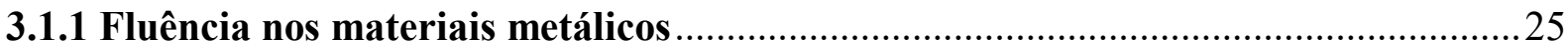

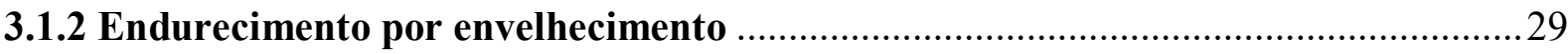

3.2 CONFORMAÇÃO POR FLUÊNCIA COM ENVELHECIMENTO...............................33

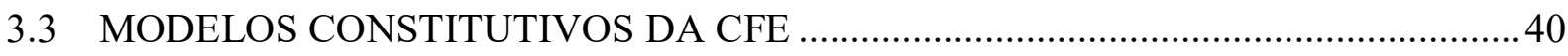

3.4 MÉTODOS PARA DETERMINAR AS CONSTANTES DO MATERIAL E

INTEGRAR AS EQUAÇÕES CONSTITUTIVAS UNIFICADAS .....................................56

3.5 MÉTODO DOS ELEMENTOS FINITOS APLICADO NA CFE.................................60

3.5.1 Implementação do comportamento de fluência no método dos elementos finitos...65

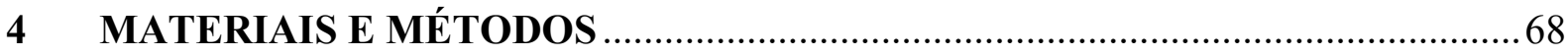

4.1 INTEGRAÇÃO NUMÉRICA DO MODELO MATEMÁTICO DA CFE.....................69

4.2 DESENVOLVIMENTO DA SUB-ROTINA DO MODELO COMPUTACIONAL .....72

4.3 IMPLEMENTAÇÃO DA SUB-ROTINA (CRPLAW) DA CFE …...............................77

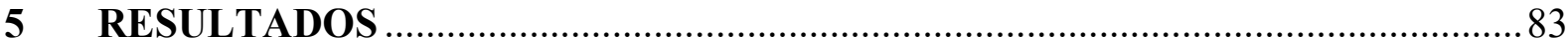

6 CONSIDERAÇÕES FINAIS SOBRE A IMPLEMENTAÇÃO DO MODELO ... 105

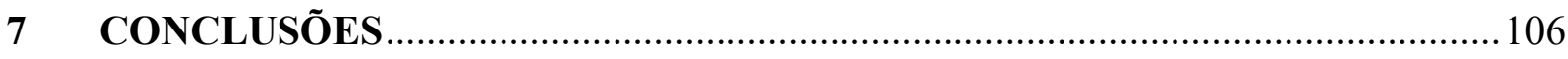

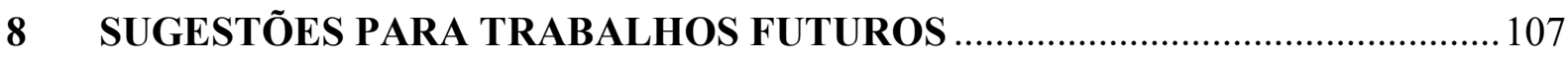

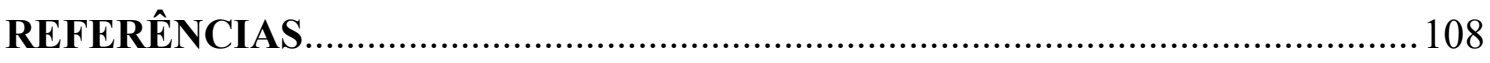

APÊNDICE A - Códigos do Matlab ${ }^{\circledR}$ para a integração das equações constitutivas . 113

APÊNDICE B - Exemplo de rotinas para realizar o ajuste do modelo da conformação por fluência com envelhecimento aos dados experimentais

APÊNDICE C - Sub-rotina da CFE implementada no MSC. Marc ${ }^{\circledR}$ 


\section{INTRODUÇÃO}

A engenharia constantemente busca melhores soluções para desenvolver produtos, seja atuando no estudo de novos materiais, processos de fabricação e de novas geometrias, com o objetivo de beneficiar a função do produto, as propriedades mecânicas do material e a redução dos custos associados à fabricação. A evolução sempre fará parte da engenharia, pois sempre se deseja buscar o máximo de conhecimento sobre determinados assuntos a fím de aplicá-los do melhor modo possível, aproveitando todas as características do conceito elaborado e ter um ótimo rendimento.

Existem muitos problemas no mundo atual, podendo-se destacar como exemplo o consumo de energia para a fabricação e a utilização de um produto, que são alguns dos aspectos fundamentais para a indústria se manter no mercado competitivo. A redução do consumo de energia demanda novos conhecimentos da engenharia; tais problemas têm gerado pesquisas para buscar soluções e a engenharia tem ajudado a achar estas soluções atuando nas mais diversas áreas.

A área de processos de fabricação necessita de muitos estudos, porque é preciso conhecer qual a melhor técnica para se fabricar um produto, seja esta técnica totalmente nova ou aprimorar algo já existente, que irá dar ao mesmo uma alta qualidade e um custo mínimo. Mas, para isso, é essencial o domínio completo sobre o processo de fabricação.

A indústria aeronáutica busca constantemente processos de fabricação mais eficazes para ter melhorias de custos, eficiência e produtividade, e assim enfrentar as exigências do mercado na qual são impostas pelos consumidores cada vez mais exigentes. Os processos de fabricação que foram desenvolvidos devido às novas demandas do mercado, por exemplo, jateamento com granalha (shot peening), conformação por fluência com envelhecimento, estiramento (stretching), soldagem por fricção e mistura (friction stir welding) geram uma economia significativa no setor aeronáutico (CANTOR; ASSENDER; GRANT, 2001).

A conformação por fluência com envelhecimento (CFE), em inglês creep age forming (CAF), age forming, creep forming ou autoclave age forming, é um processo relativamente novo que foi criado no intuito de substituir os métodos de conformação de metais que são utilizados em grandes painéis de liga de alumínio na indústria aeronáutica, pois possibilita a redução de tensão residual, melhora da resistência à fadiga e da resistência à corrosão sob tensão do material (HOLMAN, 1989).

A Figura 1 mostra a tensão residual trativa em função dos processos de fabricação. Esta figura foi resultado dos experimentos realizados por Holman (1989), na qual utilizou 
uma liga de alumínio AA 7075, com objetivo de medir as tensões residuais dos processos citados na figura e depois compará-las com as da CFE. Comparando-as, nota-se que o valor da tensão residual trativa da CFE é muito inferior à tensão residual trativa dos outros processos. Tendo redução na tensão residual trativa, logo irá melhorar a resistência a fadiga e a resistência à corrosão sob tensão do material, pois a baixa tensão residual trativa diminuirá a tendência de propagação dos defeitos no material e acarretará em componentes com um ciclo de vida maior. A tensão residual não só afeta o desempenho de uma estrutura durante o seu ciclo de vida em serviço, mas também segundo Sim (2011) irá afetar a qualidade do componente durante a manufatura e a montagem.

Figura 1 - Tensão residual trativa em função dos processos de fabricação

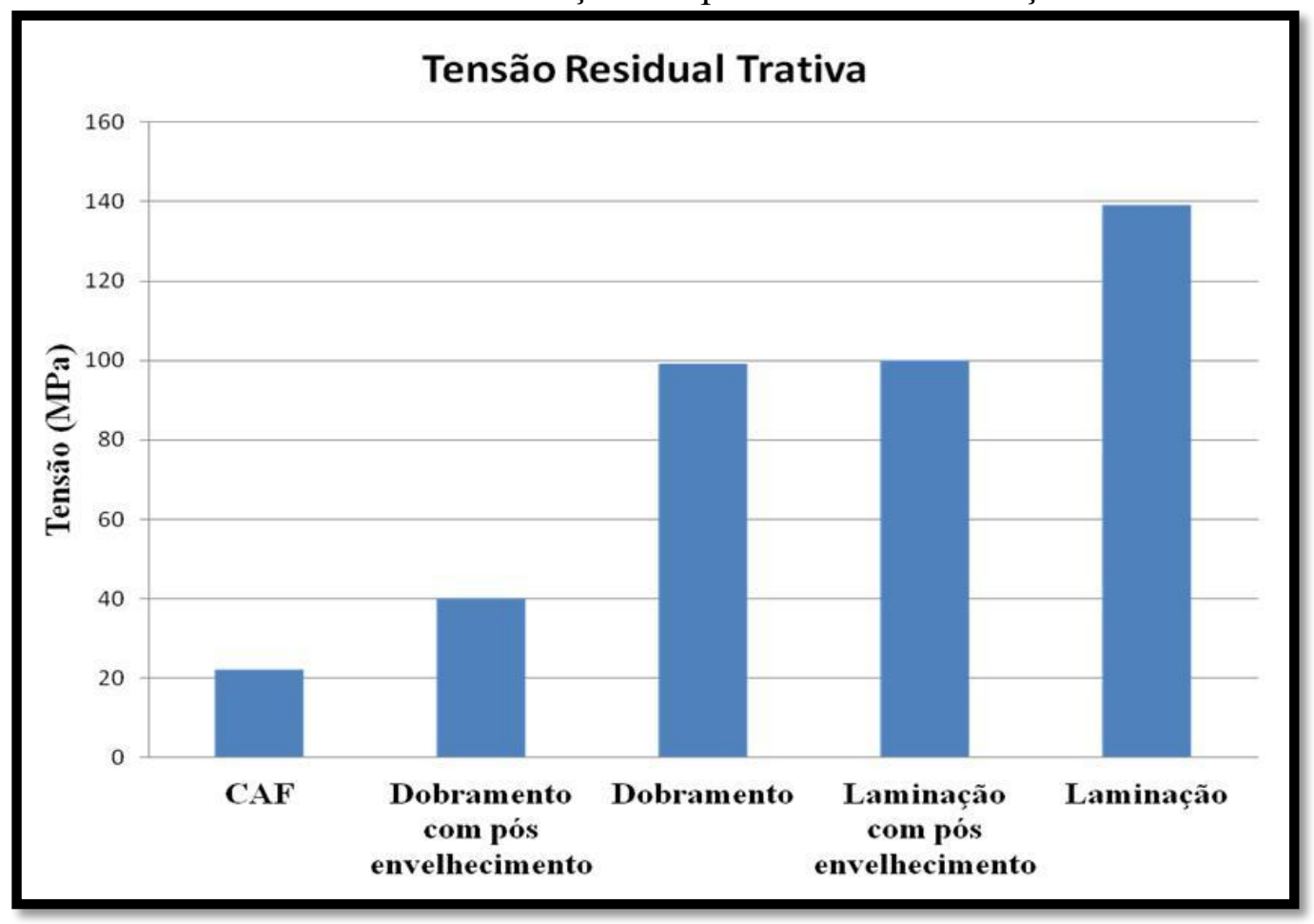

Fonte: Autor "adaptado de" Holman, 1989, p. 483

A indústria, principalmente a aeronáutica, tem interesse nas vantagens do processo e já desenvolveu produtos com a CFE, porém muitas pesquisas ainda podem ser feitas sobre o processo, para ampliar as suas aplicações, não só na indústria aeronáutica, mas também em outros ramos industriais.

A primeira empresa a utilizar o processo foi a Textron Aerostructures que usou este tipo de conformação na produção dos painéis que revestem a asa do avião de combate B-1B em meados da década de 80. Essa empresa também aplicou a CFE na fabricação da asa dos aviões Gulfstream G-IV (Figura 2) e Airbus A330/340 (HOLMAN, 1989). A fabricação das 
asas dos aviões A330 e A340 tiveram a produtividade aumentada em 20\% através da transferência de tecnologia desenvolvida no projeto do avião de combate B-1B e essa melhoria teve influência da CFE que pode conformar grandes painéis de configurações e espessuras variadas com uma boa qualidade (REED, 1992). A empresa BAE System utilizou essa tecnologia na manufatura da asa do avião HAWK, e as empresas Bennetts Associates e Airbus trabalharam juntas para da mesma forma conseguirem implantar a CFE nos painéis da asa da aeronave A380 SuperJumbo (ZHAN; LIN; BALINT, 2012), o painel de revestimento da asa é mostrado na Figura 3.

Os exemplos anteriores mostraram a aplicação da CFE na indústria aeronáutica principalmente na manufatura de asas, mas já existem aplicações em outros setores, como, os motores aeronáuticos da Rolls Royce que utilizam esta tecnologia nas pás do fan (ventilador), que são feitas por conformação por fluência (MAVROMIHALES; MASON; WESTON, 2003). Segundo Kallivayalil (2006) também é utilizada em perfis extrudados para a indústria do transporte, os perfis extrudados e conformados são mostrados na Figura 4.

Figura 2 - Gulfstream G-IV

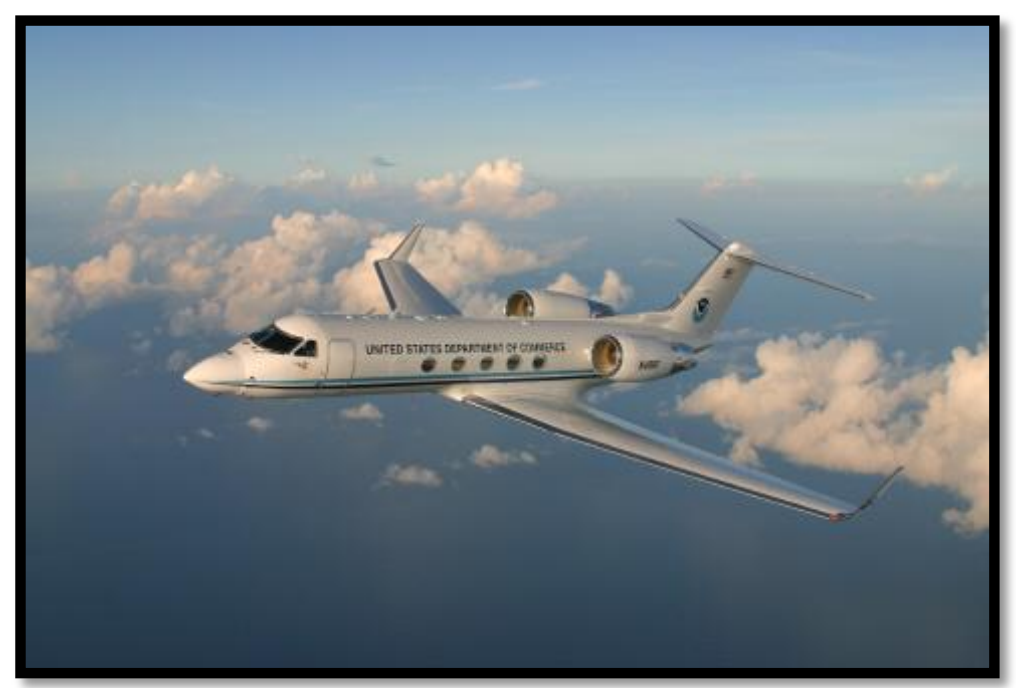

Fonte: Aircraft Operations Center 
Figura 3 - Painel de revestimento da asa da aeronave A380

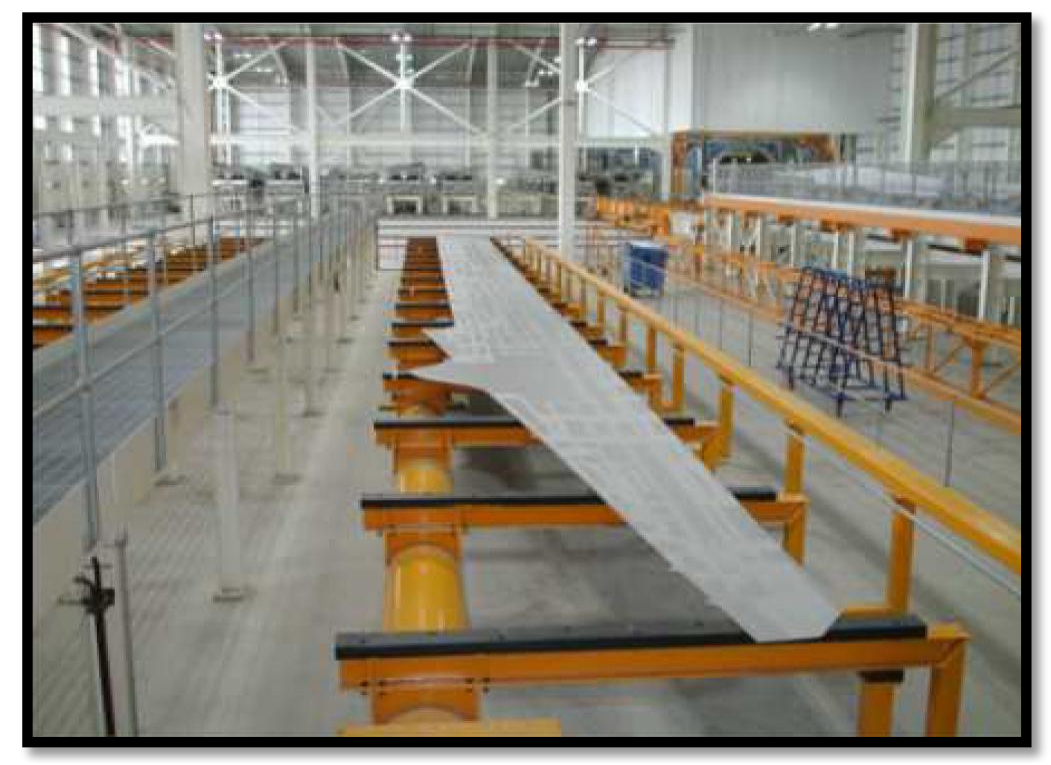

Fonte: Atkins

Figura 4 - Perfis extrudados e conformados por fluência com envelhecimento.

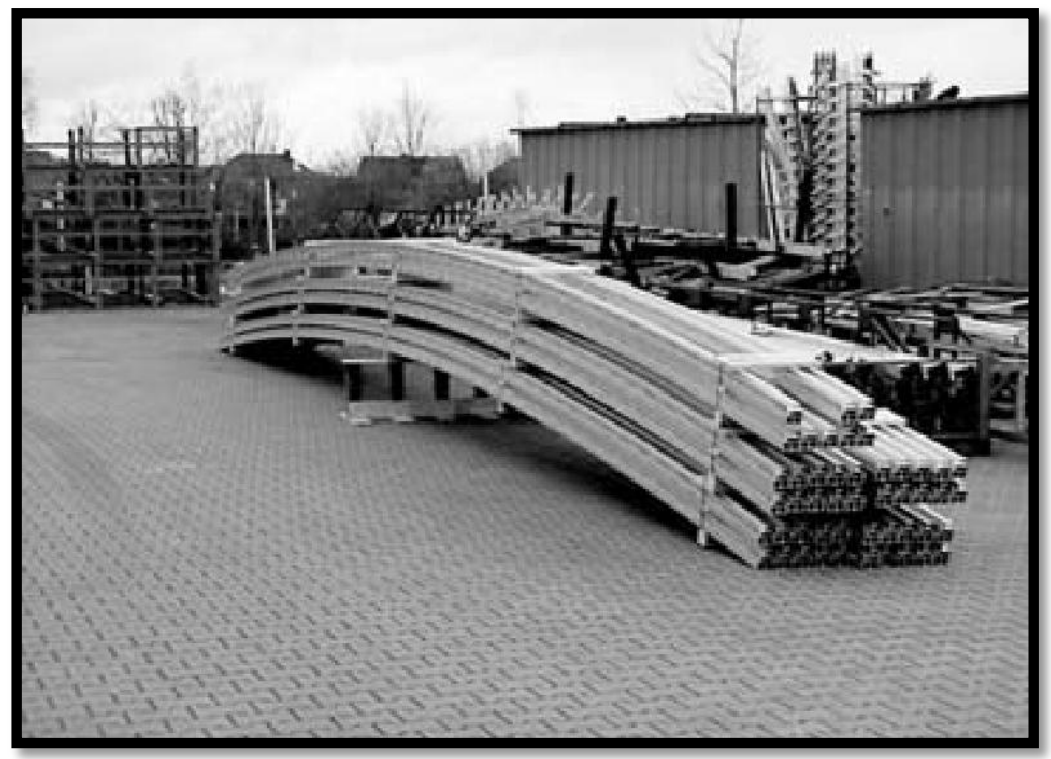

Fonte: Kallivayalil, 2006, p. 438

O panorama industrial sempre estará envolvido na diminuição de custos e tempo de fabricação, mas buscando aumentar a qualidade do produto para continuar no mercado competitivo, isto exemplifica o motivo de novos processos de fabricação interessar diversos setores, pois eles poderão mudar as variáveis de tempo, custo e qualidade. 
A engenharia assistida por computador tem sido uma ferramenta útil para melhorar as variáveis citadas anteriormente, principalmente nas etapas de manufatura.

Existem muitos programas de simulação por elementos finitos no mercado, capazes de realizar vários tipos de simulações em diversas áreas. Podendo ser dentro da área estrutural realizando análises lineares, não lineares, dinâmicas e entre outros tipos de análise, mas também fora da área estrutural, como, análises térmicas, eletroestática e acústicas.

Esses programas possuem um amplo registro de elementos, modelos constitutivos e condições de contorno. Porém mesmo com um amplo registro para as mais diversas aplicações, novas tecnologias surgem, tal como novos materiais e processos de fabricação, e há necessidade de ampliar mais esse registro, incluindo novos comportamentos mecânicos ou aperfeiçoando os já existentes, no intuito de aproximar as simulações da realidade. Há programas de elementos finitos que possibilitam ao usuário criar uma sub-rotina para complementar o código. Podem-se destacar os programas Abaqus ${ }^{\circledR}$, Ansys ${ }^{\circledR}$ e MSC. Marc ( como exemplo de programas que permitem sub-rotinas.

As sub-rotinas escritas para os programas citados anteriormente devem estar na linguagem de programação Fortran (Formula Translation), o presente trabalho utilizou o programa MSC. Marc ${ }^{\circledR}$ que utiliza a linguagem Fortran 77.

A CFE está entre as novas tecnologias que não possuem um código desenvolvido especialmente para a sua simulação.

Para realizar a simulação da CFE com um modelo de comportamento mecânico desenvolvido especialmente para o processo, há a necessidade de implementar esse modelo no programa de elementos finitos através de uma sub-rotina. 


\section{OBJETIVO}

O presente trabalho tem como objetivo geral implementar um modelo unificado de comportamento mecânico da CFE para a liga AA2124 em um programa de elementos finitos através de uma sub-rotina desenvolvida na linguagem de programação Fortran 77. Esta subrotina irá possibilitar a simulação do processo de conformação por fluência com envelhecimento, via método dos elementos finitos no programa MSC. Marc ${ }^{\circledR}$. Tal implementação é necessária, pois atualmente os programas de elementos finitos não tem um modelo unificado da CFE no seu código.

\subsection{OBJETIVOS ESPECÍFICOS}

a) integrar numericamente o modelo matemático da CFE a partir dos métodos de Euler (explícito) e de Runge-Kutta de quarta ordem e comparar os dois métodos de integração numérica em relação ao passo necessário para a resposta convergir;

b) desenvolver a sub-rotina com o modelo da CFE e criar um programa principal em Fortran 77 para auxiliar na verificação da sub-rotina;

c) verificar a sub-rotina, comparando os resultados da deformação por fluência gerados no Matlab ${ }^{\circledR}$ e Fortran;

d) implementar a sub-rotina no programa MSC. Marc ${ }^{\circledR}$, primeiramente em um modelo bidimensional. Comparar os resultados gerados na simulação uniaxial do MSC. Marc ${ }^{\circledR}$ com os resultados gerados no programa em Fortran;

e) simular a conformação por fluência com envelhecimento (utilizando a sub-rotina criada) em dois tipos de matrizes, uma matriz de dupla curvatura e outra com uma curvatura. Nas simulações observar a relaxação de tensão, deformação por fluência, tensões principais e o retorno elástico;

f) comparar os dados das simulações numéricas com dados de outras simulações encontradas na literatura (analisando principalmente os valores do retorno elástico), para verificar se os resultados gerados pela sub-rotina são plausíveis. 


\section{REVISÃO BIBLIOGRÁFICA}

Esta seção apresenta a revisão bibliográfica realizada para desenvolver o objetivo geral proposto no presente trabalho.

\subsection{CONCEITOS BÁSICOS}

A fluência e o envelhecimento artificial são dois fenômenos que fazem parte da CFE e para melhor compreender o processo, esta subseção apresenta os conceitos fundamentais da fluência nos materiais metálicos e do endurecimento por envelhecimento.

\subsubsection{Fluência nos materiais metálicos}

Materiais metálicos quando submetidos a carregamento e temperatura constante, por certo intervalo de tempo, poderão apresentar deformação permanente, mesmo que a tensão inicial não ultrapasse o limite de escoamento do material. Esse tipo de deformação recebe o nome de fluência. No geral, a fluência se torna significativa em altas temperaturas, temperaturas aproximadamente entre $0,3 \mathrm{Tf}$ a $0,5 \mathrm{Tf}$ (onde Tf é a temperatura de fusão do material) ou superiores (CAMPBELL, 2008).

Os principais mecanismos de deformação durante a fluência são controlados por difusão atômica ou movimentação de discordâncias.

A difusão atômica acontece em temperaturas acima do zero absoluto. Para que possa ter difusão, o átomo tem que atingir a energia de ativação necessária para conseguir migrar de uma região da estrutura cristalina. Os átomos migram através dos defeitos na estrutura e esses defeitos podem ser lacunas ou interstícios (quanto maior a quantidade de defeitos mais fácil de ocorrer difusão). A difusão atômica não só dependerá dos defeitos da estrutura cristalina citados anteriormente, mas também das discordâncias e dos contornos de grão, que são caminhos de elevada difusividade (CAMPBELL, 2008).

A temperatura e a tensão aplicada são fatores que geram grande influência na fluência e, por conseguinte, influencia nos mecanismos de deformação. Tais fatores citados servem para classificar qual será o mecanismo de deformação atuante que terá maior cooperação em gerar deformação. De modo geral, tem sido observado que os mecanismos dominantes em altas temperaturas e baixas tensões são aqueles controlados por difusão atômica (fluência por 
difusão atômica), para baixas temperaturas e altas tensões prevalecem a movimentação de discordâncias (CAMPBELL, 2008).

A fluência por difusão pode ainda ser subdividida, visto que, materiais metálicos quando submetidos a baixas temperaturas, menos significativa é a difusão dentro do grão e mais significativa nos contornos do grão, pois nos contornos o espaço entre os átomos é um pouco maior que na estrutura, onde exigirá uma energia de ativação menor e facilitará o transporte de massa, de modo a favorecer a fluência por difusão classificada como fluência Coble. Conforme a temperatura aumenta o número de lacunas no material também aumenta e a difusão dentro do grão se torna cada vez mais relevante, a fluência por difusão é classificada neste caso como fluência de Nabarro-Herring (STOUFFER; DAME, 1996).

A deformação do material durante a fluência por difusão será resultado do fluxo dos átomos de regiões comprimidas para regiões tracionadas (Figura 5), e do fluxo das lacunas de regiões tracionadas para regiões comprimidas, em que promove o alongamento do grão na direção do carregamento (CAMPBELL, 2008).

Figura 5 - Mecanismos de deformação durante a fluência por difusão

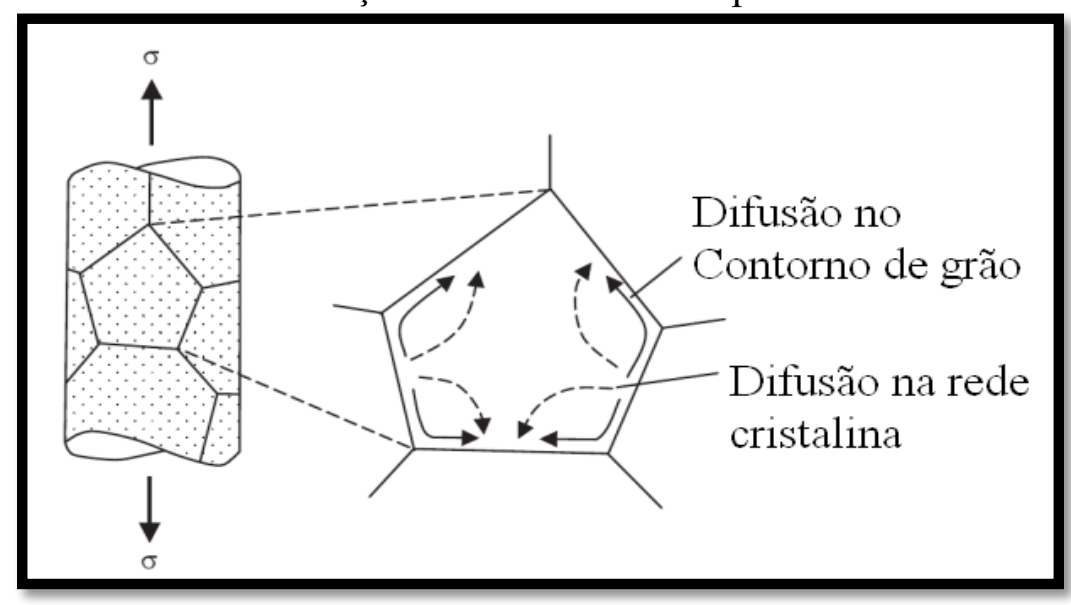

Fonte: Autor "adaptado de" Campbell, 2008, p. 270

O fenômeno de difusão durante a fluência não só influencia diretamente em gerar deformação, mas também irá ajudar na movimentação das discordâncias através do movimento de escalagem. A escalagem de discordâncias ocorre através da difusão de lacunas ou átomos intersticiais para a discordância (Figura 6), ou podem migrar a partir dela.

A combinação dos movimentos de deslizamento e escalagem gera a fluência por discordâncias ou fluência por deslizamento e escalagem. Os dois movimentos ocorrem sequencialmente. Por exemplo, as discordâncias que se encontram bloqueadas, com uma tensão não suficiente para causar o escorregamento dos planos na estrutura cristalina ou a 
energia de ativação do obstáculo que bloqueia a discordância é maior do que a disponível. Conforme a temperatura aumenta, o trabalho mecânico para causar o deslizamento delas diminui e a difusão das lacunas faz as discordâncias superarem os obstáculos que as bloqueiam por escalagem, para assim continuar o movimento de deslizamento até encontrar outro obstáculo e realizar a escalagem novamente (STOUFFER; DAME, 1996).

Figura 6 - Escalagem de discordância: vacância migrando para a discordância

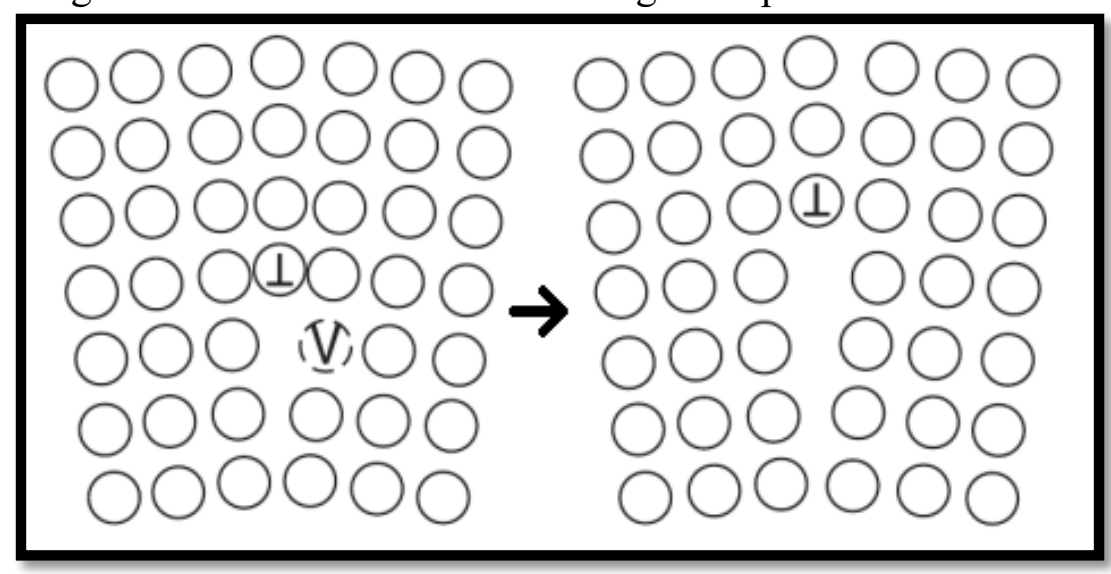

Fonte: Autor "adaptado de" Smallman; Ngan, 2014, p. 254

O mecanismo de deformação por fluência dominante durante a conformação por fluência com envelhecimento, foi estudado por alguns pesquisadores, tendo como exemplo os estudos realizados por Chen et al. (2012), Jeshvaghani, Shahverdi e Hadavi (2012), na qual realizaram experimentos representativos da conformação. Nesses estudos foi sugerido que a fluência por movimentação de discordâncias é dominante durante o processo, e irá interagir com os precipitados. Chen et al. (2014), em estudos mais recentes, propõe também a fluência de Coble como sendo o mecanismo predominante nos instantes finais da conformação.

Os mecanismos de deformação assim como o comportamento do material na fluência são estudados a partir de ensaios experimentais. O ensaio mecânico para avaliar o comportamento do material na fluência é realizado em temperatura constante, aplicando uma carga ou tensão constante ao corpo de prova. A deformação do corpo de prova que é medida ao longo do ensaio, dará origem à curva de fluência (Figura 7), possibilitando observar a variação da deformação em função do tempo.

Analisando-se a curva de fluência é possível notar a variação da taxa de deformação. Esta variação da taxa exibe três estágios diferentes, na qual a curva de fluência é dividida.

O primeiro estágio da curva é conhecido como fluência primária ou transiente, durante esse estágio a taxa de deformação segue decrescente até atingir um valor aproximadamente 
constante. Neste instante ocorre à fluência secundária ou estacionária. A fluência secundária é caracterizada por apresentar um processo competitivo entre os mecanismos de encruamento e de recuperação que resulta em uma taxa de deformação aproximadamente constante. Quando a taxa de deformação deixa de ser constante e se torna crescente, a fluência atingiu o estágio terciário. A fluência terciária se verifica quando existe uma grande redução na seção transversal, em que acarretará na fratura do material (DIETER, 1981).

Figura 7 - Curva típica de fluência. Curva A, ensaio de carregamento constante. Curva B, ensaio de tensão constante

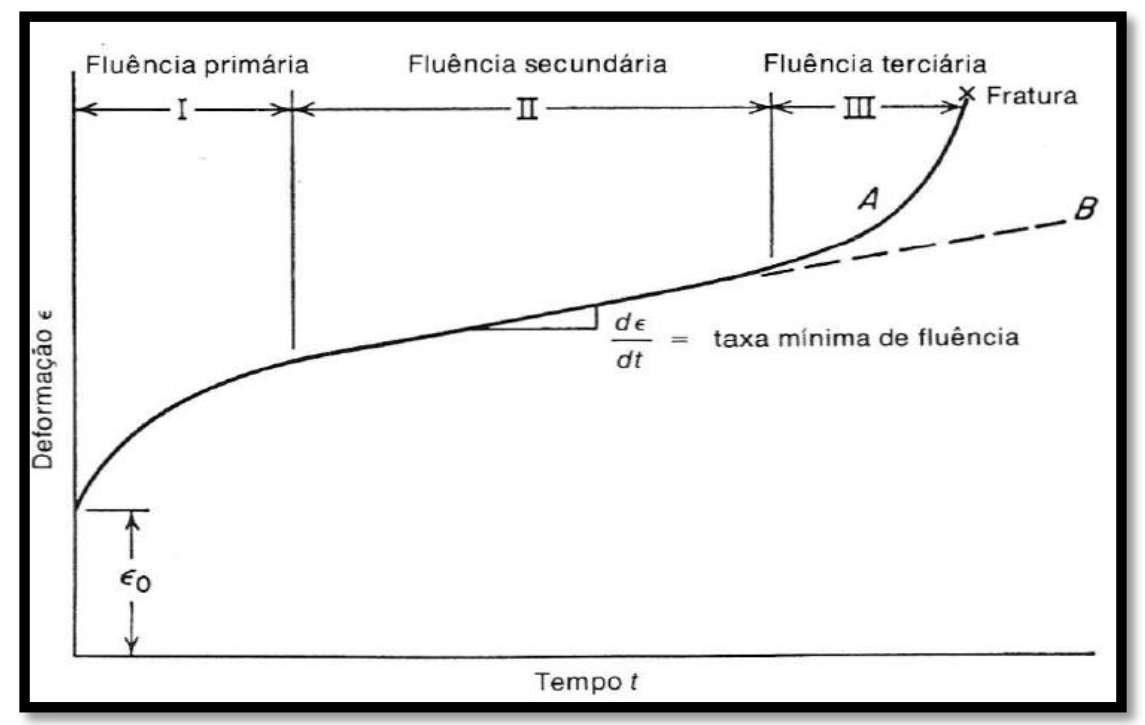

Fonte: Dieter, 1981, p. 387

Durante a CFE não só existem a fluência e o envelhecimento, mas também há o relaxamento da tensão. O ensaio mecânico para avaliar a relaxação de tensão é realizado na mesma condição de temperatura que o ensaio de fluência, porém é imposta uma deformação inicial no corpo de prova (que será mantida constante durante o ensaio) e se avalia a variação da tensão em função do tempo. A deformação imposta inicialmente tem caráter elástico. Conforme o ensaio é executado a deformação elástica diminui e a parcela de deformação inelástica aumenta, a soma das duas parcelas será igual à deformação imposta inicialmente.

Os ensaios de fluência e relaxação de tensão são importantes para determinar as equações constitutivas do material para assim conseguir prever o comportamento do material durante a conformação.

O presente trabalho não realizou ensaios de fluência e de relaxação de tensão. Os dados experimentais foram adquiridos do trabalho de Zhang et al. (2013). 


\subsubsection{Endurecimento por envelhecimento}

O envelhecimento em ligas de alumínio tem sido muito utilizado para atingir as propriedades mecânicas desejadas do material, a partir de partículas de segunda fase que dificultam o movimento das discordâncias. $\mathrm{O}$ endurecimento por precipitação não é utilizado somente para fortalecer ligas de alumínio, mas também as ligas de magnésio, superligas a base de níquel, ligas de berílio-cobre e aços inoxidáveis (CAMPBELL, 2008).

Geralmente, as partículas de segunda fase exibirão características eletroquímicas diferentes do comportamento da matriz, tornando a liga suscetível a formas de corrosão localizada (BIRBILIS; BUCHHEIT, 2005). Segundo Burleigh (2003) a liga de alumínio com resistência a corrosão ideal seria com uma única fase e homogênea. Mas para alcançar as propriedades mecânicas desejadas principalmente nas ligas de alumínio de alta resistência de aplicações aeronáuticas, implicará em ter uma microestrutura heterogênea formada a partir da adição de elementos de liga e da aplicação de tratamentos térmicos (BIRBILIS; BUCHHEIT, 2005).

O tratamento térmico de envelhecimento consiste em um ciclo térmico de solubilização, têmpera e envelhecimento. A solubilização para dissolver a fase rica em soluto na fase rica em solvente requer o aquecimento do material a uma temperatura acima da linha solvus por certo intervalo de tempo, quando solubilizado é realizado a têmpera. A têmpera ocorre com o resfriamento do material, normalmente até a temperatura ambiente, a uma taxa de transferência de calor que evite a difusão para não formar precipitados. Depois da têmpera terá uma solução sólida supersaturada e o sistema estará fora do equilíbrio. Na terceira etapa o material é aquecido a certa temperatura e mantido por tempo determinado, para a formação dos precipitados (SMALLMAN; NGAN, 2014). Ao longo do processo quanto maior o tempo para dada temperatura, o raio do precipitado é cada vez maior.

Conforme o precipitado cresce ele pode assumir diferentes arranjos atômicos de fases estáveis e metaestáveis, com interfaces coerentes, semi-coerentes e incoerentes, que poderão ter o formato de disco, agulha ou esférico. O precipitado assumirá novas formas para reduzir a energia livre e tender ao equilíbrio. Nas ligas de alumínio a precipitação ocorre com o aparecimento de uma ou mais fases de transição metaestáveis antes de atingir a fase final de equilíbrio, cada transição de fase irá baixar a energia livre do sistema (CAMPBELL, 2008). A variação das fases metaestáveis em função do tempo de envelhecimento para a liga AA2024 pode ser observada na Figura 8. A figura possibilita demonstrar que o aumento de resistência mecânica durante o envelhecimento dependerá das fases metaestáveis. 
Figura 8- Variação da tensão de escoamento em função do tempo de envelhecimento de uma liga AA 2024

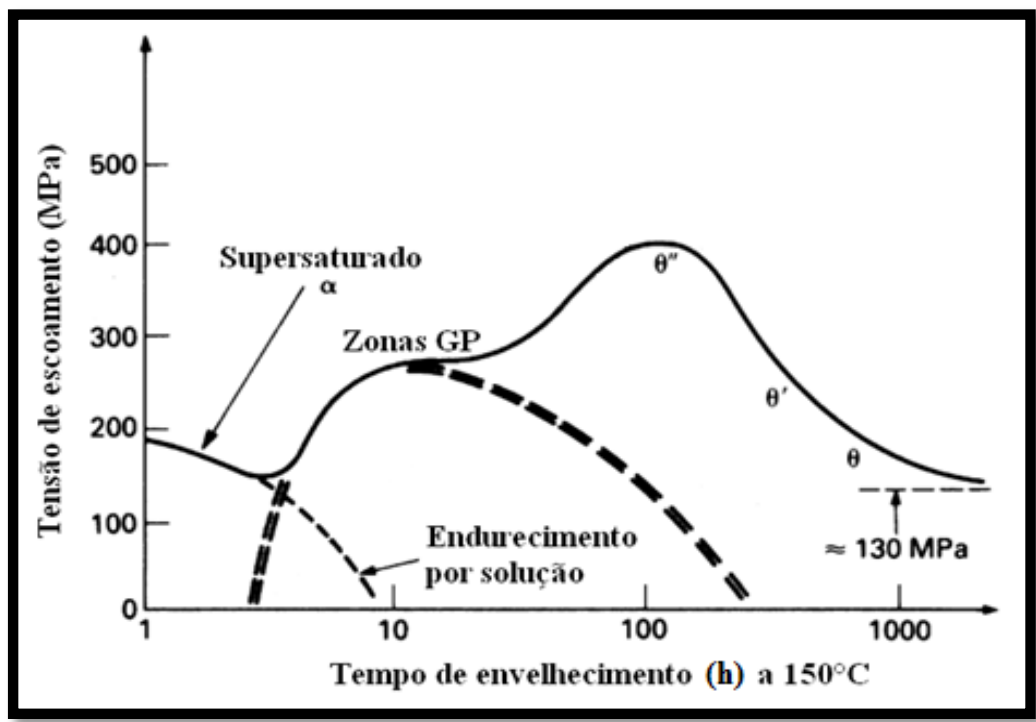

Fonte: Autor "adaptado de" Ashby; Jones, 2014, p. 100

Os parâmetros do envelhecimento (tempo e temperatura) são selecionados de modo que o processo seja viável e o material atinja as propriedades desejadas. O envelhecimento em algumas ligas de alumínio pode ser realizado a temperatura ambiente, este tipo de envelhecimento é chamado de envelhecimento natural (o envelhecimento realizado com o aquecimento do material é chamado de envelhecimento artificial).

As ligas de alumínio da série 2000, 6000, 7000 e a maioria das ligas da série 8000 podem ser endurecidas por envelhecimento (CAMPBELL, 2008). Grande parte das pesquisas existentes sobre a CFE estudam a aplicação das ligas de alumínio das séries 2000, 6000 e 7000, sendo que as ligas da série 7000 são amplamente utilizadas com a CFE nas asas das aeronaves da Airbus segundo Eberl et al. (2006).

A utilização de uma liga não endurecível por meio de tratamento térmico de solubilização e envelhecimento na conformação por fluência também tem sido de interesse para conformar partes da fuselagem do avião. Jambu et al. (2002) estudou a liga Al-Mg-Sc da série 5000 para realizar a conformação por fluência sem envelhecimento, no que se diferencia da CFE.

O material quando submetido a CFE, além de ser solubilizado, pode ser previamente envelhecido. Quando o material é previamente envelhecido é dito que está na condição TAF (Temper for Age Forming).

No envelhecimento realizado durante a CFE, o material está sob tensão externa e existe a deformação por fluência, que influenciarão na formação dos precipitados e também 
nas propriedades mecânicas do material. Na deformação por fluência há o aumento do número de discordâncias, na qual irá gerar maior nucleação heterogênea (CHEN et al., 2012), pois as discordâncias são zonas preferenciais para o precipitado nuclear por necessitar de uma quantidade menor de átomos para formar o núcleo, logo será mais fácil de acontecer à nucleação.

Segundo Bakavos et al. (2006) que pesquisou a liga AA7475, esse aumento de discordâncias pode resultar no coalescimento dos precipitados de modo a ter uma pequena perda de resistência mecânica quando comparado a um material submetido somente ao envelhecimento artificial com o mesmo tempo de ensaio.

Resultados similares foram obtidos no trabalho de Chen et al. (2012), que estudaram a liga AA7050. Chen et al. (2012) notaram o aumento do tamanho médio dos precipitados, o decréscimo da ductilidade (Figura 9) e da tensão limite de escoamento nas amostras da CFE, se comparado com as amostras somente envelhecidas artificialmente.

Figura 9 - Alongamento percentual em função do tempo de envelhecimento para a liga AA7050, depois da CFE e do envelhecimento artificial, ambos a $160^{\circ} \mathrm{C}$

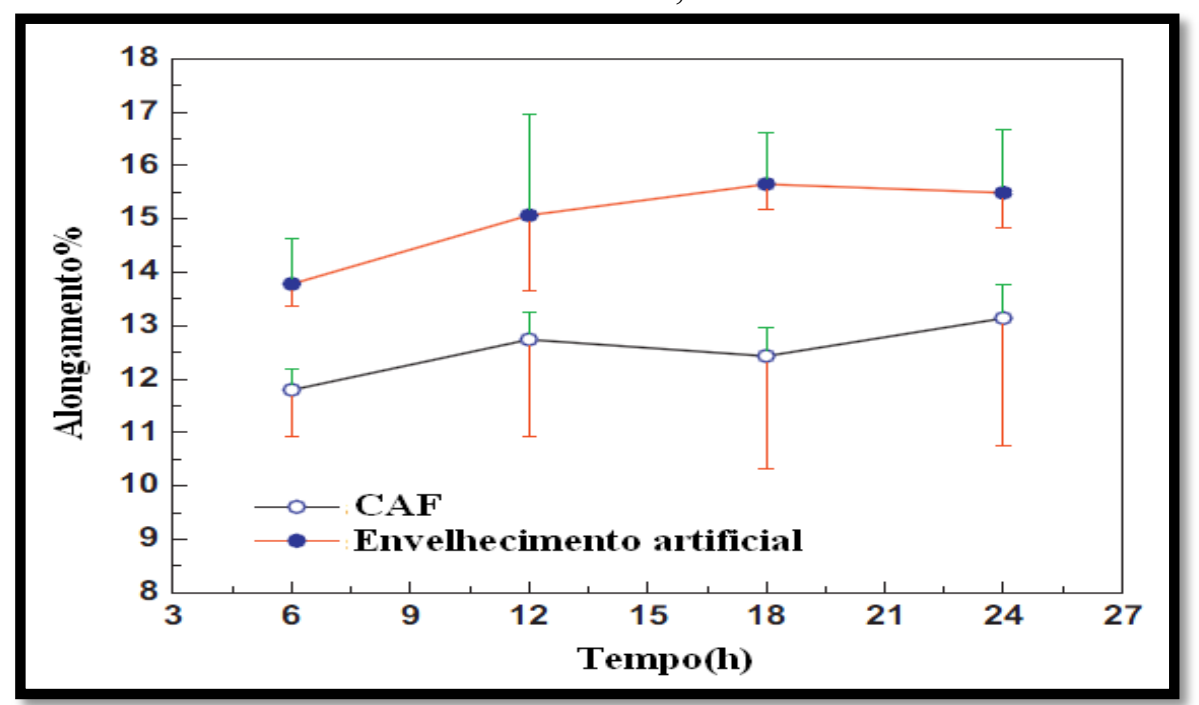

Fonte: Autor "adaptado de" Chen et al., 2012, p. 120

A tensão externa aplicada também afetará na orientação dos precipitados. Tal efeito tem sido investigado na CFE principalmente nas ligas Al-Cu (2XXX). As ligas Al-Cu têm mostrado uma relevante orientação dos precipitados na direção em que a carga é aplicada no corpo de prova. Zhu e Starke (2001) estudaram este efeito e concluíram que a orientação dos precipitados dependerá da tensão aplicada, temperatura e da composição da liga. Pesquisas mais recentes realizadas por $\mathrm{Xu}$ et al. (2014) propõem que, o controle da orientação dos 
precipitados na liga de alumínio da série AA2124, pode ser feito através de uma prédeformação na amostra antes da CFE.

Sabendo que o mecanismo de endurecimento por precipitação na CFE sofre influência da tensão aplicada e da fluência, Zhan et al. (2011) e Zhang et al. (2013) propuseram representar a evolução da tensão de escoamento durante o processo em etapas, como demonstrado no diagrama da Figura 10, em que a tensão de escoamento será dependente do endurecimento por solução sólida, endurecimento por precipitação e do endurecimento devido às discordâncias.

O estágio I mostrado no diagrama tem uma solução sólida supersaturada, esse estágio se encontra antes da CFE. Analisando o diagrama se nota que o endurecimento da liga é principalmente devido à solução sólida supersaturada. Conforme a CFE começa, a resistência mecânica da liga aumenta e a resistência devido à solução sólida supersaturada começa a diminuir, pois está tirando soluto da matriz para formar precipitados.

A resistência no estágio II depende do endurecimento por precipitação e do encruamento do material gerado por causa da fluência. No segundo estágio nota-se também que o endurecimento devido às discordâncias atinge um valor constante, no instante em que o material passa para a fluência secundária.

A tensão de escoamento no estágio II segue crescente até atingir o valor máximo, depois no estágio III ocorre o superenvelhecimento da liga em que a resistência mecânica cairá por causa do coalescimento dos precipitados.

Figura 10 - Diagrama das tensões que influenciam a tensão de escoamento durante a CFE

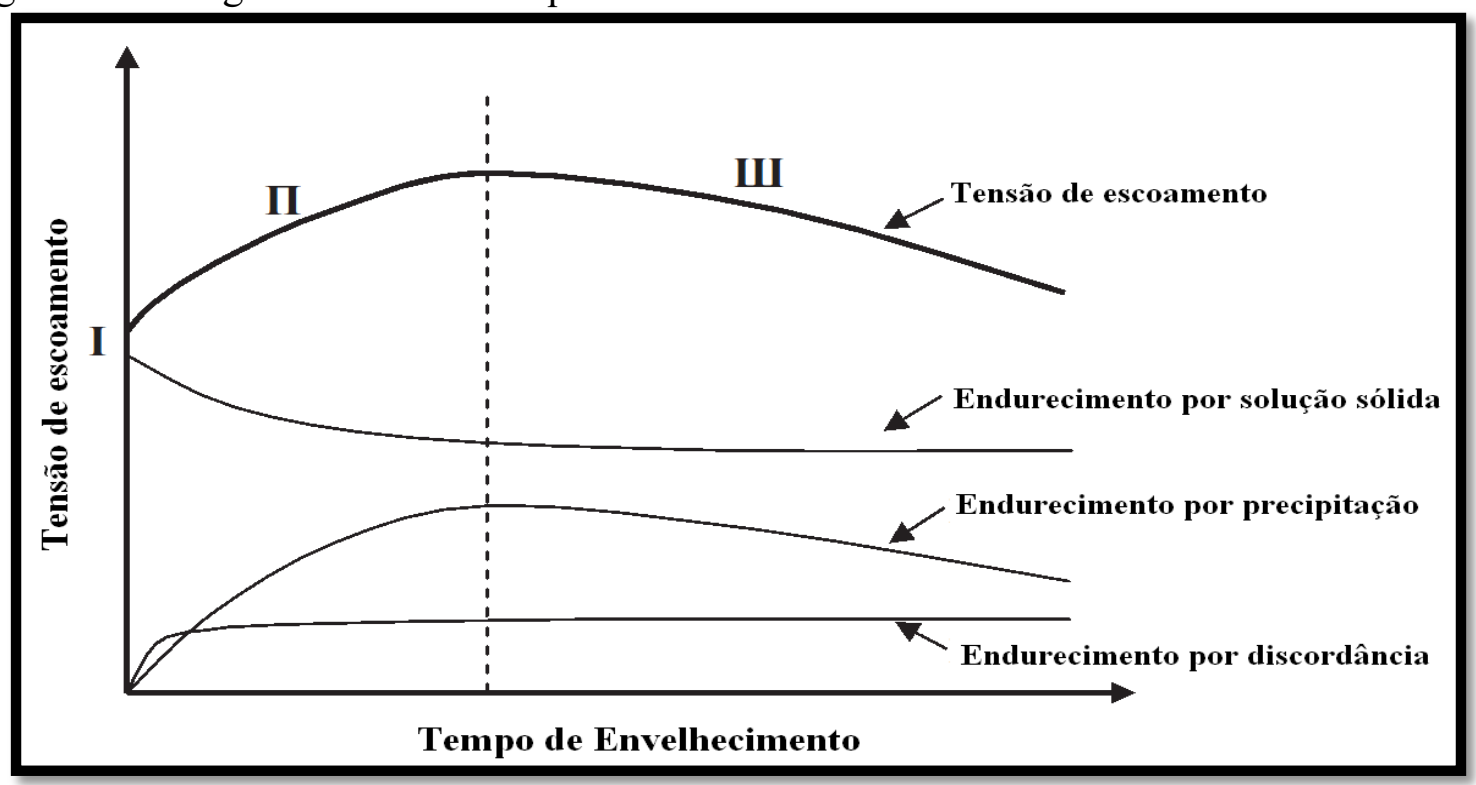

Fonte: Autor "adaptado de" Zhang et al., 2013, p. 10 


\subsection{CONFORMAÇÃO POR FLUÊNCIA COM ENVELHECIMENTO}

A conformação por fluência com envelhecimento é realizada com a combinação dos processos de conformação e tratamento térmico, ocorrendo simultaneamente, durante a conformação (também há o relaxamento de tensão). O envelhecimento artificial do material tem o intuito de aumentar a resistência mecânica. Portanto é essencial para o processo de fabricação determinar experimentalmente o tempo e a temperatura necessários para atingir as propriedades do material desejadas, esses parâmetros do envelhecimento serão os mesmos da conformação por fluência.

Como dito na introdução do presente trabalho a CFE tem sido aplicada nos painéis de alumínio que revestem a asa do avião. Os revestimentos necessitam de materiais que tenham certas propriedades, na qual não podem sofrer queda significativa durante a CFE. As principais propriedades que devem ser considerados na seleção do material na construção da asa do avião são (PRASAD; GOKHALE; WANHILL, 2013):
a) alta resistência mecânica;
b) resistência à fadiga;
c) alta tenacidade à fratura;
d) resistência ao crescimento da trinca;
e) resistência à corrosão.

As ligas que atendem a essas propriedades são as ligas da série 2XXX que têm sido aplicadas no revestimento inferior da asa e as ligas da série 7XXX aplicadas no revestimento superior da asa (CAMPBELL, 2011).

As ligas da série 7XXX são suscetíveis a propagação de trinca por corrosão sob tensão. Para resolver este problema é utilizado às têmperas T7 que consiste na solubilização e no superenvelhecimento artificial da liga. O envelhecimento pode ser realizado em duas etapas ou em uma única etapa (CAMPBELL, 2011). O ciclo para duas etapas de envelhecimento é demonstrado na Figura 11.

Tendo a liga AA7475 na têmpera T73 como exemplo, a primeira etapa de envelhecimento a $121^{\circ} \mathrm{C}$ tem duração de 6 a 8 horas e a segunda etapa a $163^{\circ} \mathrm{C}$ tem duração de 24 a 30 horas, segundo a norma AMS2772E (INFORZATO et al., 2012). Quando a primeira etapa de envelhecimento termina a liga está na condição TAF e no segundo estágio de envelhecimento ocorre a CFE. 
Figura 11 - Representação do tratamento térmico T7 em função da temperatura e do tempo

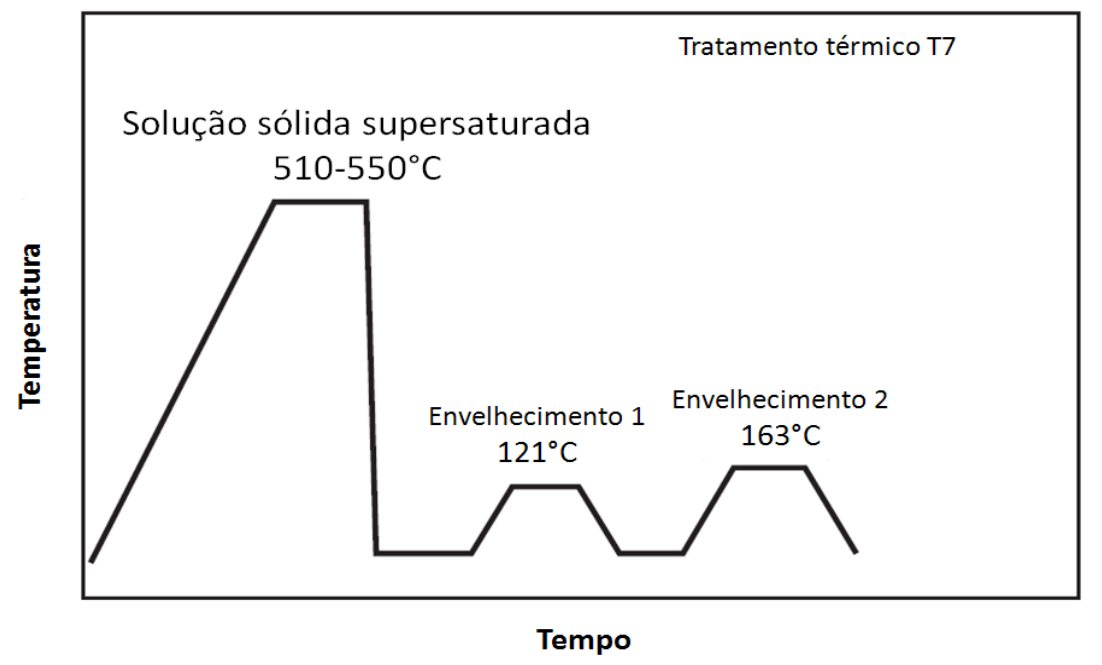

Fonte: Autor "adaptado de" Campbell, 2008, p. 148

A liga AA2124 na tempera T851 (solubilizada, alívio de tensão por estiramento e envelhecimento artificial) é aplicada no revestimento de aviões de combate de alto desempenho (ALCOA, 2016) e tem sido estudada na CFE.

Antes da liga AA2124 ser submetida a CFE ela estará na condição T351 (solubilizada e alívio de tensão por estiramento) e depois do processo, na condição T851. Na Figura 12 é demonstrado o ciclo térmico, na qual se pode observar o tempo e a temperatura de processo recomendados segundo a norma AMS2772E. A liga AA2124 foi utilizada no presente trabalho através dos dados experimentais de Zhang et al. (2013) para simular a CFE.

Figura 12 - Representação do tratamento térmico T851 em função da temperatura e do tempo

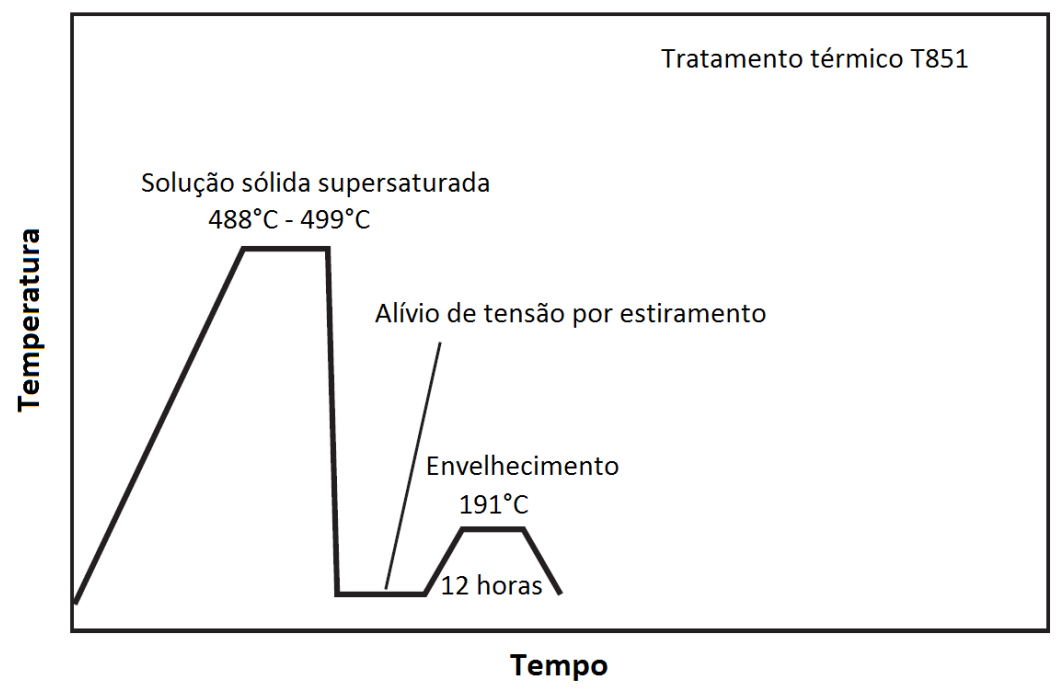

Fonte: Autor 
Foi visto anteriormente que antes da liga de alumínio ser submetida a CFE ela passa por um tratamento térmico, na qual poderá sofrer alterações conforme a escolha da liga. A próxima etapa deste trabalho será explicar o processo de conformação por fluência com envelhecimento.

O processo pode ser dividido em três etapas (Figura 13), a primeira fase o blank é colocado no molde e cria-se um vácuo entre os mesmos, na qual é introduzida uma deformação de caráter elástica pela pressão atmosférica. Existem casos em que a pressão atmosférica não é suficiente para estabelecer uma deformação elástica no blank ao ponto de manter o contato com o molde, e há necessidade de utilizar um forno pressurizado ou autoclave (Figura 14). A autoclave é o método para estabelecer contato mais aplicado, principalmente na fabricação de painéis de liga de alumínio que revestem a asa do avião - a aplicação de fixação mecânica não é viável, pois pode causar concentração de tensão (LEVERS, 2003). A segunda fase, o componente é colocado em uma autoclave pressurizada, pois a pressão exercida manterá a deformação inicial durante o processo, em seguida a peça é aquecida - a duração do processo é estabelecida para que a peça seja envelhecida e ganhe as propriedades mecânicas desejadas. A segunda fase é caracterizada pelo envelhecimento e pelo comportamento não linear da relaxação da tensão (Figura 15) e da deformação por fluência, em que difere da primeira e da terceira fase que apresentam um comportamento linearmente elástico (SALLAH; PEDDIESON; FOROUDASTAN, 1991). A terceira fase ocorre a retirada da pressão e do vácuo, e depois se faz o resfriamento até a temperatura ambiente. Quando a pressão e o vácuo são retirados a peça sofre um retorno elástico (ZHAN; LIN; DEAN, 2011).

Figura 13 - Representação do processo de conformação por fluência com envelhecimento

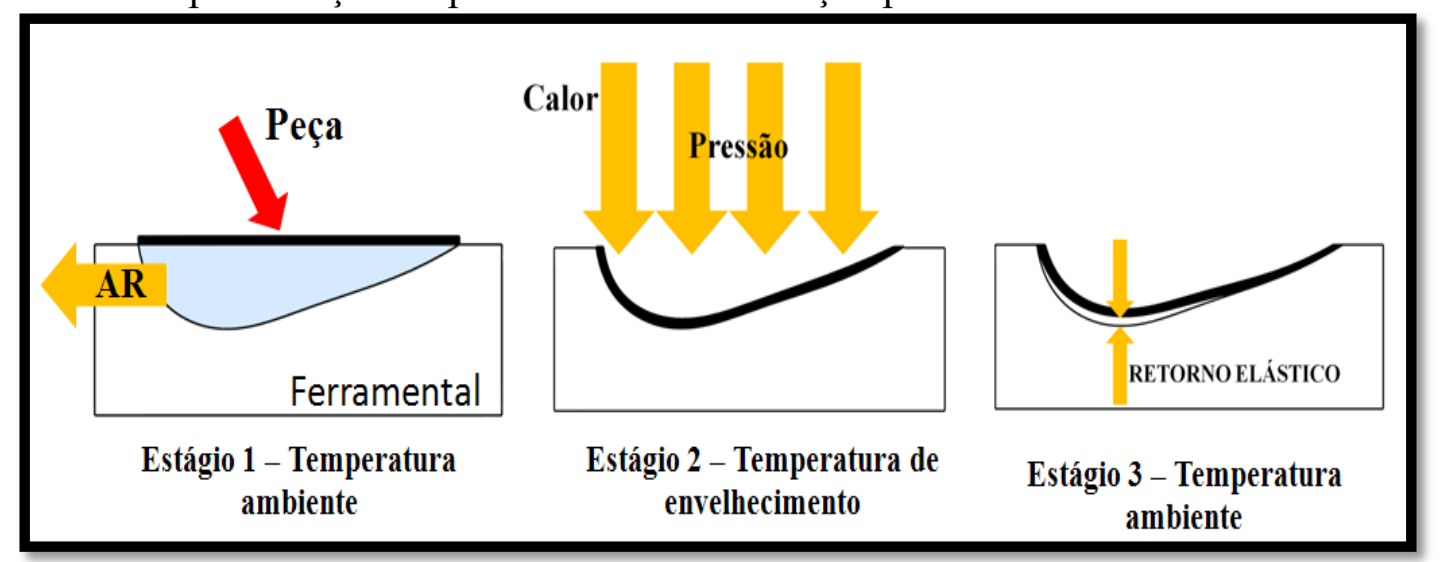

Fonte: Autor "adaptado de" Levers, 2003, p. 44 
Figura 14 - Autoclave

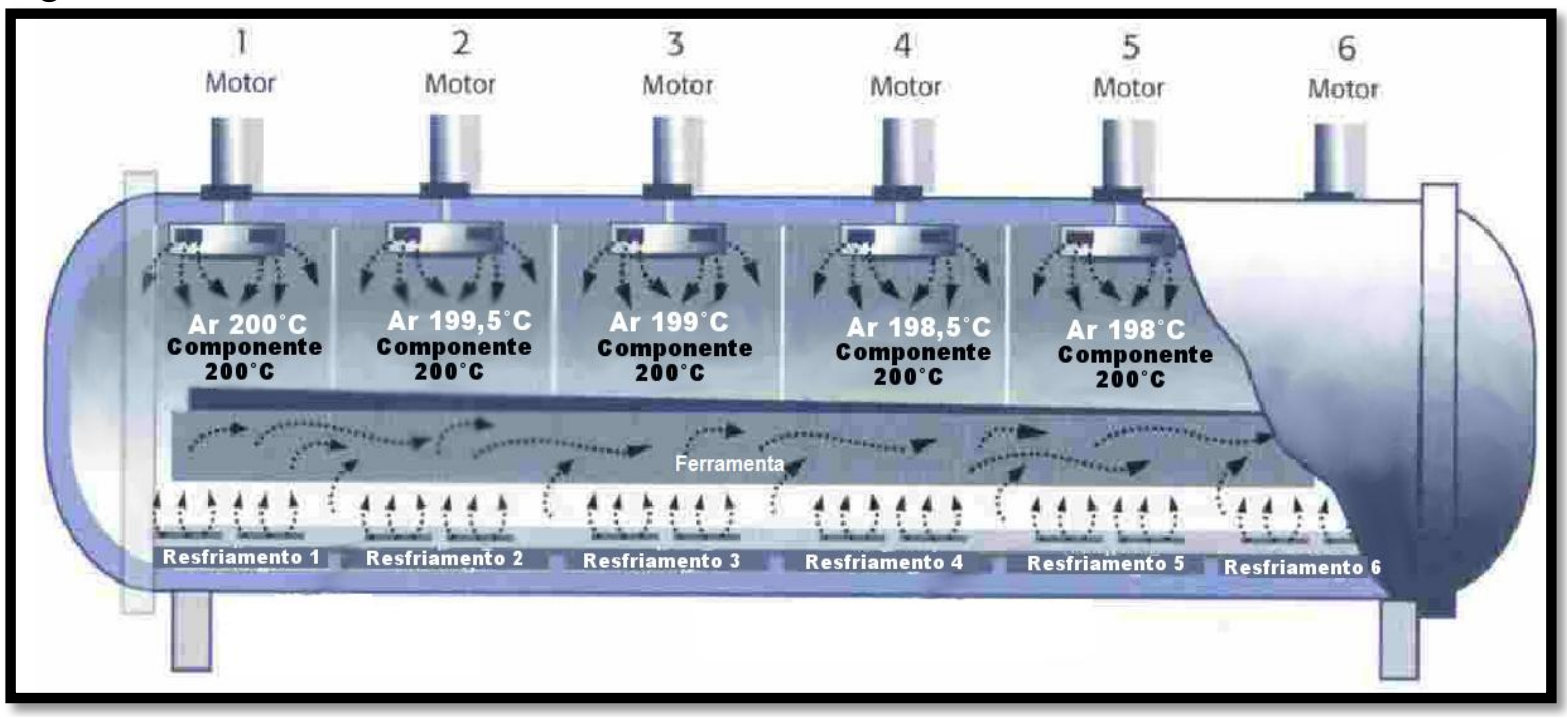

Fonte: Autor "adaptado de" Levers, 2003, p. 44

Figura 15 - Curva de relaxação de tensão, $\sigma_{1}$ tensão inicial e $\sigma_{2}$ tensão após a relaxação

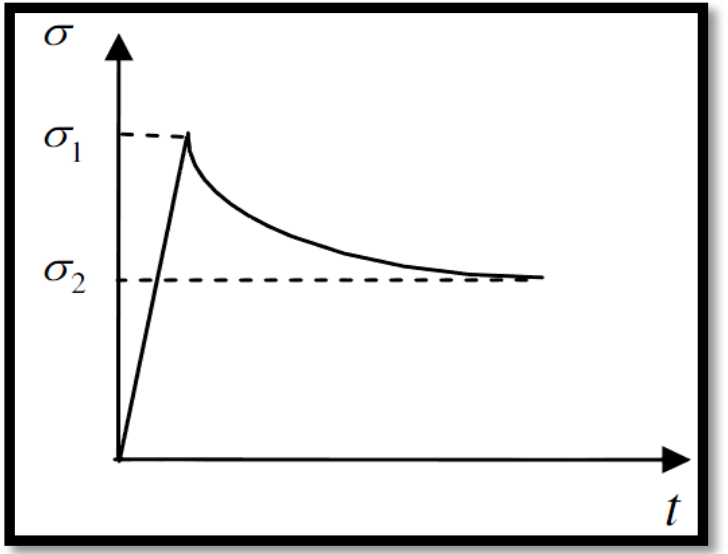

Fonte: Zhan et al., 2011, p. 597

No instante final da CFE é possível notar que o fenômeno de relaxação diminuiu a tensão até certo valor e esta tensão remanescente será o ponto de partida para que ocorra o retorno elástico. Este efeito pode ser observado na Figura 16, na qual Zhan et al. (2011) mostra a variação da tensão em função da deformação durante o processo. Na figura a tensão $\sigma_{1}$ é a tensão imposta inicialmente, a tensão $\sigma_{2}$ ocorre após a relaxação de tensão, as deformações $\varepsilon_{\mathrm{T}}, \varepsilon_{\mathrm{c}} \mathrm{e} \varepsilon_{\mathrm{e}}$ são: a deformação total imposta no estágio 1 do processo, a parcela de deformação por fluência (Estágio 2) e a parcela de deformação elástica. 
Figura 16 - Relaxação de tensão no processo da CFE

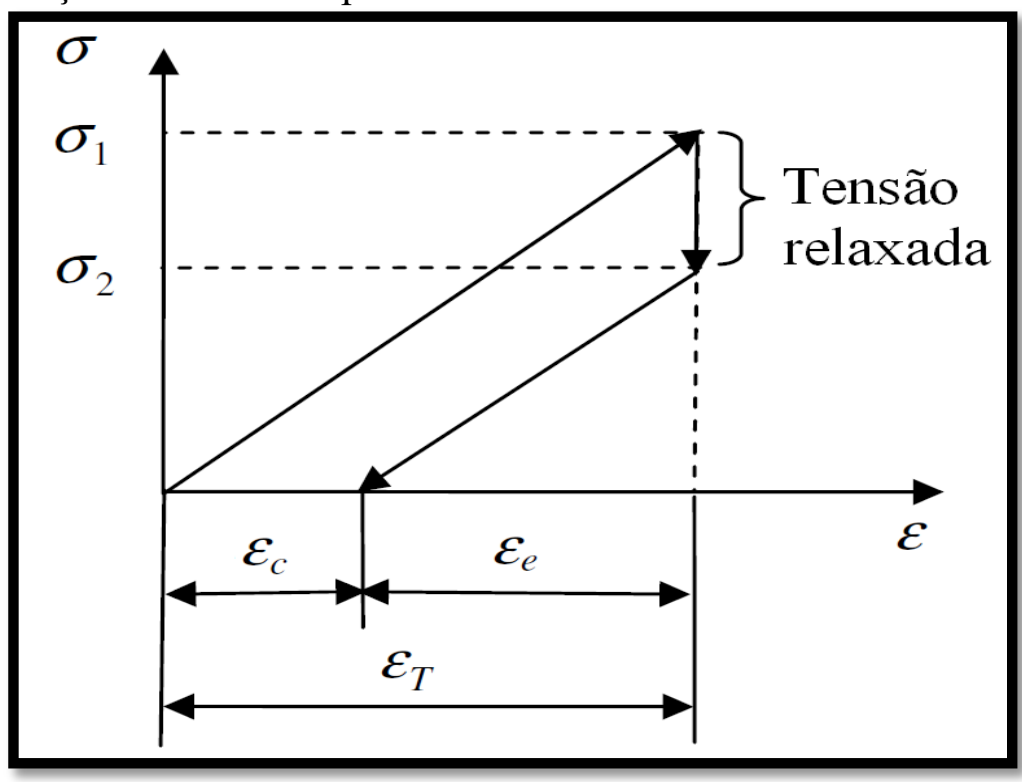

Fonte: Autor "adaptado de" Zhan et al., 2011, p. 597

Durante a CFE existe um retorno elástico elevado devido principalmente ao tempo e temperatura do processo de envelhecimento que tem como objetivo melhorar as propriedades mecânicas do material e não de causar o máximo alivio de tensão, que traria ao material uma deformação final mais próxima possível da deformação imposta no início do processo (HOLMAN, 1989).

O aumento do tempo de processo para diminuir o retorno elástico tem certas limitações, pois o maior relaxamento de tensão e a maior deformação por fluência ocorrem nos instantes iniciais da CFE ou no estágio primário de fluência que tem curta duração. Depois que o estágio secundário de fluência é atingido o material não sofre grandes deformações em curtos intervalos de tempos, para atingir deformações mais significativas seria necessário aumentar muito o tempo da conformação. Quanto mais tempo a liga permanecer envelhecendo, ou seja, ultrapassar o tempo pré-estabelecido, ela correrá o risco de perder resistência mecânica.

Ho, Lin e Dean (2004) citaram que, não só a temperatura e o tempo irão influenciar no retorno elástico, mas a espessura do componente e a curvatura consequente da deformação elástica imposta inicialmente, também serão relevantes.

Ho, Lin e Dean (2004) desenvolveram estudos através de simulações computacionais, observando o retorno elástico em dois tipos de geometria: superfície com uma curvatura e outra superfície com dupla curvatura, para conhecerem o nível de influência dos parâmetros, tempo de processo, espessura, e curvatura do ferramental, no retorno elástico. Durante as 
simulações notou-se que, quanto maior o tempo de processo, mais deformação por fluência ocorrerá e irá diminuir a parcela elástica, tendo assim menos retorno elástico. A partir dos parâmetros atribuídos nas simulações e das condições de contorno adotadas pelos pesquisadores para representar o efeito do retorno elástico, se constatou que o aumento da espessura, diminui o efeito do retorno elástico, assim como o aumento da quantidade de curvatura, de uma para duas, da mesma forma diminui este efeito.

Jeunechamps et al. (2006) também realizou simulações computacionais, relacionadas a influência da espessura e da curvatura do ferramental no retorno elástico, e verificou que aumentando a curvatura, há diminuição do retorno elástico. O gráfico (Figura 17) do retorno elástico em função da espessura, para três curvaturas diferentes, demonstra claramente o efeito. No gráfico a variação do retorno elástico é estuda para uma geometria de dupla curvatura (curvaturas $\mathrm{K}_{11}$ e $\mathrm{K}_{22}$ ). Conforme as curvaturas aumentam de 0,002 $\mathrm{mm}^{-1}$ para $0,007 \mathrm{~mm}^{-1}$, considerando uma mesma espessura, nota-se a redução do retorno elástico.

Figura 17 - Retorno elástico em função da espessura para superfícies de dupla curvatura (curvaturas $\mathrm{K}_{11}$ e $\mathrm{K}_{22}$ ).

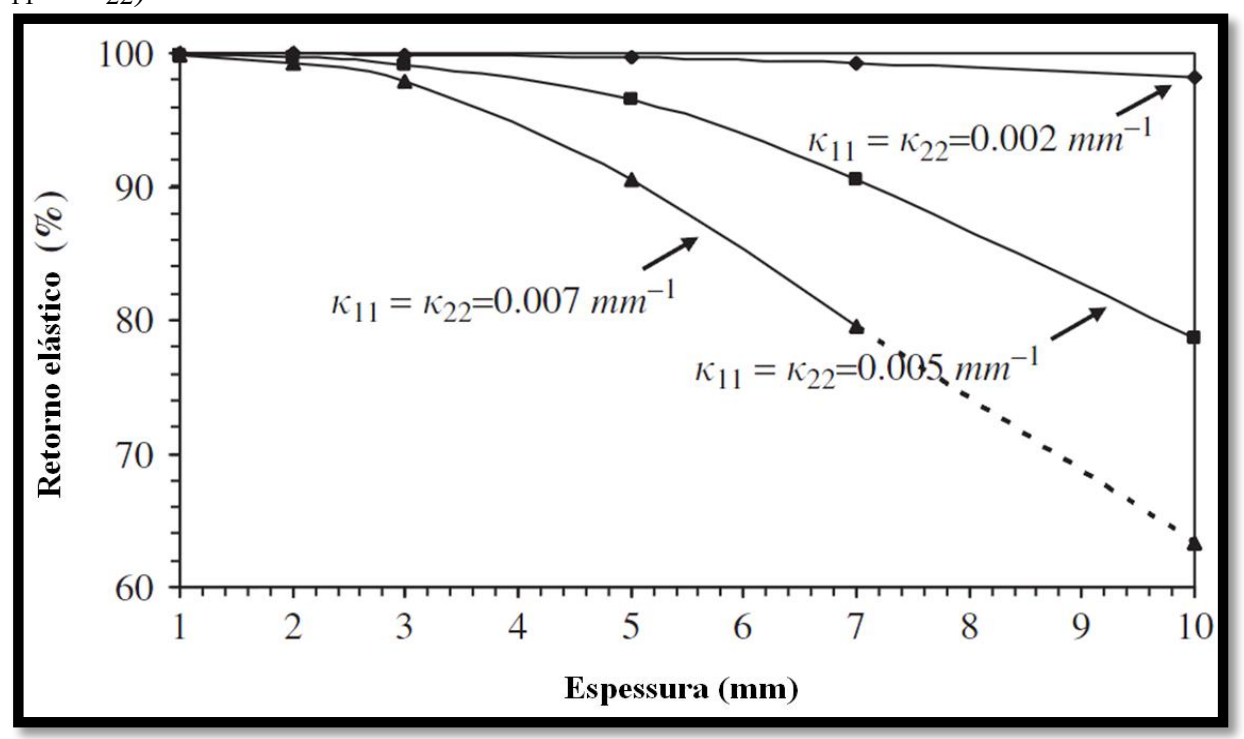

Fonte: Jeunechamps et al., 2006, p. 627

A diminuição do retorno elástico acontece, porque, quando se aumenta a espessura, a quantidade de curvatura, ou outra mudança geométrica em que os níveis de tensão no corpo aumentem, este aumento de tensão irá favorecer o fenômeno de relaxação de tensão e a deformação por fluência. Este efeito foi observado por Zhan et al. (2014), na qual estudaram o gradiente da tensão ao longo da espessura. 
Zhan et al. (2014) compararam componentes com espessura e raio de curvatura diferentes, mas mantendo a mesma tensão máxima. A Figura 18 demonstra dois componentes de geometrias diferentes com a mesma relação de raio de curvatura-espessura e com tensões máximas iguais, porém as geometrias possuem gradientes de tensão diferentes. A partir de dados experimentais Zhan et al. (2014) concluíram que a redução do gradiente de tensão ao longo da espessura da placa causa o aumento do retorno elástico.

Figura 18 - Representação do gradiente de tensão entre dois componentes com a mesma relação de raio de curvatura-espessura $\left(\mathrm{R}_{1} / \mathrm{H}_{1}=\mathrm{R}_{2} / \mathrm{H}_{2}\right)$

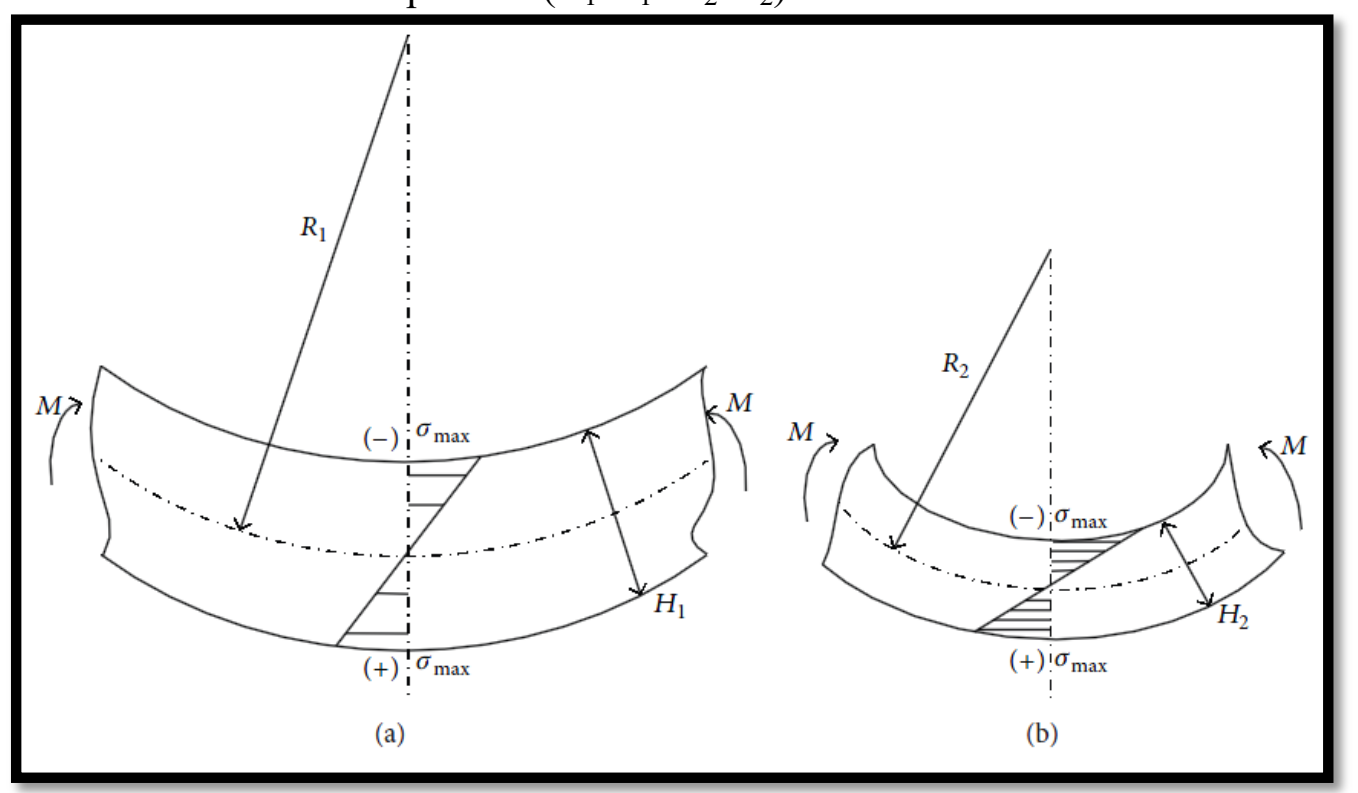

Fonte: Zhan et al., 2014, p. 5

Muitas pesquisas foram desenvolvidas em relação aos fenômenos que ocorrem durante a CFE, para compreender o comportamento do material diante de determinadas condições de processo, e uma das principais linhas de pesquisa é sobre o retorno elástico, na qual se deseja saber o melhor modelo para representá-lo e qual parâmetro gerará influência sobre o mesmo. A previsão do retorno elástico é importante para conseguir determinar a geometria do ferramental que compense esse problema, a fim de evitar erros de tolerância na peça (Jeunechamps et al., 2006). 


\subsection{MODELOS CONSTITUTIVOS DA CFE}

Os modelos constitutivos da CFE se dividem em dois grupos, os modelos simplificados e os unificados. Os modelos simplificados são governados apenas pela fluência pura, ou seja, não se considera o envelhecimento artificial da CFE e as variações na microestrutura - esses modelos são os mesmos utilizados para prever a deformação por fluência em materiais metálicos. Os modelos unificados são baseados em um conjunto de equações que possibilitam simular vários fenômenos, por exemplo, a deformação por fluência, o endurecimento por solução sólida e o aumento da densidade de discordâncias, em que todos são controlados pelo mesmo conjunto de mecanismos físicos. As equações constitutivas referenciadas de unificadas tratam a deformação inelástica com uma única equação cinética e um conjunto de variáveis internas, estas governadas por uma estrutura auxiliar de equações de evolução. Este princípio das equações constitutivas unificadas pode ser entendido através das equações 1 e 2, na qual a taxa de deformação será em função da tensão, temperatura e de uma ou mais variáveis relacionadas à microestrutura (HENSHALL; HELLING; MILLER, 1996).

$$
\begin{aligned}
& \dot{\varepsilon}=f(\sigma, T, X) \\
& \dot{X}=g(\dot{\varepsilon}, T, X)
\end{aligned}
$$

Onde:

$\sigma=$ Tensão

$\mathrm{T}=$ Temperatura

$\mathrm{X}=$ Variável dependente da microestrutura

Peddieson e Buchanan (1990) desenvolveram um dos primeiros modelos específicos para caracterizar o comportamento dos corpos de prova na CFE se fundamentando na viscoelasticidade linear. Sallah et al. (1991) desenvolveram um novo modelo baseado no modelo de Maxwell e Walker, validando com dados experimentais de ensaios de relaxação de tensão fornecidos pela empresa Textron Aerostructures.

Alguns pesquisadores utilizaram um modelo baseado no de Kowalewski et al. (1994) de mecânica do dano contínuo, que tem o objetivo de ser aplicado em situações de dano por fluência. Lin et al. (2007) simplificou esse modelo e aplicou a CFE, e comparou as 
simulações com os dados experimentais, tendo um erro relativo do retorno elástico entre $5.2 \%$ e $8,8 \%$.

Ho, Lin e Dean (2004) utilizando o conjunto de equações unificadas propostas por Kowalewski et al. (1994) também implementaram as equações, através de uma sub-rotina no programa Abaqus ${ }^{\circledR}$ de elementos finitos, em que realizaram simulações para prever o retorno elástico. Esse modelo de equações não é representativo da CFE mesmo podendo prever o retorno elástico, porém depois Ho et al. (2004) desenvolveram um novo conjunto de equações unificadas para simular os fenômenos envolvidos na CFE.

O modelo de Ho et al. (2004) possibilita simular a deformação por fluência, o endurecimento por precipitação, a evolução do tamanho do precipitado e a evolução da tensão de escoamento. A tensão de escoamento no modelo está em função do endurecimento por precipitação e do endurecimento por solução sólida (Figura 19 - b). Ho et al. (2004) assumiram o envelhecimento isotérmico e o crescimento das partículas a fração de volume constante. Esse modelo descreve bem a deformação por fluência que pode ser observado na Figura 19 (a). Mas segundo Ribeiro (2013) é limitado ao simular a tensão de escoamento no superenvelhecimento, pois a tensão de escoamento é sempre crescente no que contradiz ao modelo real que a tensão de escoamento diminui com o aumento do tempo de envelhecimento durante o superenvelhecimento. A Figura 19 (b) demonstra este efeito da tensão de escoamento $\left(\sigma_{\mathrm{y}}\right)$, na qual está sempre crescente durante o processo.

Figura 19 - (a) Comparação entre o modelo (linhas sólidas) e o experimental (símbolos) para a liga AA7010 em $150^{\circ} \mathrm{C}$; (b) Contribuição do endurecimento por precipitação $\left(\sigma_{\mathrm{A}}\right)$ e do endurecimento por solução sólida $\left(\sigma_{\mathrm{SS}}\right)$ a tensão de escoamento $\left(\sigma_{\mathrm{y}}\right)$

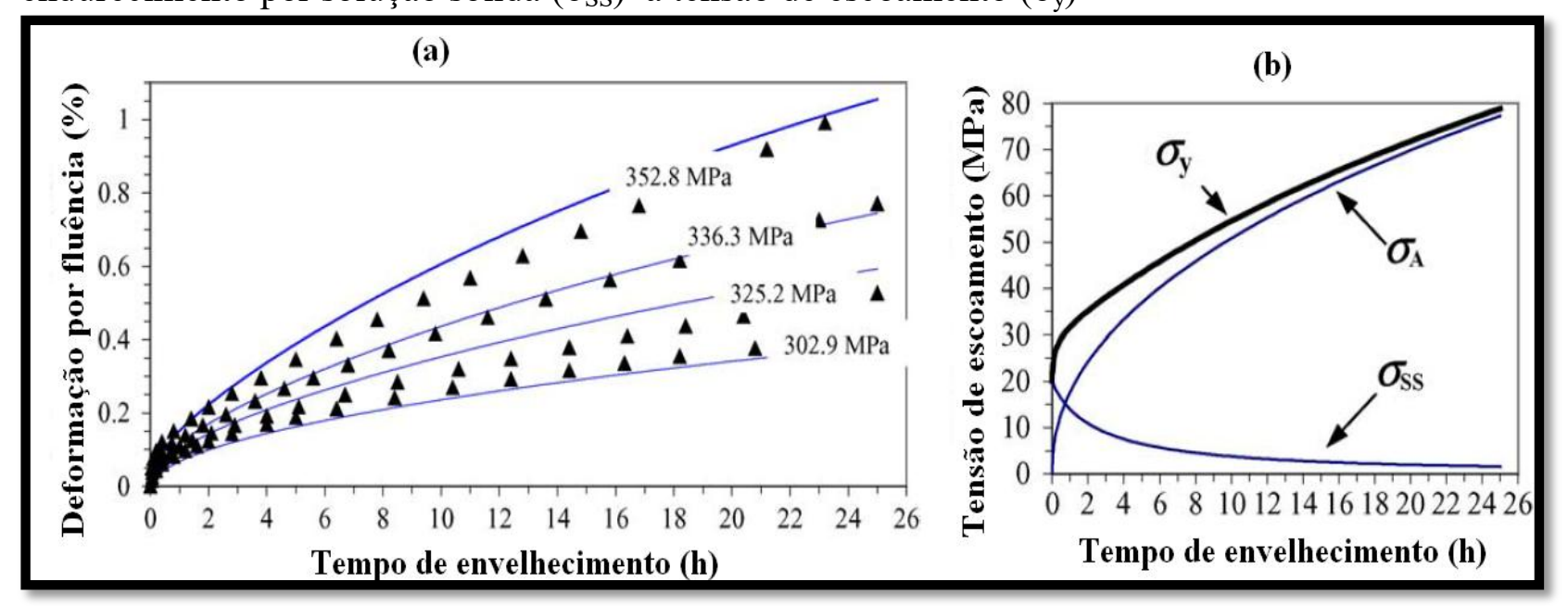

Fonte: Autor "adaptado de" Ho et al., 2004, p. 126 
O modelo de Ho et al. (2004) segundo Zhan et al. (2011) é rudimentar, por causa das considerações realizadas que não admite a variação da fração de volume dos precipitados, a forma do precipitado e só o raio do precipitado é utilizado para considerar o efeito do endurecimento por precipitação na deformação por fluência, limitando o modelo a ser aplicado somente em ligas de alumínio com precipitados esféricos.

Li et al. (2010) aplicou um modelo constitutivo unificado da CFE na liga de alumínio AA7B04, considerando mais características do precipitado, como, o tamanho, a forma e a variação da fração volumétrica.

Zhan et al. (2011) propôs um novo modelo unificado, conseguindo modelar o crescimento dos precipitados, o aumento da densidade de discordâncias, a deformação por fluência, o endurecimento devido a precipitação, o encruamento e o endurecimento por solução sólida supersaturada.

O modelo de Zhan et al. (2011) é demonstrado no seguinte conjunto de equações.

$$
\dot{\varepsilon}_{\mathrm{c}}=\mathrm{A}_{1} \operatorname{senh}\left\{\mathrm{B}_{1}\left[|\sigma|(1-\bar{\rho})-\mathrm{k}_{0} \sigma_{\mathrm{y}}\right]\right\}
$$

Onde $\mathrm{A}_{1}, \mathrm{~B}_{1}, \mathrm{k}_{0}$ são constantes do material. A equação 3 representa a evolução da deformação por fluência, em que a taxa de deformação está em função das constantes do material, mas também está em função da tensão inicial aplicada $(\sigma)$, da densidade de discordância $(\bar{\rho})$ e da tensão de escoamento $\left(\sigma_{\mathrm{y}}\right)$. Analisando a equação 3 , caso a parcela $|\sigma|(1-\bar{\rho})$ seja menor do que $\mathrm{k}_{0} \sigma_{\mathrm{y}}$, a taxa de deformação terá um valor negativo.

A tensão de escoamento (Equação 4) no modelo considera as parcelas de tensão referentes à variação do endurecimento por precipitação $\left(\sigma_{\mathrm{A}}\right)$, à variação do encruamento $\left(\sigma_{\text {dis }}\right)$ e à variação do endurecimento por solução sólida $\left(\sigma_{\mathrm{SS}}\right)$ durante o processo.

$$
\sigma_{\mathrm{y}}=\sigma_{\mathrm{ss}}+\sqrt{\sigma_{\mathrm{A}}^{2}+\sigma_{\mathrm{dis}}^{2}}
$$

A parcela da tensão de escoamento referente à variação de resistência mecânica devido à precipitação é descrita pela equação 5, na qual depende do valor do raio do precipitado normalizado $(\overline{\mathrm{r}})$, e essa equação consegue descrever a variação de resistência mecânica que ocorre no envelhecimento, como demonstrado na Figura 8. Ao contrário do modelo de Ho et al. (2004), o modelo de Zhan et al. (2011) descreve o superenvelhecimento. 


$$
\dot{\sigma}_{\mathrm{A}}=\mathrm{C}_{\mathrm{A}} \dot{\overline{\mathrm{r}}}^{\mathrm{m}^{\prime}}{ }(1-\overline{\mathrm{r}})
$$

Segundo Zhan et al. (2011), $\mathrm{m}_{1}^{\prime}$ é uma constante do material e a constante $\mathrm{C}_{\mathrm{A}}$ descreve a interação entre as discordâncias e os precipitados.

A equação 6 descreve a perda de resistência devido à diminuição de solução sólida supersaturada. Essa equação além de depender das constantes do material, depende também da variação do raio do precipitado normalizado.

$$
\dot{\sigma}_{\mathrm{ss}}=\mathrm{C}_{\mathrm{ss}}^{\prime} \dot{\mathrm{r}}^{\mathrm{m}^{\prime}}{ }_{2}(\overline{\mathrm{r}}-1)
$$

Onde $\mathrm{C}_{\mathrm{SS}}^{\prime} \mathrm{e} \mathrm{m}_{2}^{\prime}$ são constantes relacionadas à redução de soluto na matriz.

Durante a deformação por fluência há o encruamento do material, a influência do encruamento na resistência ao escoamento é descrita na equação 7 , que depende das constantes do material $\left(A_{2}\right.$ e $\left.n^{\prime}\right)$ e da densidade de discordâncias.

$$
\dot{\sigma}_{\text {dis }}=\mathrm{A}_{2} \cdot \mathrm{n}^{\prime} \cdot \bar{\rho}^{\mathrm{n}^{\prime}-1} \dot{\bar{\rho}}
$$

O modelo de Zhan et al. (2011) considera a interação entre o envelhecimento e a fluência do material, ou melhor, a interação do precitado com o aumento de discordâncias durante o processo. Esse efeito pode ser analisado na equação 8, na qual o raio do precipitado está em função da densidade de discordâncias e conforme o número de discordâncias aumenta, a taxa de crescimento dos precipitados aumentará também. Nesta equação, Zhan et al. (2011) utilizaram o raio do precipitado normalizado para simplificar a modelagem do crescimento do precipitado.

$\mathrm{O}$ raio do precipitado normalizado varia de 0 a 1 durante o envelhecimento. Quando $\overline{\mathrm{r}}>1$ o material atingiu o superenvelhecimento.

$$
\dot{\overline{\mathrm{r}}}=\mathrm{C}_{\mathrm{r}}\left(\mathrm{Q}^{\prime}-\overline{\mathrm{r}}\right)^{\mathrm{m}^{\prime}{ }_{3}}\left(1+\gamma_{0} \bar{\rho}^{\mathrm{m}_{4}}\right)
$$

O efeito das discordâncias na nucleação dos precipitados e no crescimento é controlado pelas constantes $\gamma_{0}$ e $\mathrm{m}_{4}$. A constante $\mathrm{Q}^{\prime}$ descreve a redução de soluto na matriz e as constantes $C_{r}$ e $m_{3}^{\prime}$ são relacionadas ao crescimento do precipitado (Zhan et al., 2011). 
A Figura 20 demonstra a variação do raio do precipitado normalizado e a variação da tensão de escoamento. Nesta figura nota-se que para $\overline{\mathrm{r}}>1$ o material atingiu $\mathrm{o}$ superenvelhecimento e a tensão de escoamento segue decrescente a partir do tempo de 22 horas.

Figura 20 - (a) Raio do precipitado normalizado em função do tempo para a liga AA7055 em $120^{\circ} \mathrm{C}$; (b) Tensão de escoamento em função do tempo e as suas parcelas $\left(\sigma_{\mathrm{ss}}, \sigma_{\mathrm{A}} \mathrm{e} \sigma_{\mathrm{dis}}\right)$. As linhas vermelhas (sólidas) indicam o ponto que ocorre o pico de envelhecimento e a tracejada indica a transição da fluência primária para a secundária

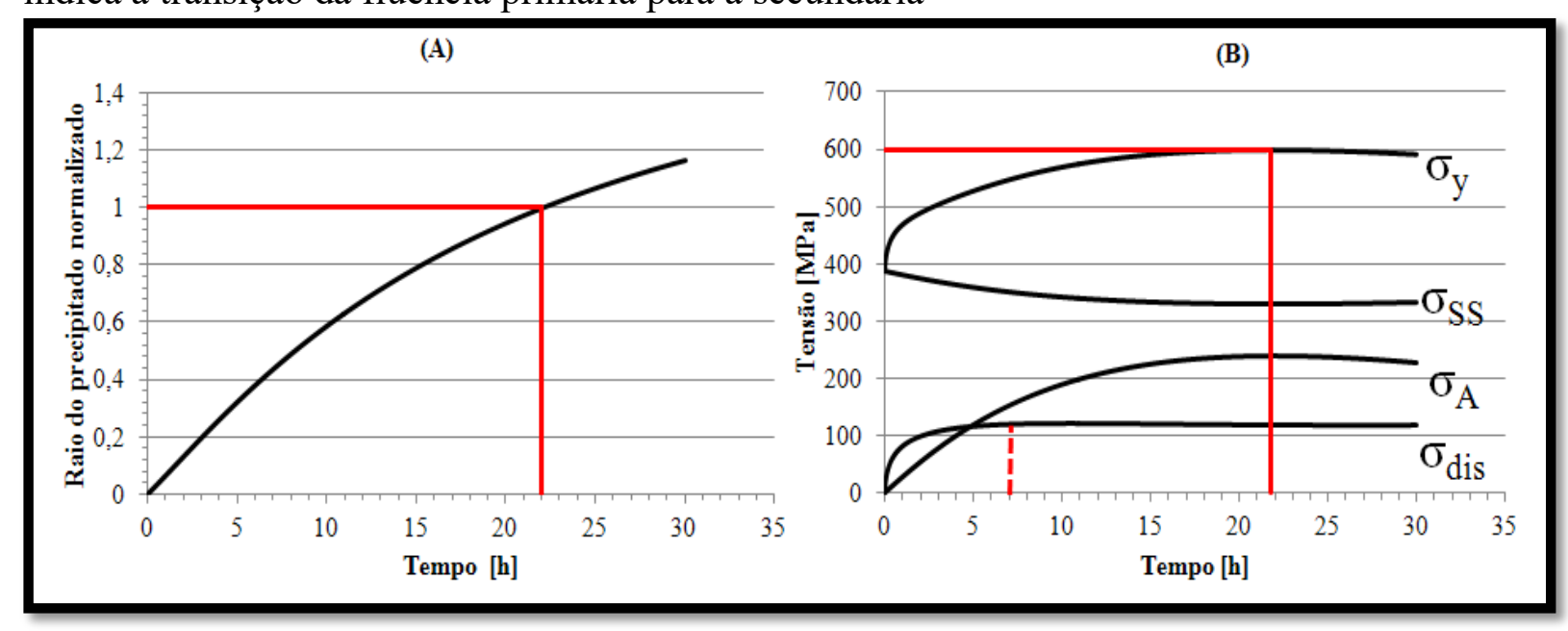

Fonte: Autor "adaptado de" Zhan et al., 2011

A Figura 20 (B) demonstra também o instante que ocorre a fluência secundária. Neste instante a tensão referente ao encruamento $\left(\sigma_{\text {dis }}\right)$ da liga segue aproximadamente constante. A fluência secundária é atingida em $\mathrm{t}=7$ horas (linhas tracejadas na Figura 20 B).

A variação da densidade de discordâncias é descrita na equação 9. Zhan et al. (2011) também normalizaram a densidade de discordância que varia de 0 a 1 .

O primeiro termo na equação 9 modela a fluência primária. Este termo depende da constante do material $A_{3}$ e da taxa de deformação por fluência. Quando a fluência passa para o estágio secundário em que a taxa de deformação é aproximadamente constante, a variação de discordâncias será afetada. O segundo termo da equação descreve a recuperação estática (aniquilação e rearranjo de discordâncias) na densidade discordâncias em altas temperaturas e as constantes $\mathrm{C}_{\mathrm{p}}$ e $\mathrm{m}_{5}$ são relacionadas a esse efeito (ZHAN et al., 2011).

$\dot{\bar{\rho}}=A_{3}(1-\bar{\rho})\left|\dot{\varepsilon}_{c}\right|-C_{p} \bar{\rho}^{m_{5}}$ 
A partir da Figura 21 nota-se o comportamento da densidade de discordâncias que é descrito pela equação 9. A taxa da densidade de discordâncias normalizada é reduzida significativamente quando o material atinge a fluência secundária.

Figura 21 - (A) Densidade de discordâncias normalizada em função do tempo;

(B) Deformação por fluência em função do tempo. Ambas as figuras são para a liga AA 7055 em $120^{\circ} \mathrm{C}$. As linhas tracejadas indicam a transição da fluência primária para a secundária

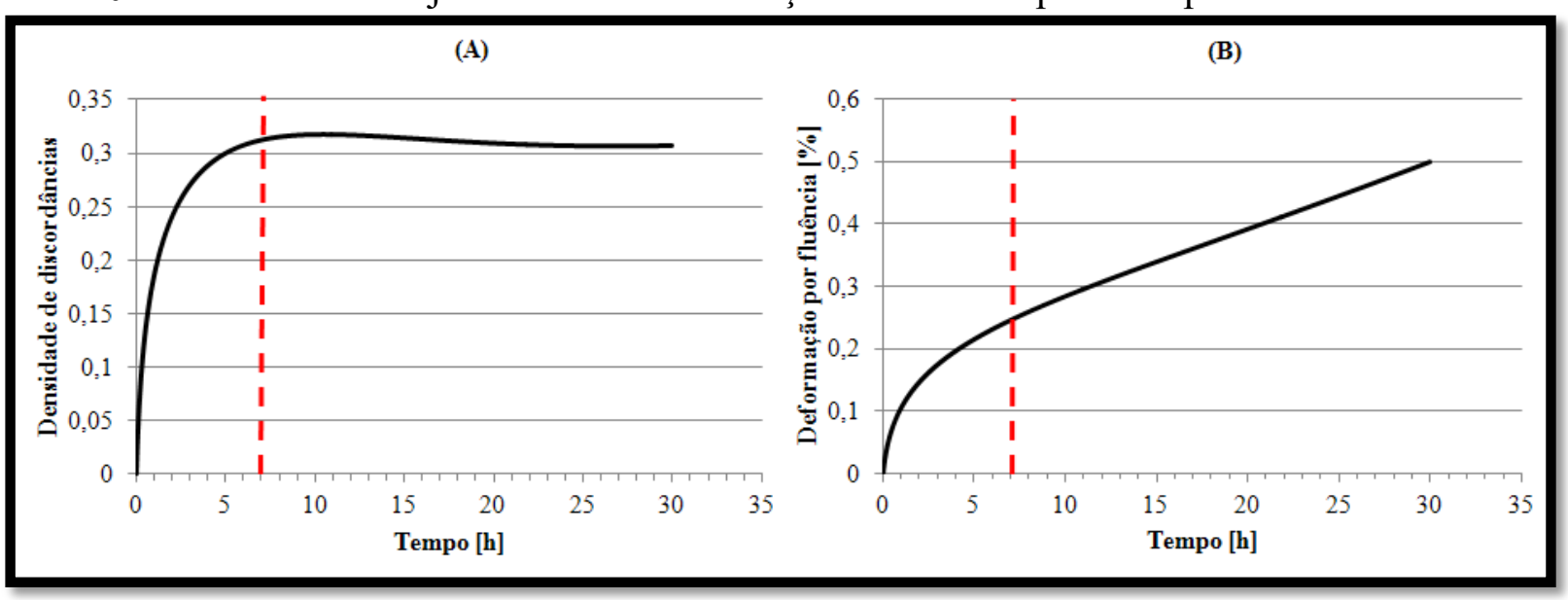

Fonte: Autor "adaptado de" Zhan et al., 2011

Os valores das constantes do modelo de Zhan et al. (2011) são apresentadas na Tabela 1 para as ligas AA7055, AA2219 e AA7B04. Esses valores foram publicados no artigo de Zhan et al. (2011) para a liga AA7055, no artigo de Lam et al. (2015a) para a liga AA2219 e no artigo de Lam et al. (2015b) para a liga AA7B04. A composição dessas ligas pode ser observada nas tabelas 2,3 e 4 .

Tabela 1- Constantes do modelo de Zhan et al. (2011)

\begin{tabular}{|c|c|c|c|c|}
\hline Constantes & $\begin{array}{l}\text { AA7055 } \\
\left(120^{\circ} \mathrm{C}\right)\end{array}$ & $\begin{array}{r}\text { AA2219 } \\
\left(175^{\circ} \mathrm{C}\right)\end{array}$ & $\begin{array}{c}\mathbf{A A 7 B 0 4} \\
\left(115^{\circ} \mathrm{C}\right)\end{array}$ & Equação \\
\hline A1 & $5 \mathrm{E}-05$ & $1 \mathrm{E}-10$ & $1,95 \mathrm{E}-06$ & \multirow{3}{*}{3} \\
\hline B1 & 0,0279 & 0,101 & 0,042 & \\
\hline Ko & 0,2 & 0,08 & 0,16 & \\
\hline $\mathrm{C}_{\mathrm{A}}$ & 94,3 & 50,1 & 4 & \multirow{2}{*}{5} \\
\hline ml' & 0,44 & 0,42 & 0,9 & \\
\hline C'ss & 20 & 15 & 0,2 & \multirow[b]{2}{*}{6} \\
\hline $\mathrm{m2}^{\prime}$ & 0,4 & 0,85 & 0,45 & \\
\hline $\mathbf{n}^{\prime}$ & 0,8 & 0,9 & 0,7 & \multirow{2}{*}{7} \\
\hline A2 & 291,5 & 520 & 260 & \\
\hline $\mathrm{Cr}$ & 0,032 & 0,032 & 0,098 & \multirow{5}{*}{8} \\
\hline $\mathbf{Q}^{\prime}$ & 1,69 & 7,76 & 1,8 & \\
\hline$\gamma o$ & 2,7 & 2,7 & 3 & \\
\hline m3' & 1,3 & 1,6 & 2,2 & \\
\hline m4 & 1,98 & 2,1 & 2 & \\
\hline $\mathbf{A 3}$ & 200 & 35 & 150 & \multirow{3}{*}{9} \\
\hline$C_{\mathbf{p}}$ & 0,07 & 0,318 & 0,145 & \\
\hline m5 & 1,3 & 1,01 & 1,5 & \\
\hline
\end{tabular}

Fonte: Autor “adaptado de” Zhan et al., 2011; Lam et al., 2015a; Lam et al., 2015b 
Tabela 2 - Composição química dos principais elementos da liga AA7055 (\% peso)

\begin{tabular}{|c|c|c|}
\hline \multicolumn{3}{|c|}{$\mathrm{AA} 7055$} \\
\hline $\mathrm{Cu}$ & $\mathrm{Mg}$ & $\mathrm{Zn}$ \\
\hline $2,0-2,6$ & $1,8-2,3$ & $7,6-8,4$ \\
\hline
\end{tabular}

Fonte: Zhan et al., 2011

Tabela 3 - Composição química da liga AA2219 (\% peso)

\begin{tabular}{|c|c|c|c|c|c|}
\hline \multicolumn{6}{|c|}{ AA2219 } \\
\hline $\mathrm{Cu}$ & $\mathrm{Mn}$ & $\mathrm{Si}$ & $\mathrm{Fe}$ & $\mathrm{Ti}$ & $\mathrm{Cr}$ \\
\hline 6,3 & 0,3 & 0,2 & 0,3 & 0,06 & 0,18 \\
\hline
\end{tabular}

Fonte: Lam et al., 2015a

Tabela 4 - Composição química da liga AA7B04 (\% peso)

\begin{tabular}{|c|c|c|c|c|c|c|c|c|}
\hline \multicolumn{10}{|c|}{ AA7B04 } \\
\hline $\mathrm{Zn}$ & $\mathrm{Mg}$ & $\mathrm{Cu}$ & $\mathrm{Mn}$ & $\mathrm{Fe}$ & $\mathrm{Cr}$ & $\mathrm{Si}$ & $\mathrm{Ni}$ & $\mathrm{Ti}$ \\
\hline 5,97 & 2,48 & 1,51 & 0,33 & 0,16 & 0,16 & 0,07 & $<0,05$ & $<0,05$ \\
\hline
\end{tabular}

Fonte: Lam et al., 2015b

O modelo unificado de Zhan (2011) consegue descrever a CFE mesmo considerando que o precipitado cresce a fração de volume constante e sem considerar a variação da relação de aspecto do precipitado.

Lam et al. (2015a) aplicou o modelo de Zhan (2011) em simulações de elementos finitos (para algumas geometrias) e comparou com os dados experimentais de uma liga de alumínio AA2219 na condição T4 (solubilizada e envelhecida naturalmente) e T87 (solubilizada, trabalhada a frio e envelhecida artificialmente), os resultados obtidos são mostrados na Tabela 5. Os resultados mostram que o modelo gerou uma boa estimativa do retorno elástico quando comparado aos resultados experimentais.

Tabela 5 - Medidas experimentais e previstas do retorno elástico

\begin{tabular}{lcccc}
\hline & Geometrias & Experimento (T4) & Simulação (T4) Simulação (T87) \\
\hline Deslocamento (mm) & 1 & 24,3 & 23,8 & 22,0 \\
& 2 & 24,4 & 23,8 & 22,4 \\
& 3 & 24,1 & 24,4 & 23,0 \\
& 4 & 25,1 & 24,2 & 22,4 \\
Retorno elástico (\%) & 1 & & & \\
& 2 & 15,0 & 16,8 & 23,1 \\
& 3 & 14,7 & 16,8 & 21,7 \\
& 4 & 15,7 & 14,7 & 19,6 \\
& & 12,2 & 15,4 & 21,7 \\
\hline
\end{tabular}

Fonte: Autor “adaptado de" Lam et al., 2015a 
Os modelos unificados da CFE exigem a realização de muitos ensaios experimentais, desde ensaios de fluência e relaxação de tensão à caracterização microestrutural da liga para determinar as constantes do material nas equações. Devido a esse problema alguns pesquisadores preferem buscar modelos mais simples que sejam mais viáveis, mas que forneça valores o mais próximo possível do modelo real. Inforzato et al. (2012) calculou o valor do retorno elástico de um painel com reforçadores, (ambos de liga de alumínio da série AA7475) aplicando um modelo semi empírico, no qual é calibrado com os valores dos deslocamentos medidos experimentalmente.

A maioria dos modelos matemáticos de fluência que estão implementados nos códigos de elementos finitos são modelos empíricos, baseados na análise experimental da fluência. Os modelos expressam a deformação por fluência ou a taxa de deformação por fluência em função da tensão, tempo e temperatura - em algumas equações a temperatura não está explícita, pois os parâmetros dos materiais são considerados em função da temperatura (STOUFFER; DAME, 1996).

Alguns modelos desenvolvidos desprezam o estágio primário de fluência e são limitados por descrever apenas o estágio secundário da fluência, como a lei de fluência de Norton (1929), demonstrada na equação 10. Esta é amplamente utilizada nos códigos de elementos finitos, principalmente em problemas que envolvem a previsão do ciclo de vida de um componente, para realizar a manutenção corretamente.

$$
\dot{\varepsilon}_{\mathrm{c}}=\mathrm{K} * \sigma_{\text {inicial }} \mathrm{n}_{\text {norton }}
$$

Onde:

$\mathrm{K}=$ Constante do material

$\mathrm{n}_{\text {norton }}=$ Expoente de tensão para fluência

$\dot{\varepsilon}_{\mathrm{c}}=$ Taxa de deformação por fluência

$\sigma_{\text {inicial }}=$ Tensão aplicada

A lei de fluência de Norton (1929) foi utilizada no estudo da CFE por Brandão (2013) para prever o retorno elástico. Nesse trabalho as constantes da equação foram ajustadas utilizando dados experimentais da CFE para diferentes níveis de tensão de modo a possibilitar a previsão somente da deformação final do componente, devido à limitação do modelo, como demonstra a Figura 22. O autor comparou os dados experimentais de retorno elástico com os dados de simulação com uma geometria de curvatura simples e obteve valores bem próximos. 
Adicionalmente, os resultados do retorno elástico se assemelharam aos encontrados na literatura.

Figura 22 - Comparação entre modelo simplificado e curva de fluência

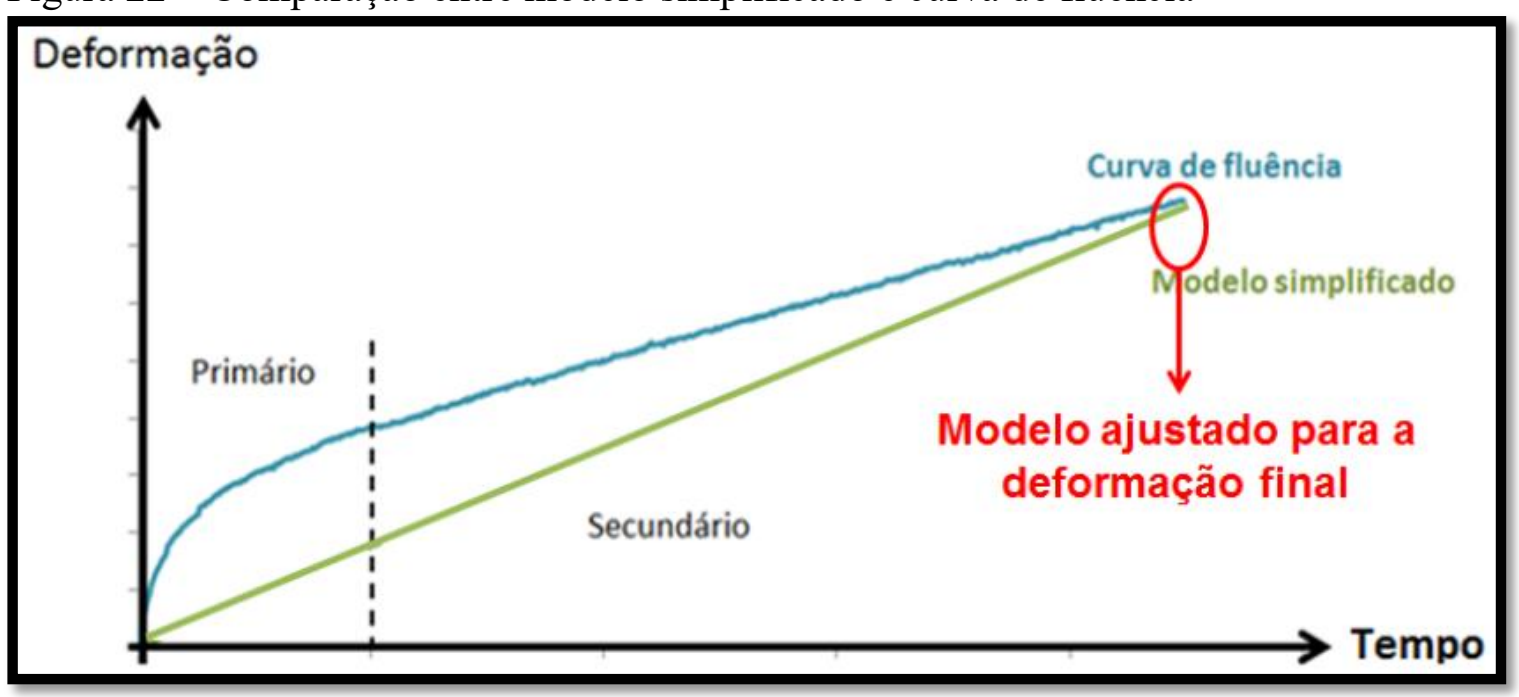

Fonte: Brandão, 2013, p. 39

O modelo de fluência de Norton (1929) que é uma lei de potência, também foi estudado por Ribeiro (2013) para prever o retorno elástico. O erro relativo do retorno elástico entre os dados experimentais e simulados foi de $20 \%$, para as condições utilizadas pelo autor nos experimentos e nas simulações. Ribeiro (2013) em seu trabalho abordou também o modelo de Marin-Pao, demonstrado na equação 11, inclusive propôs a modificação do modelo para aderir melhor às curvas experimentais de fluência. O modelo de Marin-Pao pode ser encontrado nas seguintes referências: Marin e Pao (1951); Stourffer e Dame (1996).

A equação 12 descreve o modelo de Marin-Pao modificado, que teve as suas constantes substituídas por leis de potência.

$$
\varepsilon_{c}=A_{m p}\left(1-e^{-k t}\right)+B_{m p} t
$$

As constantes $\mathrm{A}_{\mathrm{mp}}$ e $\mathrm{k}$ representam o comportamento de fluência no estágio primário e $\mathrm{B}_{\mathrm{mp}}$ a fluência no estágio secundário.

$$
\varepsilon(t)=\alpha_{1} \sigma^{N_{1}}\left(1-\exp \left(-\left(\alpha_{2} \sigma^{N_{2}}\right) t\right)\right)+\alpha_{3} \sigma^{N_{3}} t
$$


Os modelos simplificados de Norton (1929) e Marin-Pao (1951) são modelos de fluência que podem ser utilizados na CFE, porém desde quando a CFE foi utilizado pela primeira vez, foram criados novos modelos constitutivos especialmente para o processo. A escolha do modelo (simplificado ou unificado) a ser aplicado leva em consideração os ensaios que poderão ser realizados no projeto.

O modelo constitutivo aplicado no presente trabalho foi o de Zhang et al. (2013), o qual possibilita simular mais fenômenos relacionados ao envelhecimento da liga de alumínio, quando comparados aos modelos constitutivos unificados comentados anteriormente. Nesse modelo é considerada a variação da fração de volume e da relação de aspecto do precipitado. Os dois fenômenos citados anteriormente, no modelo de Zhan (2011) eram representados por alguma constante do material, ou seja, não eram explícitos. Alguns pesquisadores indicaram que a relação de aspecto afeta a tensão de escoamento em ligas de alumínio envelhecidas (ZHANG et al., 2013). Portanto, considerando a variação da relação de aspecto, o modelo se aproximará mais da realidade.

O modelo de Zhang et al. (2013) pode ser aplicado em ligas de alumínio com precipitados em forma de disco ou agulha (Figura 23). Nas equações do modelo a forma do precipitado é descrita através do comprimento (l) e da relação de aspecto (q), esta inclui a espessura (h) ou o diâmetro (d) do precipitado na sua fórmula (Figura 23). Segundo Zhang et al. (2013) o modelo trata os efeitos dos precipitados de diferentes fases de maneira geral, para as ligas de alumínio com precipitados complexos o modelo poderá não ser adequado.

Figura 23 - Parâmetros da geometria do precipitado e morfologias dos precipitados: (a) Disco/Placa; (b) Bastão/Agulha

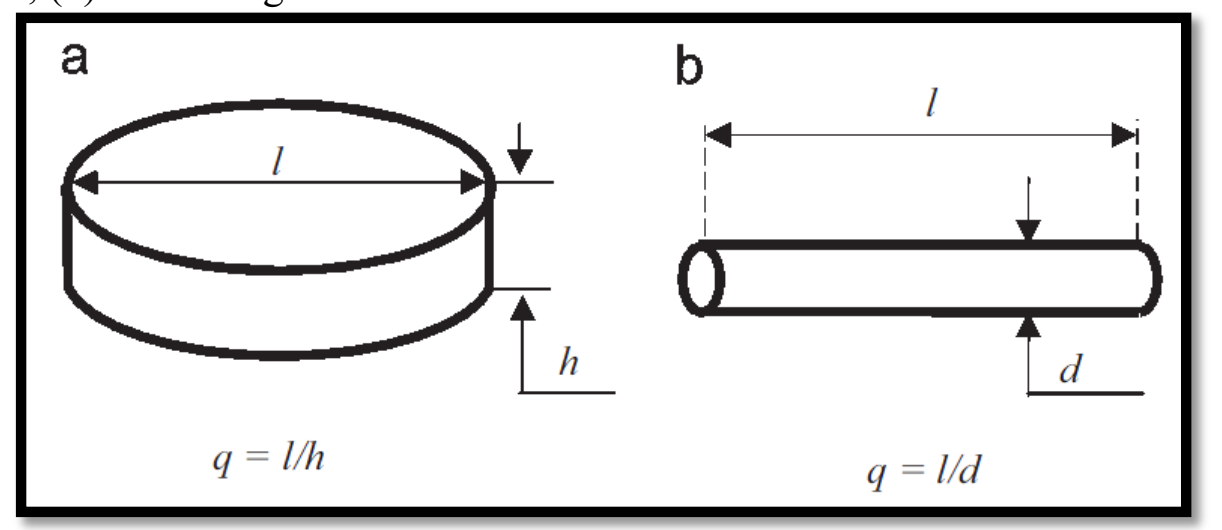

Fonte: Zhang et al., 2013, p. 9

Os precipitados em forma de placa podem ser observados na Figura 24 que mostra a micrografia da liga da série AA7000 na têmpera T6 (solubilização e envelhecimento 
artificial). Segundo Nicolas (2002) os precipitados em forma de placas consistem na fase de transição n’ (precipitados destacados na Figura 24).

Figura 24 - Micrografia eletrônica de transmissão da liga da série AA7000 na têmpera T6, destacando o precipitado em forma de placa

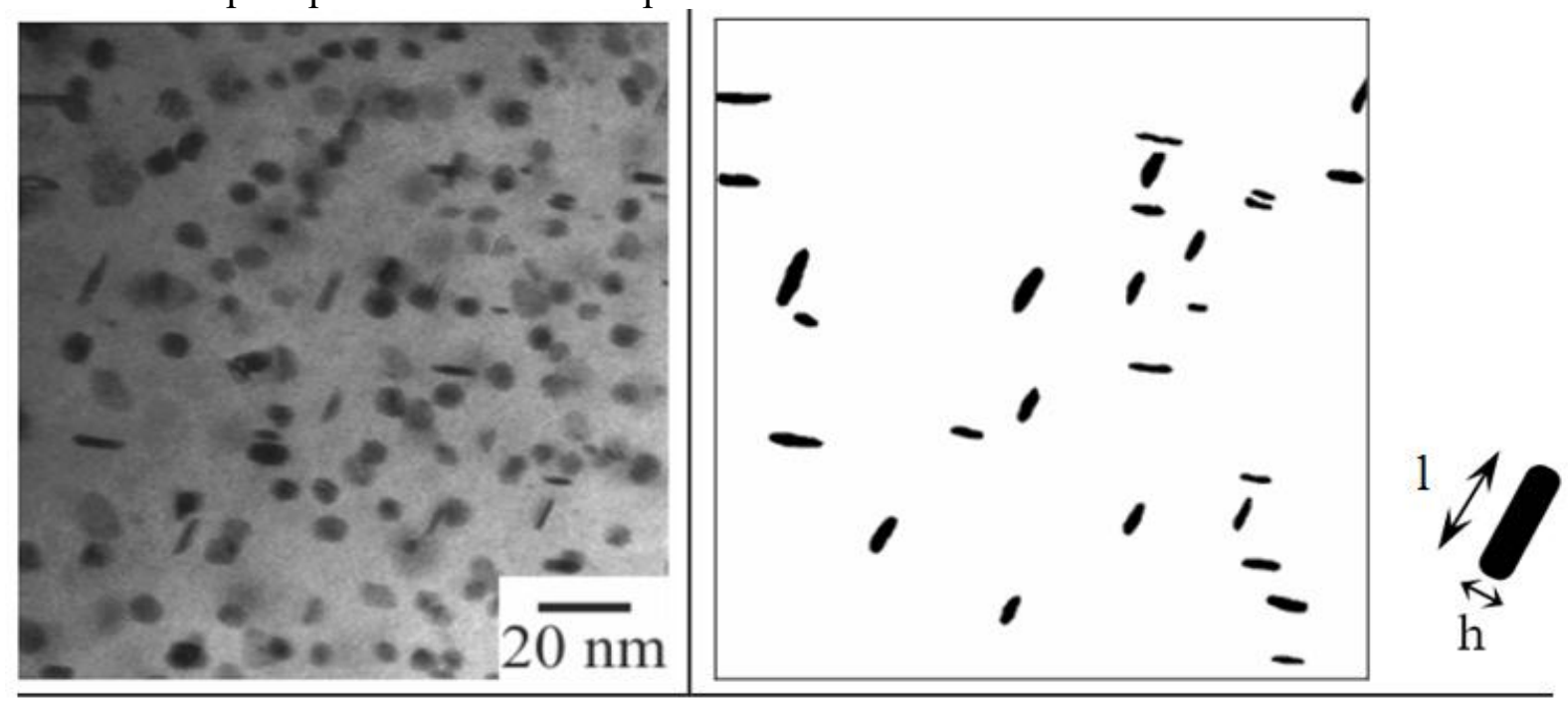

Fonte: Autor “adaptado de" Nicolas, 2002, p.66

A Figura 25 mostra os precipitados em forma de bastão da fase $\beta$ ' para a liga da série AA 6000 depois de 30 horas de envelhecimento na temperatura de $180^{\circ} \mathrm{C}$.

Figura 25 - Micrografia eletrônica de transmissão da liga da série AA 6000

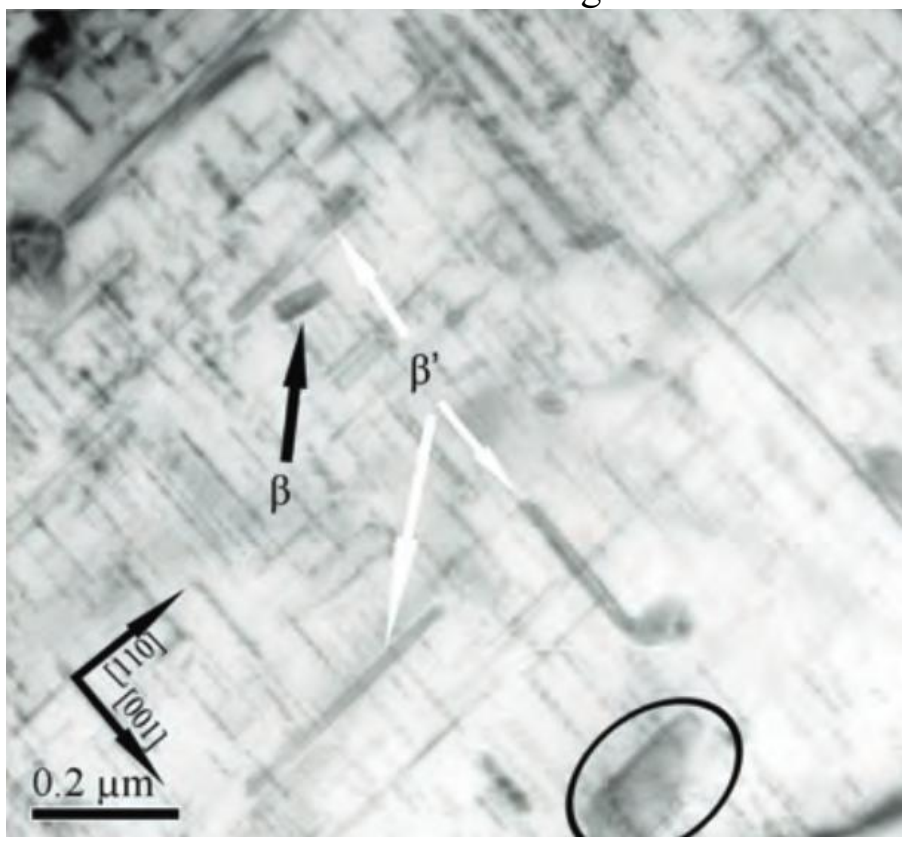

Fonte: Fang et al., 2010, p.177 
É importante destacar que o modelo proposto por Zhang et al. (2013) foi desenvolvido para modelar a CFE em uma liga de alumínio, devido a aplicação do processo ser direcionada as ligas de alumínio.

O modelo de Zhang et al. (2013) é demonstrado no seguinte conjunto de equações:

a) a equação 13 descreve a taxa de deformação $\left(\dot{\varepsilon}_{\mathrm{c}}\right)$ durante a CFE, o único parâmetro que varia na equação durante o processo é a tensão de escoamento $\sigma_{\mathrm{y}}$ que é dependente da evolução da microestrutura e da variação das propriedades da liga de alumínio. A equação também é função da tensão aplicada $(\sigma)$ e das constantes do material (A, B, n e Q);

$\dot{\varepsilon}_{\mathrm{c}}=\operatorname{Asenh}\left(\frac{\mathrm{B} \sigma}{\sigma_{\mathrm{y}}}\right)^{\mathrm{n}} \exp \left(-\frac{\mathrm{Q}}{\mathrm{RT}}\right)$

b) a equação 14 representa a taxa de fração volumétrica $\left(\dot{\overline{\mathrm{f}}}_{\mathrm{v}}\right)$ de precipitados normalizada (a fração é normalizada em relação à máxima fração volumétrica), quando a fração volumétrica normalizada atingir o valor máximo, ou seja, for igual a 1 , o valor da taxa é igual a 0 , atingiu a saturação. A influência da temperatura na equação é através da relação de aspecto, do tamanho característico do precipitado (1) e da taxa de crescimento do tamanho característico do precipitado ( i). A equação também está em função das constantes do material $\left(\mathrm{C}_{1}, \mathrm{n}_{1}, \mathrm{~m}_{1}\right)$ e do parâmetro $\mathrm{n}_{2}$ que é relacionado com a forma do precipitado. Precipitados com formato de disco $\mathrm{n}_{2}$ é igual a 1 e precipitados com formato de agulha $\mathrm{n}_{2}$ é igual a 2 .

$\dot{\bar{f}}_{\mathrm{v}}=\frac{\mathrm{C}_{1} \mathrm{I}^{\mathrm{n}_{1}} \dot{\mathrm{l}}}{\mathrm{q}^{\mathrm{n}_{2}}}\left(1-\overline{\mathrm{f}}_{\mathrm{v}}\right)^{\mathrm{m}_{1}}$

A Figura 26 demonstra o comportamento da fração volumétrica relativa em função do tempo que pode ser descrita pela equação 14; 
Figura 26 - Fração volumétrica relativa em função do tempo simulada por Zhang et al. (2013) com os dados experimentais de Liu et al. (2003)

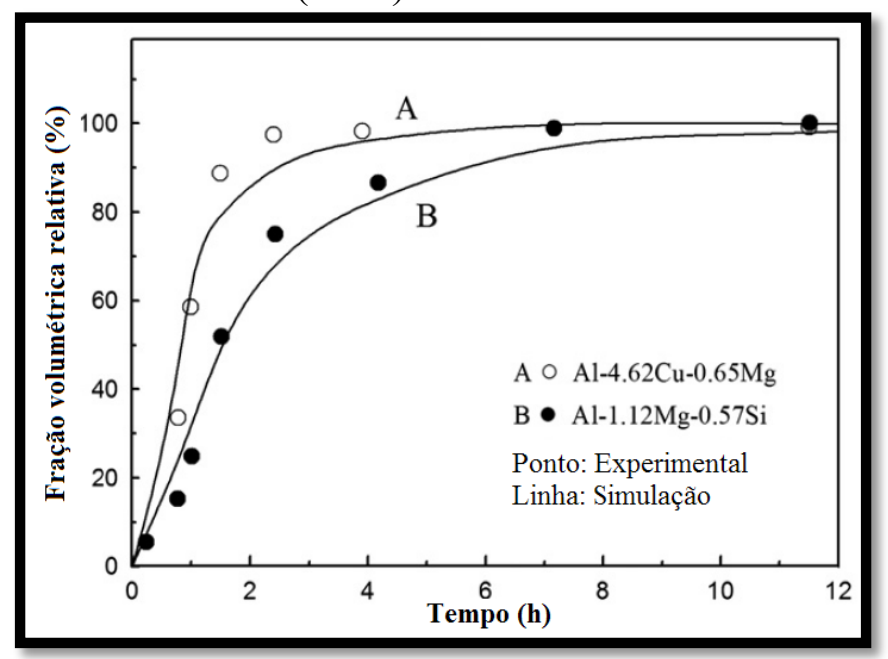

Fonte: Zhang et al. (2013); Liu et al. (2003)

c) a equação 15 representa a taxa de crescimento do tamanho característico do precipitado ( $\mathrm{l}$ ), em que $\mathrm{m}_{2}, \mathrm{C}_{2}$ e $\mathrm{Q}_{1}$ são constantes do material, $\mathrm{Q}_{2}$ é a energia de ativação relacionada ao crescimento dos precipitados. Na CFE o crescimento dos precipitados é afetado pelo aumento da densidade de discordâncias, na equação as constantes $\mathrm{k}_{1}$ e $\mathrm{n}_{3}$ controlam esse efeito, assim como a densidade de discordâncias móveis normalizada $\left(\bar{\rho}_{\mathrm{m}}\right)$ e a taxa de densidade de discordâncias móveis normalizada $\left(\dot{\bar{\rho}}_{\mathrm{m}}\right)$. Analisando a equação percebe-se a possibilidade de descrever também somente o fenômeno de envelhecimento artificial, caso o valor da densidade de discordâncias móveis normalizada for igual a 0 (não terá fluência);

$\mathrm{i}=\mathrm{C}_{2}\left(\mathrm{Q}_{1}-\mathrm{l}\right)^{\mathrm{m}_{2}}\left(1+\mathrm{k}_{1} \bar{\rho}_{\mathrm{m}} \mathrm{n}_{3} \dot{\bar{\rho}}_{\mathrm{m}}\right) \exp \left(-\frac{\mathrm{Q}_{2}}{\mathrm{RT}}\right)$

d) a taxa de densidade de discordâncias móveis normalizada é descrita na equação 16, onde $\mathrm{C}_{3}$ e $\mathrm{Q}_{3}$ são constantes do material. A equação 16 é semelhante à equação 9 do modelo de Zhan et al. (2011), porém a equação 16 não descreve a recuperação estática;

$\dot{\bar{\rho}}_{\mathrm{m}}=\mathrm{C}_{3}\left(\mathrm{Q}_{3}-\bar{\rho}_{\mathrm{m}}\right) \dot{\varepsilon}_{\mathrm{c}}$ 
e) na equação 17 tem-se a relação de aspecto do precipitado em função das constantes do material $\left(\mathrm{C}_{4}, \mathrm{k}_{2}\right.$ e $\left.\mathrm{k}_{3}\right)$, da temperatura $\left(\mathrm{T}^{*}\right)$ e do tempo $\left(\mathrm{t}^{*}\right)$ na máxima relação de aspecto.

$$
q=\frac{C_{4}}{\exp \left[k_{2}\left(T-T^{*}\right)^{2}+k_{3}\left(t-t^{*}\right)^{2}\right]}
$$

A Figura 27 demonstra o comportamento da relação de aspecto em função do tempo que pode ser descrita pela equação 17. Zhang et al. (2013) adaptaram a função da distribuição normal para representar a relação de aspecto no processo de envelhecimento, visto que a relação de aspecto exibe um comportamento semelhante ao de uma curva normal;

Figura 27 - Representação da relação de aspecto do precipitado em função do tempo

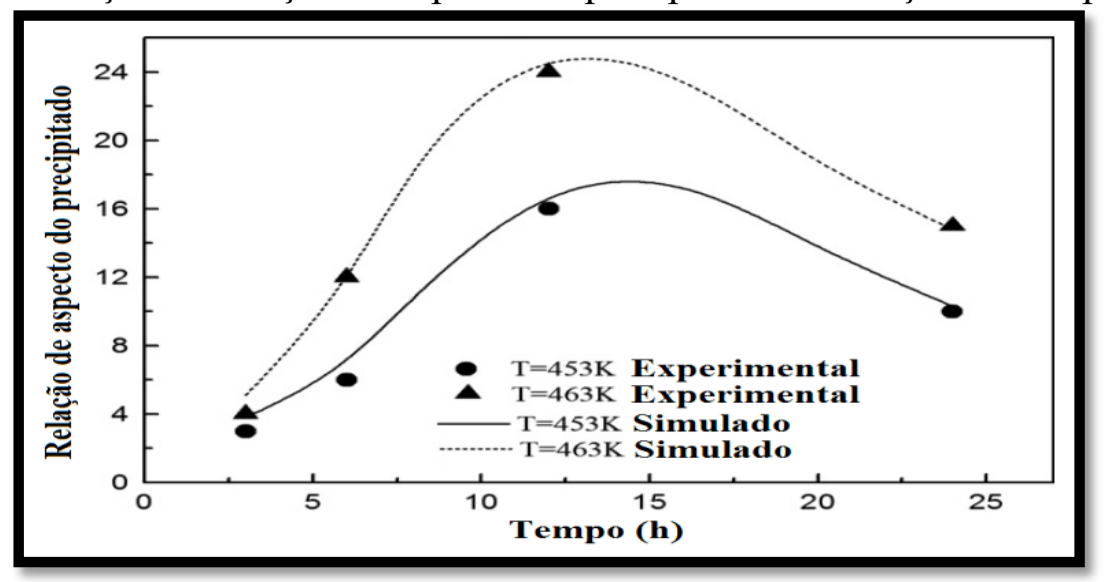

Fonte: Zhang et al. (2013)

f) a tensão de escoamento na CFE é descrita na equação 18 , em que esta equação é a soma das tensões referentes ao endurecimento da matriz de alumínio $\left(\sigma_{0}\right)$, endurecimento por solução sólida supersaturada $\left(\sigma_{\mathrm{ss}}\right)$, endurecimento por precipitação $\left(\sigma_{\mathrm{ppt}}\right)$ e ao encruamento $\left(\sigma_{\text {dis }}\right)$;

$\sigma_{\mathrm{y}}=\sigma_{0}+\sigma_{\mathrm{ss}}+\sigma_{\mathrm{ppt}}+\sigma_{\mathrm{dis}}$

g) a parcela da tensão de escoamento referente à solução sólida supersaturada é descrita na equação 19 , onde $\mathrm{C}_{\mathrm{ss}}$ é uma constante dependente da concentração de soluto na matriz e $\mathrm{m}_{3}$ é uma constante do material; 
$\sigma_{\mathrm{ss}}=\mathrm{C}_{\mathrm{sS}}\left(1-\overline{\mathrm{f}}_{\mathrm{v}}\right)^{\mathrm{m}_{3}}$

h) quando a CFE inicia, a equação 20 proposta por Zhang et al. (2013) descreve a mudança da tensão de escoamento devido à precipitação, onde $C_{\mathrm{ppt}}, \mathrm{n}_{4} \mathrm{e} \mathrm{n}_{5}$ são constantes do material;

$\sigma_{\text {ppt }}=C_{p p t}\left(\bar{q}_{\mathrm{v}}\right)^{\mathrm{n} 4} l^{\mathrm{n}_{5}}$

i) conforme a deformação na CFE aumenta, ocorre o encruamento do material, o ganho de resistência ao escoamento por causa do encruamento é descrito pela equação 21 , onde $\mathrm{C}_{\text {dis }}$ é uma constante do material. A equação 21 segue aproximadamente constante quando o material atinge a fluência secundária e exibe um comportamento semelhante ao demonstrado na Figura 21 (B) para o modelo de Zhan et al. (2011).

$\sigma_{\text {dis }}=\mathrm{C}_{\mathrm{dis}} \bar{\rho}_{\mathrm{m}}{ }^{1 / 2}$

A Tabela 6 demonstra os valores das constantes do modelo publicadas por Zhang et al. (2013) para a liga AA2124. O presente trabalho tentou utilizar as constantes publicadas por Zhang et al. (2013) no modelo da CFE, mas não obteve êxito (as constantes não conseguiram descrever as curvas de fluência). Para contornar este problema, foi proposto um novo ajuste do modelo da CFE aos dados experimentais de Zhang et al. (2013). Tal ajuste será discutido no capítulo de materiais e métodos.

Tabela 6 - Constantes do modelo de Zhang et al. (2013) para a liga AA2124

\begin{tabular}{|c|c|c|c|c|c|}
\hline $\mathbf{A}$ & $6,77 \mathrm{E}+09$ & $\mathbf{m}_{2}$ & 2 & $t^{*}$ & 16 \\
\hline B & 1,54 & $\mathbf{k}_{1}$ & -1 & $\mathrm{C}_{\mathrm{ss}}$ & 176 \\
\hline $\mathbf{n}$ & 4,2 & $\mathbf{n}_{3}$ & 2,4 & $\mathbf{m}_{3}$ & 1,2 \\
\hline $\mathbf{Q}$ & 121600 & $\mathbf{Q}_{2}$ & 54400 & $\mathbf{C}_{\mathrm{ppt}}$ & 0,36 \\
\hline $\mathrm{C}_{1}$ & $1,8 \mathrm{E}-09$ & $\mathrm{C}_{3}$ & 1,12 & $\mathbf{n}_{4}$ & $-0,38$ \\
\hline $\mathbf{n}_{1}$ & 3 & $\mathbf{Q}_{3}$ & 1,76 & $\mathbf{n}_{5}$ & 1,34 \\
\hline $\mathbf{n}_{2}$ & 1 & $\mathrm{C}_{4}$ & 28,3 & $\mathbf{C}_{\mathrm{dis}}$ & 197,2 \\
\hline $\mathbf{m}_{1}$ & 1,33 & $\mathbf{k}_{2}$ & 0,0022 & $\sigma_{0}$ & 80 \\
\hline $\mathrm{C}_{2}$ & 345,5 & $\mathbf{k}_{3}$ & 0,01 & & \\
\hline $\mathbf{Q}_{1}$ & 660 & $\mathbf{T}^{*}$ & 193 & & \\
\hline
\end{tabular}

Fonte: Zhang et al., 2013 
Nos modelos constitutivos da CFE citados anteriormente ao de Zhang et al. (2013), a temperatura não está explicita, como no modelo de Zhan et al. (2011), e isso implicará que o modelo só será representativo para uma dada temperatura. Caso seja necessário descrever a CFE em outra temperatura, novas constantes do material devem ser encontradas. No modelo de Zhang et al. (2013) a temperatura é tratada como uma variável independente, que possibilita estabelecer a base para representar a CFE em temperaturas variadas.

A fim de calibrar o modelo, Zhang et al. (2013) realizaram uma série de ensaios de fluência variando a tensão aplicada (192MPa, 241MPa e $265 \mathrm{MPa})$ nas temperaturas de $180^{\circ} \mathrm{C}$ e $190^{\circ} \mathrm{C}$. Depois de calibrado foram realizados novos ensaios de fluência variando somente a tensão aplicada na temperatura de $185^{\circ} \mathrm{C}$. Por fim, os resultados experimentais foram comparados com os dados obtidos utilizando o modelo na temperatura de $185^{\circ} \mathrm{C}$. Os resultados finais são demonstrados na Figura 28. Analisando os resultados de Zhang et al. (2013) observa-se a aproximação do modelo em relação aos dados experimentais.

Figura 28 - Comparação entre a deformação por fluência prevista no modelo e a experimental, para a liga de alumínio AA2124

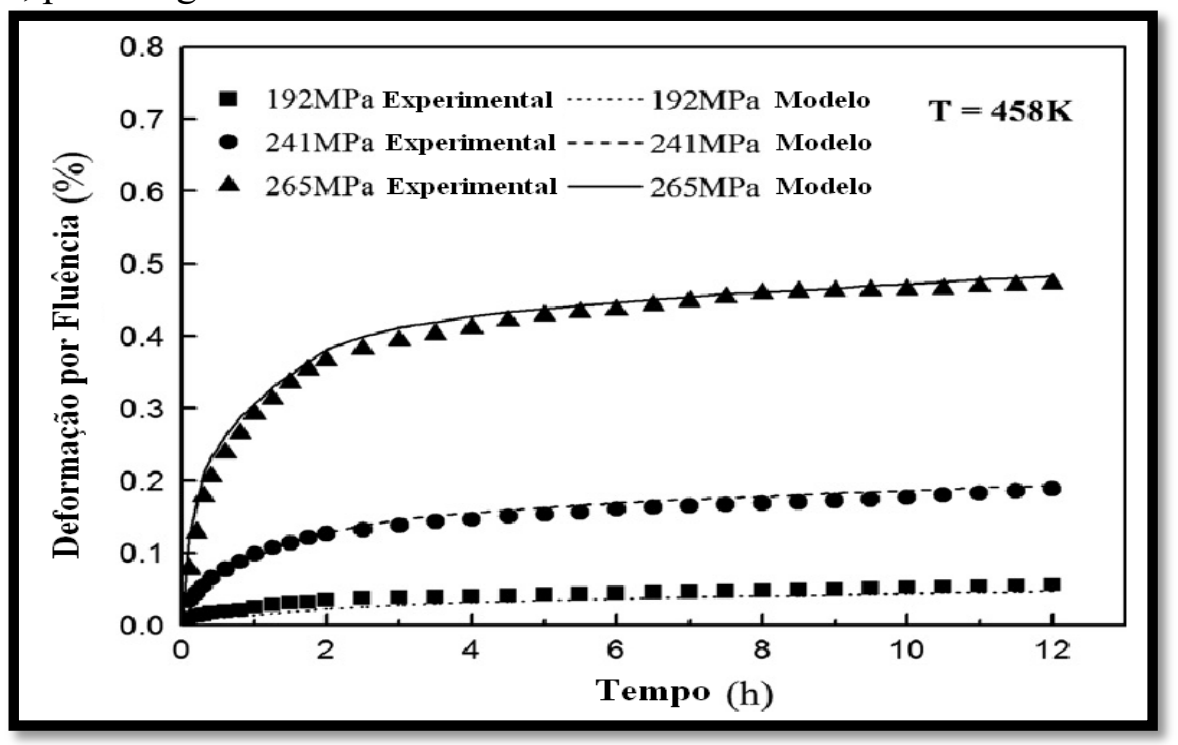

Fonte: Autor "adaptado de" Zhang et al., 2013, p. 15

Uma observação importante realizada por Brandão (2013), que pode ser observada nos modelos constitutivos apresentados, é o fato do mecanismo de fluência, aliado ao envelhecimento da liga, possuir comportamentos diferentes entre regiões sob tração e compressão e os modelos não levam em consideração tal fato, mesmo a placa (conformada na CFE) tendo tensões trativas e compressivas ao longo de sua espessura. 
Yang, Zhan e Li (2015) consideraram a fluência na compressão e analisaram a influência dessa consideração no retorno elástico após a CFE. Os autores estabeleceram um modelo para descrever o comportamento da fluência sob tração e outro para descrever o comportamento da fluência sob compressão. A Figura 29 mostra as curvas de fluência determinadas por Yang, Zhan e Li (2015) para o corpo de prova sob tração e compressão.

Figura 29 - Deformação por fluência em função do tempo para a liga AA2524 em $180^{\circ} \mathrm{C}$ (a) e $190^{\circ} \mathrm{C}(\mathrm{b})$

(a)

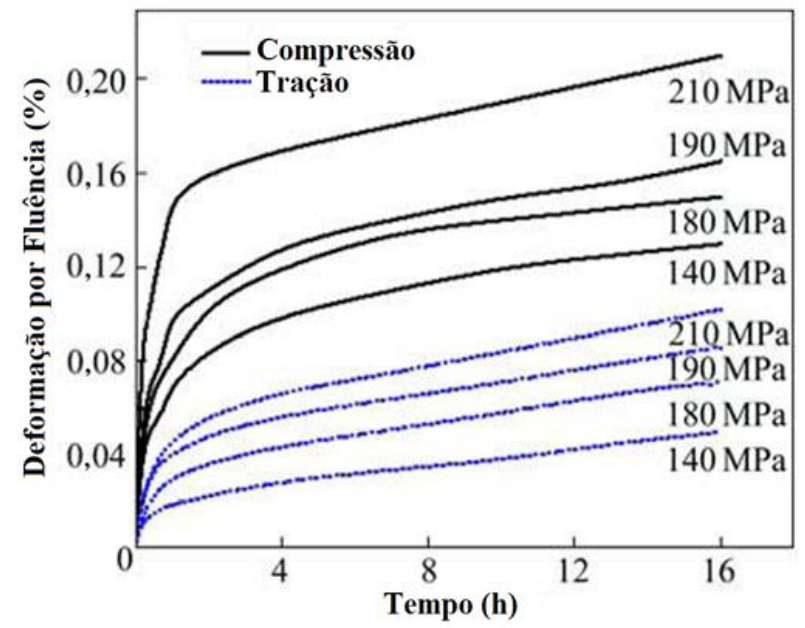

(b)

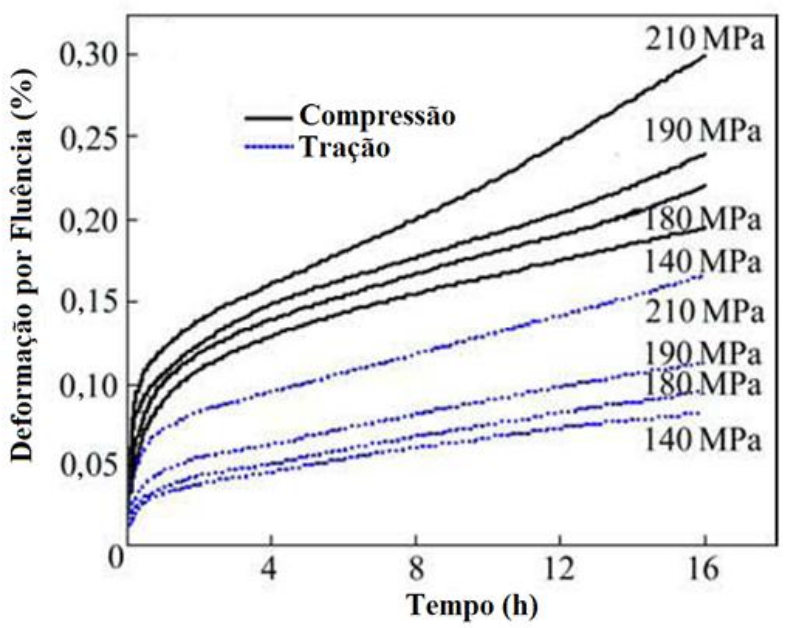

Fonte: Yang; Zhan; Li, 2015, p. 3050

Yang, Zhan e Li (2015) calibraram os modelos propostos com os dados experimentais e realizaram duas simulações da CFE no programa de elementos finitos. A primeira simulação que considerou somente o comportamento da fluência sob tração teve um retorno elástico de 61,12\%. A segunda simulação considerou o comportamento da fluência sob tração e compressão. Na segunda simulação o retorno elástico foi de $65,93 \%$ e se aproximou mais do retorno elástico determinado experimentalmente que foi de 68,20\%. Yang, Zhan e Li (2015) concluíram que as tensões trativas e compressivas ao longo da espessura da placa deveriam ser consideradas para melhor prever o retorno elástico.

\subsection{MÉTODOS PARA DETERMINAR AS CONSTANTES DO MATERIAL E INTEGRAR AS EQUAÇÕES CONSTITUTIVAS UNIFICADAS}

As constantes do material têm sido encontradas utilizando técnicas de otimização. Os problemas de otimização basicamente envolvem a definição de uma ou mais funções objetivo (função na qual será minimizada), das variáveis de projeto, dos vínculos ou restrições e por 
último a definição do método de otimização que encontrará as variáveis de projeto que minimizem a função objetivo satisfazendo as restrições.

Aplicando técnicas de otimização para se achar as constantes dos materiais, a função objetivo normalmente é a que define o desvio entre os dados experimentais e os simulados, por exemplo, a soma dos quadrados dos desvios descrita na equação 22, porém alguns pesquisadores, como, Li, Lin e Yao (2012) desenvolveram funções mais complexas para tentar achar o menor erro. As variáveis de projeto são as constantes do material, as restrições são os intervalos em que serão encontradas as constantes e o método de otimização aplicado nas equações constitutivas unificadas tem sido os algoritmos genéticos, por se tratar de equações complexas, em que métodos mais simples como o método dos mínimos quadrados que utiliza o cálculo diferencial não consegue determinar as constantes do material. Segundo Lin, Balint e Cao (2012) o método do gradiente conjugado que é mais elaborado não consegue determinar também as constantes do material de modelos mais avançados com um número alto de constantes.

Fun o objetivo $=\sum_{\mathrm{k}=1}^{\mathrm{m}}\left[\mathrm{f}_{\text {experimento }}\left(\mathrm{x}_{\mathrm{k}}\right)-\mathrm{f}_{\text {modelo }}\left(\mathrm{x}_{\mathrm{k}}\right)\right]^{2}$

Os algoritmos genéticos para buscar as constantes dos materiais geram populações iniciais e a partir dos indivíduos da população realizam cruzamentos e mutações, gerando descendentes. Os descendentes são avaliados por algum critério de otimização para saber quais são os melhores e os piores indivíduos gerados, se o critério estabelecido para terminar o algoritmo não for atingido, a nova população (gerada a partir do cruzamento da anterior) realizará novos cruzamentos e mutações para obter novas soluções e assim o algoritmo funcionará até atingir a solução ótima (EIBEN; SMITH, 2013). A Figura 30 mostra o esquema de um algoritmo evolucionário. 
Figura 30 - Fluxograma de um algoritmo evolucionário

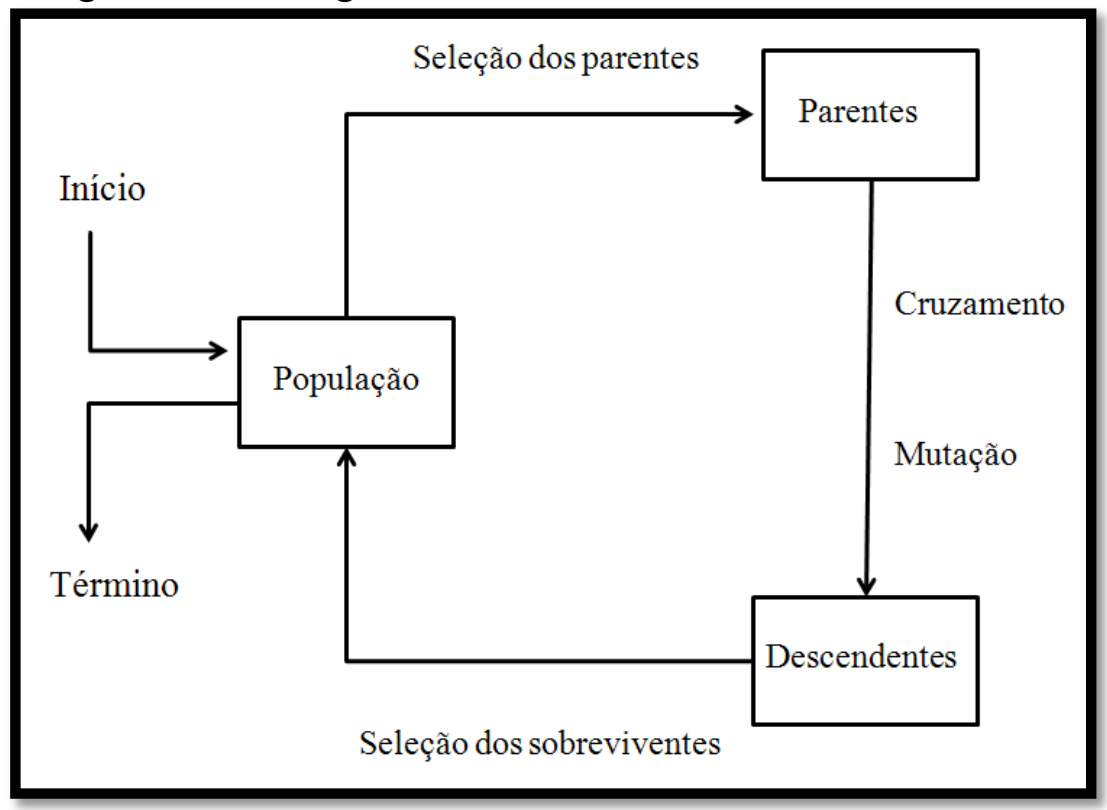

Fonte: Eiben; Smith, 2013, p. 17

$\mathrm{Na}$ fase de seleção dos melhores descendentes, o algoritmo aplica a função objetivo para saber quais constantes do material geradas diminuem o erro, mas para isso há a necessidade da integração das equações constitutivas unificadas. A integração das equações constitutivas unificadas não só é necessária na fase em que se deseja encontrar as constantes do material, mas também para implementar o modelo em um programa de elementos finitos através de uma sub-rotina.

As equações constitutivas unificadas são um conjunto de equações diferenciais ordinárias não lineares. Assim, solucionar analiticamente essas equações se torna muito difícil e tem-se utilizado métodos numéricos de integração. Os métodos numéricos de integração são divididos entre os métodos explícitos e os implícitos, em que nos métodos implícitos a incógnita $\left(\mathrm{y}_{\mathrm{K}+1}\right)$ aparece em ambos os lados da equação, esta diferença pode ser observada comparando a equação 23 que descreve o método de Euler explícito com a equação 24 que descreve o método de Euler implícito. Os métodos implícitos são mais trabalhosos de serem implementados por necessitarem de métodos iterativos para solucionar as equações não lineares em cada iteração, porém eles são incondicionalmente estáveis, isto significa que durante a integração numérica a estabilidade da solução é garantida, mesmo aplicando um passo de integração alto (CHAPRA; CANALE, 2008).

$$
\mathrm{y}_{\mathrm{K}+1}=\mathrm{y}_{\mathrm{K}}+\mathrm{hf}\left(\mathrm{x}_{\mathrm{K}}, \mathrm{y}_{\mathrm{K}}\right)
$$




$$
\mathrm{y}_{\mathrm{K}+1}=\mathrm{y}_{\mathrm{K}}+\mathrm{hf}\left(\mathrm{x}_{\mathrm{K}+1}, \mathrm{y}_{\mathrm{K}+1}\right)
$$

O presente trabalho irá se concentrar nos métodos explícitos para desenvolver a subrotina. A integração das equações constitutivas deve ser realizada de tal maneira que garanta a estabilidade das equações. A figura 31 demonstra a instabilidade que pode ser gerada durante a integração. A instabilidade pode ocorrer durante a integração de equações diferenciais, em que a solução possui um comportamento transiente, ou melhor, os dados variam rapidamente com o tempo, como, durante a fluência primária na qual se tem uma alta taxa de deformação. Para garantir a estabilidade quando se utiliza métodos explícitos, é necessário aplicar passos pequenos para a integração, pois analisando a equação 23 , caso a taxa de variação seja alta e o passo também, os dados serão extrapolados para valores não representativos do comportamento em estudo.

Figura 31 - Esquema demonstrando a instabilidade que pode ser gerada durante a integração numérica

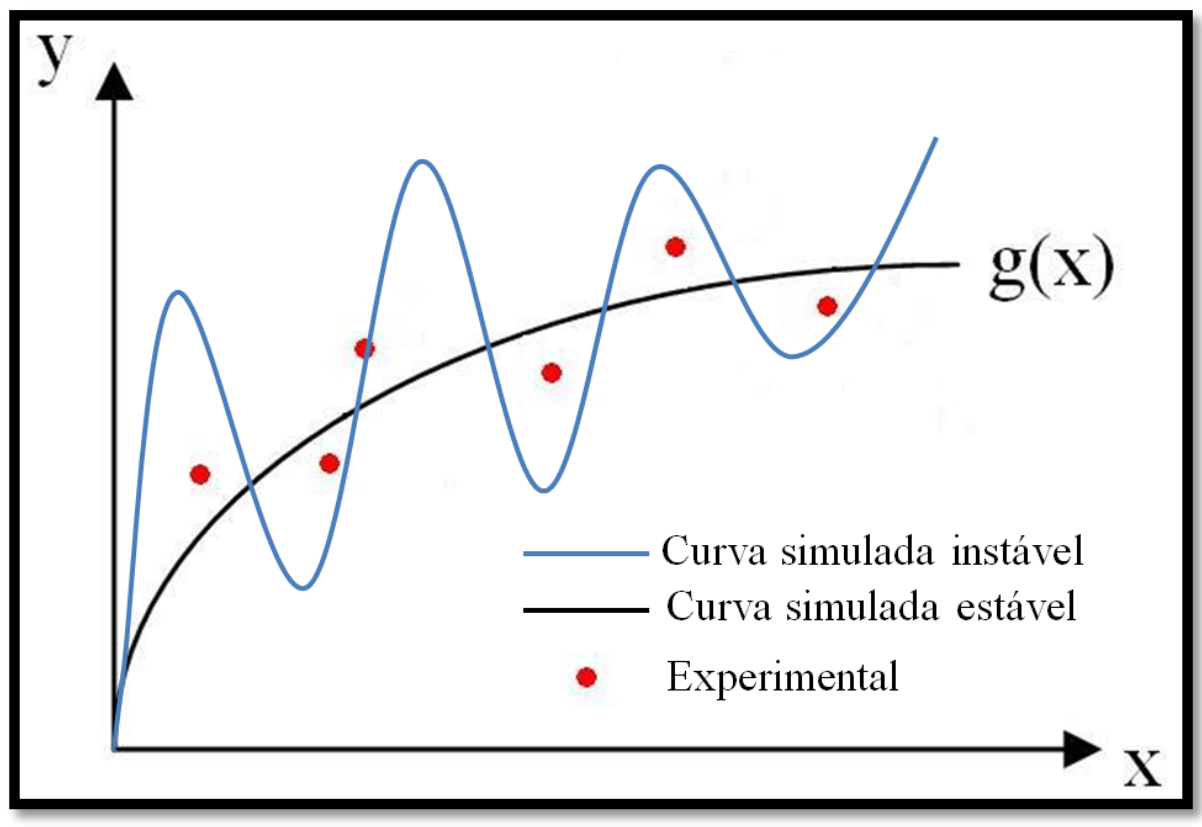

Fonte: Autor 


\subsection{MÉTODO DOS ELEMENTOS FINITOS APLICADO NA CFE}

O estudo da conformação por fluência com envelhecimento tem sido realizado através de técnicas experimentas e numéricas com o auxílio do método dos elementos finitos, no qual tem sido uma ferramenta importante para obter variáveis aceitáveis, reduzindo gastos na construção de protótipos ou ensaios e excluindo métodos de tentativa e erro.

O método dos elementos finitos é uma ferramenta muito utilizada na engenharia para solucionar problemas matemáticos principalmente em estruturas complexas que seria difícil de resolver aplicando métodos clássicos e tratando o sistema como contínuo, por envolver muitas variáveis e equações diferenciais. O método dos elementos finitos é um método numérico que se baseia na discretização de um sistema contínuo em formas geométricas simples, e as mesmas são denominadas de elementos que são conectadas por nós (BATHE, 1996). Alguns elementos são demonstrados na Figura 32, na qual é possível observar que, para uma mesma geometria do elemento é possível ter mais graus de liberdades ou nós.

Figura 32 - Exemplos de elementos aplicados na análise numérica por elementos finitos

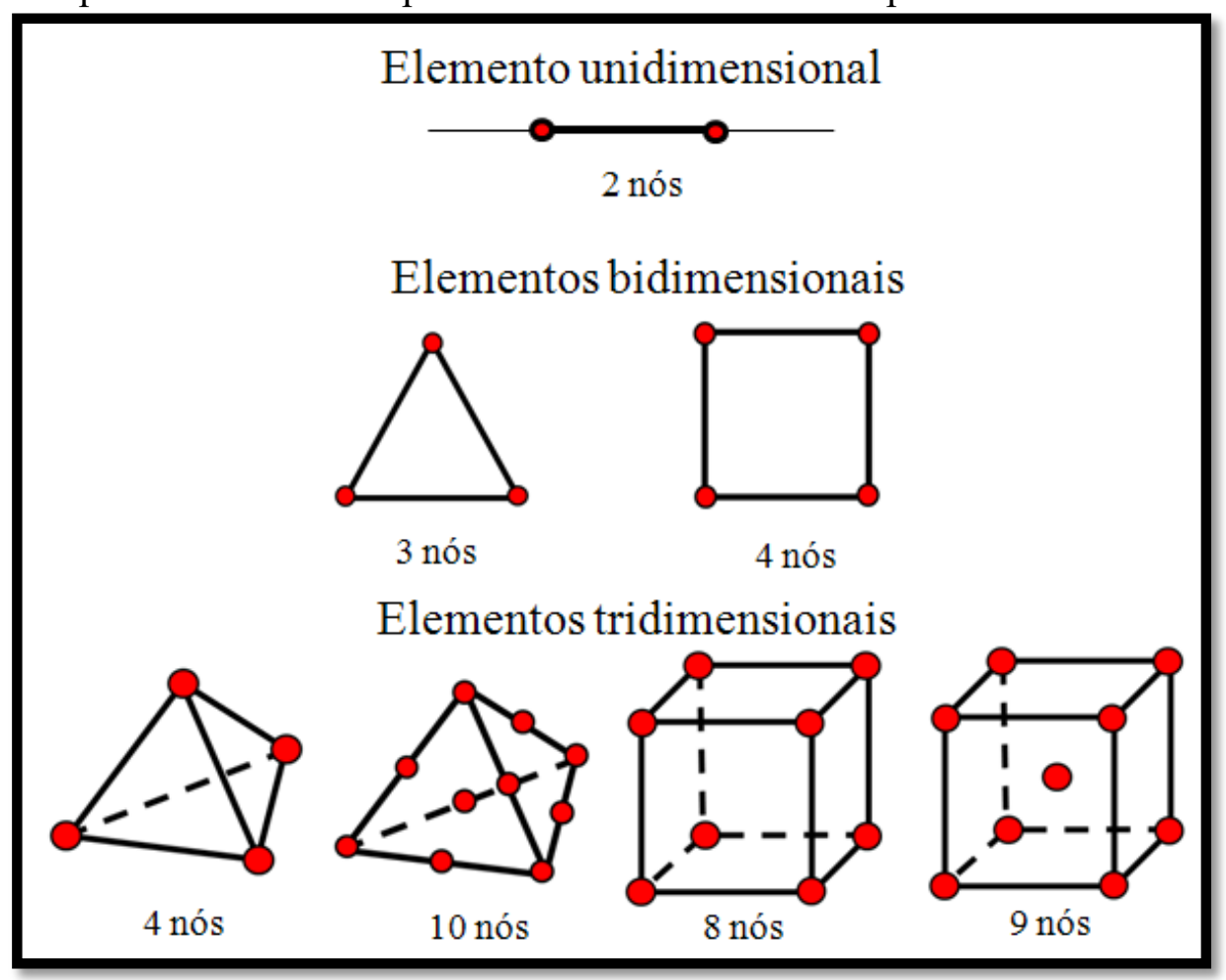

Fonte: Autor 
Discretizando o sistema em elementos é possível definir as equações que governam cada elemento. Se tratasse um sistema complexo como contínuo seria impossível definir uma equação para descrever o comportamento do sistema inteiro. $\mathrm{O}$ aumento da discretização aumentará o número de elementos finitos e quanto mais elevado esse número a resposta irá sendo convergida ao valor da solução integral do sistema, porém quanto menor o tamanho do elemento maior será o tempo de processamento.

As equações que regem os elementos podem ser determinadas a partir de métodos que aplicam uma abordagem variacional. A abordagem variacional em uma análise estrutural linear consiste em determinar a equação de equilíbrio para a solução dos graus de liberdade correspondentes ao ponto de mínima energia potencial total (BATHE, 1996), tal equação pode ser ajustada para a forma de matriz, resultando na fórmula descrita na equação 25.

$$
[\mathrm{K}] .\{\mathrm{u}\}=\{\mathrm{F}\}
$$

Onde $[\mathrm{K}]$ é a matriz de rigidez, $\{\mathrm{u}\}$ é vetor de deslocamentos e $\{\mathrm{F}\}$ é o vetor de carregamentos. A equação 25 é utilizada em análises lineares, o deslocamento será diretamente proporcional à força aplicada e a rigidez constante, ou melhor, a matriz de rigidez não dependerá dos deslocamentos e das forças. Caso a matriz de rigidez dependa do carregamento e do deslocamento, como demonstra a equação 26 , o problema é não linear. Os problemas não lineares são resolvidos com auxílio de métodos iterativos, tal como o método de Newton-Raphson. O fluxograma da Figura 33 exemplifica o processo para obter uma solução iterativa.

$$
[\mathrm{K}(\mathrm{u}, \mathrm{F})] \cdot\{\mathrm{u}\}=\{\mathrm{F}\}
$$


Figura 33 - Fluxograma demonstrando o processo para obter uma solução iterativa

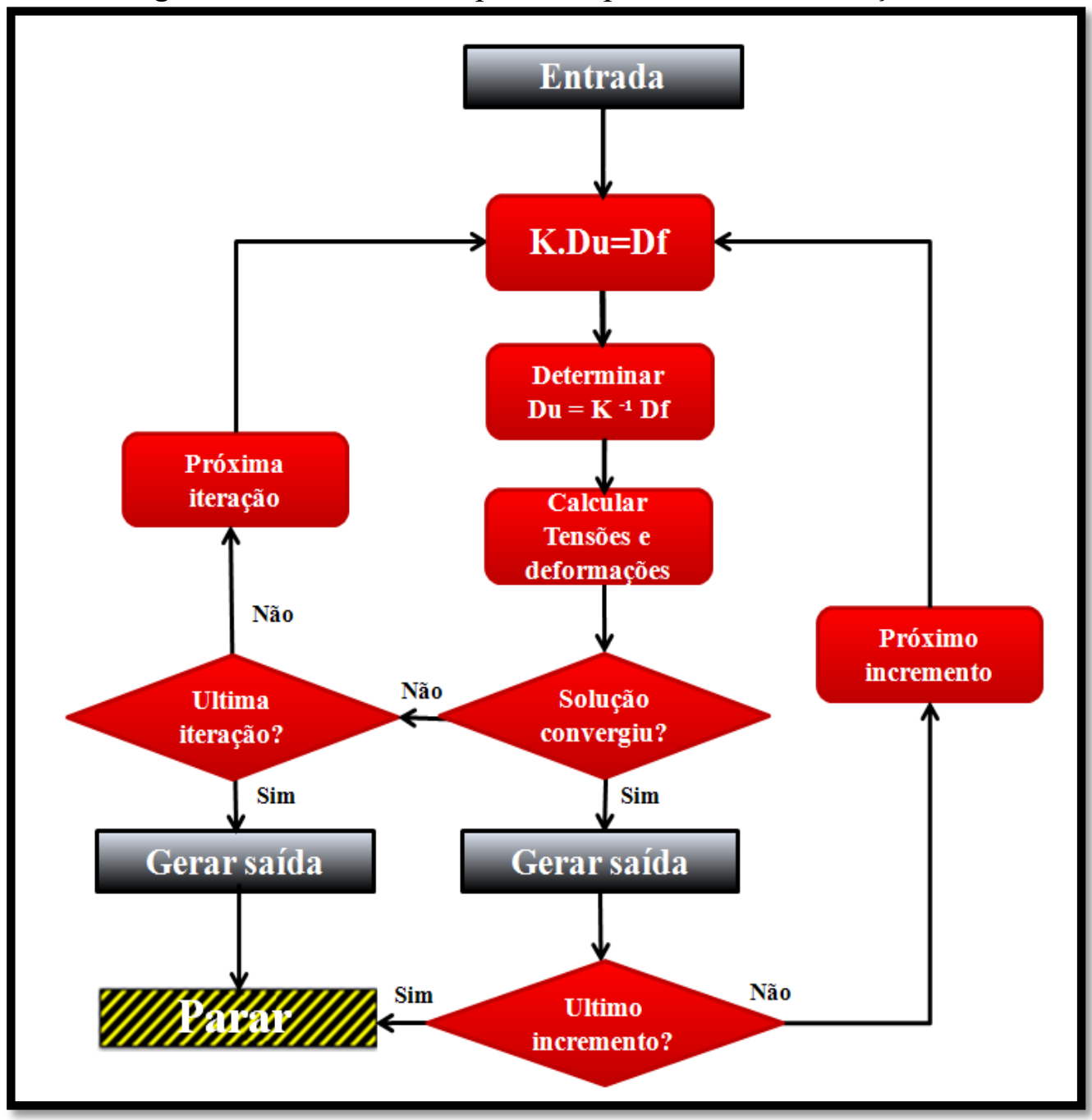

Fonte: Autor "adaptado de" MSC. Software, 2015

No fluxograma após os cálculos das deformações e das tensões é realizado um teste para saber se a resposta obtida dos deslocamentos garantirá o equilíbrio do corpo ou se os deslocamentos encontrados são representativos do comportamento não linear do material. Esse teste é realizado com o cálculo da força residual, na qual deve ser nula para a resposta convergir. A força residual é a diferença entre as forças externas e internas aplicadas. Se existir a força residual, ela será utilizada para calcular novos incrementos de deslocamentos até que a resposta seja convergida. A Figura 34 exemplifica o processo de maneira gráfica, em que é aplicado o método de Newton-Raphson modificado, neste a matriz de rigidez permanece constante durante as iterações. 
Figura 34 - Método de Newton-Raphson modificado

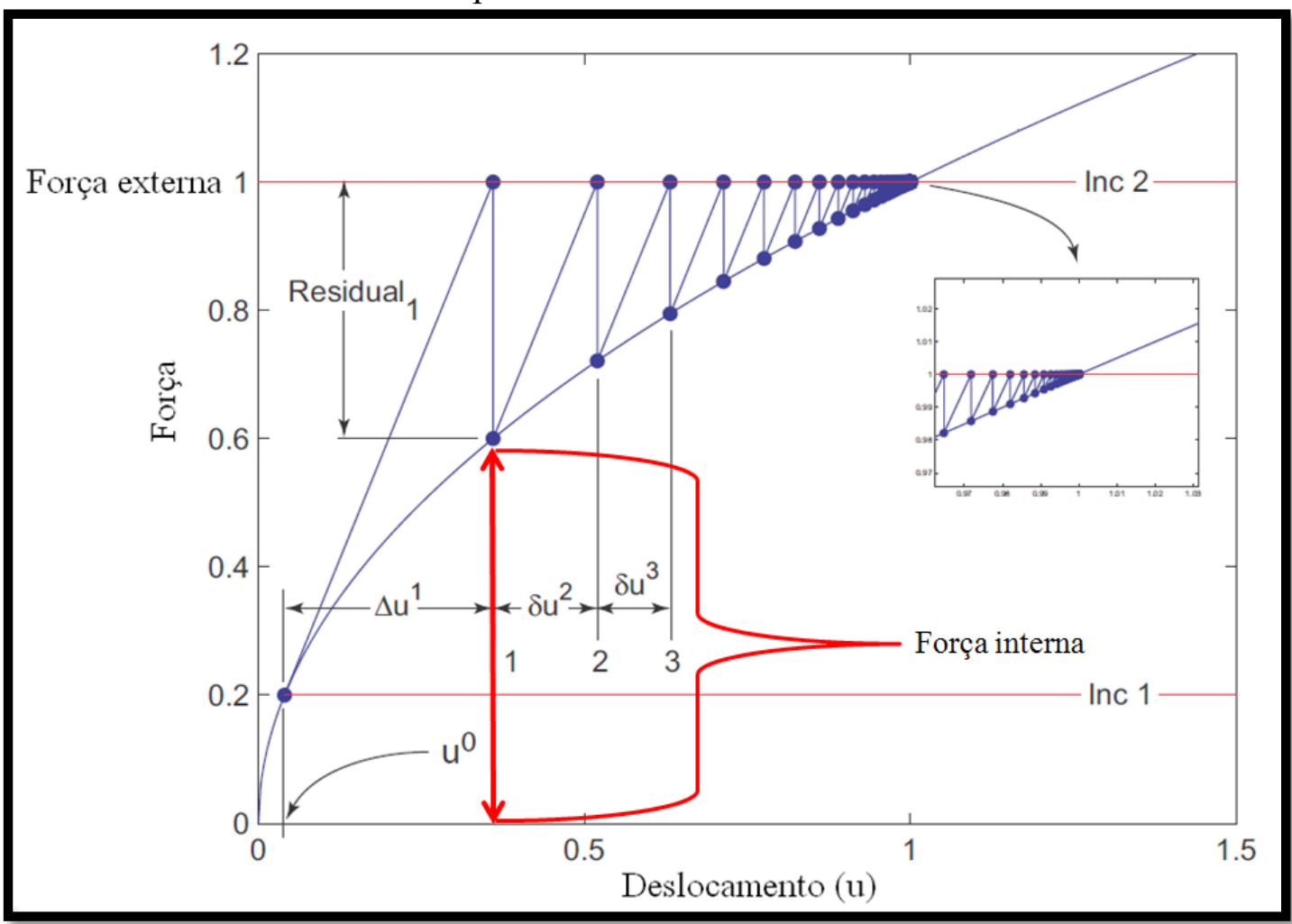

Fonte: Autor "adaptado de" Marc, 2013a

Existem três fatores que podem causar a não linearidade: o material, a geometria e as condições de contorno. A não linearidade do material ocorre quando o material não exibe relação linear entre as tensões e deformações, por exemplo, um material de comportamento elasto-plástico quando atinge o regime plástico e nos materiais durante a fluência. A não linearidade da geometria ocorre em estruturas que a rigidez é dependente dos deslocamentos, ela pode ser observada durante o fenômeno de flambagem de uma estrutura. As condições de contorno impostas na simulação, como, simulações que envolvem contato e atrito também devem ser analisadas como não linear (MARC, 2013a).

O estudo de uma estrutura, sempre levará a um problema tridimensional que terá um alto nível de complexidade, porém são adotadas hipóteses simplificadoras que podem ser aplicadas ao escolher o elemento. Na análise de conformação de chapas utilizando o método dos elementos finitos pode-se aplicar condições de contorno, simplificando a geometria estudada, ao invés de discretizar a chapa com elementos em três dimensões, é possível representar em duas dimensões aplicando elementos bidimensionais. A simplificação do problema real é comum, desde que o modelo simulado gere resultados representativos do modelo real. 
Os programas de análise em elementos finitos dividem a simulação em três etapas:

a) Pré-processamento - A geometria a ser estudada é exportada de um programa de CAD (Catia, Pro-E, Unigraphics Nx) ou pode ser criada no próprio programa que realizará a simulação. A estrutura é discretizada ou é criada a malha de elementos finitos selecionando o elemento que melhor represente o problema. O processo para definir uma boa malha poderá ser iterativo, ou seja, com base nos resultados da primeira análise, é realizado o refinamento da malha nas regiões de interesse para a segunda análise. Definindo a malha é realizada a escolha do modelo constitutivo e das propriedades mecânicas do material. Depois são definidas as condições de contorno, como, carregamentos e deslocamentos;

b) Processamento - O programa realiza os cálculos definidos no pré-processamento. A solução do problema irá depender da escolha adequada do código de elementos finitos que será utilizado para resolver as equações. Existem códigos implícitos e explícitos, cada um desses códigos pode variar conforme o método numérico adotado. Os códigos implícitos são mais aplicados em problemas estáticos e quase estáticos, os códigos explícitos em problemas dinâmicos, como, problemas de impacto e alguns casos de conformação mecânica;

c) Pós-processamento - O programa exibe os resultados da etapa de processamento, por exemplo, a distribuição de tensão na estrutura, deslocamentos, deformações e modos de vibrar. 


\subsubsection{Implementação do comportamento de fluência no método dos elementos finitos}

O procedimento utilizado para implementar o comportamento de fluência em um código de elementos finitos é similar ao procedimento em um caso elasto-plástico, no qual se deseja encontrar o estado de equilíbrio de um corpo, sobre um dado carregamento. A equação incremental que representa as condições de equilíbrio durante a fluência é representada na equação 27.

$$
[\mathrm{K}]\{\Delta \mathrm{u}\}=\{\Delta \mathrm{P}\}+\{\Delta \mathrm{R}\}+\int_{\mathrm{V}}[\beta]^{\mathrm{T}}[\mathrm{D}]\left\{\Delta \varepsilon^{\mathrm{C}}\right\} \mathrm{dV}
$$

Onde $\{\Delta \mathrm{u}\}$ e $\{\Delta \mathrm{P}\} \mathrm{s}$ o os vetores dos deslocamentos incrementais e das forças nodais incrementais.

[K] é a matriz de rigidez, definida pela seguinte relação:

$$
[K]=\int_{V}[\beta]^{T}[D][\beta] d V
$$

[ß] é a matriz de transformação de deslocamentos para deformação.

[D] é a matriz de propriedades elásticas.

$\mathrm{O}$ vetor $\{\Delta \mathrm{R}\}$ representa o carregamento residual, que é aplicado como uma força de correção para garantir o equilíbrio. O carregamento residual é a diferença entre as forças externas e internas aplicadas.

A segunda parcela da equação 27 é um vetor da pseudo força devido ao incremento da deformação por fluência. Esse vetor da pseudo força representa uma força teórica, criada para conseguir calcular os deslocamentos do corpo.

O cálculo dos deslocamentos em um programa de elementos finitos, para uma simulação de fluência pode ser desenvolvido do seguinte modo.

Inicialmente são estabelecidas as condições iniciais, tais condições são a solução de um problema linear elástico, pois o carregamento inicial irá gerar uma deformação elástica no início da simulação. Neste exemplo está sendo considerado um material com comportamento linear durante o regime elástico, pois existem materiais que podem exibir um comportamento não linear durante o regime elástico. A seguir para calcular os deslocamentos que ocorre na 
próxima iteração (i), o programa encontra a pseudo força. A pseudo força é determinada com o incremento da deformação por fluência, que é desenvolvido utilizando as formulações de fluência do próprio programa de elementos finitos, ou pode ser desenvolvido a partir de uma sub-rotina com o comportamento de fluência determinado pelo usuário, em que basicamente o valor de entrada da sub-rotina será a tensão equivalente de von Mises aplicada e o valor de saída será a deformação por fluência na forma incremental. Tal deformação incremental é o produto do incremento de tempo com a taxa de deformação por fluência (Equação 29).

$$
\Delta \varepsilon^{\mathrm{c}}=\Delta \mathrm{t} . \dot{\varepsilon}^{\mathrm{c}}
$$

Realizando o cálculo do pseudo vetor é possível obter os deslocamentos incrementais da equação 27 e os deslocamentos da iteração atual com a equação 30 . A deformação total é obtida multiplicando o vetor dos deslocamentos pela matriz de transformação de deslocamentos para deformação.

$$
\mathrm{u}_{\mathrm{i}}=\mathrm{u}_{\mathrm{i}-1}+\Delta \mathrm{u}_{\mathrm{i}}
$$

Por fim é calculado o incremento da tensão utilizando a equação 31, caso a tensão seja variada durante a simulação, se a tensão for constante o incremento é nulo.

$$
\Delta \sigma=\mathrm{D}\left(\Delta \varepsilon-\Delta \varepsilon^{\mathrm{c}}\right)
$$

O procedimento é repetido até que a simulação atinja a última iteração.

A descrição do modo para implementar o comportamento de fluência em um código de elementos finitos pode sofrer variações, tal procedimento descrito anteriormente pode ser consultado nas seguintes referências: Zhang e Moore (1997); Naumenko e Altenbach (2007).

O estudo da fluência em casos multiaxiais é semelhante ao da plasticidade, na qual se aplica a lei de escoamento associada a um critério de escoamento, como o critério de von Mises, que dará origem a equação de Prandtl-Reuss. As formulações da teoria da plasticidade são realizadas através de algumas hipóteses relacionadas à plasticidade dos metais, as mesmas hipóteses são aplicadas no estudo da fluência para estender um modelo uniaxial para um modelo multiaxial, porém não são totalmente válidas à fluência (Stourffer; Dame, 1996). As hipóteses básicas são descritas a seguir: 
a) O material é isotrópico e homogêneo;

b) A tensão hidrostática não afeta a deformação;

c) A deformação volumétrica pode ser desprezada durante a fluência;

d) A resposta é a mesma em tração e em compressão.

Como é desprezada a parcela hidrostática da tensão, as leis de escoamento da fluência são descritas em função da tensão desvio. A lei de escoamento da fluência, descrita na equação 32, pode ser gerada analogamente aplicando a lei de escoamento de Levy-Mises e substituindo a deformação plástica pela taxa de deformação por fluência.

$$
\dot{\varepsilon}_{\mathrm{ij}}^{\mathrm{c}}=\frac{3 \dot{\varepsilon}_{\mathrm{e}}^{\mathrm{c}}}{2 \sigma_{\mathrm{e}}} \sigma_{\mathrm{ij}}^{\prime}
$$




\section{MATERIAIS E MÉTODOS}

O presente trabalho utilizou a liga de alumínio AA2124, cuja composição é demonstrada na Tabela 7.

Tabela 7 - Composição química da liga AA2124 (fração em massa \%)

\begin{tabular}{|c|c|c|c|c|c|c|c|}
\hline $\mathrm{Cu}$ & $\mathrm{Mg}$ & $\mathrm{Mn}$ & $\mathrm{Ti}$ & $\mathrm{Zn}$ & $\mathrm{Cr}$ & $\mathrm{Fe}$ & $\mathrm{Si}$ \\
\hline 4,18 & 1,46 & 0,52 & 0,15 & 0,25 & 0,1 & 0,3 & 0,2 \\
\hline
\end{tabular}

Fonte: Zhang et al., 2013, p. 12

O comportamento da liga de alumínio AA2124 durante a fluência (Figura 35) na temperatura de $190^{\circ} \mathrm{C}$ foi retirado do artigo de Zhang et al. (2013). Os dados da deformação por fluência foram necessários para calibrar o modelo da CFE e assim conseguir simular o processo no programa de elementos finitos através da sub-rotina.

Figura 35 - Deformação por fluência em função do tempo para a liga de alumínio AA2124 (Experimental)

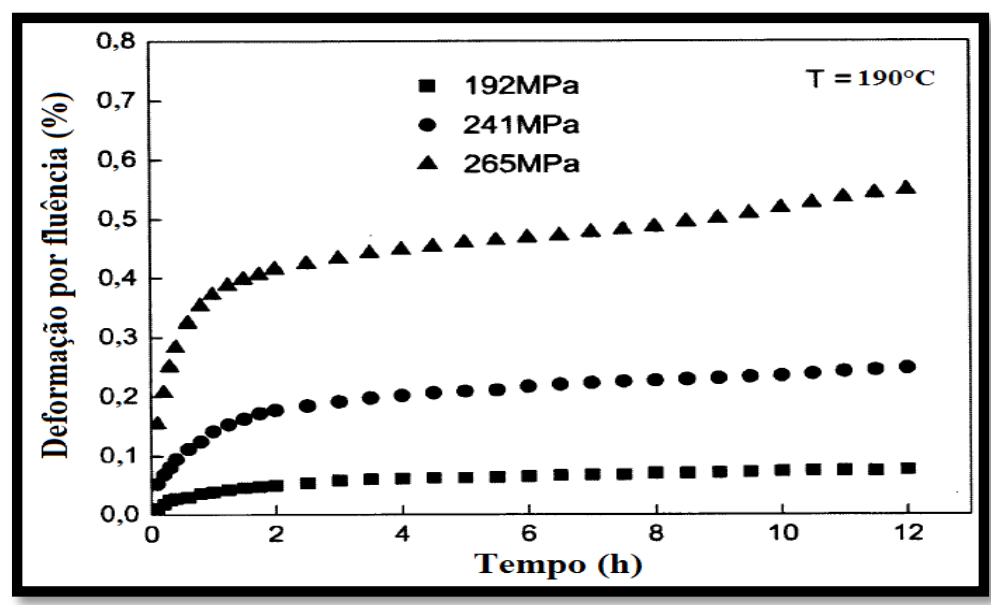

Fonte: Zhang et al., 2013, p. 14

As duas simulações realizadas tiveram placas de espessura igual a $6 \mathrm{~mm}$ e o comprimento e a largura foram igual a: $600 \mathrm{~mm}$ x $300 \mathrm{~mm}$ e $800 \mathrm{~mm}$ x $400 \mathrm{~mm}$.

Antes das simulações em elementos finitos a sub-rotina foi escrita e foram desenvolvidas as etapas descritas nos próximos tópicos deste capítulo. 


\subsection{INTEGRAÇÃO NUMÉRICA DO MODELO MATEMÁTICO DA CFE}

O modelo utilizado na construção da sub-rotina foi o de Zhang et al. (2013), descrito no capítulo 3.3. Antes de criar a sub-rotina, dois algoritmos para a integração do modelo matemático foram escritos no Matlab ${ }^{\circledR}$, um algoritmo contendo o método de Euler de primeira ordem e o outro contendo o método de Runge-Kutta de quarta ordem. Alguns pesquisadores aplicaram para a integração numérica o método explícito de Runge-Kutta de quarta ordem. Pode-se destacar os trabalhos de Ho et al. (2004) e Ribeiro (2013) que aplicaram o método e obtiveram bons resultados.

O método de Runge-Kutta de quarta ordem comparado ao método de Euler de primeira ordem possui uma precisão muito boa, mesmo aplicando um passo de integração maior, tal comparação pode vista no livro de Burden e Faires (2010). Embora o método tenha uma boa precisão, o número de cálculos por passo de integração aumenta ao contrário do método de Euler que possui uma formulação muito simples. Para entender melhor os dois métodos, os dois foram implementados no Matlab ${ }^{\circledR}$.

As fórmulas para o método de Runge-Kutta de quarta ordem para um sistema de equações diferenciais são dadas por:

$$
\begin{aligned}
& \frac{d y}{d t}=f(t, y(t), z(t)), \quad y\left(t_{0}\right)=y_{0} \\
& \frac{d z}{d t}=g(t, y(t), z(t)), \quad z\left(t_{0}\right)=z_{0} \\
& K_{1}=h \cdot f\left(t_{n}, y_{n}, z_{n}\right) \\
& L_{1}=h \cdot g\left(t_{n}, y_{n}, z_{n}\right) \\
& K_{2}=h \cdot f\left(t_{n}+\frac{h}{2}, y_{n}+\frac{K_{1}}{2}, z_{n}+\frac{L_{1}}{2}\right) \\
& L_{2}=h \cdot g\left(t_{n}+\frac{h}{2}, y_{n}+\frac{K_{1}}{2}, z_{n}+\frac{L_{1}}{2}\right)
\end{aligned}
$$




$$
\begin{aligned}
& \mathrm{K}_{3}=h \cdot f\left(\mathrm{t}_{\mathrm{n}}+\frac{\mathrm{h}}{2}, \mathrm{y}_{\mathrm{n}}+\frac{\mathrm{K}_{2}}{2}, \mathrm{z}_{\mathrm{n}}+\frac{\mathrm{L}_{2}}{2}\right) \\
& \mathrm{L}_{3}=\mathrm{h} \cdot \mathrm{g}\left(\mathrm{t}_{\mathrm{n}}+\frac{\mathrm{h}}{2}, \mathrm{y}_{\mathrm{n}}+\frac{\mathrm{K}_{2}}{2}, \mathrm{z}_{\mathrm{n}}+\frac{\mathrm{L}_{2}}{2}\right) \\
& \mathrm{K}_{4}=\mathrm{f}\left(\mathrm{t}_{\mathrm{n}}+\mathrm{h}, \mathrm{y}_{\mathrm{n}}+\mathrm{K}_{3}, \mathrm{z}_{\mathrm{n}}+\mathrm{L}_{3}\right) \\
& \mathrm{L}_{4}=\mathrm{g}\left(\mathrm{t}_{\mathrm{n}}+\mathrm{h}, \mathrm{y}_{\mathrm{n}}+\mathrm{K}_{3}, \mathrm{z}_{\mathrm{n}}+\mathrm{L}_{3}\right) \\
& \mathrm{K}=\frac{1}{6} \cdot\left(\mathrm{K}_{1}+2 \cdot \mathrm{K}_{2}+2 \cdot \mathrm{K}_{3}+\mathrm{K}_{4}\right) \\
& \mathrm{L}=\frac{1}{6} \cdot\left(\mathrm{L}_{1}+2 \cdot \mathrm{L}_{2}+2 \cdot \mathrm{L}_{3}+\mathrm{L}_{4}\right) \\
& \mathrm{z}_{\mathrm{n}+1}=\mathrm{z}_{\mathrm{n}}+\mathrm{L} \\
& \mathrm{t}_{\mathrm{n}+1}=\mathrm{t}_{\mathrm{n}}+\mathrm{h} \\
&
\end{aligned}
$$

O Matlab ${ }^{\circledR}$ possui funções prontas que podem integrar o sistema de equações, como as funções ODE45 e ODE23 que são baseadas no método de Runge-Kutta, porém mesmo sabendo da existência destas funções, foi criado um novo algoritmo para integrar, pois uma vez criado o algoritmo, ele também poderá ser utilizado na sub-rotina desde que mude a linguagem de programação.

Inicialmente o modelo de Zhang et al. (2013) foi integrado numericamente com as constantes do material publicadas (Tabela 6) por Zhang et al. (2013). Mas a integração não obteve êxito, notou-se que as constantes não conseguem representar as curvas de deformação por fluência em função do tempo. Para contornar este problema e conseguir testar a sub-rotina no programa de elementos finitos foi proposto um novo ajuste do modelo aos dados experimentais publicados por Zhang et al. (2013). Lembrando que o presente trabalho não realizou experimentos com a liga AA2124, os dados foram adquiridos do trabalho de Zhang et al. (2013). 
O ajuste realizado utilizou o algoritmo genético do Matlab ® da ferramenta de otimização (Otimization Toolbox) e para aplicar o algoritmo foram criadas duas rotinas. Uma contendo o algoritmo para integrar as equações constitutivas e a outra a função objetivo representada na equação 22. Quando se executa o solver da Otimization Toolbox, inicialmente o algoritmo genético gera as constantes do material dentro do intervalo pré-estabelecido de maneira randômica. Essas constantes são aplicadas na rotina de integração numérica, resultando nos dados utilizados na rotina com a função objetivo para comparar com os dados experimentais. $\mathrm{O}$ algoritmo genético gera novas constantes novamente, a partir dos métodos já comentados no capítulo 3.4, essas novas constantes são aplicadas novamente na rotina de integração e todo o processo é repetido, o solver só irá terminar quando atingir o critério de convergência. A apêndice B exemplifica as rotinas necessárias para realizar o ajuste.

O modelo da CFE possui 27 constantes no total. Tentar encontrar todas de uma vez é um trabalho muito difícil, portando foram criadas 5 funções objetivo, cada função contendo o desvio entre os dados experimentais e simulados relacionados ao tamanho do precipitado, relação de aspecto do precipitado, fração volumétrica, tensão de escoamento e deformação por fluência.

O procedimento para localizar as constantes foi dividido em etapas. Primeiramente foram achadas as constantes do material relacionadas ao tamanho do precipitado da equação 15 , sem a aplicação de uma tensão. Na sequência realizou-se o ajuste das equações 17,14 e 18. Depois desses ajustes as constantes do material da equação 15 relacionadas ao tamanho do precipitado com uma tensão aplicada foram achadas juntamente com as constantes da equação 16, devido à dependência da equação 15 em relação à equação 16. As constantes restantes foram ajustadas com os dados experimentais da deformação por fluência. Após obter todas as constantes, alguns recálculos das constantes foram realizados na tentativa de diminuir o erro entre os dados experimentais e os simulados principalmente entre os dados da deformação por fluência. A sequência para achar as constantes foi a mesma que Zhang et al. (2013) utilizaram.

Lembrando que as constantes não foram encontradas de maneira totalmente aleatória, foi pré-estabelecido um intervalo para o algoritmo genético gerar as mesmas, e esse intervalo foi baseado nas constantes publicadas por Zhang et al. (2013), o intervalo foi aproximadamente de 0,1 a 10, por exemplo para a constante $\mathrm{C}_{1}$ (Tabela 6), Zhang et al. (2013) acharam o valor de $1,8 \times 10^{-9}$, o intervalo estabelecido para esta constante foi de $0,1 \times 10^{-9}$ a $10 \times 10^{-9}$. Estabelecendo restrições na geração das constantes do material o tempo de convergência é reduzido de maneira muito significativa. 
Tendo estabelecido as constantes dos materiais, estas foram implementadas nos algoritmos de integração numérica contendo o método de Euler e Runge-Kutta, com o objetivo de reproduzir as curvas de deformação por fluência em função do tempo de Zhang et al. (2013) para as tensões de 265MPa, 241MPa e $192 \mathrm{MPa}$ na temperatura de $190^{\circ} \mathrm{C}$.

\subsection{DESENVOLVIMENTO DA SUB-ROTINA DO MODELO COMPUTACIONAL}

A sub-rotina para a CFE foi criada no ambiente de desenvolvimento do Microsoft Visual Studio ${ }^{\circledR} 10$ na linguagem de programação Fortran 77. O MSC. Marc ${ }^{\circledR}$ disponibiliza muitas sub-rotinas para que o usuário possa modificar de modo que atenda as suas necessidades. Tais sub-rotinas existentes podem ser encontradas no manual do MSC. Marc Volume D, que disponibiliza a descrição das mesmas.

A sub-rotina que permite definir o modelo da taxa de deformação por fluência é a CRPLAW, cujo cabeçalho é apresentado na Figura 36. Toda sub-rotina criada na linguagem Fortran 77, deve ser escrita com o comando SUBROUTINE, seguido do nome da sub-rotina e dentro dos parênteses as variáveis que são passadas do programa principal.

Figura 36 - Cabeçalho da sub-rotina CRPLAW

SUBROUTINE CRPLAW (eqcp, eqcpnc, s, crpe, t, dt, timinc, cptim, m, nn * kc, mat, ndi, nshear)

\section{Código do usuário}

RETURN

END

Fonte: Autor

As variáveis mais relevantes passadas do programa principal são descritas a seguir:

$\mathrm{EQCP}=$ Deformação equivalente por fluência total

$\mathrm{EQCPNC}=$ Deformação equivalente por fluência incremental $\left(\Delta \varepsilon^{c}\right)$

$t_{\text {Marc }}(1)=$ Tensão equivalente de von Mises

TIMINC $=$ Incremento de tempo $(\Delta \mathrm{t})$ 
CPTIM = Tempo total no início do incremento

Durante a criação da sub-rotina foi criado também um programa principal antes de testar no MSC. Marc ${ }^{\circledR}$, para verificar se houve algum erro na programação. O programa criado chama a sub-rotina para calcular a deformação por fluência na tensão de $265 \mathrm{MPa}$, este programa fornece a sub-rotina o número do incremento e o passo da integração que também é chamado de TIMINC. Na sub-rotina é realizada a integração numérica do sistema de equações diferenciais, fornecendo o resultado desejado ao programa principal, e este escreve os valores de deformação gerados em um arquivo texto. O programa é demonstrado na Figura 37.

Figura 37 - Programa para testar a sub-rotina CRPLAW

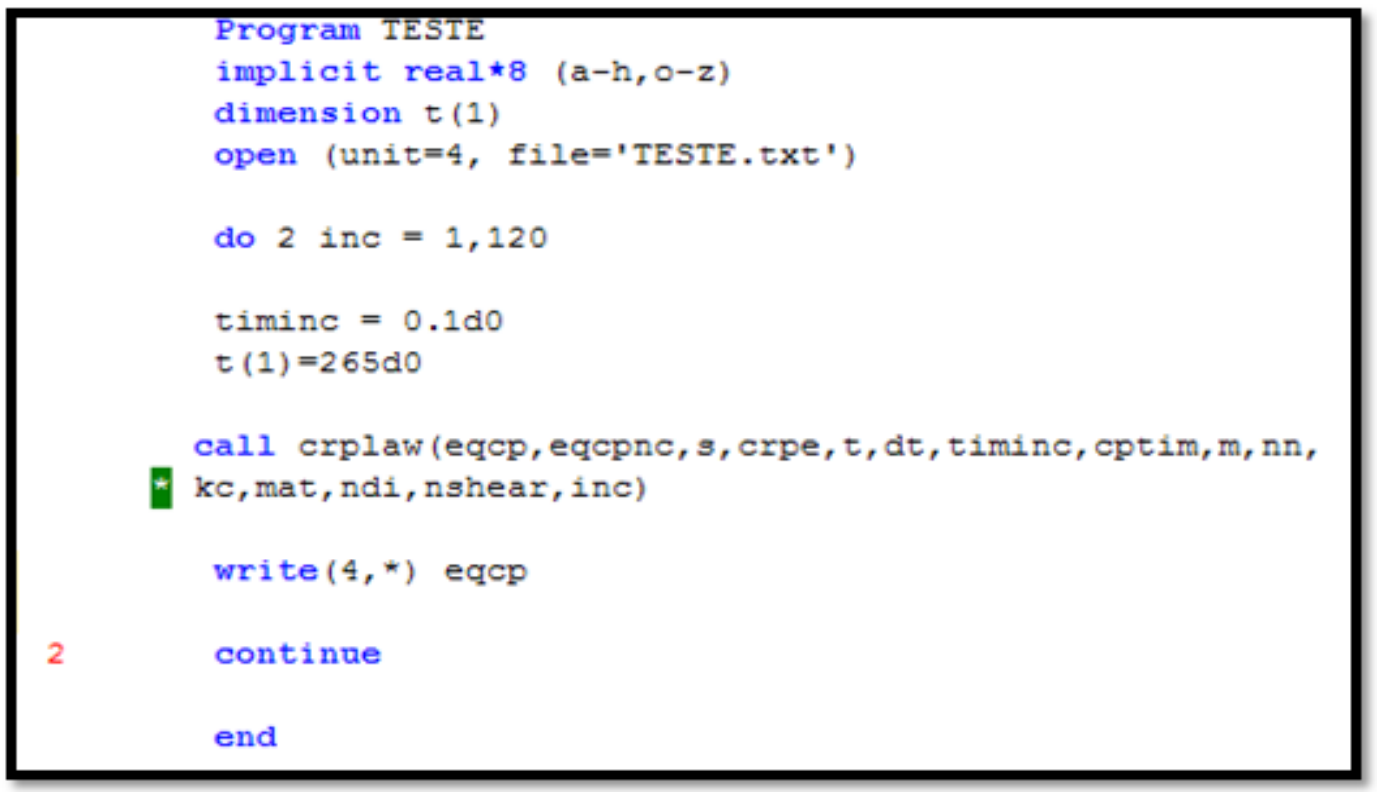

Fonte: Autor

Sabendo que a sub-rotina não apresentava erros de programação foi implementada no MSC. Marc ${ }^{\circledR}$, com o acréscimo de novos comandos. Embora o MSC. Marc ${ }^{\circledR}$ tenha uma ampla biblioteca de sub-rotinas que permitem editar as variáveis fornecidas do programa a ela, tal como as variáveis demonstradas na Figura 36, em alguns casos pode haver a necessidade de mais informações da simulação do que as fornecidas pela sub-rotina. $\mathrm{O}$ acesso a novas informações é disponibilizado através dos blocos comuns (Common Blocks).

Os blocos comuns adicionados à sub-rotina foram o DIMEN, NZRO1 e o CONCOM, este permitiu acessar o número do incremento da simulação aplicando o comando INC. $\mathrm{O}$ 
número do incremento é importante para conseguir armazenar os valores das variáveis calculadas em uma iteração e aplicar na iteração seguinte.

A sub-rotina foi verificada no programa de elementos finitos em um modelo bidimensional com um elemento e foram realizadas simulações em modelos tridimensionais.

Durante a execução da sub-rotina no MSC.Marc ${ }^{\circledR}$ foi analisado quantas vezes a subrotina é acessada por incremento e o instante inicial em que a mesma é chamada pelo programa para realizar os cálculos da deformação por fluência. Para a simulação bidimensional no incremento de número zero, o MSC. Marc ® calcula a deformação inicial, que é a deformação elástica resultante do carregamento imposto, a partir do incremento de número 1, a sub-rotina é chamada, e são realizados os cálculos da deformação por fluência.

No incremento de número zero do modelo tridimensional ocorre o contado entre a placa e o ferramental e a partir do incremento 1 é imposto o carregamento. Essa observação é importante para designar corretamente na sub-rotina as condições iniciais e as matrizes que armazenarão as variáveis em cada incremento, para que os dados calculados em um instante de tempo sejam acessados somente no instante de tempo seguinte e não tenha nenhum conflito.

O código da sub-rotina implementada no MSC. Marc ${ }^{\circledR}$ é demonstrado no apêndice C e a Figura 38 demonstra o algoritmo da sub-rotina, a partir de um fluxograma com as principais etapas da sub-rotina.

A aplicação da sub-rotina $C R P L A W$ em problemas que envolvem vários elementos finitos, o número de cálculos realizados por iteração aumenta, principalmente quando se aplica o elemento de casca, na qual é dividido em camadas (Layers) e para cada camada é calculada a deformação por fluência.

O valor da deformação por fluência requer a solução de outras equações que complementam o modelo da CFE, a solução dessas equações deve ser armazenada corretamente para que somente no próximo incremento seja possível acessá-las, porque em um mesmo incremento o MSC. Marc ${ }^{\circledR}$ acessa a sub-rotina mais de uma vez por motivos de convergência da análise não linear. Caso o armazenamento das variáveis esteja errado, quando o programa entrar na sub-rotina depois da primeira vez, os cálculos serão realizados como se o incremento estivesse avançado. Portanto se o programa acessar a sub-rotina em um mesmo incremento mais de cinco vezes seria como se o tempo na simulação avançasse cinco vezes também, ou seja, o erro será acumulado ao longo da simulação.

Durante as simulações algumas falhas ocorreram principalmente devido ao armazenamento errado das variáveis que dificultou a convergência da simulação. Depois de 
definir a programação da sub-rotina, os ajustes foram realizados no programa de préprocessamento, por exemplo, o tamanho dos elementos na malha e o número de camadas por elemento.

Figura 38 - Fluxograma das principais etapas da sub-rotina

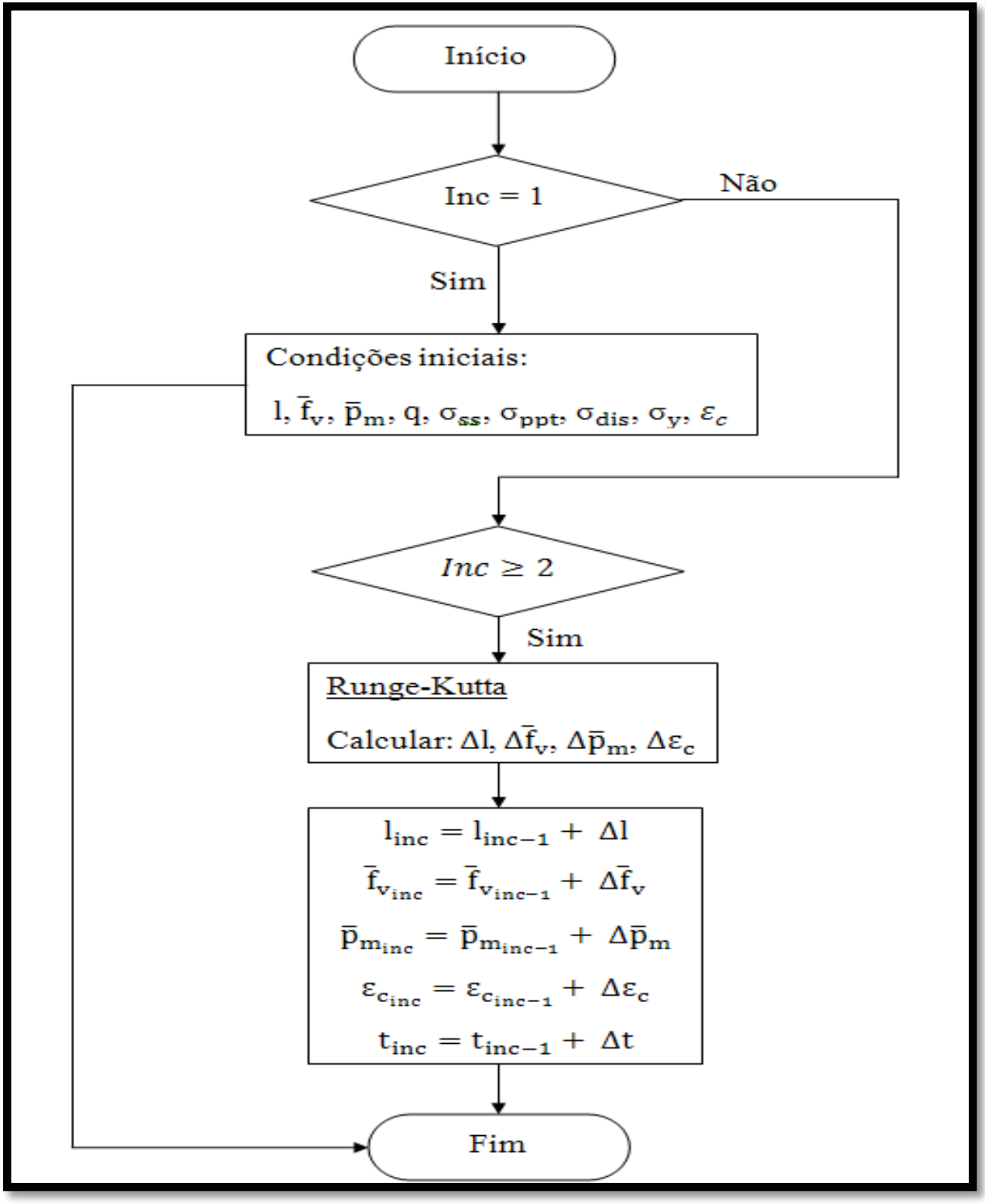

Fonte: Autor 
Todo código Fortran necessita ser compilado, ou melhor, transformado em um programa executável. O MSC. Marc ${ }^{\circledR}$ não realiza a compilação da sub-rotina e necessita de um programa externo que faça a compilação. O MSC Marc ${ }^{\circledR}$ aceita somente compiladores da Intel, porém a versão do programa de elementos finitos deve ser compatível com a versão do compilador da Intel. Portando foi utilizado a versão 2014 do MSC. Marc ${ }^{\circledR}$ e o compilador Intel ${ }^{\circledR}$ Parallel Studio XE 2015, pois segundo a MSC Software ambos são compatíveis. Durante o término da instalação deste compilador, é importante destacar a necessidade de configurar as variáveis de ambiente do Windows nas propriedades do sistema, para disponibilizar os comandos do compilador para todos os programas do sistema operacional, na qual inclui o programa de elementos finitos. Tendo assegurado que o MSC. Marc ${ }^{\circledR}$ possa acessar os comandos do compilador, o próximo passo foi criar um modelo em elementos finitos para testar a sub-rotina. 


\subsection{IMPLEMENTAÇÃO DA SUB-ROTINA (CRPLAW) DA CFE}

O programa de elementos finitos na simulação de fluência ou na simulação da CFE realizará os cálculos dos deslocamentos conforme descrito no capítulo 3.5.1. Para realizar tais cálculos, há a necessidade de acessar um modelo de fluência que pode estar contido no próprio código do programa ou em uma sub-rotina, para assim determinar a deformação por fluência incremental. É importante ressaltar que as equações descritas no capitulo 3.5.1 já estão implementadas no código do programa para simulações de fluência. O presente trabalho desenvolveu uma sub-rotina com o modelo da CFE publicado por Zhang et al. (2013) que foi acessada pelo código do programa de elementos finitos para simulações de fluência.

A primeira simulação realizada a partir da sub-rotina desenvolvida foi em um modelo bidimensional em estado plano de tensão e a geometria estudada pode ser vista na Figura 39. Esta geometria foi criada no MSC. Mentat ${ }^{\circledR}$ 2014, que fez a parte de pré-processamento e pós-processamento da simulação numérica.

Figura 39 - Geometria simulada com carregamento uniaxial.

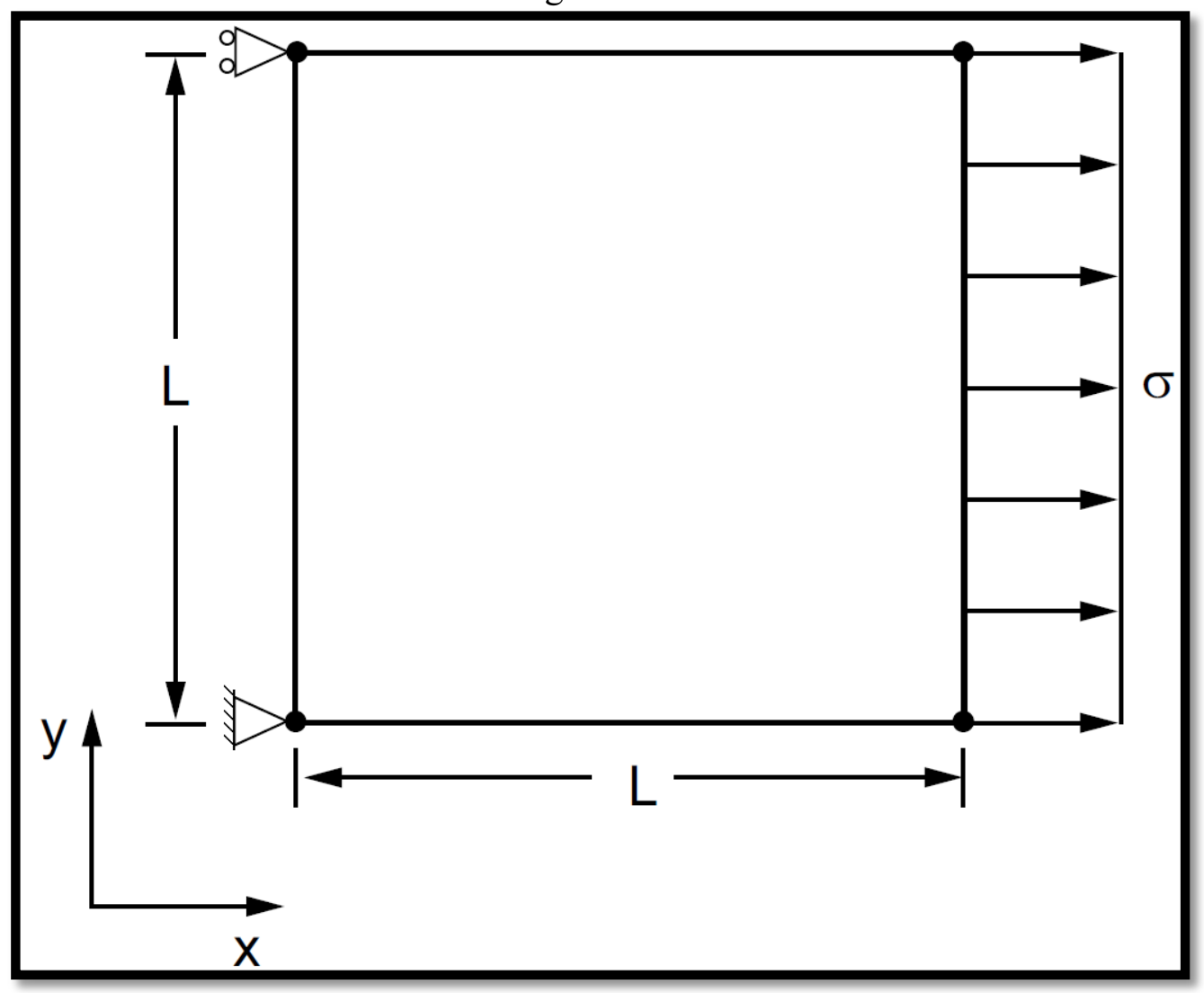

Fonte: Marc, 2013c 
O elemento quadrangular com quatro nós e dois graus de liberdade por nó foi aplicado ao modelo (somente um elemento foi utilizado), no MSC. Mentat ${ }^{\circledR}$ o elemento é o tipo 3. O painel de seleção do tipo de elemento é demonstrado na Figura 40.

Figura 40 - Painel de seleção dos elementos bidimensionais

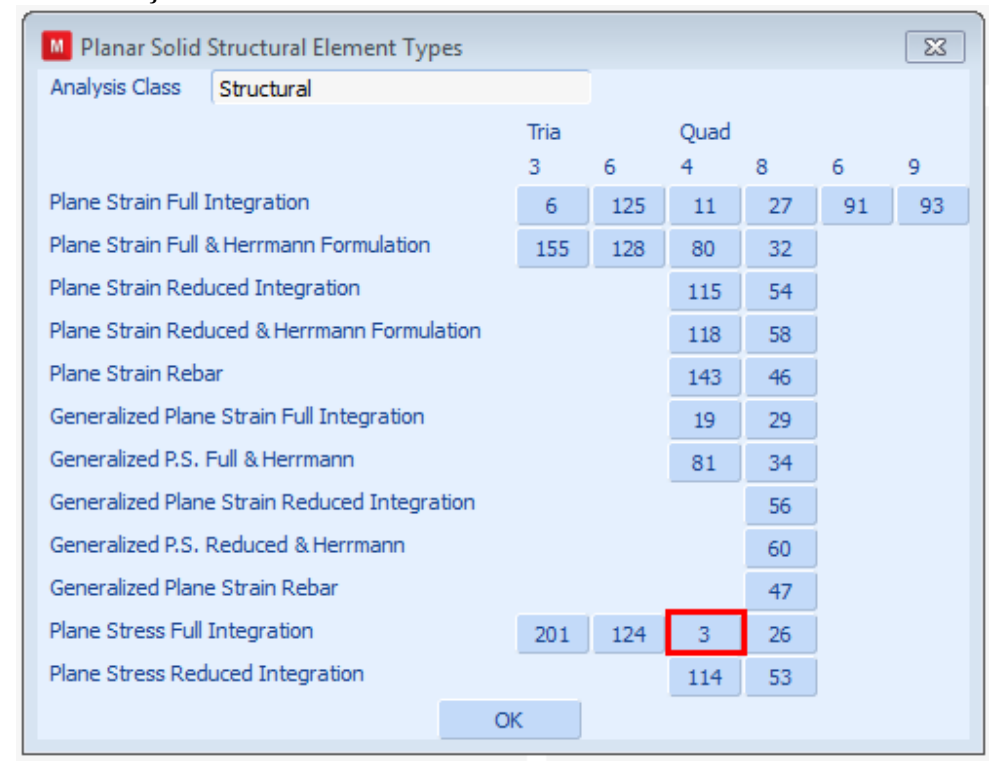

Fonte: MSC Marc, 2014

As dimensões da geometria (L) foram de $100 \mathrm{~mm}$ e as propriedades do material especificadas para a liga AA2124 são:

a) Módulo de elasticidade (E) $=73 \mathrm{GPa}$;

b) Coeficiente de Poisson $(v)=0,3$.

As propriedades do material foram consideradas na temperatura ambiente.

As condições de contorno da simulação são demonstradas na Figura 39 representadas por um apoio móvel e um fixo, em que a tensão aplicada foi de $265 \mathrm{MPa}$ para a primeira simulação, 241MPa para a segunda e 192MPa para a terceira. No total foram realizadas três simulações, que sofreram a modificação apenas da tensão.

A simulação no MSC. Marc ${ }^{\circledR}$ na fase de pré-processamento também necessita de definir o caso de carregamento (Loadcase), para garantir que as equações do modelo da CFE na sub-rotina sejam integradas corretamente. Os parâmetros especificados no caso de carregamento são destacados na Figura 41, em que o tempo da simulação foi de 12 horas a um passo fixo de 0,1 . 
A temperatura de $190^{\circ} \mathrm{C}$ foi inserida dentro da sub-rotina, para essa simulação.

Figura 41 - Painel do caso de carregamento (Loadcase) para simulação de fluência

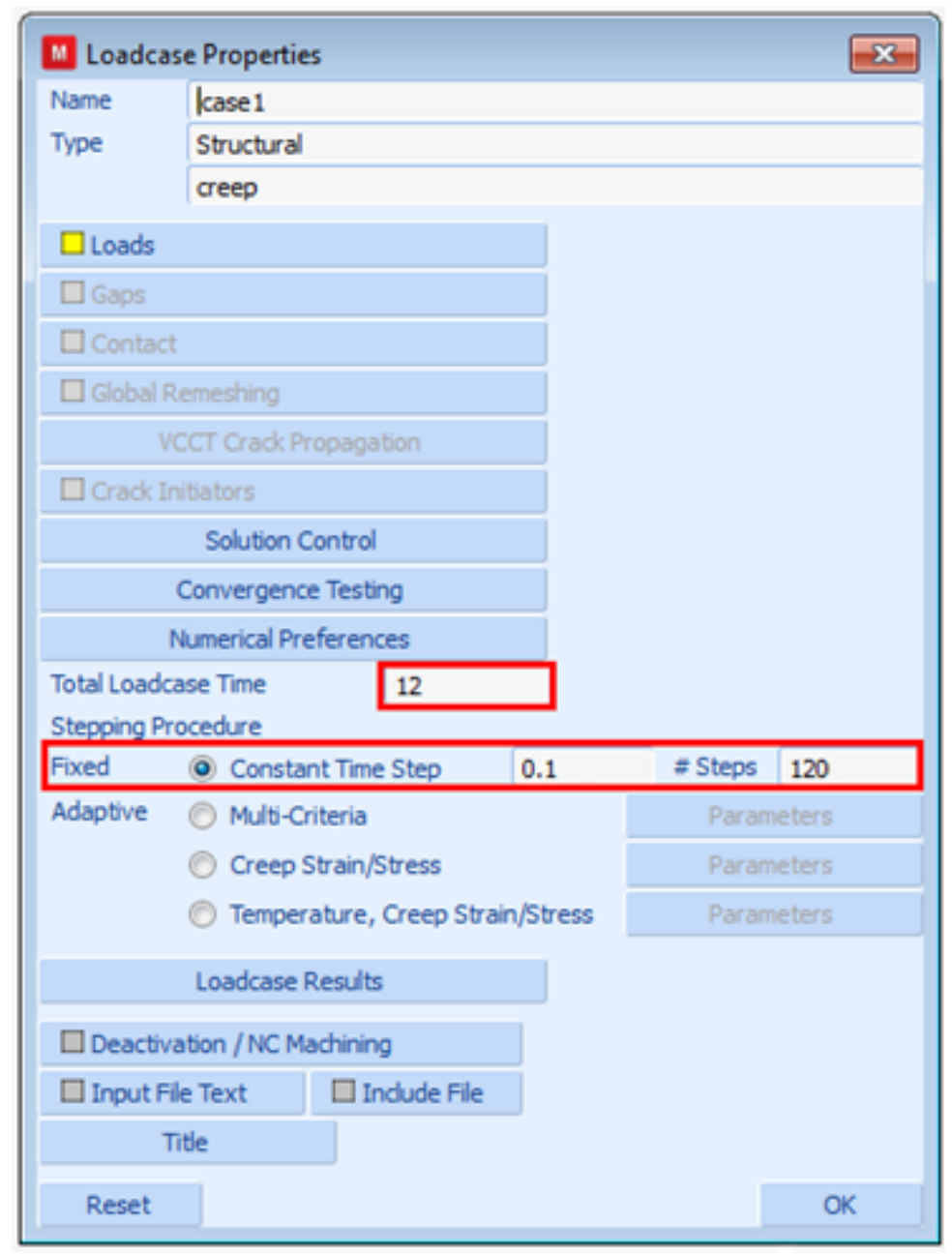

Fonte: MSC Marc, 2014

Terminada a fase de pré-processamento, a simulação foi iniciada e os dados de pósprocessamento foram apresentados no capítulo de resultados.

O MSC. Marc ${ }^{\circledR}$ executou a sub-rotina de modo semelhante à execução do programa criado em Fortran. A principal diferença está nos dados de entrada da sub-rotina que são configurados na fase de pré-processamento no MSC. Mentat ${ }^{\circledR}$, enquanto no programa criado em Fortran são designados pelo mesmo, como o número do incremento e o tempo da simulação.

A sub-rotina também foi verificada em simulações de modelos tridimensionais que representam o componente sendo conformado durante a CFE. Essas simulações seguiram as etapas da CFE, em que primeiramente é aplicada a pressão de modo a estabelecer o contado 
entre a matriz e a placa. A pressão é mantida até o final da simulação para garantir que a deformação total permaneça constante e ocorra a deformação por fluência e a relaxação de tensão. No final da simulação a pressão é retirada e ocorre o retorno elástico.

Os parâmetros de entrada no MSC. Mentat ${ }^{\circledR}$ das simulações da CFE serão descritos a seguir.

Duas geometrias do ferramental foram propostas, uma contendo dupla curvatura e outra com uma única curvatura na direção do comprimento do ferramental.

A geometria do ferramental foi simplificada para as duas simulações, porque na simulação só será relevante a superfície do ferramental que irá estabelecer contato com a placa.

A Figura 42 demonstra a geometria com uma curvatura, as dimensões dela são:

a) Placa $=600 \mathrm{~mm} \times 300 \mathrm{~mm} \times 6 \mathrm{~mm}$;

b) Raio do ferramental $=1000 \mathrm{~mm}$.

Figura 42 - Geometria simulada com uma curvatura e a geometria de um ferramental real

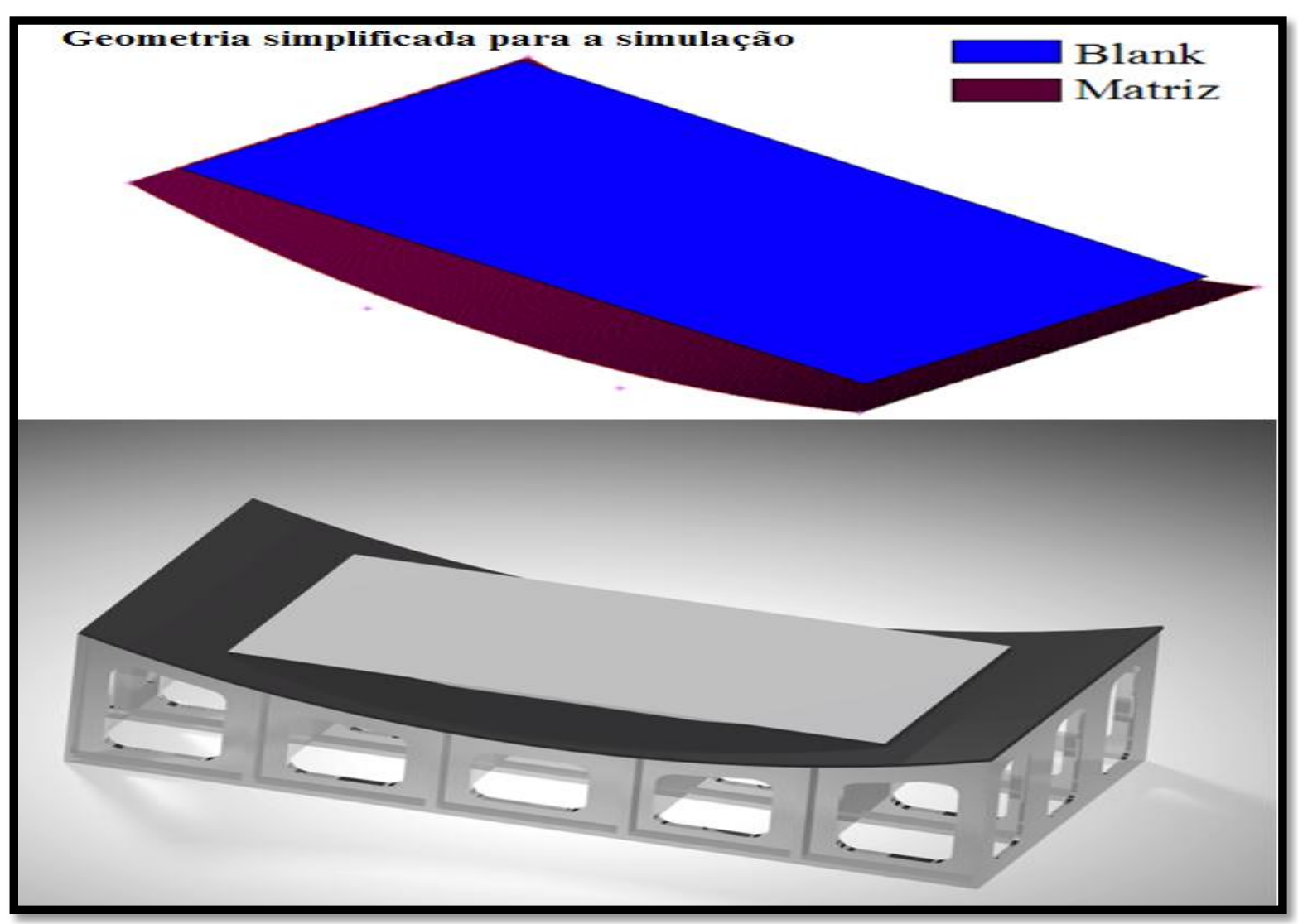

Fonte: Autor 
As dimensões da geometria de dupla curvatura apresentada na Figura 43 são:

a) Placa $=800 \mathrm{~mm} \times 400 \mathrm{~mm} \times 6 \mathrm{~mm}$;

b) Raio do ferramental (R1) $=2000 \mathrm{~mm}$;

c) Raio do ferramental (R2) $=3000 \mathrm{~mm}$.

Figura 43 - Geometria simulada de dupla curvatura

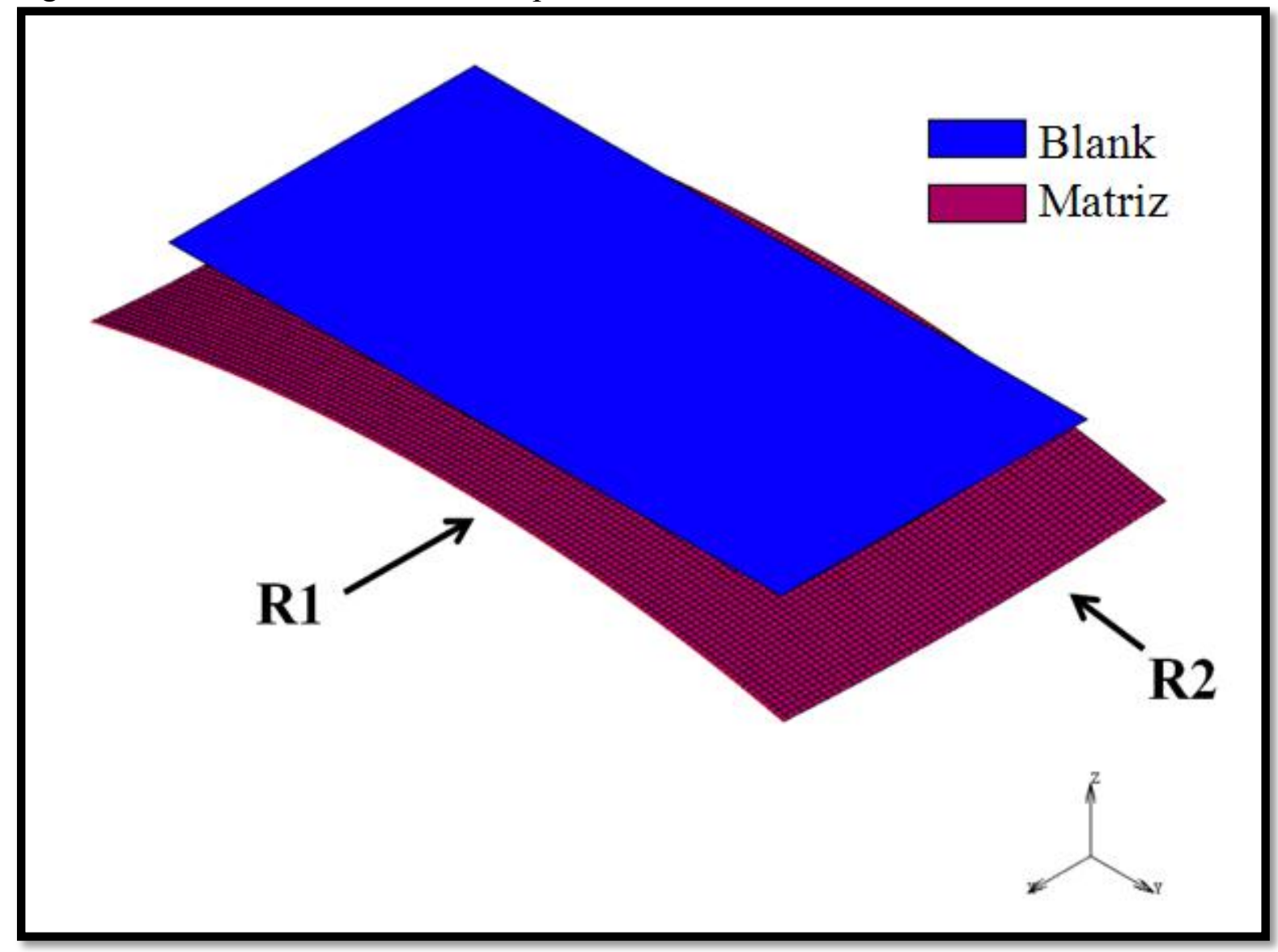

Fonte: Autor

A etapa de pré-processamento da simulação em elementos finitos seguiu a mesma sequência já comentada na simulação uniaxial, mantendo somente as propriedades do material iguais entre as simulações.

O elemento de casca quadrangular com quatro nós foi aplicado na discretização das placas, no MSC. Mentat ${ }^{\circledR}$ o elemento é o tipo 75, cuja formulação é adequada para a simulação. A malha de elementos finitos utilizada na simulação da geometria com uma curvatura teve 1800 elementos de $10 \mathrm{~mm}$ de aresta, a malha é demonstrada na Figura 44. A simulação da geometria de dupla curvatura teve uma malha de elementos finitos com 3200 elementos de $10 \mathrm{~mm}$ de aresta. 
Figura 44 - Discretização da placa com 1800 elementos de $10 \mathrm{~mm}$

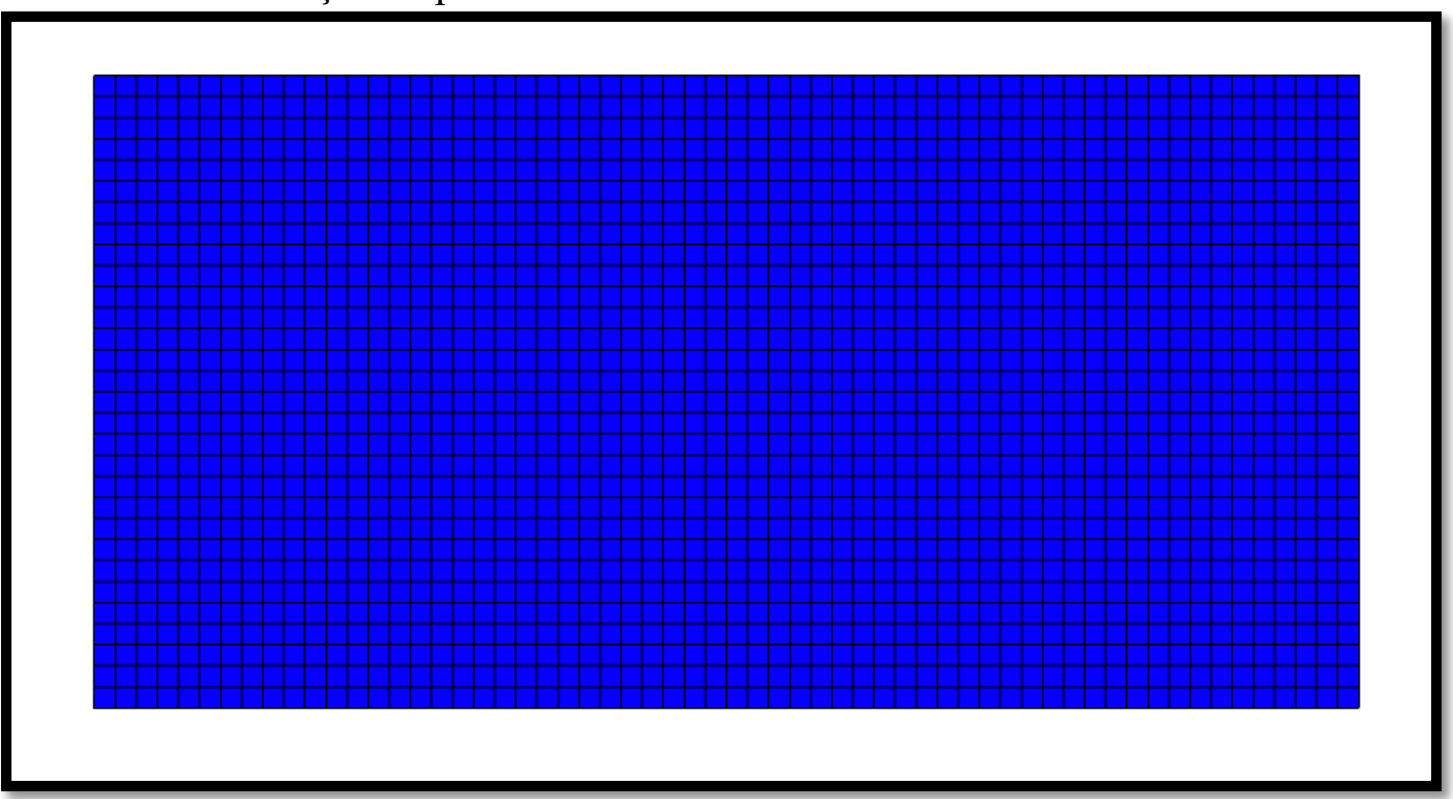

Fonte: Autor.

Os vínculos foram impostos nos planos de simetria (x e y) e a pressão de 1,5 MPa foi aplicada em ambas as simulações. A pressão foi determinada para estabelecer o contato da placa com o ferramental.

O método dos elementos finitos para satisfazer as condições de contato utiliza o conceito de corpo deformável e de corpo rígido. O corpo deformável irá entrar em contato com outro corpo e sofre a ação das forças e deforma. Este corpo na simulação é a placa. $\mathrm{O}$ corpo rígido representado pela matriz em que ficou fixo no espaço nas simulações realizadas, mas em outros tipos de simulações ele poderá ter movimentos, forças ou momentos aplicados.

A simulação da conformação por fluência com envelhecimento durou 12 horas e foi realizada na temperatura de $190^{\circ} \mathrm{C}$. 


\section{RESULTADOS}

Os resultados serão apresentados seguindo a ordem da metodologia apresentada no capítulo anterior.

As novas constantes obtidas do modelo para a liga de alumínio AA2124 em $190^{\circ} \mathrm{C}$, utilizando os dados experimentais de Zhang et al. (2013), são apresentadas na Tabela 8.

Tabela 8 - Constantes do material para o modelo

\begin{tabular}{|c|c|c|c|c|c|}
\hline $\mathbf{A}$ & $1,59 \mathrm{E}+08$ & $\mathbf{m}_{2}$ & 2 & $t^{*}$ & 14,969 \\
\hline B & 3,169 & $\mathbf{k}_{1}$ & -1 & $\mathbf{C}_{s s}$ & 100 \\
\hline $\mathbf{n}$ & 3 & $\mathbf{n}_{3}$ & 9,141 & $\mathbf{m}_{3}$ & 0,272 \\
\hline $\mathbf{Q}$ & $1,43 \mathrm{E}+05$ & $\mathbf{Q}_{2}$ & 54400 & $\mathrm{C}_{\mathrm{ppt}}$ & 2,9 \\
\hline $\mathrm{C}_{1}$ & $2,079 \mathrm{E}-09$ & $\mathrm{C}_{3}$ & 2,441 & $\mathbf{n}_{4}$ & 0,1 \\
\hline $\mathbf{n}_{1}$ & 3 & $\mathbf{Q}_{3}$ & 1,655 & $\mathbf{n}_{5}$ & 0,748 \\
\hline $\mathbf{n}_{2}$ & 1 & $\mathrm{C}_{4}$ & 29,459 & $\mathbf{C}_{\text {dis }}$ & 272,2 \\
\hline $\mathbf{m}_{1}$ & 0,522 & $\mathrm{k}_{2}$ & 0,014 & $\sigma_{0}$ & 50 \\
\hline $\mathrm{C}_{2}$ & 39,4 & $\mathbf{k}_{3}$ & 0,009 & & \\
\hline $\mathbf{Q}_{1}$ & 660 & $T^{*}$ & 459,565 & & \\
\hline
\end{tabular}

Fonte: Autor

As constantes foram inseridas nas rotinas do Matlab ${ }^{\circledR}$ contendo o método de Euler e o método de Runge-Kutta de quarta ordem. Durante esta etapa foi analisado o melhor passo para integrar as equações. As figuras 45 e 46 demonstram o comportamento da deformação por fluência em função do tempo, para diferentes passos. A partir da Figura 45 percebe-se, o aumento do desvio entre os dados experimentais e simulados, com o aumento do passo.

Os dois métodos são capazes de integrar as equações constitutivas, desde que o passo seja escolhido corretamente, de modo a não gerar um alto tempo computacional e um alto erro em relação aos dados experimentais.

Analisando os métodos de integração numérica em relação ao tempo de execução das rotinas, notou-se que o método de Euler, mesmo necessitando de um passo de integração menor que o método de Runge-Kutta, pode ser utilizado na integração, pois não gerou um acréscimo significativo no tempo de execução da rotina, até mesmo porque o método de Runge-Kutta para cada passo de integração gerou um acréscimo significativo no número de cálculos realizados. 
O método de Runge-Kutta foi aplicado na sub-rotina devido principalmente ao valor do passo de integração necessário para a resposta convergir, na qual gera menos iterações para alcançar o tempo final da simulação, e quanto menor o número de iterações durante a simulação em elementos finitos, o tempo computacional é reduzido significativamente, principalmente em análises não lineares.

Figura 45 - Deformação por fluência em função do tempo para tensão de $265 \mathrm{MPa}$, utilizando diferentes passos de integração no método de Euler

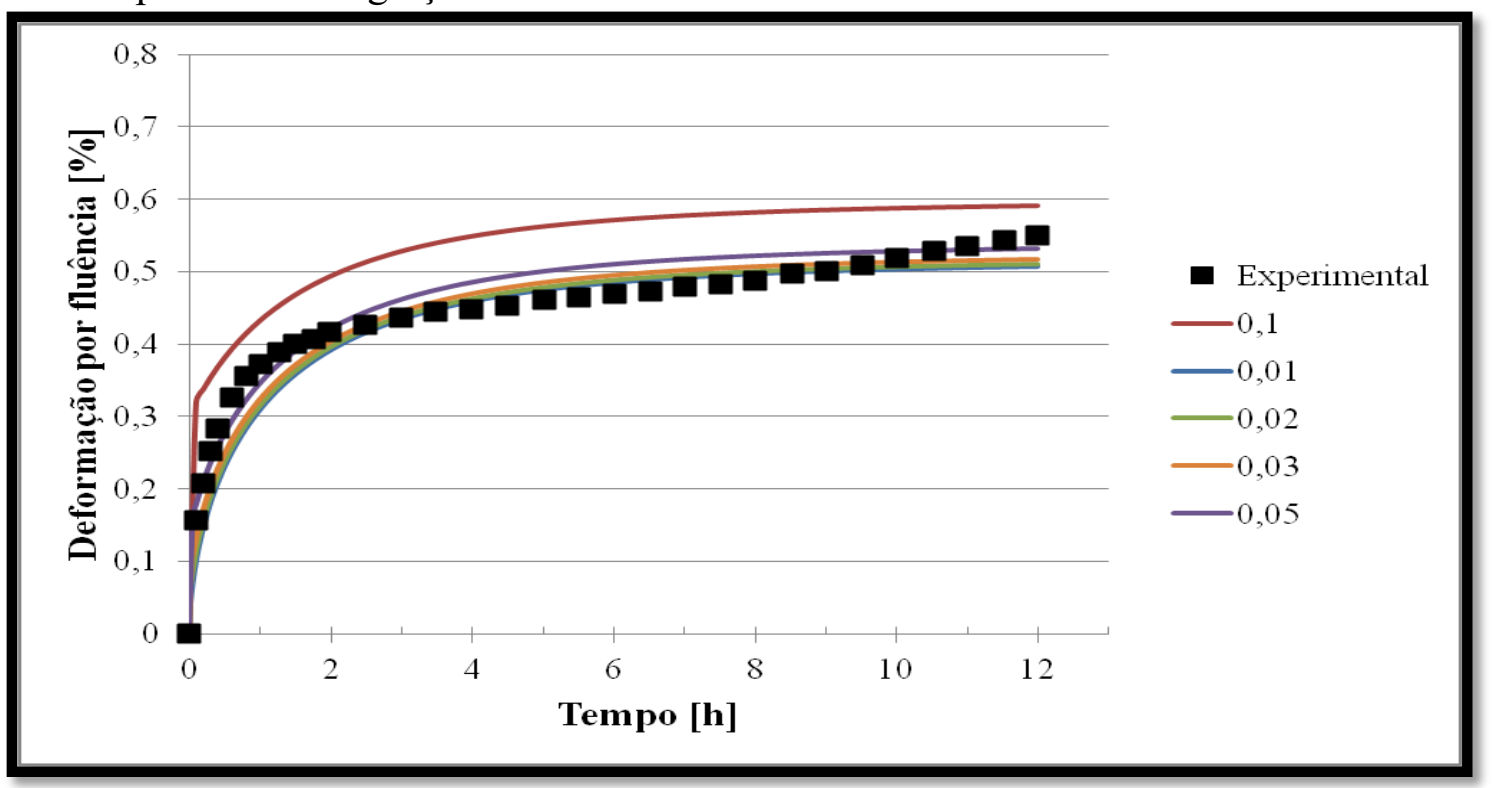

Fonte: Autor

Figura 46 - Deformação por fluência em função do tempo para tensão de $265 \mathrm{MPa}$, utilizando diferentes passos de integração no método de Runge-Kutta de quarta ordem

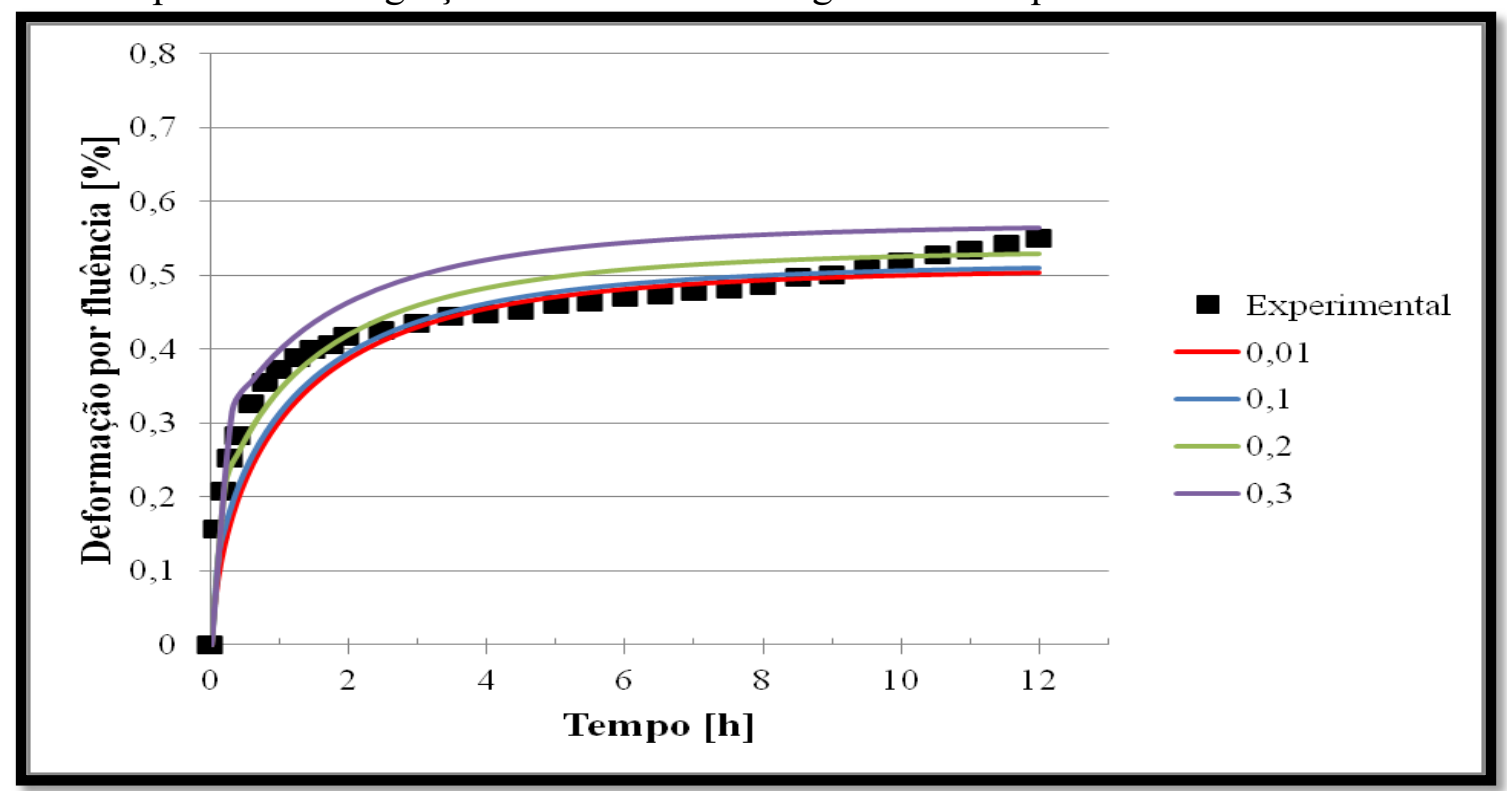

Fonte: Autor 
A resposta dada pelo método de Runge-Kutta converge em passos menores que 0,1 , enquanto no método de Euler em passos próximos de 0,01. A variação da resposta em relação ao passo para o método de Runge-Kutta foi mais bem analisada através do gráfico da Figura 47, na qual demonstra a variação da deformação por fluência em função do valor inverso do passo. A partir de valores menores que 0,1 do passo, conclui-se que a resposta não sofre variações significativas ao diminuir o passo e tal redução só acrescentaria no aumento de tempo de processamento.

Figura 47 - Deformação por fluência em $t=6$ horas para tensão de $265 \mathrm{MPa}$, utilizando diferentes passos de integração no método de Runge-Kutta de quarta ordem

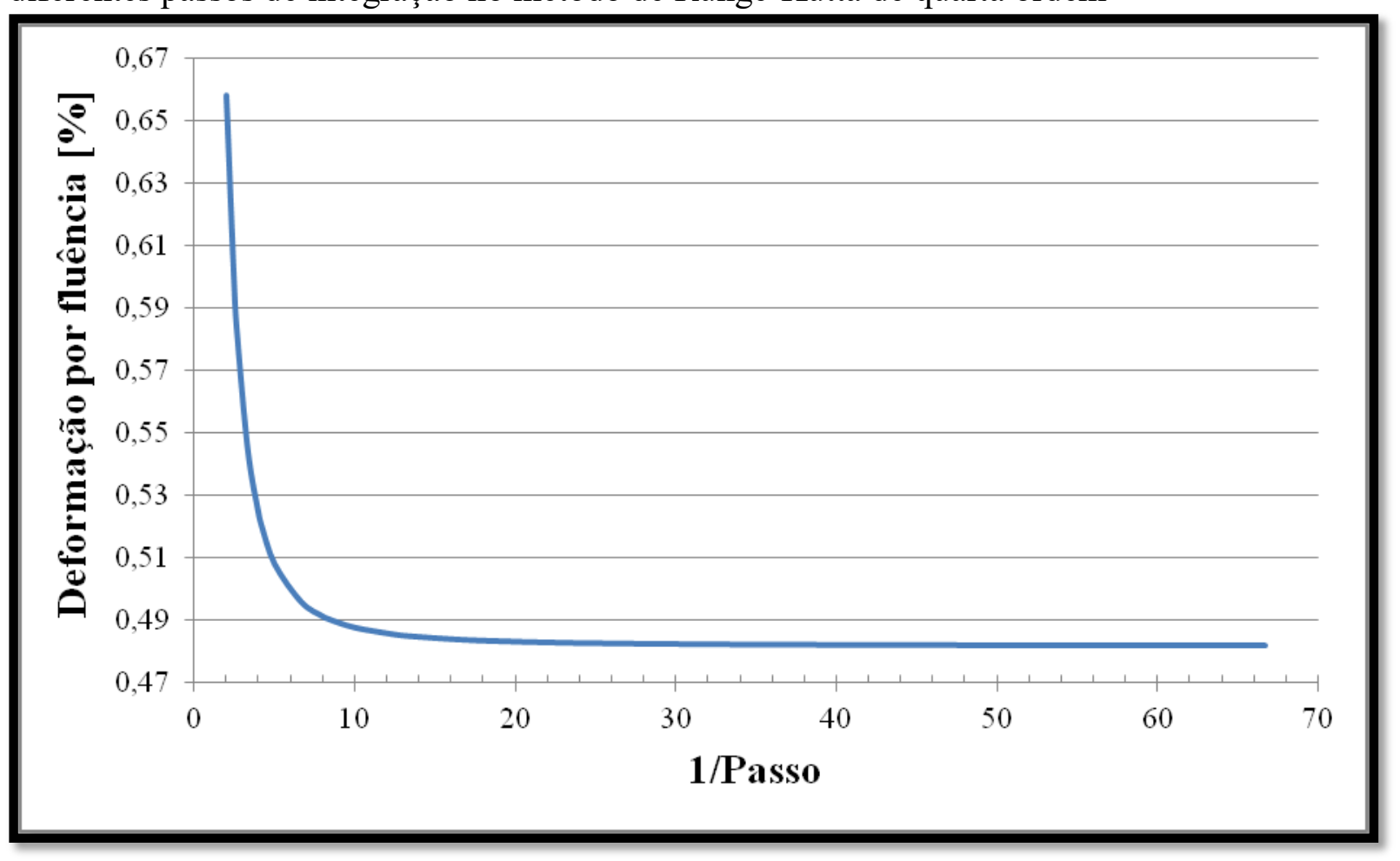

Fonte: Autor

Comparando os dados simulados da deformação por fluência para os níveis de tensão de $265 \mathrm{MPa}, 241 \mathrm{MPa}$ e $192 \mathrm{MPa}$ com os dados experimentais (Figura 48) do artigo de Zhang et al. (2013), a diferença é perceptível devido ao ajuste realizado no Matlab ${ }^{\circledR}$. A Figura 49 mostra a variação do erro residual em função do tempo, na qual é possível notar que o valor maior do erro está na curva de fluência para a tensão de 192 MPa.

O valor maior do erro (na curva de fluência para a tensão de $192 \mathrm{MPa}$ ) teve influência do ajuste realizado no Matlab ${ }^{\circledR}$, e o fato da liga AA2 124 em $190^{\circ} \mathrm{C}$ ter o limite de escoamento de $256 \mathrm{MPa}$ e na curva de fluência de $265 \mathrm{MPa}$ foi ultrapassado o limite de 
escoamento no ensaio, tal fenômeno pode ter influenciado o modelo da CFE a não aderir bem aos dados experimentais.

Os valores do erro percentual médio das curvas de fluência para as tensões de $192 \mathrm{MPa}, 241 \mathrm{MPa}$ e $265 \mathrm{MPa}$ foram de 50,66\%, 11,30\% e 8,42\%. Analisando tais valores é possível concluir que o ajuste não foi bom, porém o objetivo do presente trabalho será somente fornecer dados a sub-rotina da CFE, que torne possível a realização de testes, a fim de saber se a sub-rotina está correta.

Figura 48 - Comparação dos dados experimentais de Zhang et al. (2013) com os dados simulados da deformação por fluência, para diferentes níveis de tensão

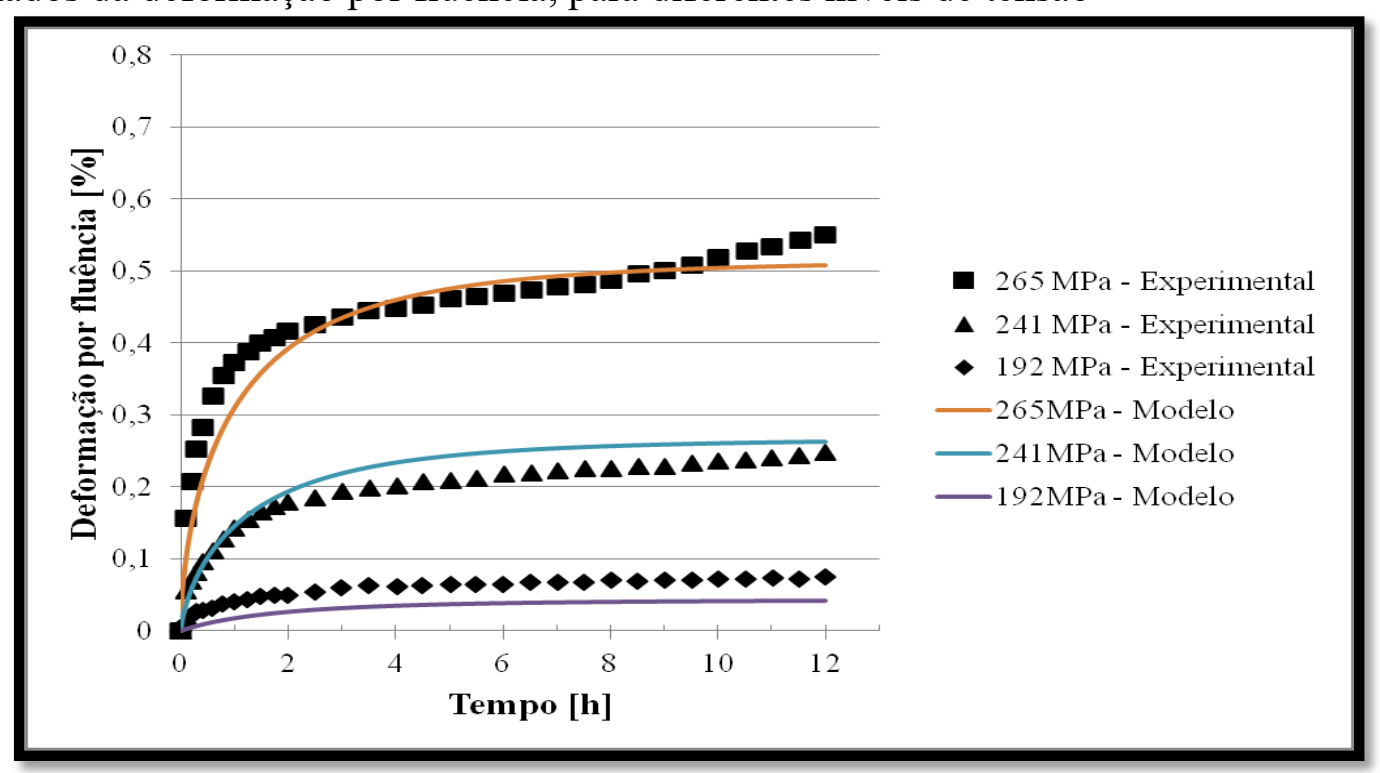

Fonte: Autor

Figura 49 - Variação do erro percentual em função do tempo

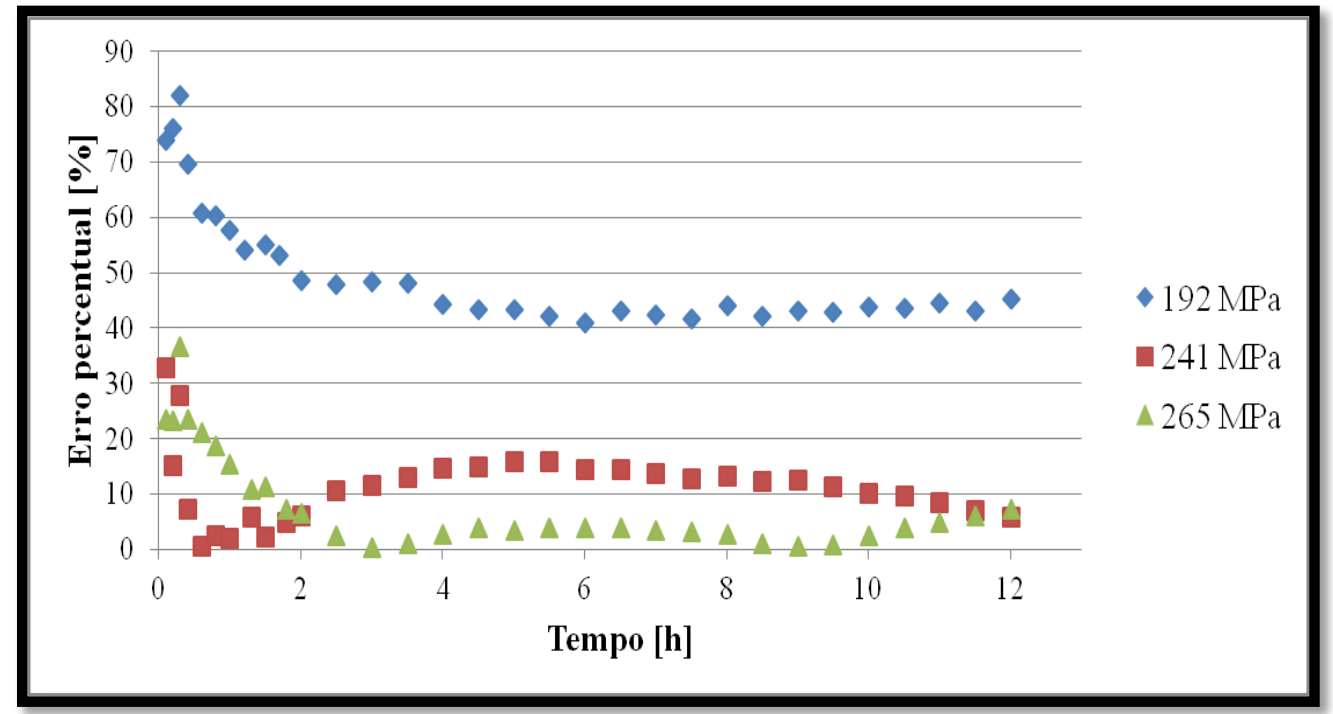

Fonte: Autor 
Primeiramente a sub-rotina foi verificada a partir de um programa em Fortran, o código utilizado é semelhante ao escrito no Matlab ${ }^{\circledR}$, a diferença entre os códigos está basicamente na linguagem de programação. A Figura 50 compara os resultados da deformação por fluência em função do tempo, gerados no Matlab ${ }^{\circledR}$ e Fortran. O erro entre os resultados foi nulo, demonstrando que os resultados gerados nos dois programas são iguais.

Figura 50 - Comparação entre os dados simulados no Matlab ${ }^{\circledR}$ e os dados simulados no Fortran da deformação por fluência, para a tensão de $265 \mathrm{MPa}$, utilizando um passo de integração de 0,1

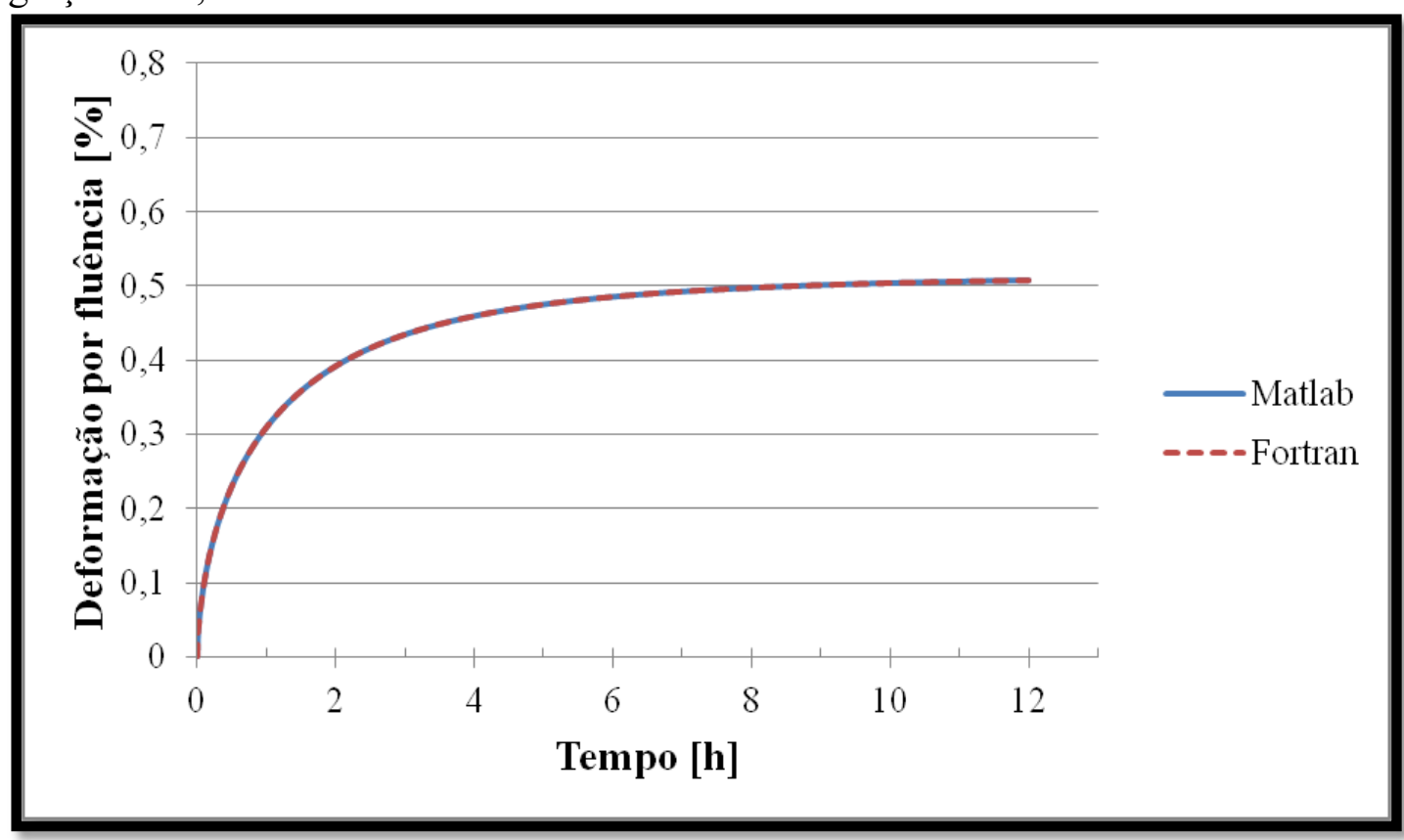

Fonte: Autor

Os resultados seguintes serão em relação à implementação da sub-rotina no programa de elementos finitos. O modelo criado no MSC. Mentat ${ }^{\circledR}$ teve o intuito de gerar resultados capazes de serem comparados aos resultados da sub-rotina implementada no programa em Fortran.

A Figura 51 demonstra o comportamento da tensão durante a simulação, na qual permaneceu constante por causa dos vínculos impostos na fase de pré-processamento. 
Figura 51 - A figura a esquerda mostra o resultado da tensão equivalente de von Mises para o último incremento da simulação exibido no MSC. Mentat ${ }^{\circledR}$; A figura a direita demonstra graficamente a evolução da tensão equivalente durante a simulação

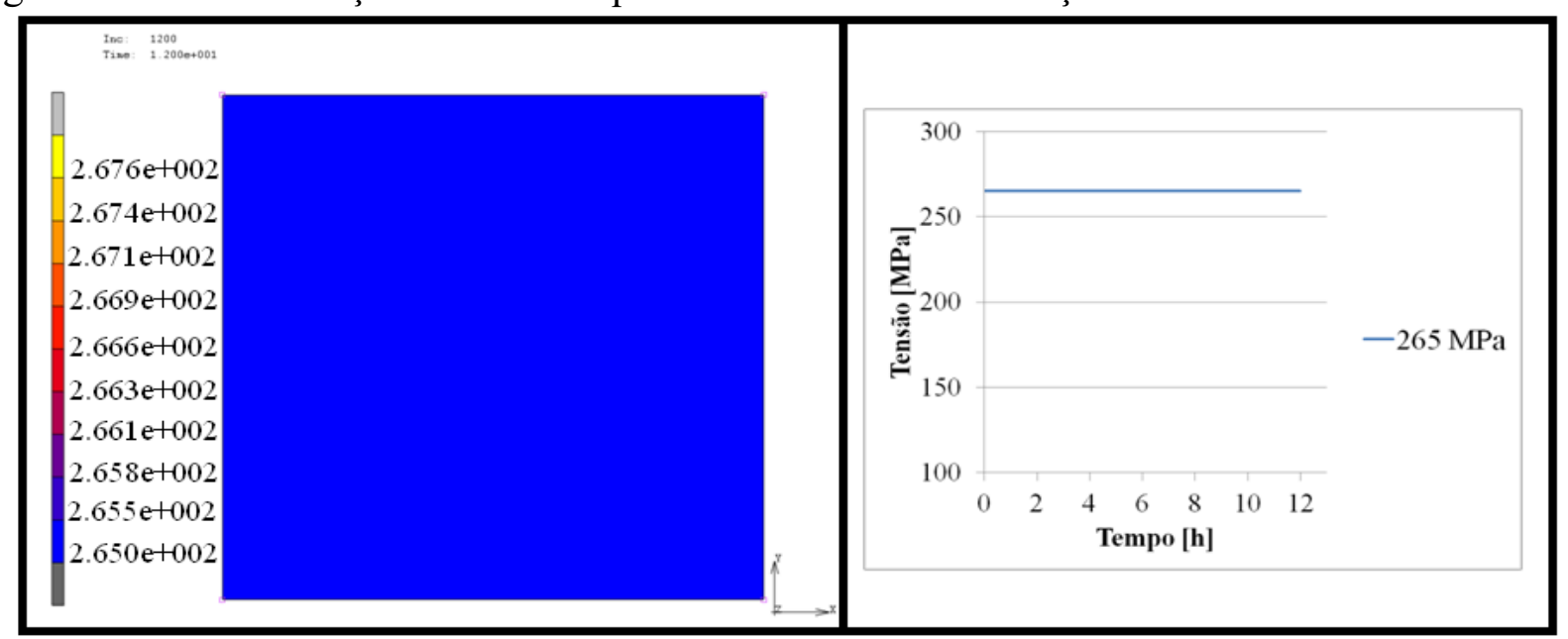

Fonte: Autor

A deformação por fluência calculada no MSC. Marc ® é demonstrada na Figura 52, nesta figura também está o resultado da deformação por fluência calculada no programa em Fortran. Comparando as curvas de deformação é possível perceber que elas são coincidentes, pois o erro absoluto foi nulo.

Figura 52 - Resultados das deformações por fluência simuladas no MSC. Marc ${ }^{\circledR}$ e no Fortran, para tensão de $265 \mathrm{MPa}$.

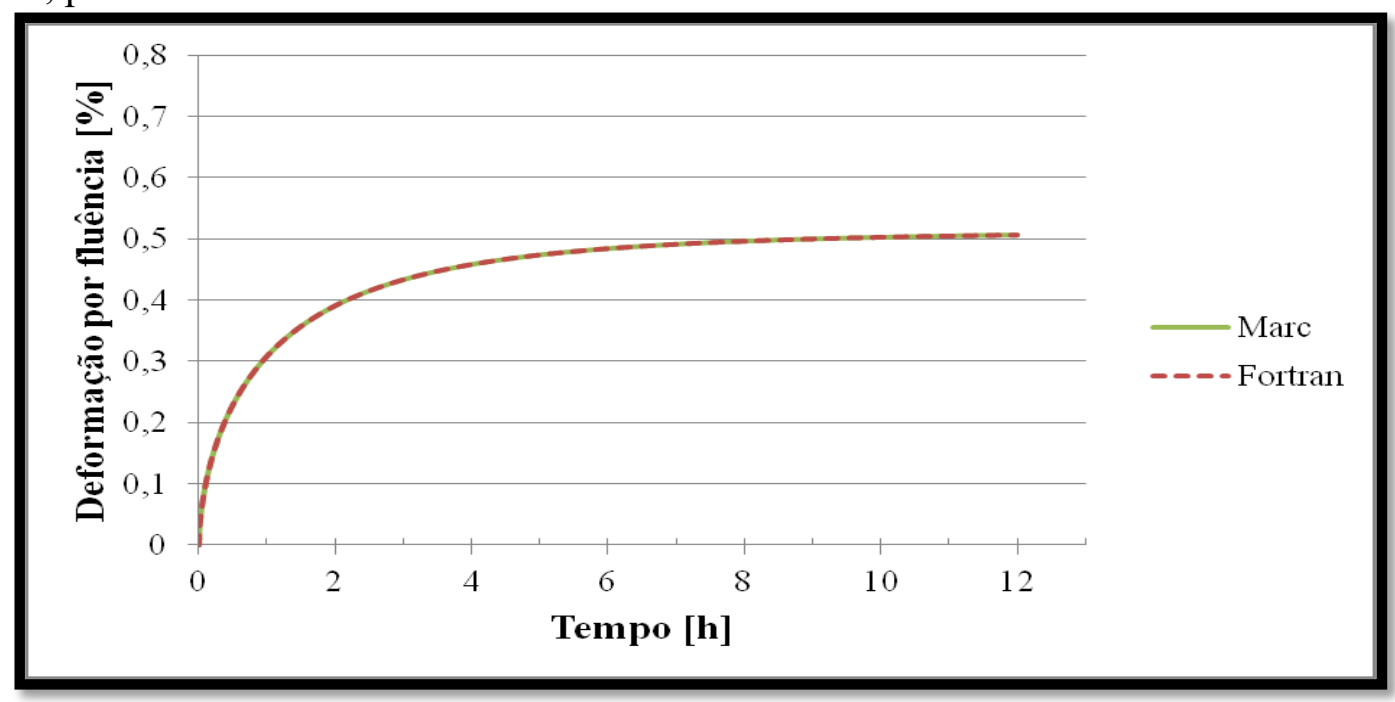

Fonte: Autor

A sub-rotina também foi verificada para as tensões de $241 \mathrm{MPa}$ e $192 \mathrm{MPa}$, os resultados são demonstrados na Figura 53. 
Figura 53 - Comparação entre os dados simulados no Fortran e os dados simulados no MSC. Marc ${ }^{\circledR}$ da deformação por fluência, para as tensões de $241 \mathrm{MPa}$ e $192 \mathrm{MPa}$

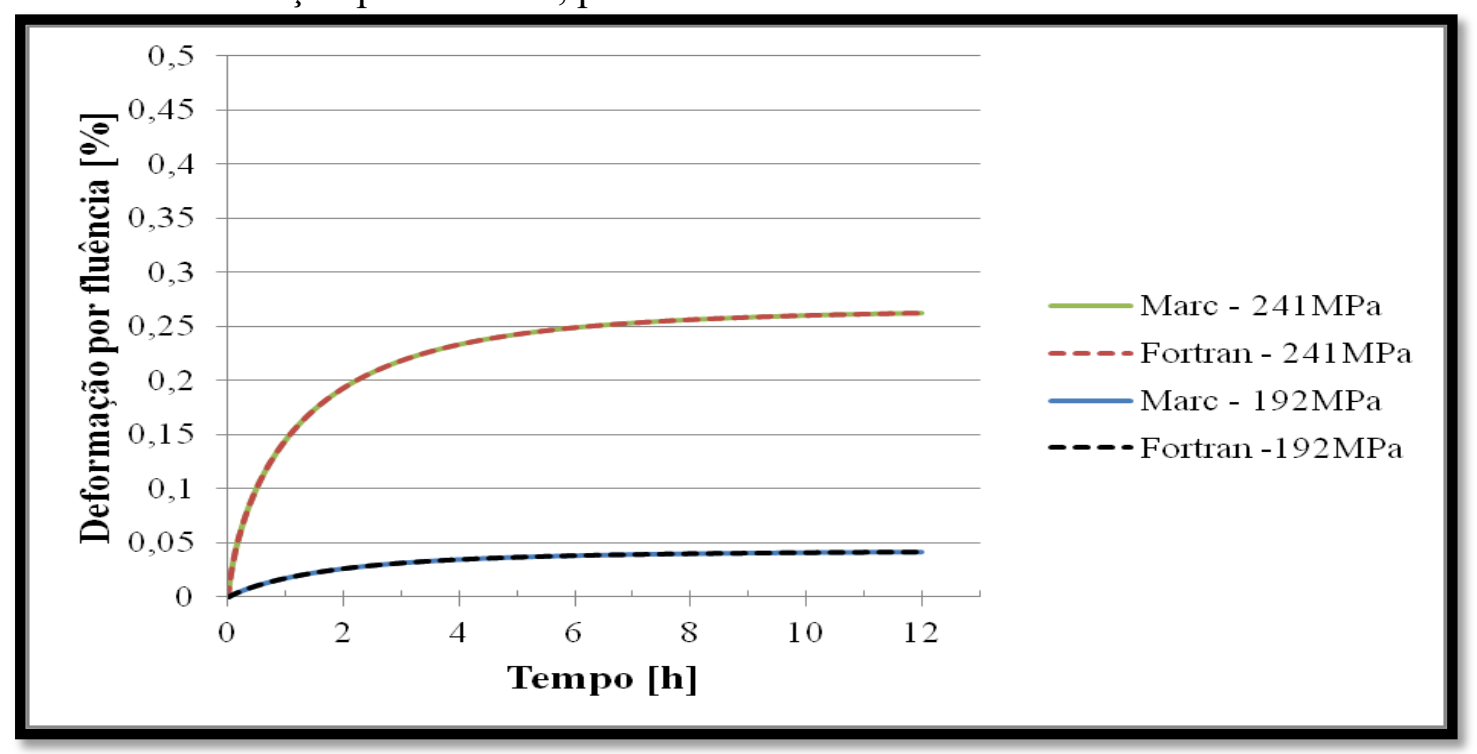

Fonte: Autor

Os próximos resultados serão sobre as simulações tridimensionais, na qual será analisado o comportamento mecânico do componente simulado em relação ao comportamento do material quando sujeito a CFE que tem sido observado na literatura.

A simulação uniaxial realizada com passo constante de 0,1 simulou somente o fenômeno de fluência, este tipo de simulação é simples e o tempo de processamento é muito baixo. A análise com um modelo mais complexo que representa as etapas da CFE, envolve o contato entre a matriz e a placa, e não só acontece a fluência; mas também a relaxação de tensão, e na etapa de descarregamento ocorre o retorno elástico. $\mathrm{O}$ aumento do número de fenômenos na simulação gera também o aumento no tempo de processamento, porque para cada elemento finito deverá ser encontrada a solução do problema. Ao contrário da simulação uniaxial, a modificação do passo para reduzir o número de iterações se torna mais interessante na simulação da CFE.

Analisando a curva da variação da deformação por fluência em função do tempo (Figura 55) e também a curva da relaxação de tensão (Figura 54), nota-se que o passo de 0,1 pode ser aumentado em certas regiões das curvas. Nestas regiões o material atinge a fluência secundária em que a taxa de variação se torna aproximadamente constante, isto permite a utilização de um passo maior, pois a deformação não sofre elevadas variações em curtos intervalos de tempo. Durante os instantes iniciais o passo também foi modificado, sendo reduzido para melhorar a convergência dos resultados. Portanto as simulações foram 
realizadas com 3 passos, nos instantes iniciais o passo de 0,01 , no intervalo seguinte o passo de 0,1 e no estágio secundário da fluência o passo igual a 2. A Figura 55 mostra as regiões em que os passos foram aplicados.

Figura 54 - Curva da relaxação de tensão para a geometria com uma curvatura na temperatura de $190^{\circ} \mathrm{C}$ (Dados coletados do nó central da placa)

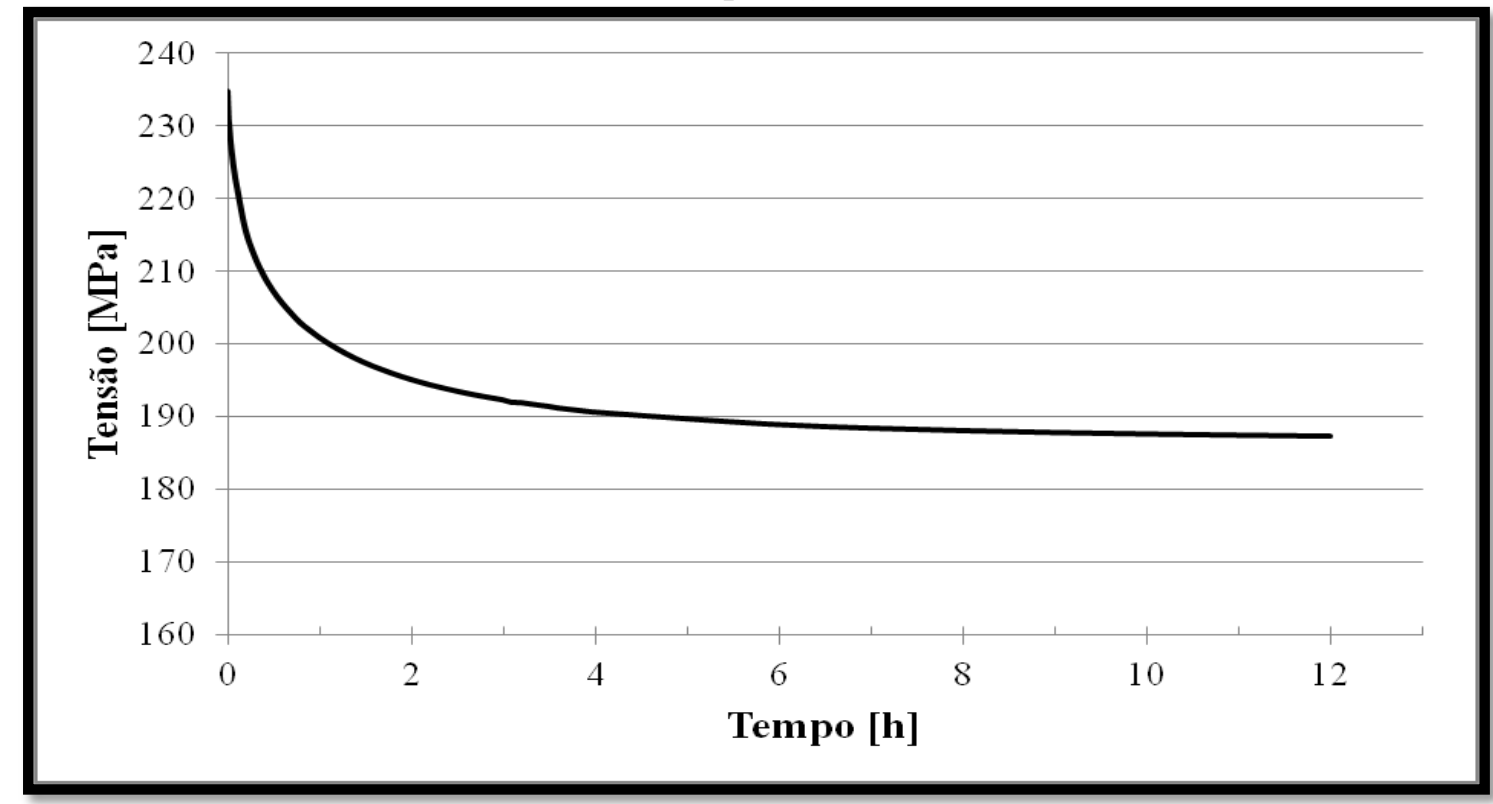

Fonte: Autor

Figura 55 - Simulação da deformação por fluência em função do tempo para a geometria com uma curvatura na temperatura de $190^{\circ} \mathrm{C}$ (Dados coletados do nó central da placa). As linhas tracejadas dividem as regiões em que os passos foram utilizados. ( $0 \mathrm{~h}$ a $0,1 \mathrm{~h}-$ passo $=0,01 \mathrm{~h}$; $0,1 \mathrm{~h}$ a $4 \mathrm{~h}-$ passo $=0,1 \mathrm{~h} ; 4 \mathrm{~h}$ a $12 \mathrm{~h}-$ passo $=2 \mathrm{~h})$

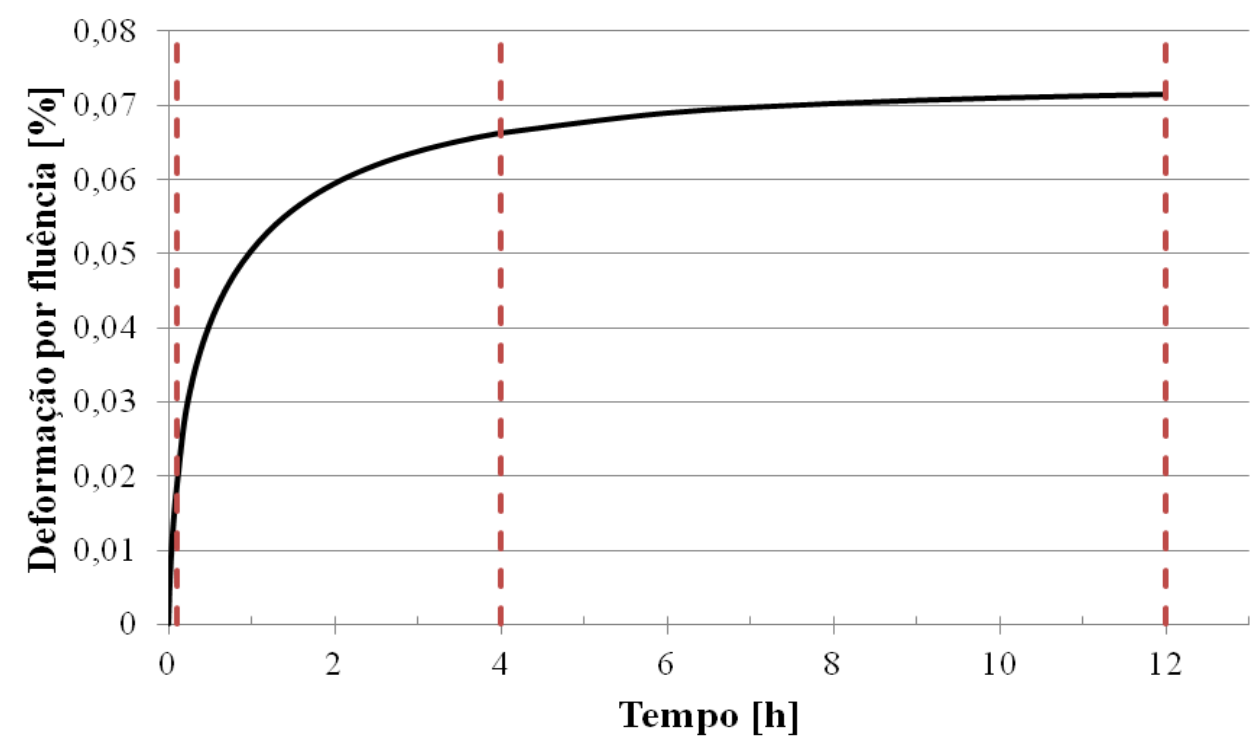

Fonte: Autor 
As geometrias foram definidas de modo que a tensão equivalente de von Mises na placa não ultrapassasse o limite de escoamento do material de $256 \mathrm{MPa}$ e também estivesse próxima das tensões (de 241MPa e 192MPa) aplicadas no ensaio de fluência das curvas apresentadas na Figura 48.

A distribuição da tensão equivalente de von Mises da superfície em tração antes de iniciar a fluência é demonstrada na Figura 56, e a Figura 57 mostra a distribuição da tensão equivalente de von Mises em 12 horas de simulação, antes de retirar o carregamento. Comparando as figuras 56 e 57 é possível notar a relaxação de tensão, e quanto menor a tensão equivalente inicial em certas regiões da placa, o fenômeno de relaxação foi reduzido durante a simulação e consequentemente a deformação por fluência também foi afetada.

Figura 56 - Distribuição da tensão equivalente de von Mises em MPa para a geometria com uma curvatura

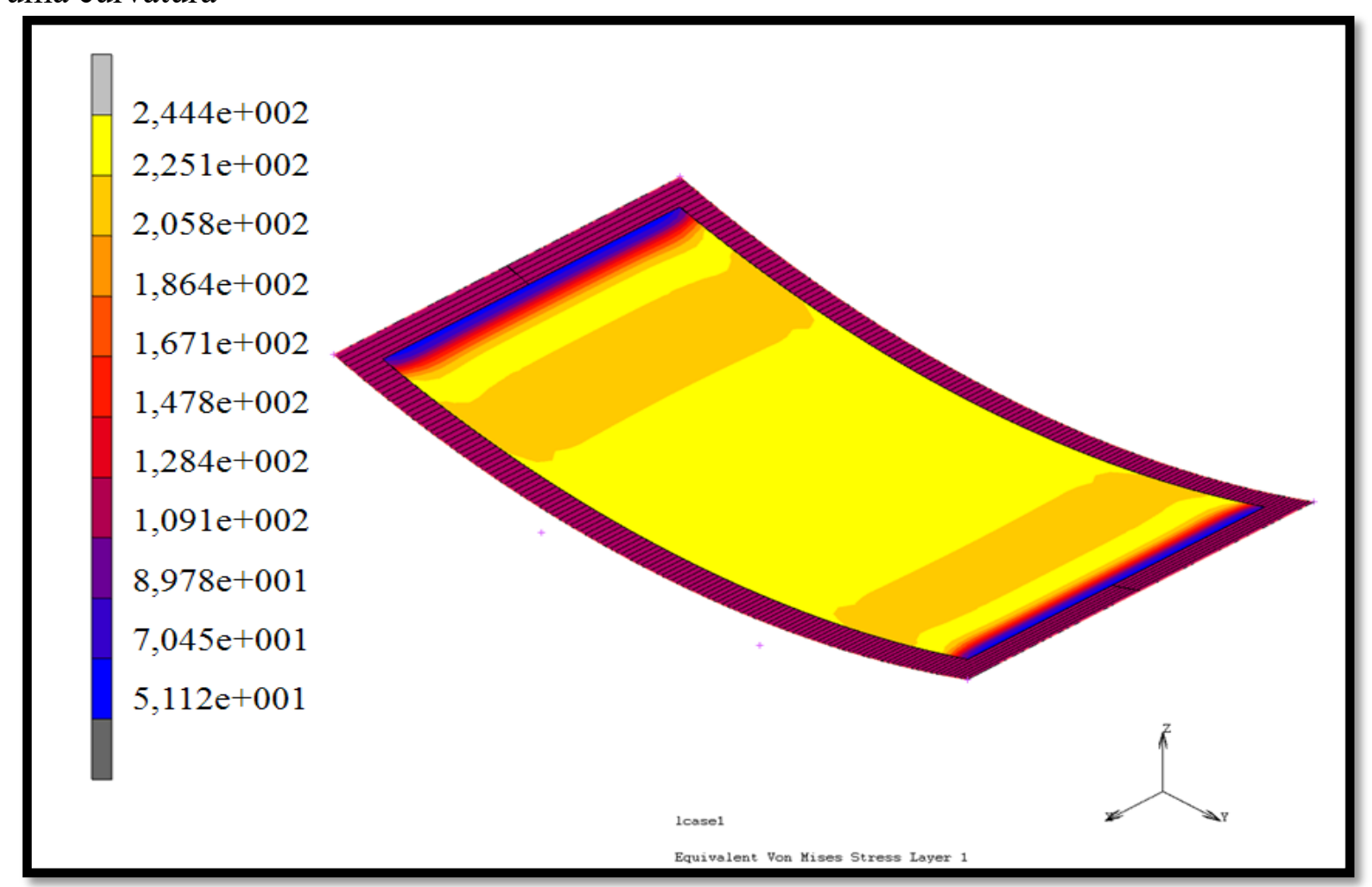

Fonte: Autor 
Figura 57 - Distribuição da tensão equivalente de von Mises em MPa para a geometria com uma curvatura em 12 horas de simulação

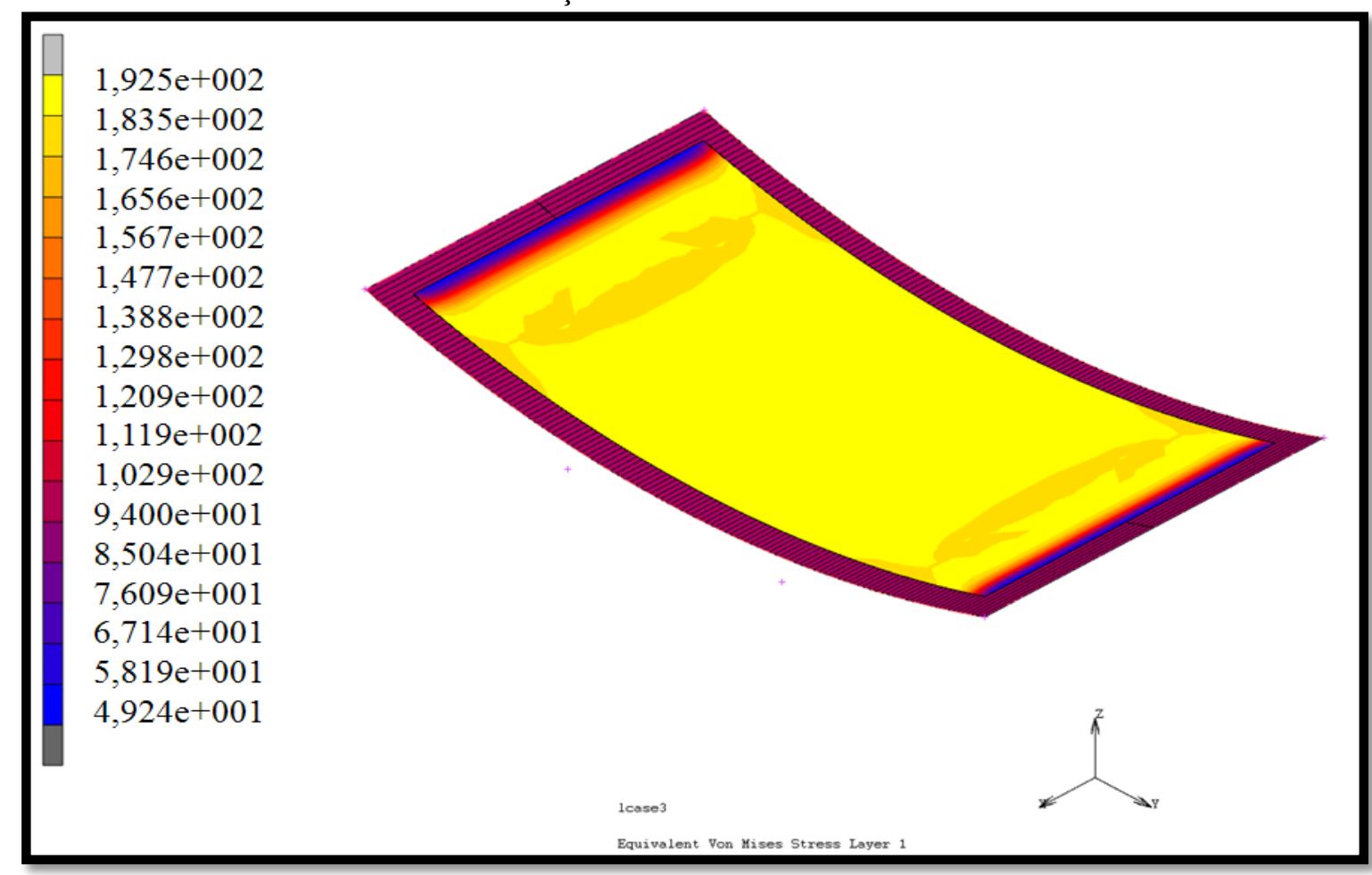

Fonte: Autor

As regiões que tiveram menor relaxação de tensão ao longo da superfície inferior da placa foram mais bem analisadas coletando os dados dos nós ao longo do comprimento da placa. A linha vermelha na Figura 58 demonstra os nós que foram selecionados.

Figura 58 - Nós selecionados para coletar os dados da tensão equivalente de von Mises

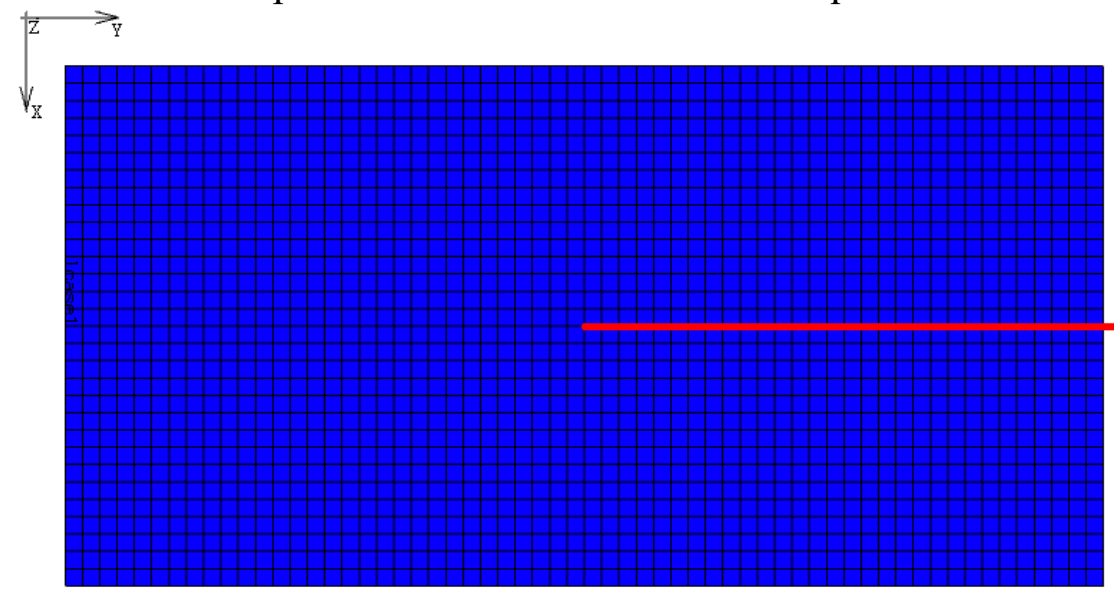

Fonte: Autor 
Os dados coletados deram origem ao gráfico demonstrado na Figura 59. Neste gráfico, comparando as tensões inicias e após 12 horas de simulação, nota-se que para as tensões menores que $150 \mathrm{MPa}$ a relaxação de tensão foi praticamente inexistente na extremidade da placa.

Figura 59 - Tensão equivalente de von Mises ao longo do comprimento da placa para a geometria com uma curvatura

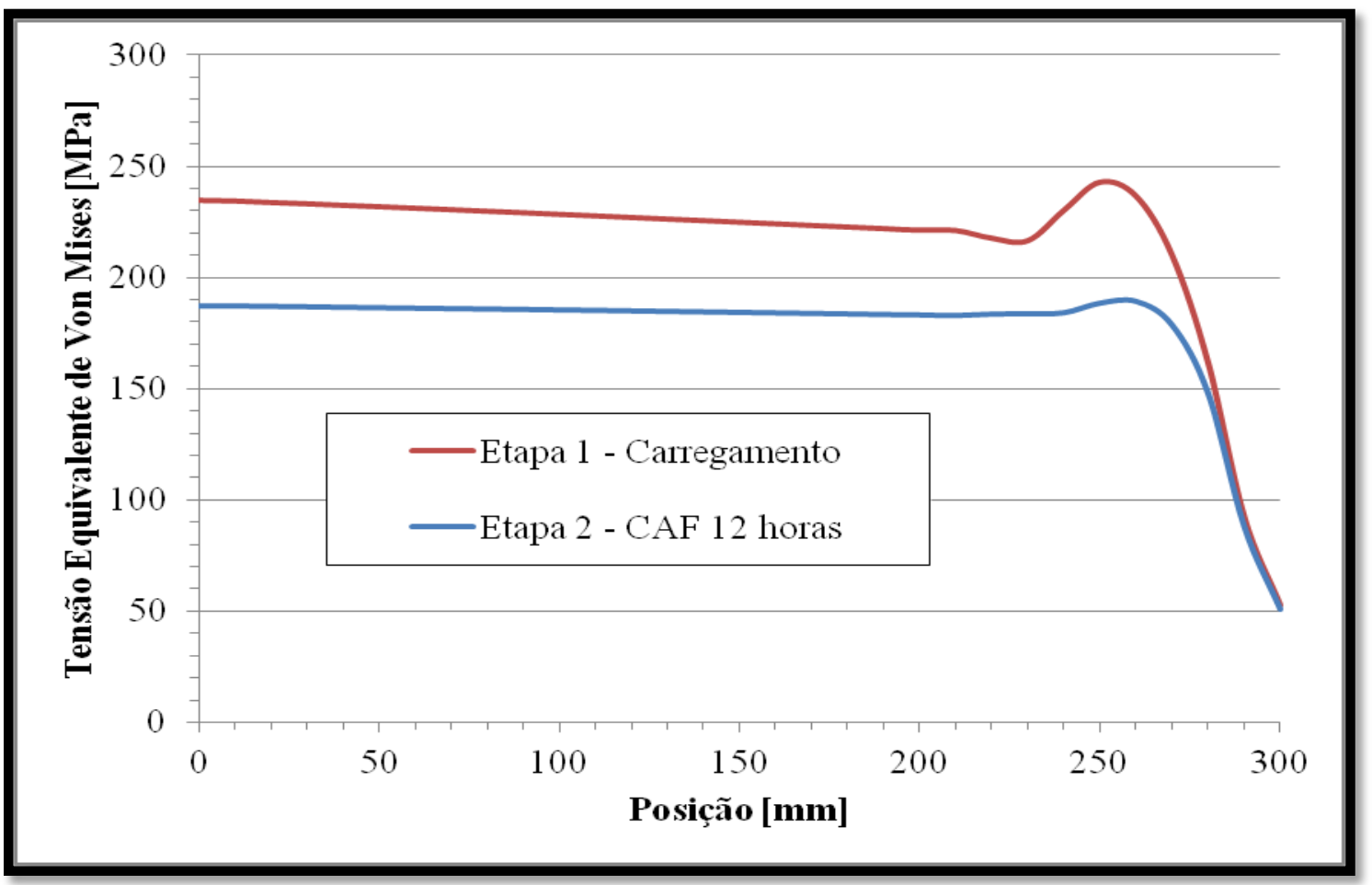

Fonte: Autor

As figuras 60 e 61 mostram a distribuição da tensão equivalente na superfície inferior da placa com dupla curvatura no instante inicial e em 12 horas de simulação.

Comparando as duas matrizes de conformação, a geometria com dupla curvatura apresentou níveis de tensão menores do que a geometria com uma curvatura devido ao aumento dos raios da matriz. 
Figura 60 - Distribuição da tensão equivalente de von Mises em MPa para a geometria de dupla curvatura

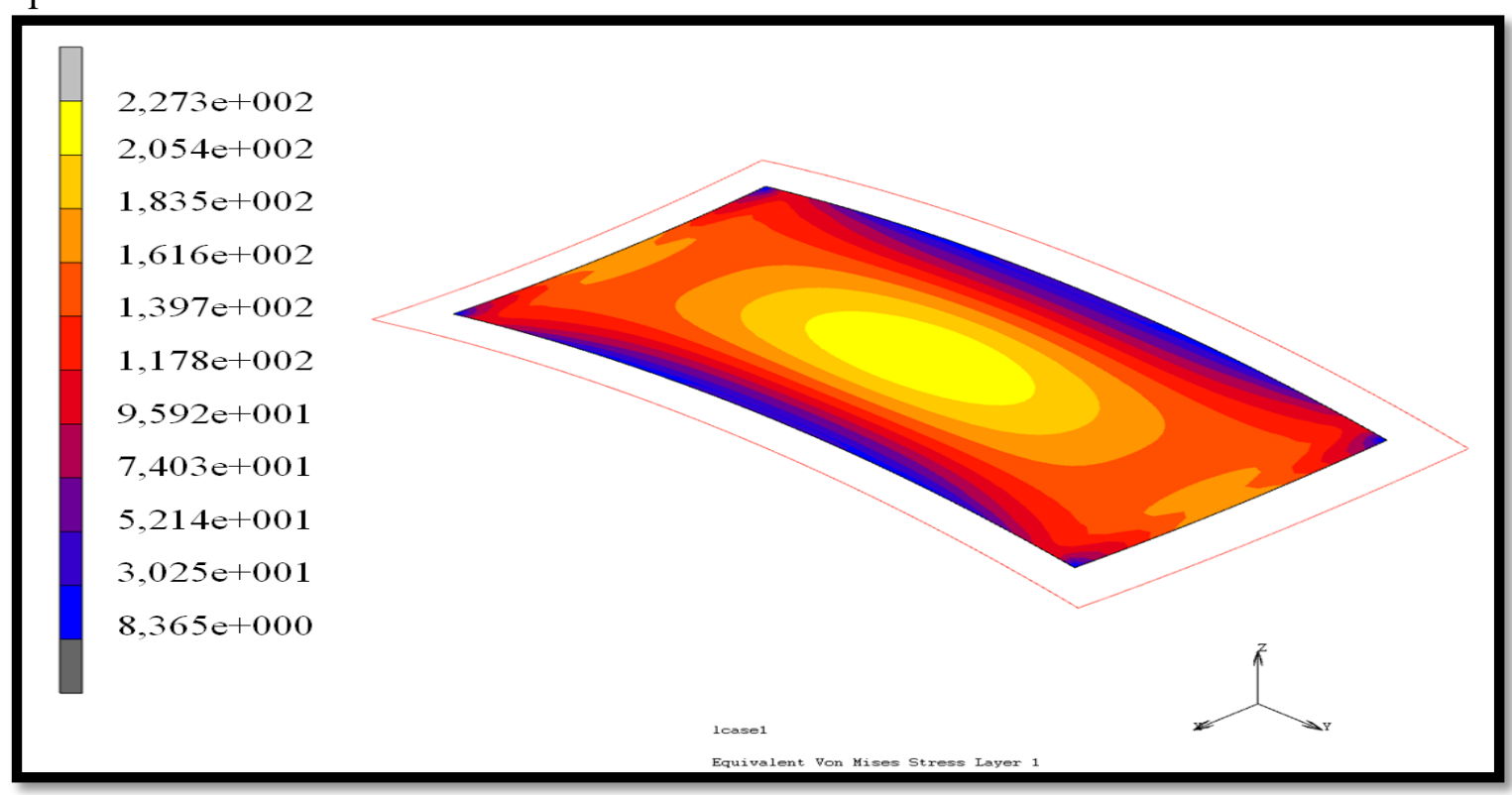

Fonte: Autor

Figura 61 - Distribuição da tensão equivalente de von Mises em MPa para a geometria de dupla curvatura em 12 horas de simulação

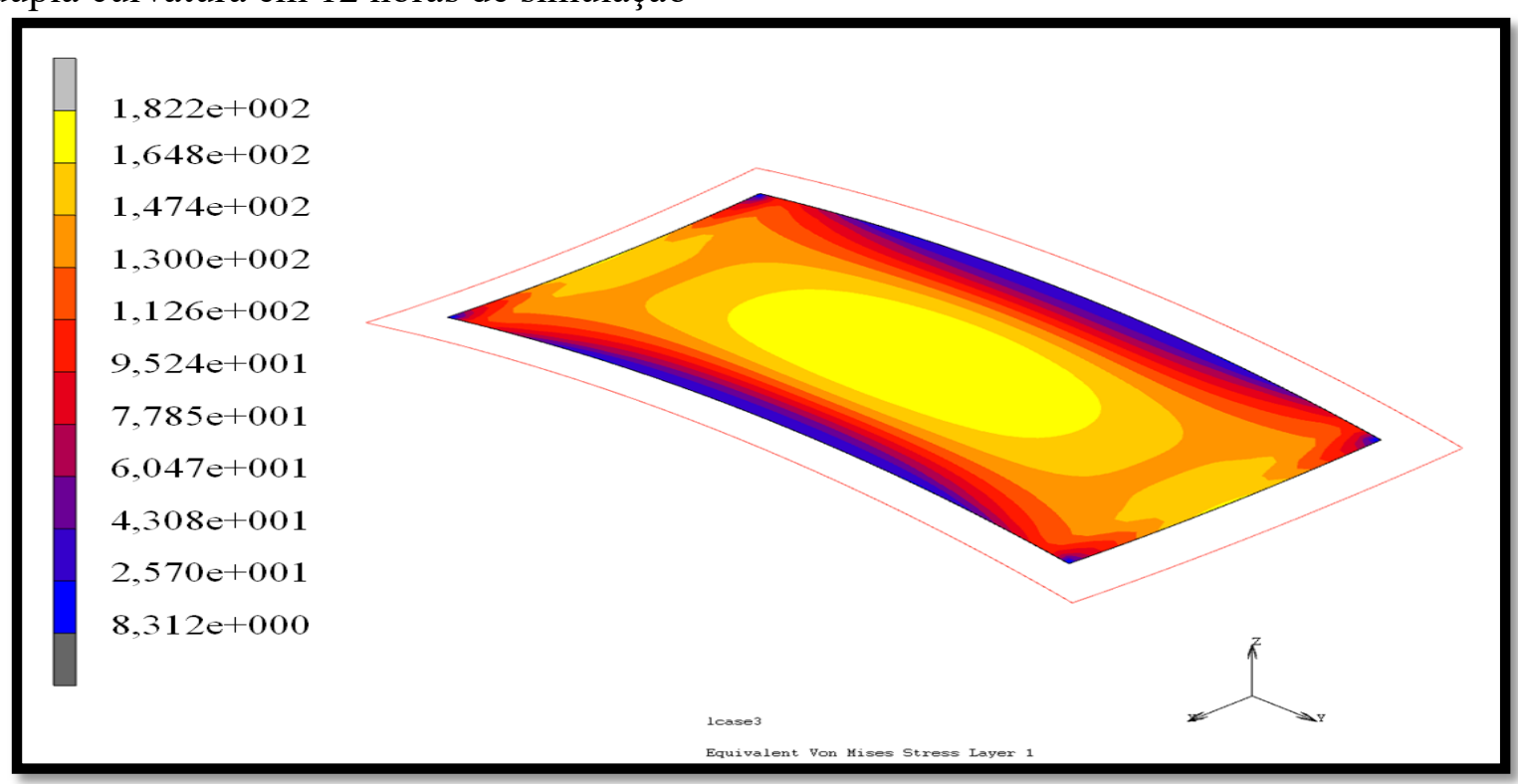

Fonte: Autor

Os dados dos nós ao longo da superfície da placa também foram coletados para a geometria de dupla curvatura, o procedimento foi o mesmo demonstrado anteriormente na Figura 58.

A tensão equivalente de von Mises ao longo do comprimento da placa para a geometria de dupla curvatura é demonstrada na Figura 62. Diferente da geometria com uma 
curvatura que teve a tensão reduzida significativamente nas extremidades da placa, a geometria de dupla curvatura apresentou tensões iniciais maiores que $150 \mathrm{MPa}$ ao longo da região estudada, por causa da geometria do ferramental. Comparando as tensões inicias e após 12 horas de simulação na Figura 62, a relaxação de tensão foi sendo reduzida ao longo do comprimento da placa, devido à redução da tensão.

Figura 62 - Tensão equivalente de von Mises ao longo do comprimento da placa para a geometria de dupla curvatura

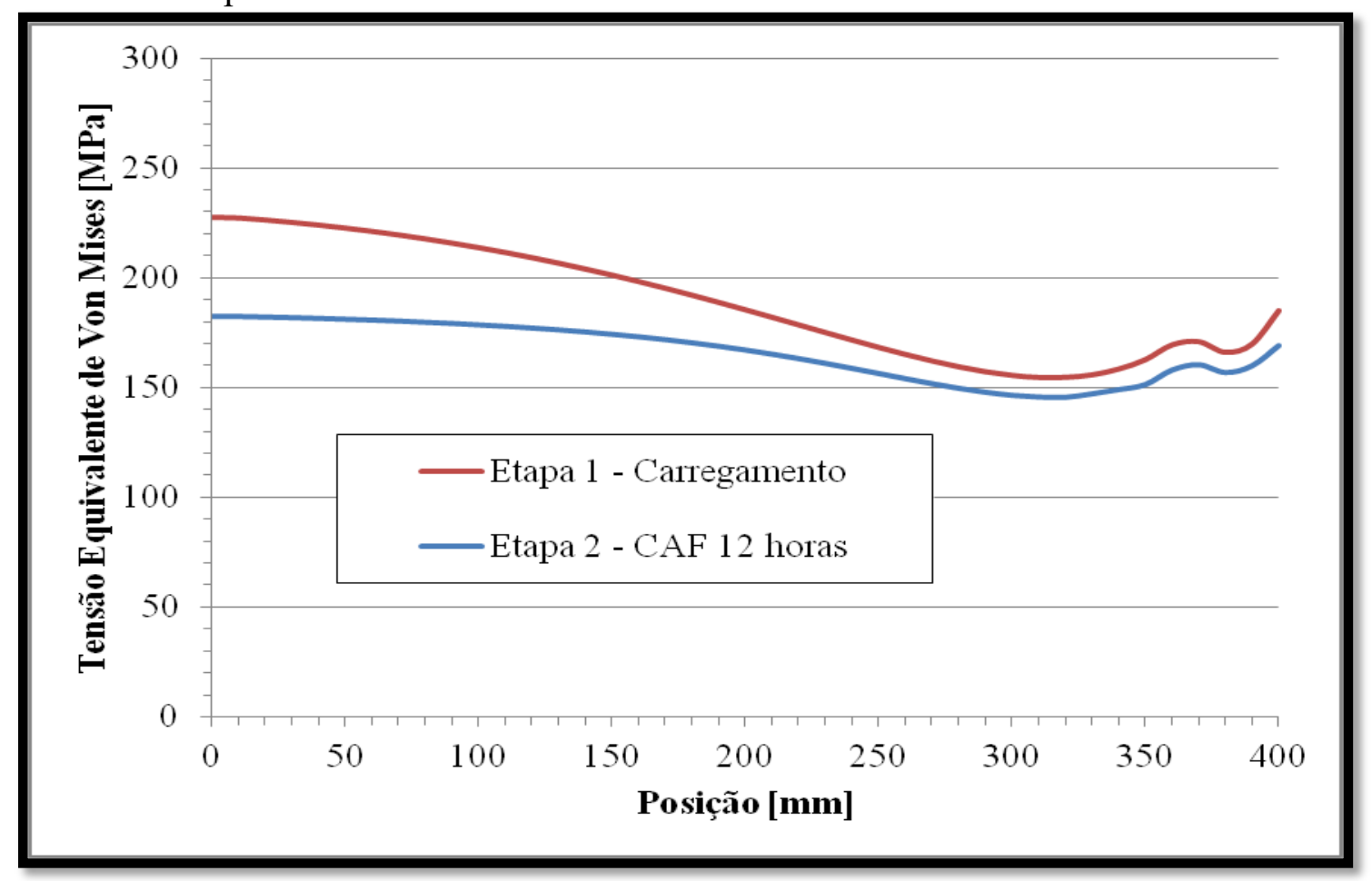

Fonte: Autor

A relaxação de tensão e a deformação por fluência não só depende das tensões distribuídas na superfície do corpo, mas também das tensões ao longo da espessura. A variação da tensão ao longo da espessura na direção do comprimento da placa pode ser analisada através do elemento casca, pois o mesmo é dividido em camadas e cada camada tem pontos de integração ao longo da espessura, possibilitando assim o cálculo das tensões e deformações. A Figura 63 mostra o gradiente de tensões (na espessura da placa) no instante inicial em que a carga é aplicada, para 12 horas de simulação e por fim após o descarregamento. O eixo vertical da Figura 63 mostra o número das camadas do elemento casca ao longo da espessura e o eixo horizontal a tensão, os dados foram coletados do nó central da placa. 
Figura 63 - Gradiente de tensões na direção do comprimento da placa, para a geometria com uma curvatura

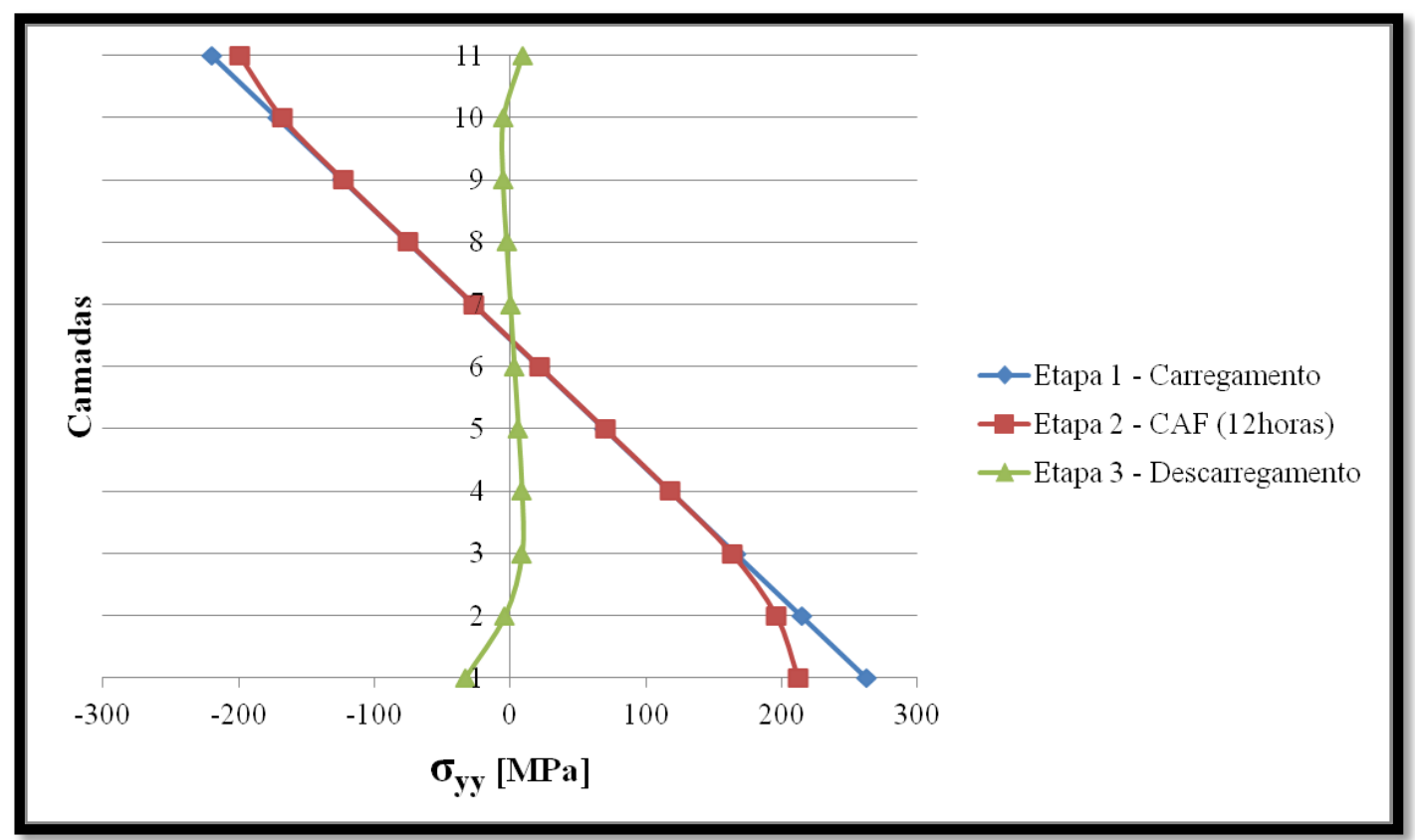

Fonte: Autor

A diferença entre as tensões na superfície superior e inferior da placa pode ter sido causada devido ao contato da placa com a matriz, fazendo com que a superfície inferior que está em contato tenha as maiores tensões.

A forma do gradiente de tensão da Figura 63 é semelhante ao apresentado por Zhan, Lin e Huang (2011), na qual realizaram simulações da CFE para geometria com uma curvatura, essa semelhança pode indicar que a sub-rotina realizou os cálculos corretamente ao longo da espessura.

A geometria de dupla curvatura apresentou um gradiente de tensões no centro da placa diferente, por causa das dimensões da matriz. Este gradiente de tensões na direção y (demonstrado na Figura 64) tem somente tensões compressivas durante a primeira e a segunda etapa da CFE. A partir da camada de número 4 do elemento, nota-se a redução da relaxação de tensão até a superfície superior da placa. 
Figura 64 - Gradiente de tensões na direção do comprimento da placa, para a geometria com dupla curvatura

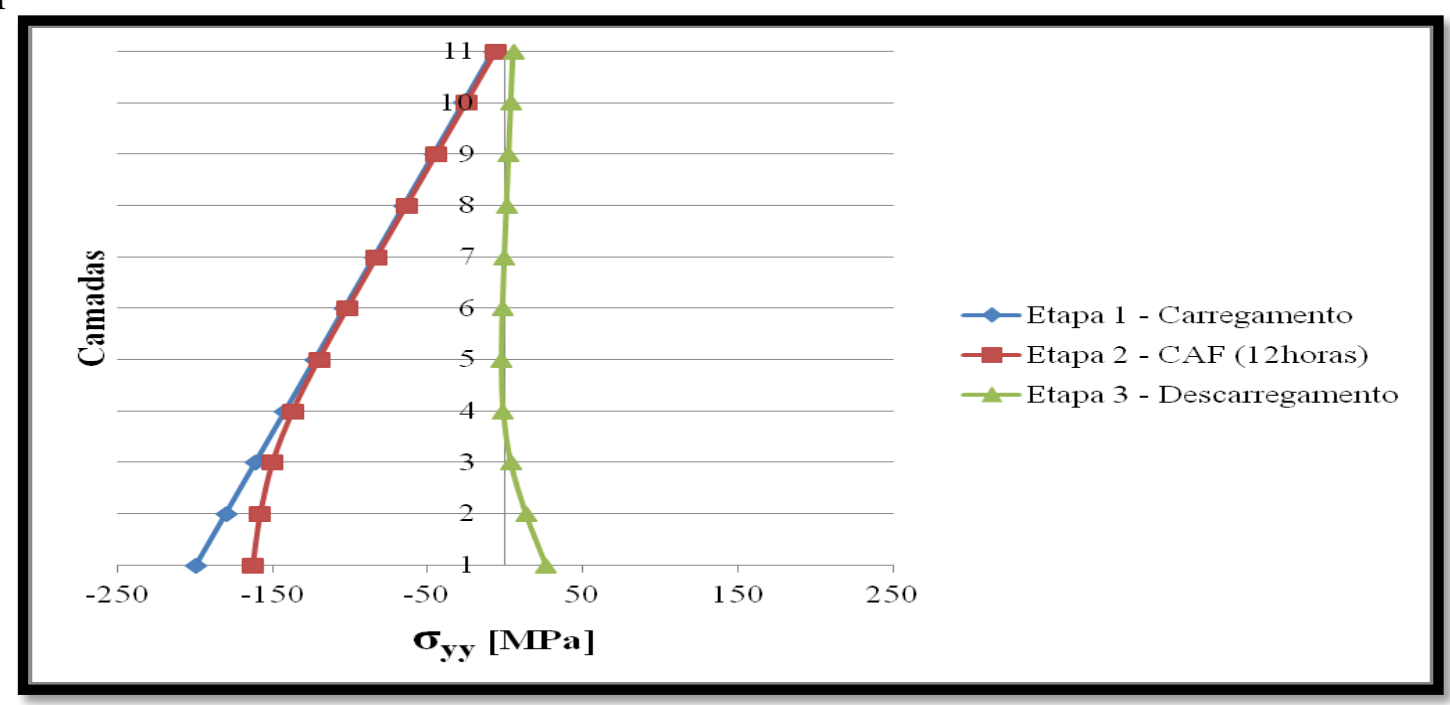

Fonte: Autor

Essa redução da relaxação pode ser mais bem compreendida analisando a Figura 65 (que demonstra o gradiente da tensão equivalente), juntamente com a Figura 48 que mostra as curvas de fluência para diferentes níveis de tensão. Na Figura 48 a curva de fluência para tensão de 192MPa exibe pouca deformação, e caso um componente seja submetido a tensões abaixo de 192MPa, a deformação por fluência será cada vez menor ou até mesmo desprezível. Tal efeito é mostrado na figura 52, para tensões abaixo de $150 \mathrm{MPa}$ a relaxação de tensão teve uma redução significativa até a superfície superior da placa.

Figura 65 - Gradiente de tensões na direção do comprimento da placa, para a geometria com dupla curvatura

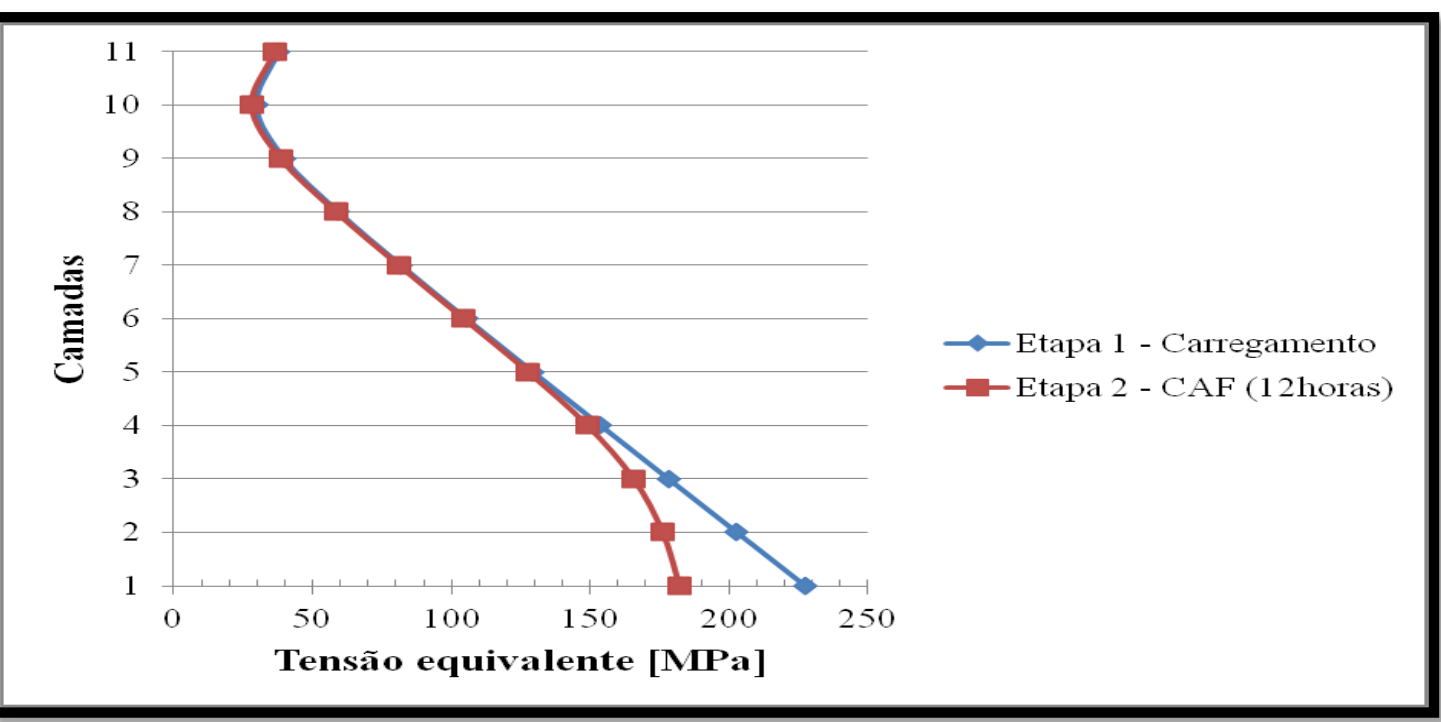

Fonte: Autor 
Os resultados anteriores mostraram a influência da tensão imposta no início do processo e que ela irá variar conforme a geometria do ferramental. A distribuição da tensão ao longo da placa não só afeta o fenômeno de relaxação e fluência, mas também afetará o envelhecimento da liga. Analisando os resultados publicados por Zhan, Li e Huang (2014) da dureza para a liga AA2124 que foi envelhecida em diferentes temperaturas e tensões por 12 horas (Figura 66), nota-se a influência da tensão.

As duas geometrias estudadas no presente trabalho tiveram certa distribuição de tensão no início do processo e a partir dos resultados de Zhan, Li e Huang (2014) pode-se dizer que a dureza ao longo das duas geometrias irá variar também. Tal distribuição de tensão pode gerar regiões superenvelhecidas em que terá o coalescimento dos precipitados, e regiões com precipitados finamente dispersos.

Figura 66 - Dureza medida após a CFE em diferentes temperaturas e tensões

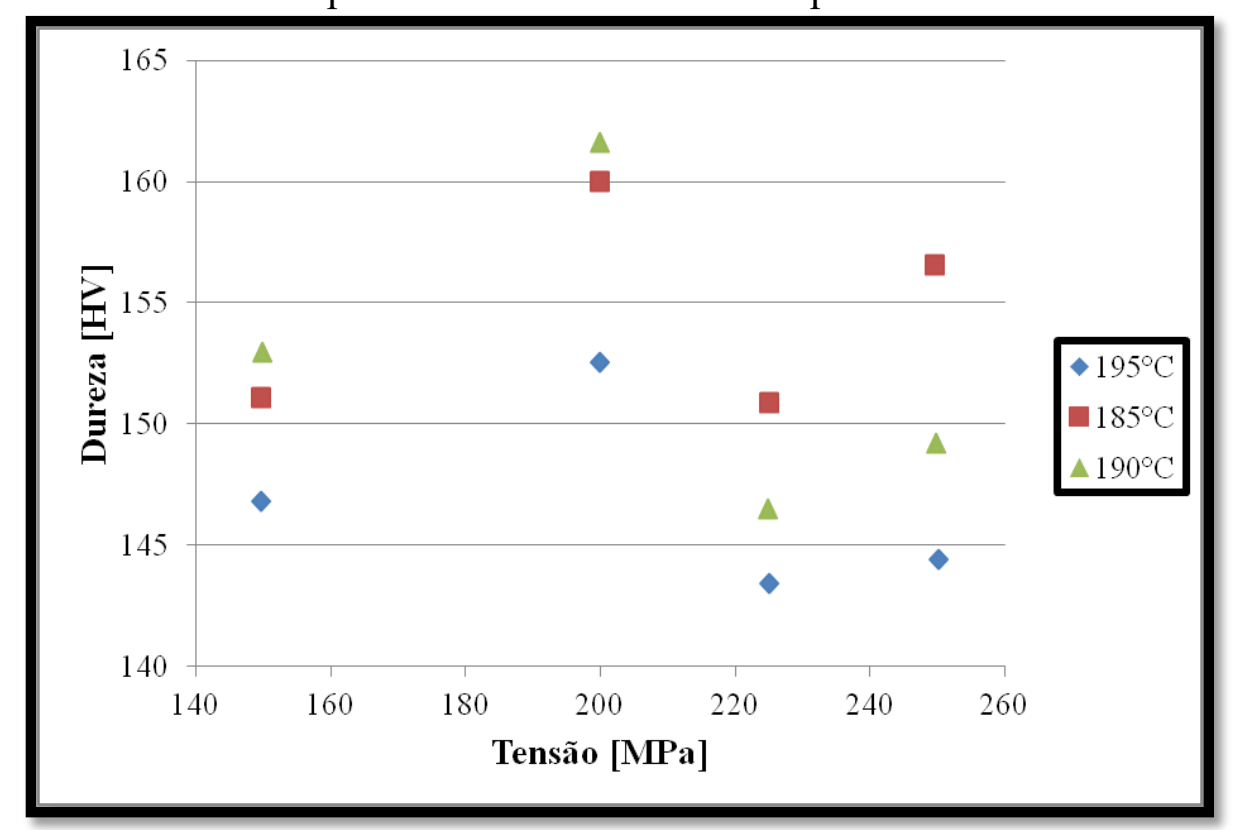

Fonte: Zhan; Li; Huang, 2014, p. 2235

A característica da CFE de não entrar no regime plástico para conformar o componente, induz baixas tensões residuais trativas e compressivas. Ao contrário de outros processos de fabricação que exigem altos carregamentos para o material ultrapassar o limite de escoamento e assim ser conformado. Na etapa que ocorre a retirada da carga nesses processos de fabricação, o componente conformado terá altas tensões residuais quando comparado com um componente que passou pela CFE.

A Figura 67 mostra às tensões máximas principais na superfície superior da placa e a Figura 68 as tensões mínimas principais. Ambas as figuras são das tensões principais depois 
do descarregamento. Os dois resultados das tensões principais para a geometria com uma curvatura demonstraram que o processo induz baixas tensões residuais. As tensões residuais ficaram no intervalo de 32,22MPa e -5,44MPa.

Figura 67 - Tensões máximas principais em MPa na superfície superior da placa com uma curvatura

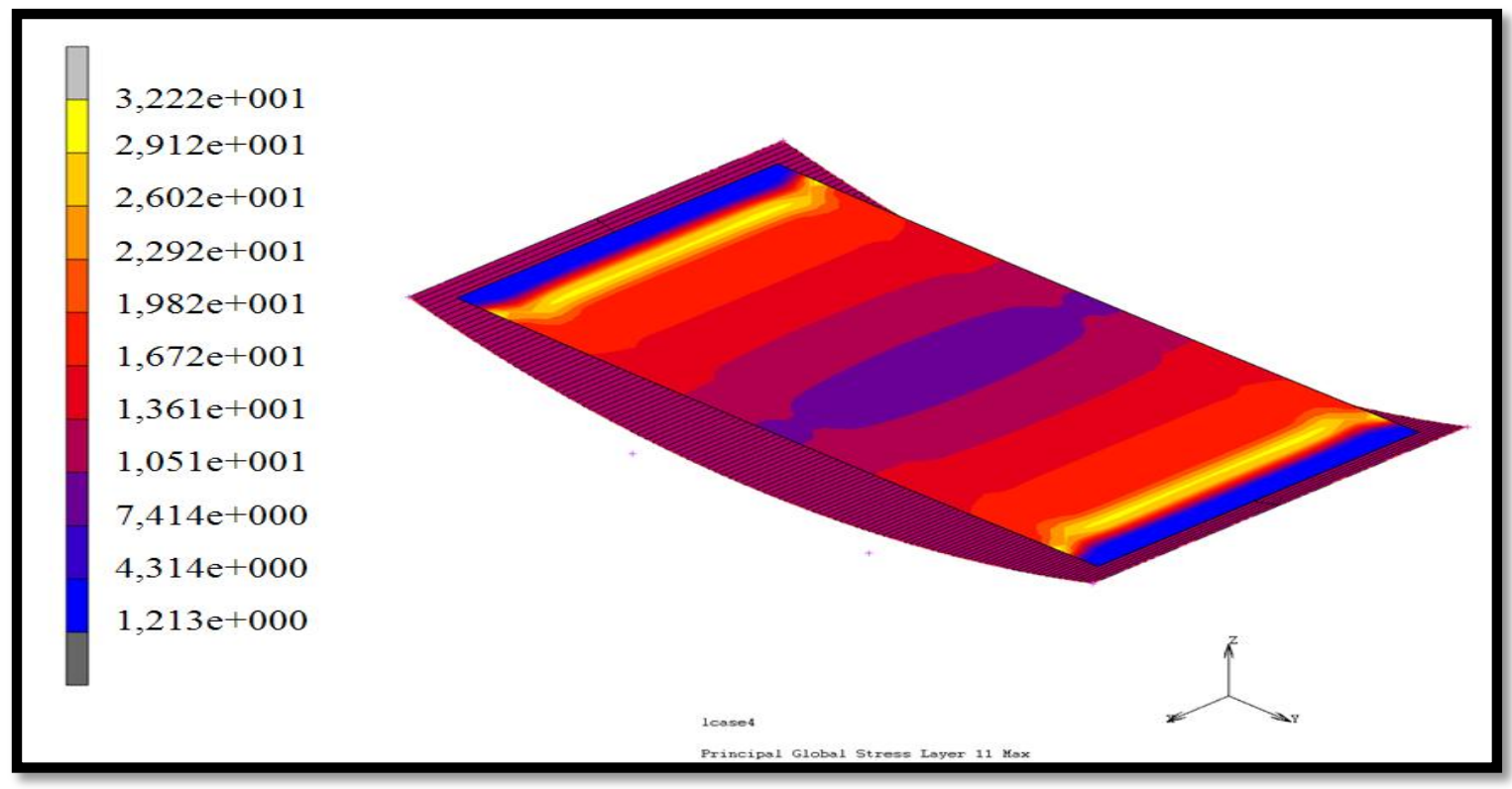

Fonte: Autor

Figura 68 - Tensões mínimas principais em MPa na superfície superior da placa com uma curvatura

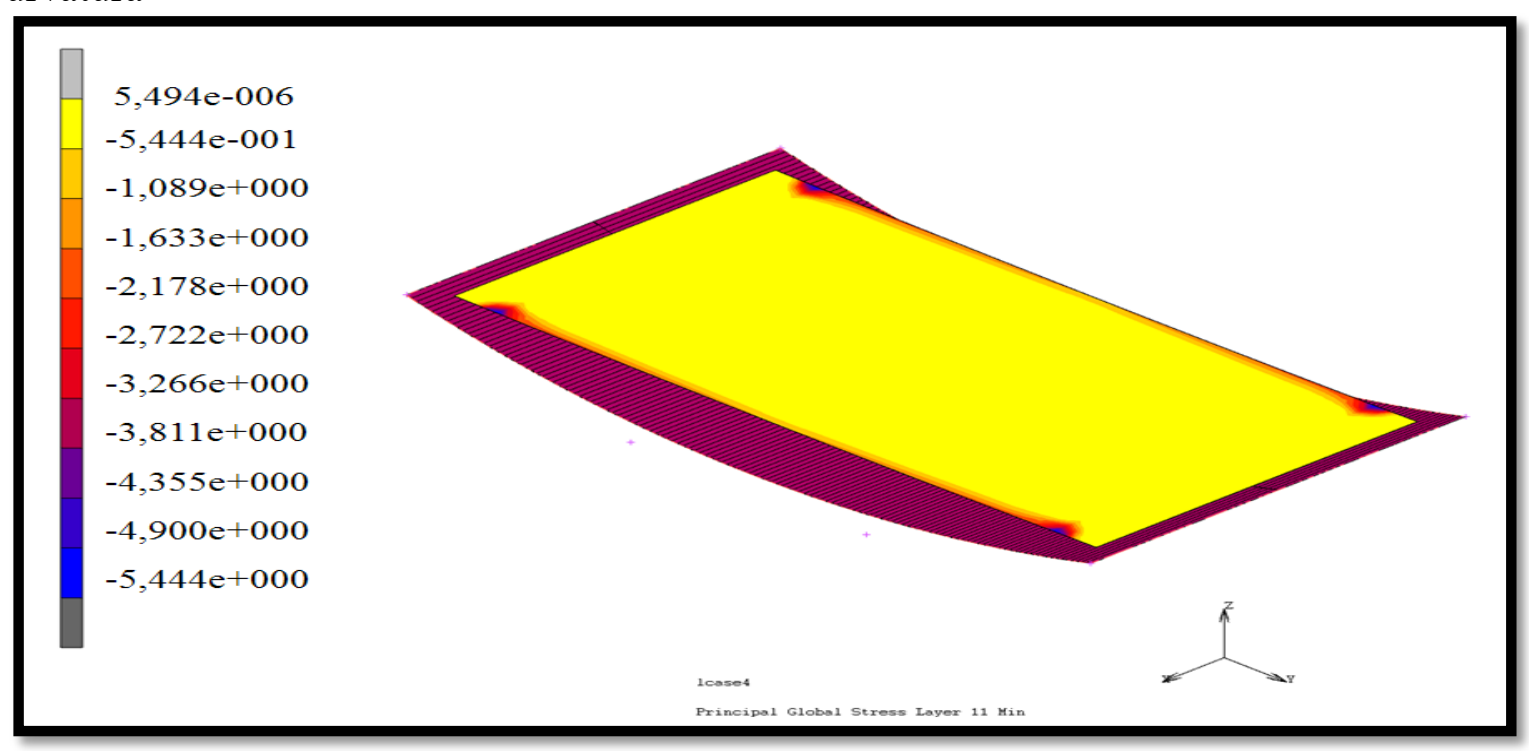

Fonte: Autor.

As tensões residuais para a geometria de dupla curvatura são demonstradas na Figura 69 e na Figura 70. As tensões residuais ficaram no intervalo de 8,02MPa e -52,05MPa. 
Ambas as geometrias apresentaram um baixo nível de tensão residual trativa e compressiva. Tal fenômeno é característico da CFE, e aconteceu nas simulações o que já se esperava sobre o processo.

Figura 69 - Tensões máximas principais em MPa na superfície superior da placa com dupla curvatura

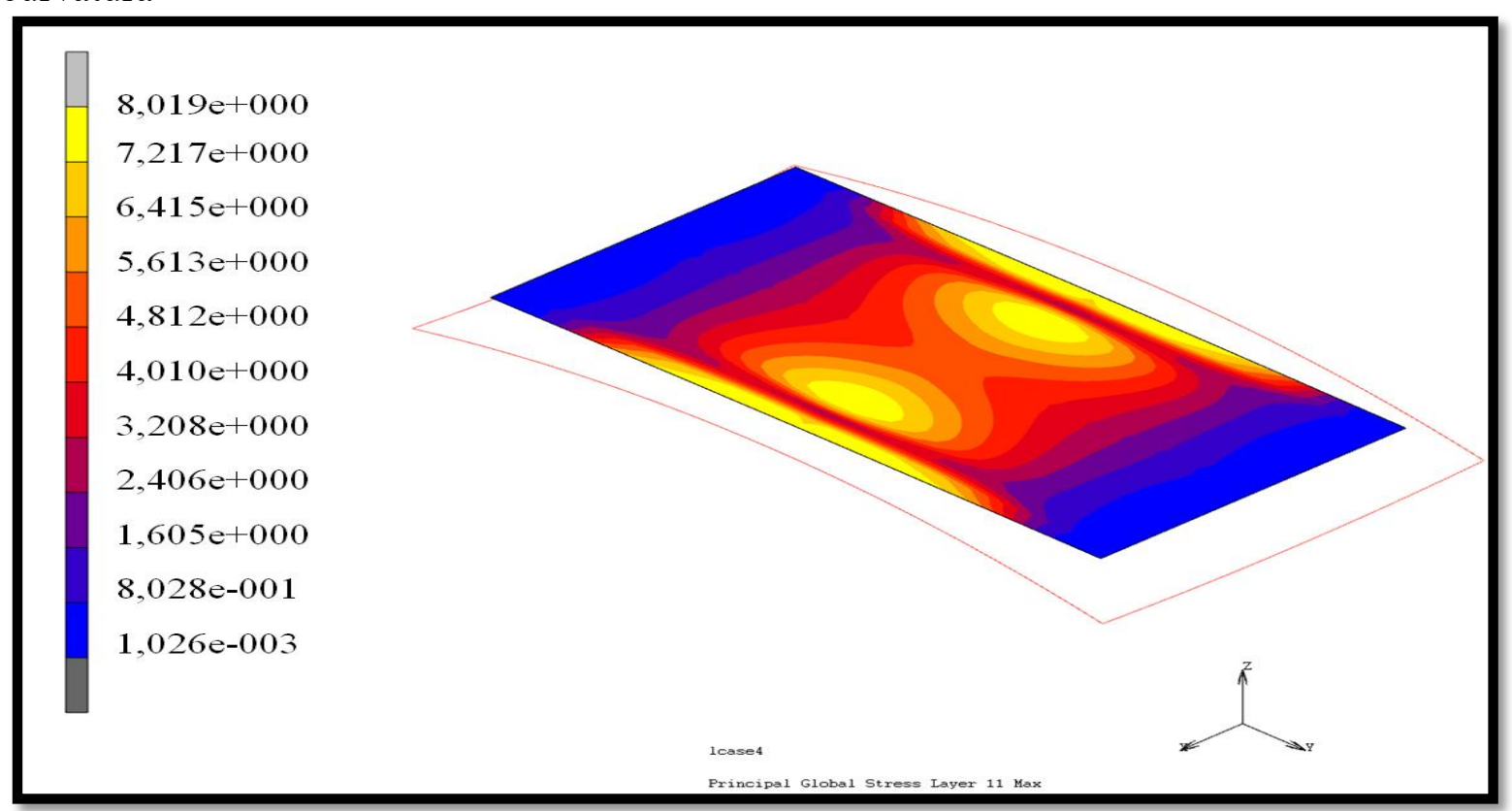

Fonte: Autor

Figura 70 - Tensões mínimas principais em MPa na superfície superior da placa com dupla curvatura

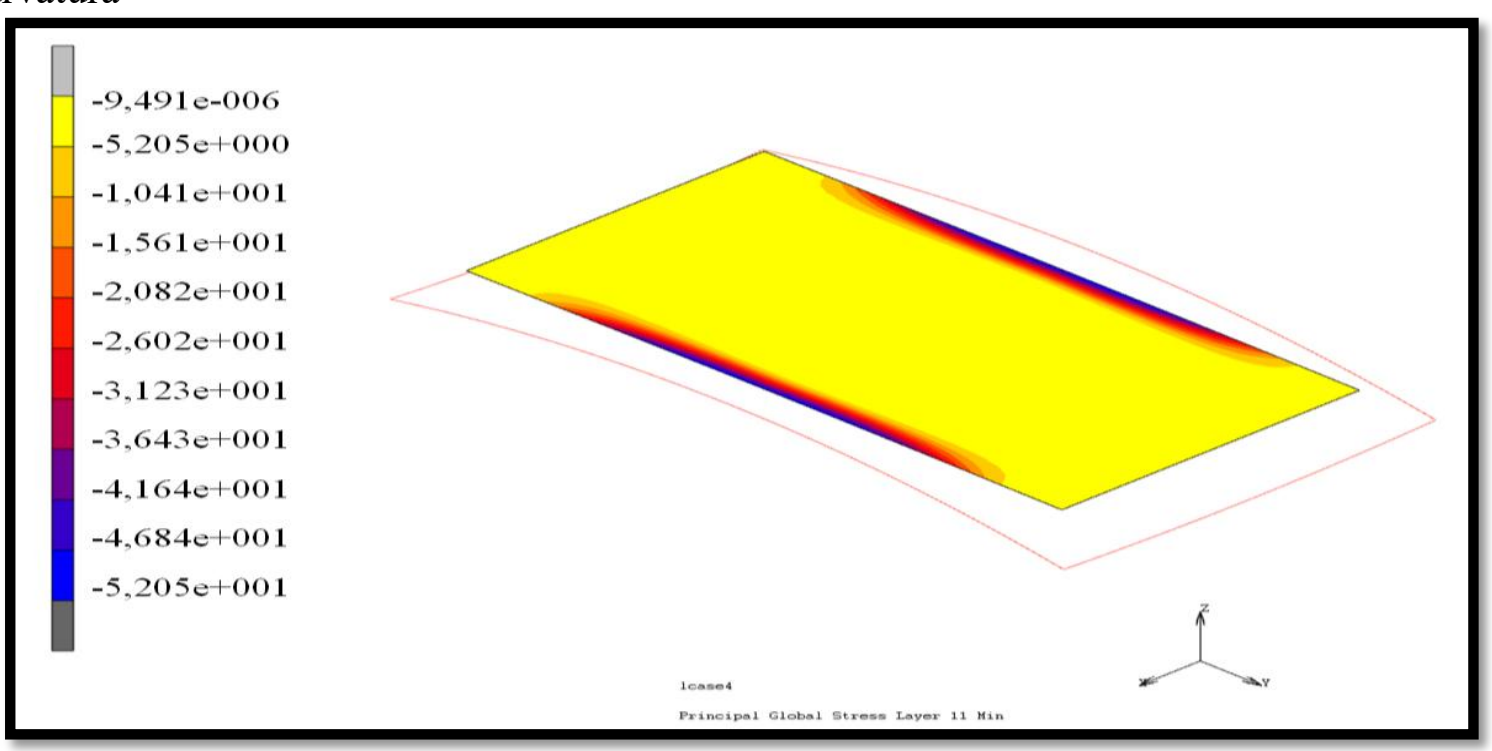

Fonte: Autor 
A distribuição da deformação por fluência demonstradas nas figuras 71 e 72 (para as duas geometrias propostas) são semelhantes à distribuição da tensão (Figura 56 e Figura 60) no instante inicial da CFE. Essa semelhança é prevista, pois a fluência irá depender da distribuição de tensão na placa e as regiões com níveis maiores de tensão favoreceram o fenômeno de fluência e relaxação. Como demonstrado anteriormente nos resultados da relaxação de tensão ao longo da espessura.

Figura 71 - Distribuição da deformação por fluência na superfície inferior da geometria com uma curvatura em 12 horas de simulação

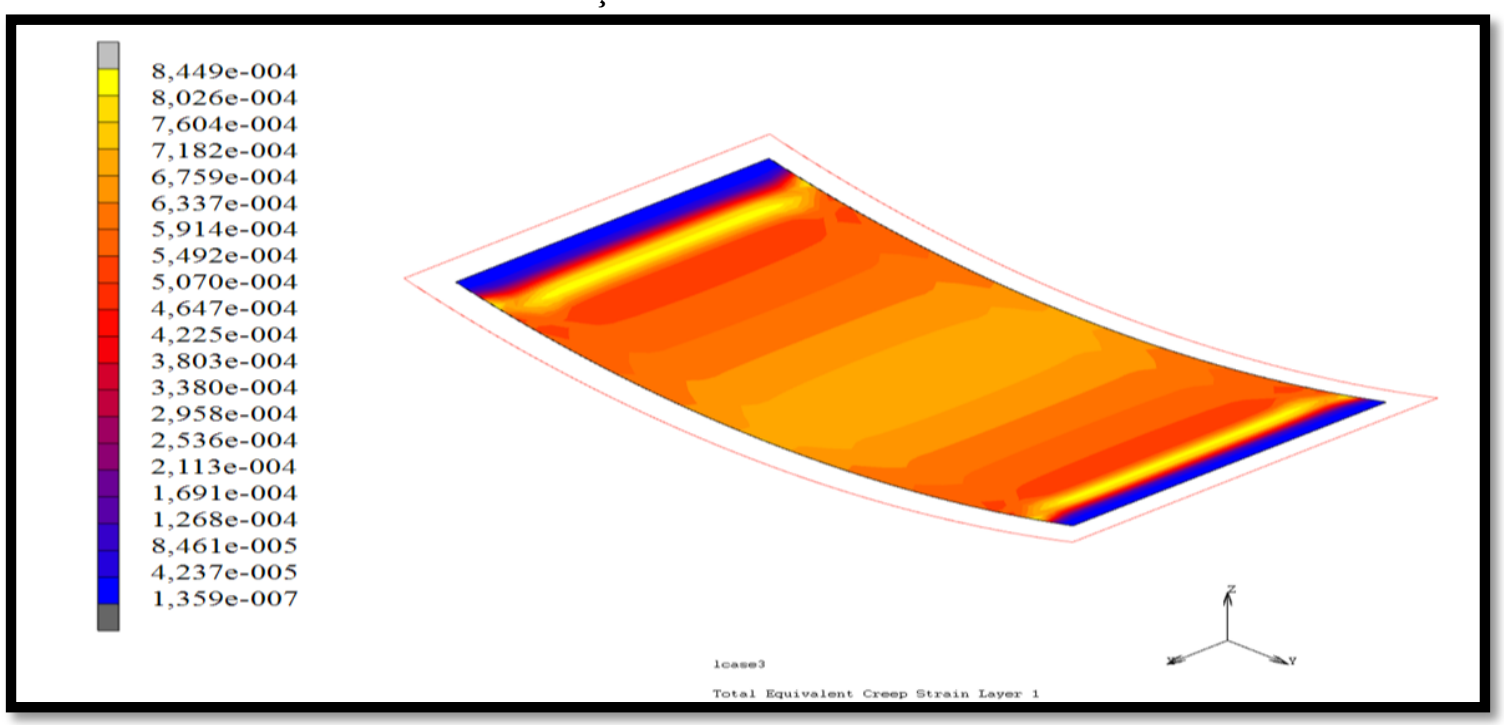

Fonte: Autor

Figura 72 - Distribuição da deformação por fluência na superfície inferior da geometria de dupla curvatura em 12 horas de simulação

$5,577 \mathrm{e}-004$

$5,298 \mathrm{e}-004$

$5,019 \mathrm{e}-004$

4,741e-004

$4,462 \mathrm{e}-004$

$4,183 \mathrm{e}-004$

3,904e-004

3,625e-004

$3,346 \mathrm{e}-004$

$3,067 \mathrm{e}-004$

2,789e-004

2,510e-004

2,231e-004

1,952e-004

$1,673 \mathrm{e}-004$

$1,394 \mathrm{e}-004$

$1,115 \mathrm{e}-004$

8,366e-005

$5,577 \mathrm{e}-005$

2,789e-005

2,646e-010
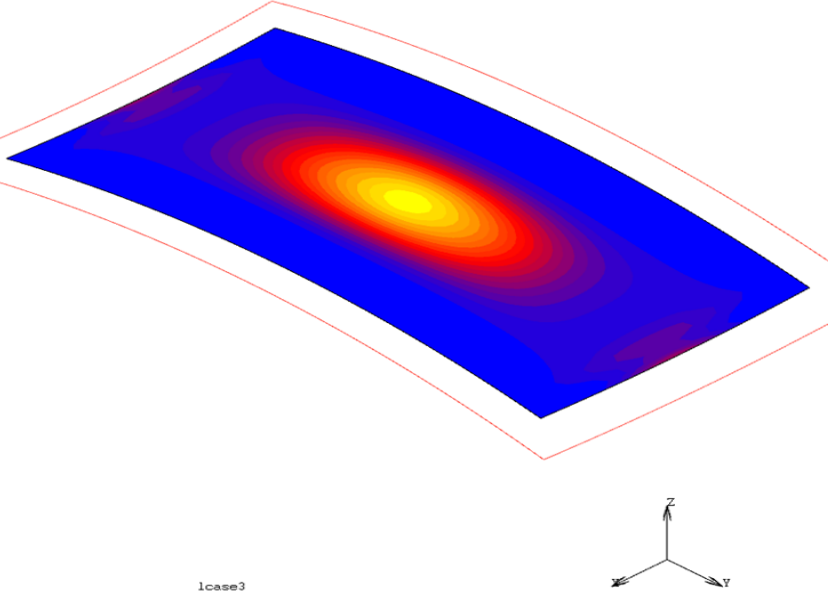

Fonte: Autor 
Comparando os resultados das figuras 71 e 72, a geometria com uma curvatura apresentou na superfície inferior maior deformação em consequência da geometria da matriz. Quando a placa foi conformada inicialmente dentro do regime elástico gerou certa distribuição de tensão, em que as tensões menores ficaram próximas das duas extremidades da placa (região em azul na Figura 71), gerando menor deformação. A superfície inferior da geometria de dupla curvatura teve as maiores tensões próximas do centro da placa e uma grande área com baixas tensões, também por causa da geometria da matriz. Nas regiões que tiveram menor tensão na geometria de dupla curvatura é encontrada a menor deformação após 12 horas de simulação.

Os resultados apresentados anteriormente mostram a forte dependência do processo de fabricação em relação à deformação elástica imposta inicialmente e da tensão inicial, que não só influenciam na deformação por fluência, mas também irão influenciar no retorno elástico.

O retorno elástico das duas geometrias propostas também foi analisado, utilizando o MSC. Marc ${ }^{\circledR}$ para determinar as flechas iniciais e finais a partir dos deslocamentos na direção Z, tendo estes valores o retorno elástico foi determinado aplicando a equação 48 .

$$
\text { Retorno elástico }=\left(\frac{\text { flecha inicial }- \text { flecha final }}{\text { flecha inicial }}\right) * 100
$$

As duas simulações realizadas no presente trabalho tiveram retorno elástico elevado, quando comparado aos dados do retorno elástico de outros trabalhos, em que os parâmetros de processo, como, tensão máxima após a etapa de carregamento, tempo e a temperatura foram abaixo dos valores utilizados neste trabalho. Essas condições de processo são demonstradas na Tabela 9 que contém os dados deste trabalho, e as tabelas 10 e 11 contém dados de outros autores. Na tabela 11, a tensão não é a tensão equivalente de von Mises, é uma componente da tensão. O valor alto do retorno elástico pode ter sido devido à liga de alumínio AA2124 que apresentou pouca deformação por fluência para os parâmetros aplicados, enquanto as ligas AA7050-TAF e AA7055 apresentam mais deformação por fluência do que a liga AA2124 quando submetidas a parâmetros inferiores. 
Tabela 9 - Dados das simulações

\begin{tabular}{|c|c|c|c|c|c|}
\hline Liga & Geometria & $\begin{array}{c}\text { Tensão máxima } \\
\text { inicial [MPa] }\end{array}$ & $\begin{array}{c}\text { Temperatura } \\
{\left[{ }^{\circ} \mathbf{C}\right]}\end{array}$ & $\begin{array}{c}\text { Tempo } \\
{[\mathbf{h}]}\end{array}$ & $\begin{array}{c}\text { Retorno } \\
\text { elás tico [\%] }\end{array}$ \\
\hline AA 2124 & Uma curvatura & 244,4 & 190 & 12 & 94,2 \\
\hline AA 2124 & Dupla curvatura & 227,3 & 190 & 12 & 94,3 \\
\hline
\end{tabular}

Fonte: Autor

Tabela 10 - Dados das simulações realizadas por Brandão (2013)

\begin{tabular}{|c|c|c|c|c|c|}
\hline Liga & Geome tria & $\begin{array}{c}\text { Tensão máxima } \\
\text { inicial [MPa] }\end{array}$ & $\begin{array}{c}\text { Temperatura } \\
{\left[{ }^{\circ} \mathbf{C}\right]}\end{array}$ & $\begin{array}{c}\text { Te mpo } \\
{[\mathbf{h}]}\end{array}$ & $\begin{array}{c}\text { Retorno } \\
\text { elástico [\%] }\end{array}$ \\
\hline AA7050-TAF & Uma curvatura & 131 & 177 & 8 & 80,35 \\
\hline AA7050-TAF & Dupla curvatura & 101 & 177 & 8 & 80,69 \\
\hline
\end{tabular}

Fonte: Autor “adaptado de” Brandão, 2013

Tabela 11 - Dados das simulações realizadas por Zhan, Lin e Huang (2011)

\begin{tabular}{|c|c|c|c|c|c|}
\hline Liga & Geometria & $\begin{array}{c}\text { Tensão máxima } \\
\text { inicial [MPa] }\end{array}$ & $\begin{array}{c}\text { Temperatura } \\
{\left[{ }^{\circ} \mathbf{C}\right]}\end{array}$ & $\begin{array}{c}\text { Tempo } \\
{[\mathbf{h}]}\end{array}$ & $\begin{array}{c}\text { Retorno } \\
\text { elás tico [\%] }\end{array}$ \\
\hline AA7055 & Uma curvatura & 212 & 120 & 24 & 79 \\
\hline
\end{tabular}

Fonte: Autor “adaptado de” Zhan; Lin; Huang, 2011

A Figura 73 mostra a curva de fluência de Zhan, Lin e Huang (2011) para as tensões de 252,2 MPa e $190 \mathrm{MPa}$, essas tensões e a tensão de $230 \mathrm{MPa}$ foram aplicadas no modelo da CFE utilizado neste trabalho, resultando nas outras curvas demonstradas na Figura 73. Analisando na Figura 73, as curvas de deformação por fluência em função do tempo das tensões entre $230 \mathrm{MPa}$ e $190 \mathrm{MPa}$ (Curva preta) em 12 horas, nota-se que apresentaram menor deformação por fluência do que as curvas simuladas por Zhan, Lin e Huang (2011).

As duas geometrias simuladas no programa de elementos finitos apresentaram grande parte das tensões abaixo de $230 \mathrm{MPa}$ (na etapa após o carregamento) e a deformação por fluência é menor nesta região, se comparar com as curvas de Zhan, Lin e Huang (2011). Caso as geometrias propostas fossem simuladas com a liga AA7055 a tendência seria de ter um retorno elástico menor, pois a partir das curvas de fluência da Figura 73 é possível notar maior deformação e se a simulação durasse 24 horas ao invés de 12 horas, o retorno elástico seria menor. 
Figura 73 - Deformação por fluência em função do tempo

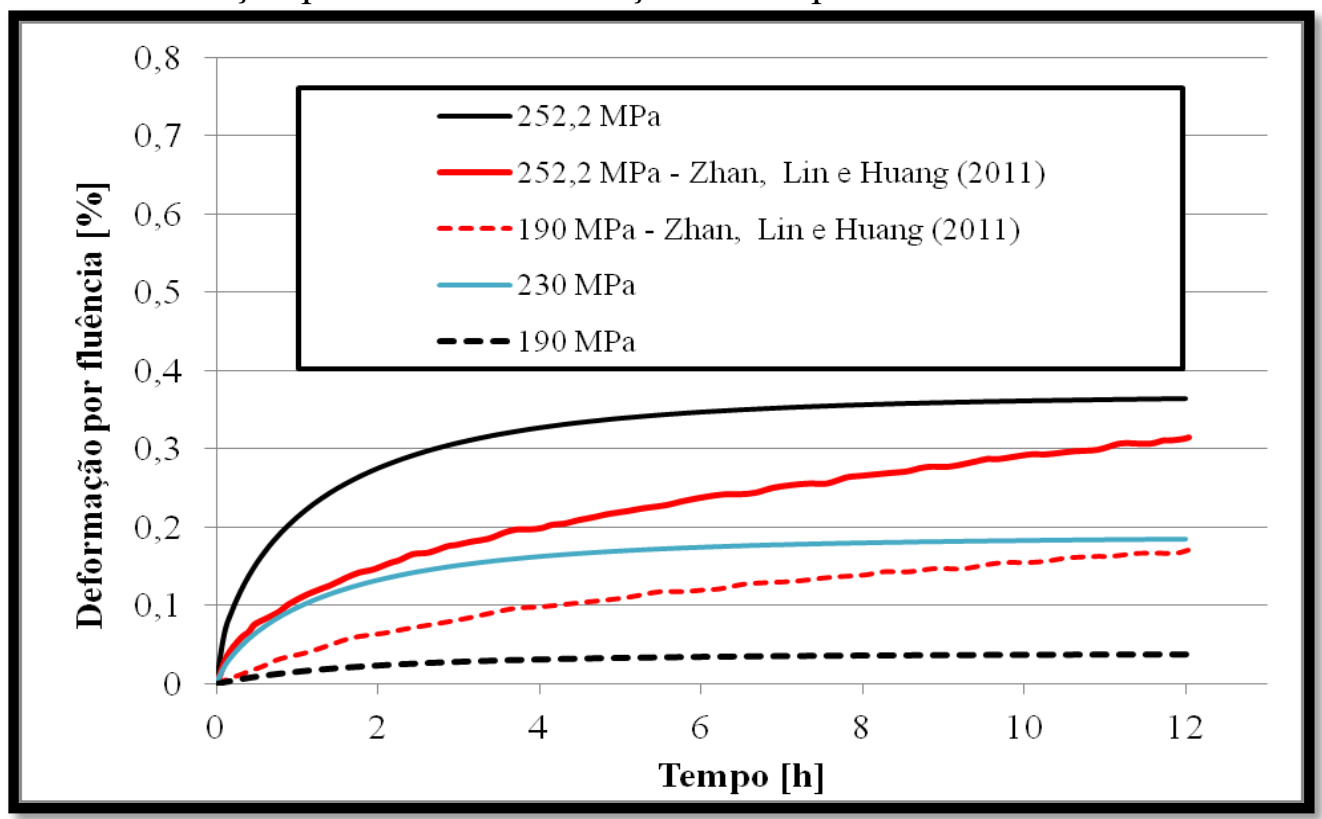

Fonte: Autor

Comparando os valores do retorno elástico apresentados na Tabela 9 e na Tabela 11 juntamente com as curvas de fluência e não só a partir da tensão, temperatura e tempo, a diferença entre os valores do retorno elástico pode ser analisada melhor e assim perceber que o valor do retorno elástico esperado teria que ser realmente maior do que o valor encontrado por Zhan, Lin e Huang (2011). 


\section{CONSIDERAÇÕES FINAIS SOBRE A IMPLEMENTAÇÃO DO MODELO}

O método de Euler integrou as equações diferenciais aplicando um passo de integração menor do que o passo aplicado no método de Runge-Kutta de quarta ordem. Esta redução aumenta o número de incrementos na simulação de elementos finitos (para atingir o tempo final da simulação) e, consequentemente o tempo de processamento.

A criação de um programa principal em Fortran para verificar a sub-rotina da CFE, facilitou na verificação da mesma em relação aos erros de programação.

O valor do retorno elástico teve influência do desvio entre os dados experimentais de Zhang et al. (2013) e os simulados da deformação por fluência. Portanto o erro residual devido ao ajuste do modelo da CFE aos dados experimentais deve ser reduzido para obter melhores resultados, porém o modelo da CFE envolve muitas constantes e isto dificulta na minimização do erro residual. Determinar as constantes nas equações do modelo que satisfaça três curvas de fluência ou mais, o erro poderá se concentrar em uma das curvas, como ocorreu neste trabalho, ou também pode estar distribuído uniformemente.

Implementar uma sub-rotina com um modelo unificado de comportamento mecânico, há a necessidade de compreender alguns fatores, como, o instante em que o programa de elementos finitos chama a sub-rotina, os dados de entrada e saída da sub-rotina e quantas vezes a sub-rotina é chamada por incremento. Quando compreendido tais fatores, a sub-rotina foi programada corretamente e os erros que ela apresentava antes, na qual dificultava a convergência da análise foram corrigidos. 


\section{CONCLUSÕES}

O presente trabalho teve o objetivo de implementar uma sub-rotina com um modelo unificado de comportamento mecânico da CFE no MSC. Marc ${ }^{\circledR}$ e apresentou as seguintes conclusões.

No método de Runge-Kutta de quarta ordem a resposta convergiu em um passo de 0,1 e para o método de Euler a resposta convergiu em um passo 0,01. O método de Runge-Kutta de quarta ordem demonstrou eficiência, quando aplicado na sub-rotina chamada pelo MSC. Marc ${ }^{\circledR}$ e por isso tem sido aplicado em sub-rotinas da CFE.

O erro absoluto entre os resultados da deformação por fluência gerados no Matlab ${ }^{\circledR}$ e Fortran foi nulo, e o erro absoluto entre os resultados gerados na simulação uniaxial no MSC. Marc ${ }^{\circledR}$ e Fortran também foram nulos. O valor nulo do erro é esperado, pois os algoritmos aplicados foram semelhantes e só mudou o programa que executou o código.

As simulações da CFE para as geometrias propostas demonstraram resultados semelhantes aos encontrados na literatura. As duas geometrias simuladas eram simétricas em relação aos eixos x e y, sendo simétricas, os resultados também devem ser simétricos e isto foi observado.

A sub-rotina foi chamada pelo MSC. Marc ${ }^{\circledR}$ para cada elemento ao longo da simulação, os cálculos realizados para a deformação por fluência de um elemento não interferiram no cálculo da deformação dos outros elementos, ou seja, não tiveram conflitos.

A princípio o valor do retorno elástico de 94,2\% e 94,3\% (geometrias de uma curvatura e dupla curvatura) das simulações da CFE era alto, quando comparado aos resultados de 80,35\%, 80,69\% (BRANDÃO, 2013) e 79\% (ZHAN; LIN; HUANG, 2011) do retorno elástico de outros trabalhos. Mas observando as curvas de fluência, a diferença de deformação entre as ligas foi notada. As curvas de fluência para as tensões aplicadas neste trabalho apresentaram pouca deformação por fluência em relação às curvas apresentadas no trabalho de Zhan, Lin e Huang (2011). Portanto o valor alto do retorno elástico pode ser explicado por causa da baixa deformação for fluência e também por causa do erro que as curvas apresentaram. 


\section{SUGESTÕES PARA TRABALHOS FUTUROS}

Realização de experimentos com as ligas aplicáveis na CFE, para calibrar o modelo de Zhang et al. (2013) e desenvolver também o ferramental para realizar a conformação, para assim realizar simulações da CFE em elementos finitos, e comparar os resultados com os dados experimentais da conformação.

Calibrar modelo da CFE a partir dos dados do ensaio de fluência e simular a relaxação de tensão, comparar esta relaxação de tensão simulada com os dados experimentais da relaxação de tensão.

Desenvolver estudos da CFE em placas que passaram pelo processo de fricção e mistura linear (Friction stir processing). 


\section{REFERÊNCIAS}

\section{AEROSPACE MATERIAL SPECIFICATION 2772 E: Heat Treatment of Aluminum} Alloy Raw Materials. EUA, 2008.

AIRCRAFT OPERATIONS CENTER. Disponível em: <http://www.bennettmg.co.uk/ Project_MD_Airbus.aspx>. Acesso em 26 Ago. 2014.

ALCOA. Alloy 2124 plate. Disponível em: <www.alcoa.com/mill_products/catalog /pdf/alloy2124techsheet.pdf>. Acesso em: 15 mar. 2016.

ASHBY, M. F.; JONES, D. R. H. Engineering materials 2: an introduction to microstructures, processing and design. Elsevier, 2014.

ATKINS. Disponível em: < http://www.atkinsglobal.co.uk/ /media/Files/A/AtkinsUK/Attachments/services/Creep\%20Forming\%20Tools\%20for\%20A380_ATKINS.pdf>. Acesso em 13 Mar. 2015.

BAKAVOS, D. et al. Microstructural interactions during stress ageing a 7475 aerospace alloy. Materials Science Forum, [s.1.], v. 519-521, p.333-338, 2006.

BATHE, K. J. Finite Element Procedures. Editora Prentice Hall, 1996.

BIRBILIS, N.; BUCHHEIT, R. G. Electrochemical Characteristics of Intermetallic Phases in Aluminum Alloys. Journal Of The Electrochemical Society, [s.1.], v. 152, n. 4, p.140-151, 2005.

BRANDÃO, F. M. Simulação pelo Método dos Elementos Finitos do Processo de Conformação por Fluência com Envelhecimento. 2013. 94 f. Dissertação (Programa de Pós Graduação em Engenharia Mecânica) - Centro Universitário da Fei, São Bernardo do Campo, 2013.

BURDEN, R. L.; FAIRES, J. D. Numerical analysis. 9. ed., EUA: Brooks/Cole, p. 290-291, 2010 .

BURLEIGH, T. D. Corrosion of Aluminum and its Alloys. In: TOTTEN, G. E.; MACKENZIE, D . S. (Ed.). Handbook of Aluminum Volume 2: Alloy Production and Materials Manufacturing. 2. ed. New Mexico: Crc Press, 2003. Cap. 11. p. 421-464.

CAMPBELL, F. C. Elements of metallurgy and engineering alloys. ASM International, 2008.

Manufacturing technology for aerospace structural materials. Elsevier, 2011.

CANTOR, B.; ASSENDER, H.; GRANT, P. Aerospace materials. CRC Press, 2001.

CHAPRA, S. C.; CANALE, R. P. Métodos numéricos para engenharia. 5 ed. AMGH Editora, p. 626, 2008. 
CHEN, J.F. et al. Microstructures and mechanical properties of age-formed 7050 aluminum alloy. Materials Science And Engineering: A, [s.1.], v. 539, p.115-123, mar. 2012.

DIETER, G. E. Metalurgia mecânica. 2. ed. Rio de Janeiro: Guanabara Dois, 1981. EBERL, F. et al. Ageformable panels for commercial aircraft. In: INTERNATIONAL CONGRESS OF THE AERONAUTICAL SCIENCES, 25., 2006, Hamburg. Proceedings... Hamburg: Optimage Ltd., 2006. p. 1 - 15.

EIBEN, A. E.; SMITH, J. E. Introduction to evolutionary computing. Springer Science \& Business Media, p. 17, 2003.

FANG, X. et al. Precipitation sequence of an aged Al-Mg-Si alloy. Journal Of Mining And Metallurgy, Section B: Metallurgy, [s.1.], v. 46, n. 2, p.171-180, 2010.

HENSHALL, G. A.; HELLING, D. E.; MILLER A. K. Improvements in the MATMOD Equations for Modeling Solute Effects and Yield-Surface Distortion. In: A.S. KRAUSZ, A. S.; KRAUSZ, K. Unified Constitutive Laws of Plastic Deformation. Academic Press, p. 153-227, 1996.

HO, K. C.; LIN, J.; DEAN, T. A. Modelling of springback in creep forming thick aluminum sheets. International Journal of Plasticity, [s.1.], v. 20, n. 4-5, p.733-751, abr. 2004.

. et al. Constitutive modelling of primary creep for age forming an aluminium alloy.

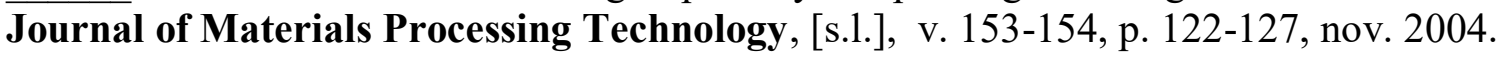

HOLMAN, M. C. Autoclave age forming large aluminum aircraft panels. Journal of Mechanical Working Technology, [s.1.], v. 20, p. 477-488, set. 1989.

INFORZATO, D. J. et al. Creep-age forming of AA7475 aluminum panels for aircraft lower wing skin application. Materials Research, [s.1.], v. 15, n. 4, p. 596-602, ago. 2012.

JAMBU, S. et al. Creep forming of AlMgSc alloys for aeronautic and space applications. In: INTERNATIONAL CONGRESS OF THE AERONAUTICAL SCIENCES, 25., 2002, Toronto. Proceedings... Toronto: Optimage Ltd., 2002. p. 632.1 - 632.7.

JESHVAGHANI, R. A.; SHAHVERDI, H. R.; HADAVI, S. M. M. Investigation of the age hardening and operative deformation mechanism of 7075 aluminum alloy under creep forming. Materials Science and Engineering: A, [s.1.], v. 552, p. 172-178, ago. 2012.

JEUNECHAMPS, P. et al. A closed form technique to predict springback in creep ageforming. International Journal of Mechanical Sciences, [s.1.], v. 48, n. 6, p. 621-629, jun. 2006.

KALLIVAYALIL, J. A. Age forming. In: SEMIATIN, S. L. (Ed.). Metalworking: Sheet Forming (ASM Handbook Volume 14 B), v. 14, p. 438-441, 2006.

KOWALEWSKI, Z. L.; LIN, J.; HAYHURST, D. R. Experimental and theoretical evaluation of a high-accuracy uni-axial creep testpiece with slit extensometer ridges. International Journal Of Mechanical Sciences, [s.1.], v. 36, n. 8, p.751-769, ago. 1994. 
LAM, A. C.L. et al. Creep-age forming AA2219 plates with different stiffener designs and pre-form age conditions: Experimental and finite element studies. Journal of Materials Processing Technology, [s.1.], v. 219, p. 155-163,maio 2015a.

. Material modelling for creep-age forming of aluminium alloy 7B04. Matec Web Of Conferences, [s.1.], v. 21, p.1-7, 2015 b.

LEVERS, A. Jumbo processes. Manufacturing Engineer, [s.1.], v. 82, n. 3, p. 42-45, Jun. 2003.

LI, B.; LIN, J.; YAO, X. A novel evolutionary algorithm for determining unified creep damage constitutive equations. International Journal of Mechanical Sciences, [s.1.], v. 44, n. 5 , p. $987-1002,2002$.

LI, C. et al. Constitutive equations in creep of 7B04 aluminum alloys. Materials Science and Engineering: A, [s.1.], v. 527, n. 16, p. 3623-3629, 2010.

LIN, H. et al. FEM Analysis of Spring-backs in Age Forming of Aluminum Alloy Plates. Chinese Journal Of Aeronautics, [s.1.], v. 20, n. 6, p.564-569, dez. 2007.

LIN, J.; BALINT, D; CAO, J. Determining unified constitutive equations for modeling hot forming of steel. In: .; PIETRZYK, M. Microstructure Evolution in Metal Forming Processes. Woodhead Publishing Series in Metals and Surface Engineering, p. 180209, 2012.

LIU, G. et al. Modeling the strengthening response to aging process of heat-treatable aluminum alloys containing plate/disc- or rod/needle-shaped precipitates. Materials Science And Engineering: A, [s.1.], v. 344, n. 1-2, p.113-124, mar. 2003.

MARC, M. S. C. Volume A: Theory and user information. MSC. Software Corporation, $2013 \mathrm{a}$. $2013 b$

Volume D: User Subroutines and Special Routines. MSC. Software Corporation,

Volume E: Demonstration problems. MSC. Software Corporation, 2013c.

MARIN, J.; PAO, Y. H. Creep Relaxation Relations for Styrene and Acrylic Plastics. In: PROCEEDINGS-AMERICAN SOCIETY FOR TESTING AND MATERIALS. A.S.M.E., p. 1277-1295, 1951.

MAVROMIHALES, M.; MASON, J.; WESTON, W. A case of reverse engineering for the manufacture of wide chord fan blades (WCFB) used in Rolls Royce aero engines. Journal Of Materials Processing Technology, [s.1.], v. 134, n. 3, p.279-286, mar. 2003.

MSC SOFTWARE. Disponível em: < http://mscsoftwareuk.blogspot.com.br/2013/06/theoryseries-implicit-vs-explicit.html >. Acesso em 1 Jun. 2015.

NAUMENKO, K.; ALTENBACH, H. Modeling of creep for structural analysis. Springer Science \& Business Media, 2007. 
NICOLAS, M. Precipitation evolution in an Al-Zn-Mg alloy during non-isothermal heat treatments and in the heat-affected zone of welded joints. 2002. $176 \mathrm{f}$. Tese (Doutorado), Institut National Polytechnique de Grenoble, Grenoble, 2002.

NORTON, F. H. The creep of steel at high temperatures. McGraw-Hill Book Company, Incorporated, 1929.

PEDDIESON, J.; BUCHANAN, G. R. Mathematical modeling of an age-forming process. Mathematical and Computer Modelling, [s.1.], v. 14, p.1057-1060, 1990.

PRASAD, N. E.; GOKHALE, A.; WANHILL, R. J. H. Aluminum-Lithium Alloys: Processing, Properties, and Applications. Butterworth-Heinemann, 2013.

REED, A. Covering the Marketplace. Air Transport World, Cleveland, v. 29, n. 7, p. 67, 07 1992.

RIBEIRO, F. C. Modelagem experimental e numérica do processo de conformação de painéis aeronáuticos pelo processo de conformação por fluência com envelhecimento (Creep Age Forming). 2013. 165 f. Dissertação (Mestrado) - Universidade de São Paulo, São Paulo, 2013.

SALLAH, M.; PEDDIESON, J.; FOROUDASTAN, S. A mathematical model of autoclave age forming. Journal of Materials Processing Technology, [s.1.], v. 28, n. 1, p. 211-219, set. 1991.

SIM, W. M.; Residual Stress Engineering in Manufacture of Aerospace Structural Parts. Technical Report of COMPACT Project, 2011.

SMALLMAN, R. E.; NGAN, A.H.W. Modern physical metallurgy. 8. ed. Elsevier, 2014.

STOUFFER, D. C.; DAME, L. T. Inelastic deformation of metals: models, mechanical properties, and metallurgy. John Wiley \& Sons, 1996.

WATCHAM, K. Airbus A380 takes creep age-forming to new heights. Materials World, [s.1.], v. 12, n. 2, p. 10-11, 2004.

XU, F. S. et al. Precipitation orientation effect of 2124 aluminum alloy in creep aging. Transactions Of Nonferrous Metals Society Of China, [s.1.], v. 24, n. 7, p.2067-2071, jul. 2014.

YANG, Y.; ZHAN, L.; LI, J. Constitutive modeling and springback simulation for 2524 aluminum alloy in creep age forming. Transactions Of Nonferrous Metals Society Of China, [s.1.], v. 25, n. 9, p.3048-3055, set. 2015.

ZHAN, L. et al. A Research on the Creep Age Forming of 2524 Aluminum Alloy: Springback, Mechanical Properties, and Microstructures. Advances in Mechanical Engineering, [s.1.], v. 2014, 2014. 
Experimental studies and constitutive modelling of the hardening of aluminium alloy 7055 under creep age forming conditions. International Journal of Mechanical Sciences, [s.1.], v. 53, n. 8, p. 595-605, ago. 2011.

.; LI, Y.; HUANG, M. Effects of process parameters on mechanical properties and microstructures of creep aged 2124 aluminum alloy. Transactions Of Nonferrous Metals Society Of China, [s.1.], v. 24, n. 7, p.2232-2238, jul. 2014.

.; LIN, J.; BALINT, D. Microstructure control in creep-age forming of aluminium panels. In: LIN, J.; BALINT, D.; PIETRZYK, M. Microstructure Evolution in Metal Forming Processes. Woodhead Publishing Series in Metals and Surface Engineering, p. 298336, 2012.

.; __ _ _ DEAN, T. A. A review of the development of creep age forming: Experimentation, modelling and applications. International Journal of Machine Tools and Manufacture, [s.1.], v. 51, n. 1, p. 1-17, jan. 2011.

;__ . . HUANG, M. Constitutive modelling and springback prediction in creep age forming of AA7055 doubly curved panels. In: INTERNATIONAL ESAFORM CONFERENCE ON MATERIAL FORMING: ESAFORM 2011, 14., 2011, Belfast (united Kingdom). Proceeding... Belfast: Aip Publishing, 2011. p. 235 - 240.

ZHANG, J.; DENG, Y.; ZHANG, X. Constitutive modeling for creep age forming of heattreatable strengthening aluminum alloys containing plate or rod shaped precipitates.

Materials Science And Engineering: A, [s.1.], v. 563, p.8-15, fev. 2013.

ZHANG, C.; MOORE, I. D. Finite element modelling of inelastic deformation of ductile polymers. Geosynthetics international, [s.1.], v. 4, n. 2, p.137-163, jan. 1997.

ZHU, A. W.; STARKE, E. A. Stress aging of $\mathrm{Al}-\mathrm{xCu}$ alloys: experiments. Acta Materialia, [s.1.], v. 49, n. 12, p.2285-2295, jul. 2001. 
APÊNDICE A - Códigos do Matlab ${ }^{\circledR}$ para a integração das equações constitutivas 
Código do Matlab ${ }^{\circledR}$ para a integração das equações constitutivas utilizando o método de Euler.

O passo de integração aplicado foi 0,01 e o número de incrementos para alcançar o tempo de 12 horas foi 1200.

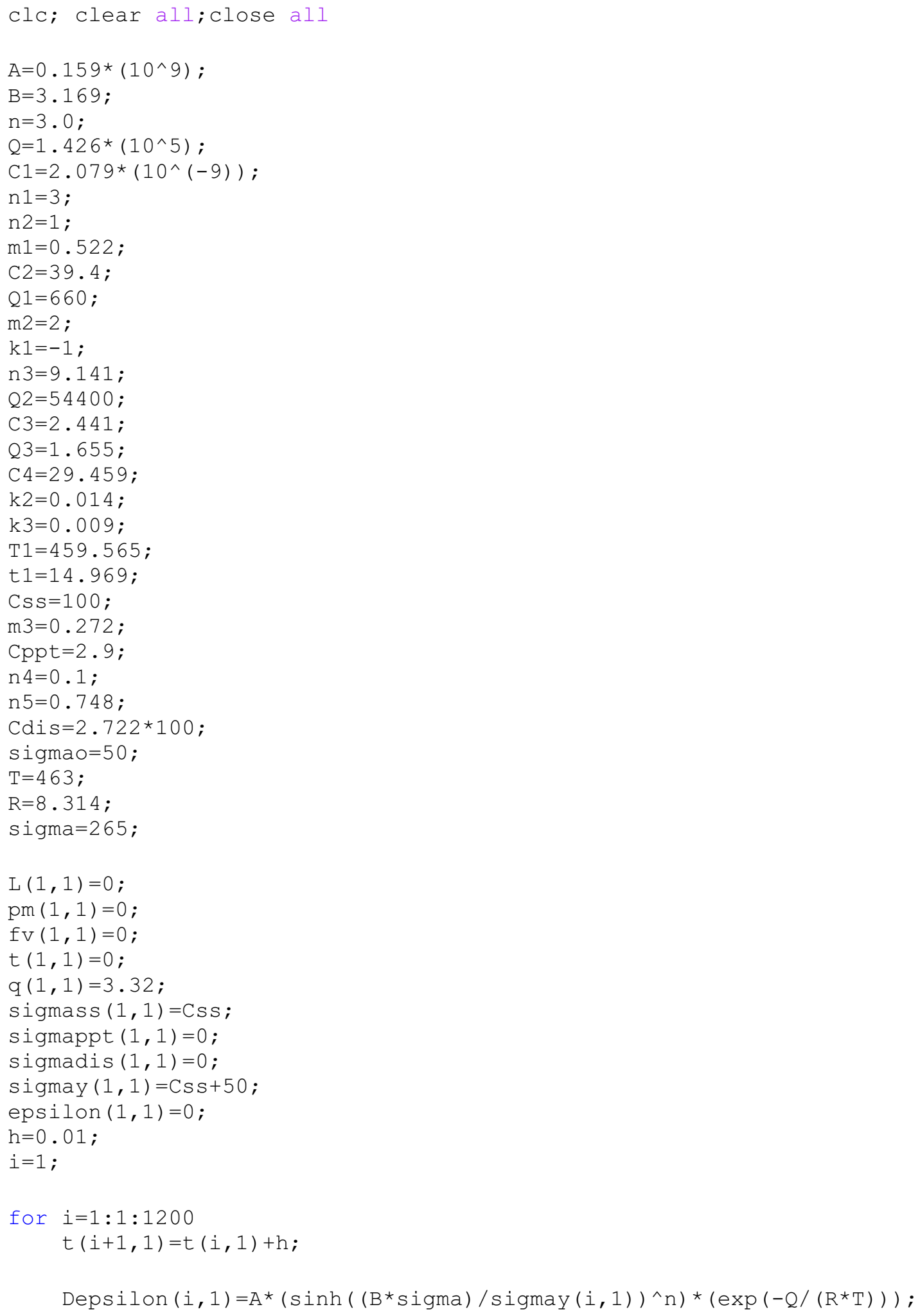




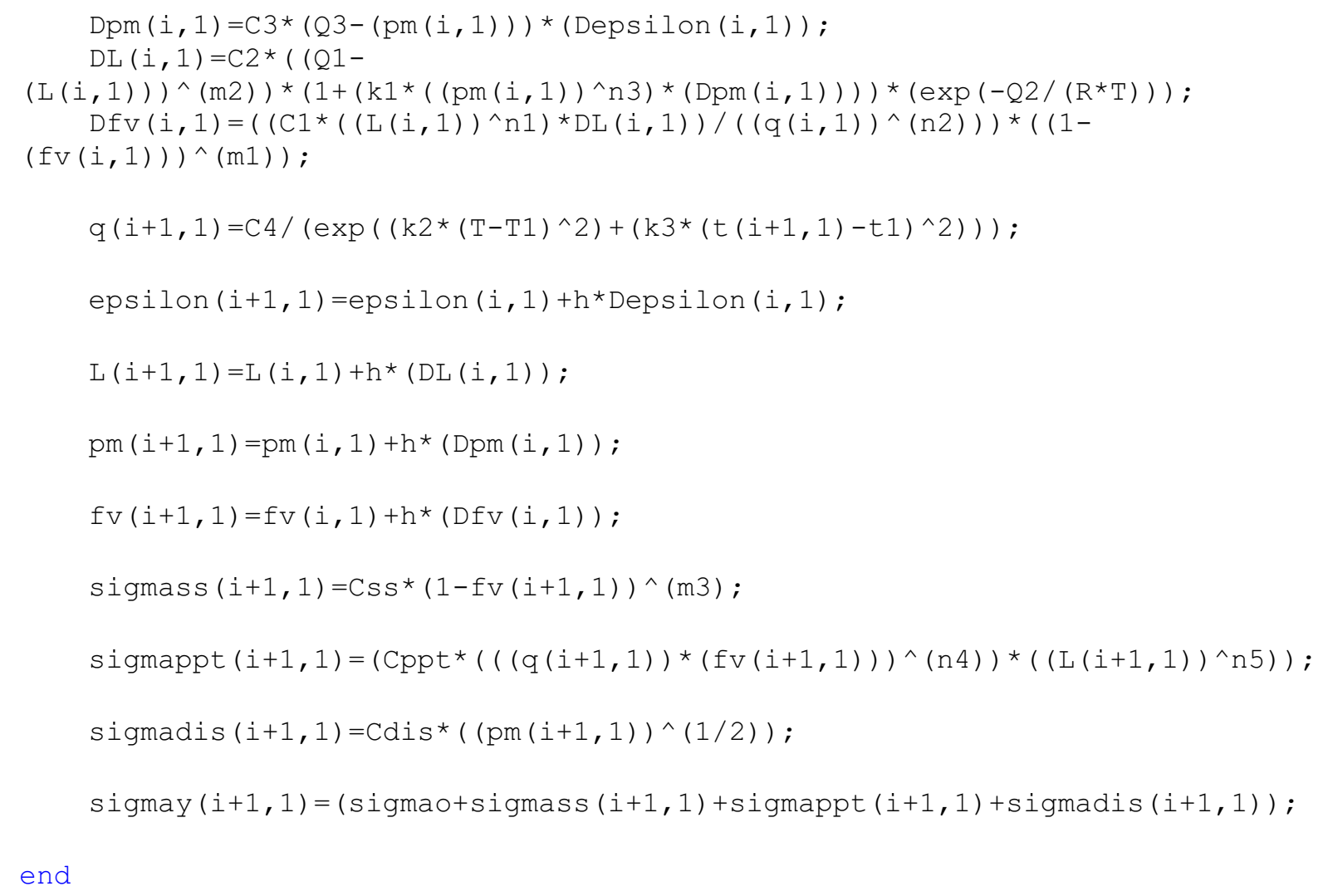

Código do Matlab ® para a integração das equações constitutivas utilizando o método de Runge-Kutta de quarta ordem. O passo de integração aplicado foi 0,1 e o número de incrementos para alcançar o tempo de 12 horas foi 120 .

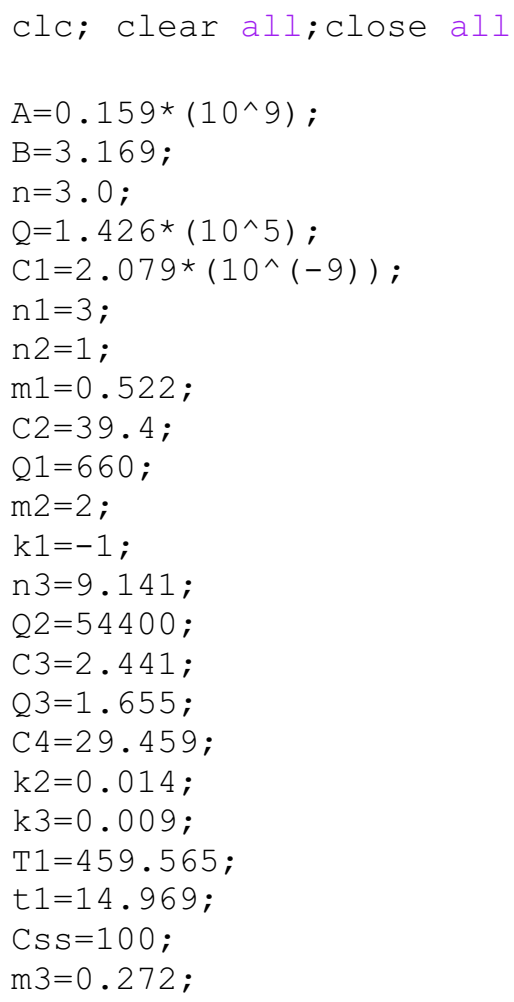




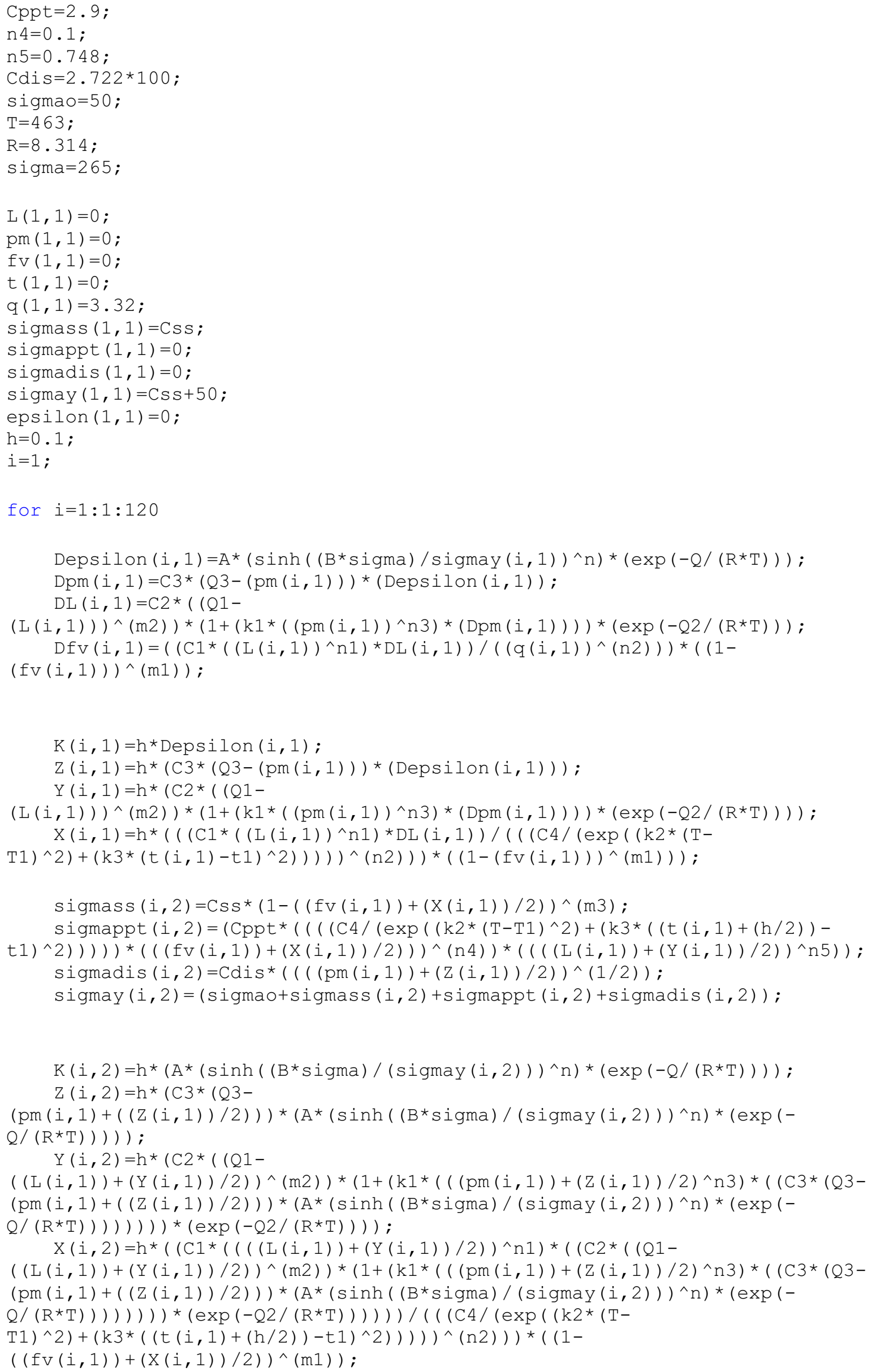


$\operatorname{sigmass}(i, 3)=\mathrm{CsS}^{*}(1-((\mathrm{fv}(i, 1))+(\mathrm{X}(\mathrm{i}, 2)) / 2))^{\wedge}(\mathrm{m} 3)$;

sigmappt $(i, 3)=\left(\operatorname{Cppt}^{*}\left(\left(\left(\left(\mathrm{C} 4 /\left(\exp \left((\mathrm{k} 2 *(\mathrm{~T}-\mathrm{T} 1) \wedge 2)+\left(\mathrm{k} 3^{*}((\mathrm{t}(\mathrm{i}, 1)+(\mathrm{h} / 2))-\right.\right.\right.\right.\right.\right.\right.\right.$

t 1$\left.\left.\left.\left.\left.\left.\left.\left.)^{\wedge} 2\right)\right)\right)\right)\right) *(((\mathrm{fv}(i, 1))+(\mathrm{X}(i, 2)) / 2))\right)^{\wedge}(\mathrm{n} 4)\right) *((((\mathrm{~L}(i, 1))+(\mathrm{Y}(i, 2)) / 2)) \wedge \mathrm{n} 5)\right)$; $\operatorname{sigmadis}(i, 3)=\operatorname{Cdis}^{*}((((\operatorname{pm}(i, 1))+(Z(i, 2)) / 2)) \wedge(1 / 2))$;

$\operatorname{sigmay}(i, 3)=(\operatorname{sigmao}+\operatorname{sigmass}(i, 3)+\operatorname{sigmappt}(i, 3)+\operatorname{sigmadis}(i, 3))$;

$\mathrm{K}(\mathrm{i}, 3)=\mathrm{h} *\left(\mathrm{~A} *\left(\sinh \left(\left(\mathrm{B}^{*} \operatorname{sigma}\right) /(\operatorname{sigmay}(i, 3))\right)^{\wedge} \mathrm{n}\right) *(\exp (-\mathrm{Q} /(\mathrm{R} * \mathrm{~T})))\right)$;

$\mathrm{Z}(\mathrm{i}, 3)=\mathrm{h} *(\mathrm{C} 3 *(\mathrm{Q} 3-$

$(\operatorname{pm}(i, 1)+((Z(i, 2)) / 2))) *(A *(\sinh ((B * \operatorname{sigma}) /(\operatorname{sigmay}(i, 3))) \wedge n) *(\exp (-$ $\mathrm{Q} /(\mathrm{R} * \mathrm{~T})))))$;

$\mathrm{Y}(\mathrm{i}, 3)=\mathrm{h} *(\mathrm{C} 2 *((\mathrm{Q} 1-$

$((\mathrm{L}(i, 1))+(\mathrm{Y}(\mathrm{i}, 2)) / 2)) \wedge(\mathrm{m} 2)) *\left(1+\left(\mathrm{k} 1 *\left(((\mathrm{pm}(\mathrm{i}, 1))+(\mathrm{Z}(\mathrm{i}, 2)) / 2)^{\wedge} \mathrm{n} 3\right) *((\mathrm{C} 3 *(\mathrm{Q} 3-\right.\right.$ $(\operatorname{pm}(i, 1)+((Z(i, 2)) / 2))) *(A *(\sinh ((B * \operatorname{sigma}) /(\operatorname{sigmay}(i, 3))) \wedge n) *(\exp (-$

$\mathrm{Q} /(\mathrm{R} * \mathrm{~T})))))))) *(\exp (-\mathrm{Q} 2 /(\mathrm{R} * \mathrm{~T}))))$;

$\mathrm{X}(\mathrm{i}, 3)=\mathrm{h} *((\mathrm{C} 1 *(((\mathrm{~L}(\mathrm{i}, 1))+(\mathrm{Y}(\mathrm{i}, 2)) / 2)) \wedge \mathrm{n} 1) *((\mathrm{C} 2 *((\mathrm{Q} 1-$

$((\mathrm{L}(i, 1))+(\mathrm{Y}(\mathrm{i}, 2)) / 2)) \wedge(\mathrm{m} 2)) *\left(1+\left(\mathrm{k} 1 *\left(((\mathrm{pm}(\mathrm{i}, 1))+(\mathrm{Z}(\mathrm{i}, 2)) / 2)^{\wedge} \mathrm{n} 3\right) *((\mathrm{C} 3 *(\mathrm{Q} 3-\right.\right.$ $(\operatorname{pm}(i, 1)+((Z(i, 2)) / 2))) *\left(A^{*}\left(\sinh \left(\left(B^{*} \operatorname{sigma}\right) /(\operatorname{sigmay}(i, 3))\right) \wedge n\right) *(\exp (-\right.$ $\mathrm{Q} /(\mathrm{R} * \mathrm{~T})))))))) *(\exp (-\mathrm{Q} 2 /(\mathrm{R} * \mathrm{~T})))))) /(((\mathrm{C} 4 /(\exp ((\mathrm{k} 2 *(\mathrm{~T}-$ $\left.\left.\left.\left.\left.\left.\left.\mathrm{T} 1)^{\wedge} 2\right)+\left(\mathrm{k} 3 *((\mathrm{t}(\mathrm{i}, 1)+(\mathrm{h} / 2))-\mathrm{t} 1)^{\wedge} 2\right)\right)\right)\right)\right)^{\wedge}(\mathrm{n} 2)\right)\right) *((1-$ $\left.((\mathrm{fv}(i, 1))+(\mathrm{X}(i, 2)) / 2))^{\wedge}(\mathrm{m} 1)\right)$;

$\operatorname{sigmass}(i, 4)=\operatorname{Css}^{\star}(1-((\operatorname{fv}(i, 1))+(X(i, 3))))^{\wedge}(\mathrm{m} 3)$;

sigmappt $(i, 4)=(\operatorname{Cppt} *((((\mathrm{C} 4 /(\exp ((k 2 *(\mathrm{~T}-\mathrm{T} 1) \wedge 2)+(\mathrm{k} 3 *((\mathrm{t}(\mathrm{i}, 1)+(\mathrm{h}))-$

t1 $\left.\left.\left.\left.\left.\left.\left.\left.)^{\wedge} 2\right)\right)\right)\right)\right) *(((\mathrm{fv}(i, 1))+(\mathrm{X}(\mathrm{i}, 3))))\right)^{\wedge}(\mathrm{n} 4)\right) *\left((((\mathrm{~L}(\mathrm{i}, 1))+(\mathrm{Y}(\mathrm{i}, 3))))^{\wedge} \mathrm{n} 5\right)\right)$; sigmadis $(i, 4)=\operatorname{Cdis}^{*}\left((((\operatorname{pm}(i, 1))+(Z(i, 3))))^{\wedge}(1 / 2)\right)$;

$\operatorname{sigmay}(i, 4)=(\operatorname{sigmao}+\operatorname{sigmass}(i, 4)+\operatorname{sigmappt}(i, 4)+\operatorname{sigmadis}(i, 4))$;

$\mathrm{K}(\mathrm{i}, 4)=\mathrm{h} *\left(\mathrm{~A} *\left(\sinh \left(\left(\mathrm{B}^{*} \operatorname{sigma}\right) /(\operatorname{sigmay}(i, 4))\right)^{\wedge} \mathrm{n}\right) *(\exp (-Q /(R * T)))\right)$; $\mathrm{Z}(\mathrm{i}, 4)=\mathrm{h} *(\mathrm{C} 3 *(\mathrm{Q} 3-$

$(\operatorname{pm}(i, 1)+((Z(i, 3))))) *\left(A *\left(\sinh \left(\left(B^{*} \operatorname{sigma}\right) /(\operatorname{sigmay}(i, 4))\right) \wedge n\right) *(\exp (-\right.$ $\mathrm{Q} /(\mathrm{R} * \mathrm{~T})))))$;

$\mathrm{Y}(\mathrm{i}, 4)=\mathrm{h} *(\mathrm{C} 2 *((\mathrm{Q} 1-$

$\left.((\mathrm{L}(i, 1))+(\mathrm{Y}(\mathrm{i}, 3))))^{\wedge}(\mathrm{m} 2)\right) *(1+(\mathrm{k} 1 *(((\mathrm{pm}(\mathrm{i}, 1))+(\mathrm{Z}(\mathrm{i}, 3))) \wedge \mathrm{n} 3) *((\mathrm{C} 3 *(\mathrm{Q} 3-$

$(\operatorname{pm}(i, 1)+((Z(i, 3))))) *\left(A^{*}\left(\sinh \left(\left(B^{*} \operatorname{sigma}\right) /(\operatorname{sigmay}(i, 4))\right) \wedge n\right) *(\exp (-\right.$

$\mathrm{Q} /(\mathrm{R} * \mathrm{~T})))))))) *(\exp (-\mathrm{Q} 2 /(\mathrm{R} * \mathrm{~T}))))$;

$\mathrm{X}(\mathrm{i}, 4)=\mathrm{h} *\left(\left(\mathrm{C} 1 *(((\mathrm{~L}(\mathrm{i}, 1))+(\mathrm{Y}(\mathrm{i}, 3))))^{\wedge} \mathrm{n} 1\right) *((\mathrm{C} 2 *((\mathrm{Q} 1-\right.$

$\left.((\mathrm{L}(i, 1))+(\mathrm{Y}(\mathrm{i}, 3))))^{\wedge}(\mathrm{m} 2)\right) *(1+(\mathrm{k} 1 *(((\mathrm{pm}(\mathrm{i}, 1))+(\mathrm{Z}(\mathrm{i}, 3))) \wedge \mathrm{n} 3) *((\mathrm{C} 3 *(\mathrm{Q} 3-$

$(\mathrm{pm}(i, 1)+((\mathrm{Z}(\mathrm{i}, 3))))) *\left(\mathrm{~A}^{*}\left(\sinh \left(\left(\mathrm{B}^{\star} \operatorname{sigma}\right) /(\operatorname{sigmay}(i, 4))\right) \wedge \mathrm{n}\right) *(\exp (-\right.$

$\mathrm{Q} /(\mathrm{R} * \mathrm{~T})))))))) *(\exp (-\mathrm{Q} 2 /(\mathrm{R} * \mathrm{~T})))))) /(((\mathrm{C} 4 /(\exp ((\mathrm{k} 2 *(\mathrm{~T}-$

$\left.\left.\left.\left.\left.\left.\left.\mathrm{T} 1)^{\wedge} 2\right)+\left(\mathrm{k} 3 *((\mathrm{t}(\mathrm{i}, 1)+\mathrm{h})-\mathrm{t} 1)^{\wedge} 2\right)\right)\right)\right)\right)^{\wedge}(\mathrm{n} 2)\right)\right) \star\left((1-((\mathrm{fv}(i, 1))+(\mathrm{X}(i, 3))))^{\wedge}(\mathrm{m} 1)\right)$;

$K(i, 5)=(1 / 6) *((K(i, 1))+2 *(K(i, 2))+2 *(K(i, 3))+(K(i, 4))) ;$
$Z(i, 5)=(1 / 6) *((Z(i, 1))+2 *(Z(i, 2))+2 *(Z(i, 3))+(Z(i, 4))) ;$
$Y(i, 5)=(1 / 6) \star((Y(i, 1))+2 *(Y(i, 2))+2 *(Y(i, 3))+(Y(i, 4))) ;$
$X(i, 5)=(1 / 6) *((X(i, 1))+2 *(X(i, 2))+2 *(X(i, 3))+(X(i, 4))) ;$

epsilon $(i+1,1)=e p s i l o n(i, 1)+K(i, 5)$;

$\mathrm{pm}(i+1,1)=\mathrm{pm}(i, 1)+\mathrm{z}(i, 5)$;

$\mathrm{L}(i+1,1)=\mathrm{L}(i, 1)+\mathrm{Y}(i, 5)$;

$\mathrm{fv}(i+1,1)=\mathrm{fv}(i, 1)+\mathrm{X}(i, 5)$;

$t(i+1,1)=t(i, 1)+h$;

$q(i+1,1)=\left(\mathrm{C} 4 /\left(\exp \left(\left(k 2 *(T-T 1)^{\wedge} 2\right)+\left(k 3 *(t(i+1,1)-t 1)^{\wedge} 2\right)\right)\right)\right)$;

$\operatorname{sigmass}(i+1,1)=\mathrm{Css}^{*}(1-\mathrm{fv}(i+1,1))^{\wedge}(\mathrm{m} 3)$; 
$\operatorname{sigmappt}(i+1,1)=(\operatorname{Cppt} *(((q(i+1,1)) *(f v(i+1,1))) \wedge(n 4)) *((L(i+1,1)) \wedge n 5))$; $\operatorname{sigmadis}(i+1,1)=\operatorname{Cdis}^{*}((\operatorname{pm}(i+1,1)) \wedge(1 / 2))$;

$\operatorname{sigmay}(i+1,1)=(\operatorname{sigmao}+\operatorname{sigmass}(i+1,1)+\operatorname{sigmappt}(i+1,1)+\operatorname{sigmadis}(i+1,1)) ;$

end 
APÊNDICE B - Exemplo de rotinas para realizar o ajuste do modelo da conformação por fluência com envelhecimento aos dados experimentais 
O ajuste do modelo da CFE aos dados experimentais foi realizado no Matlab ${ }^{\circledR}$ a partir da ferramenta de otimização, aplicando o algoritmo genético. Duas rotinas foram criadas, uma contendo o algoritmo para integrar as equações constitutivas e a outra a função objetivo. A Figura 74 mostra um exemplo de rotinas para determinar quatro constantes utilizando os dados da deformação por fluência simulada e experimental.

Figura 74 - Exemplo das rotinas necessárias para realizar o ajuste do modelo e o fluxo de cálculos realizados no Matlab ${ }^{\circledR}$

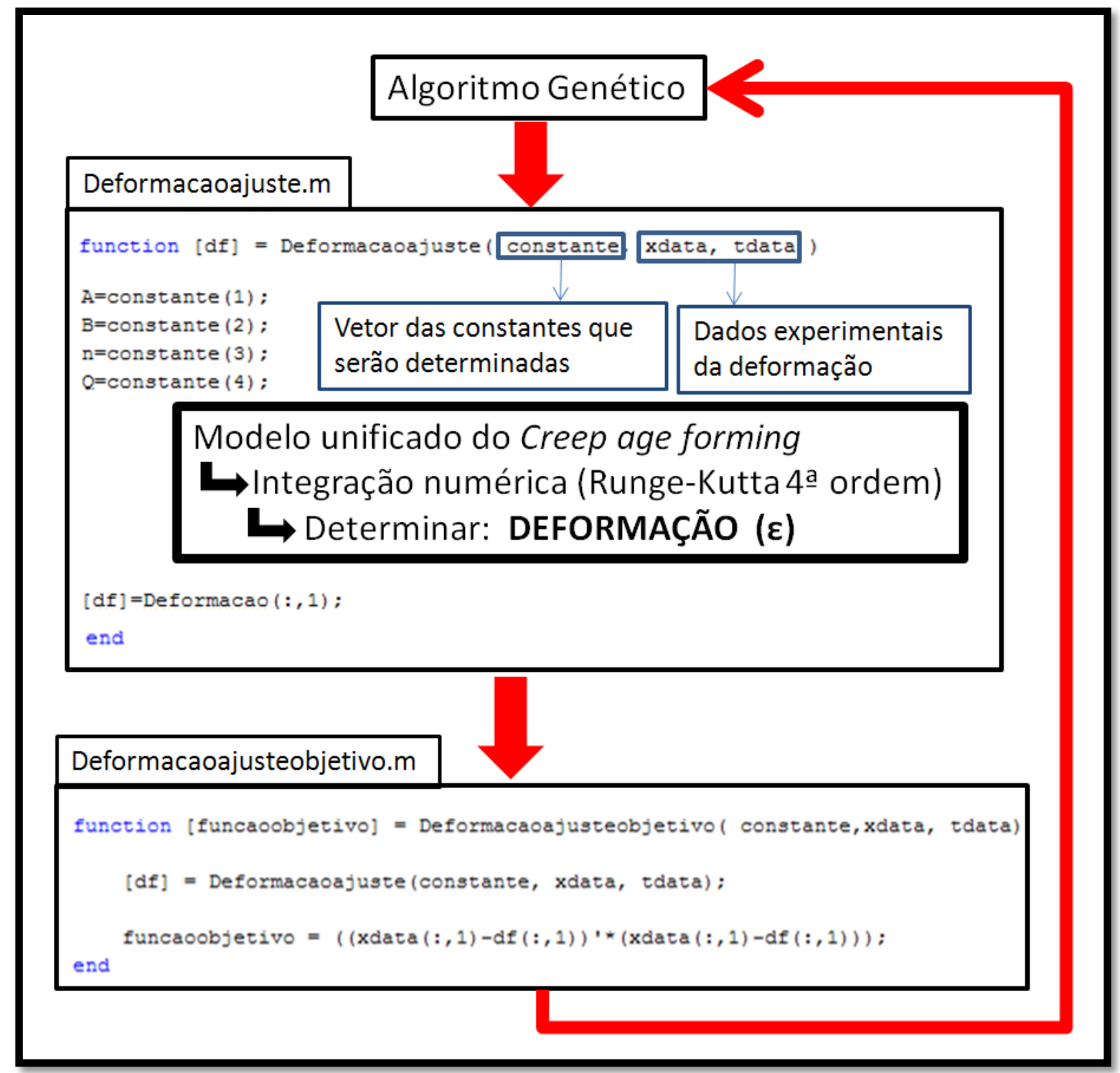

Fonte: Autor

A Figura 74 também demonstra o fluxo de cálculos realizados para determinar as constantes, em que o algoritmo genético inicialmente gera algumas constantes, elas são inseridas na rotina de integração, e nesta rotina é determinada a deformação por fluência. A deformação por fluência simulada é inserida na rotina com a função objetivo que contém a 
soma dos quadrados dos desvios. Os resultados desta última rotina são repassados ao algoritmo genético, o valor da função objetivo é comparado com o valor gerado em outra iteração, de modo a selecionar as constantes que minimizem ao máximo a função objetivo.

Depois de criar as rotinas no Matlab ${ }^{\circledR}$ é configurada a ferramenta de otimização demonstrada na Figura 75. Nesta etapa é selecionado o Solver que é o algoritmo genético, a função que será minimizada, o número de constantes que serão determinadas e os vínculos. Este painel possibilita também configurar os parâmetros relacionados ao algoritmo genético, como, o tamanho da população e o critério de convergência. Quando estiver devidamente configurado, o Solver pode ser iniciado e ele rodará até atingir o critério de convergência.

Figura 75 - Menu da ferramenta de otimização (Optimization Tool)

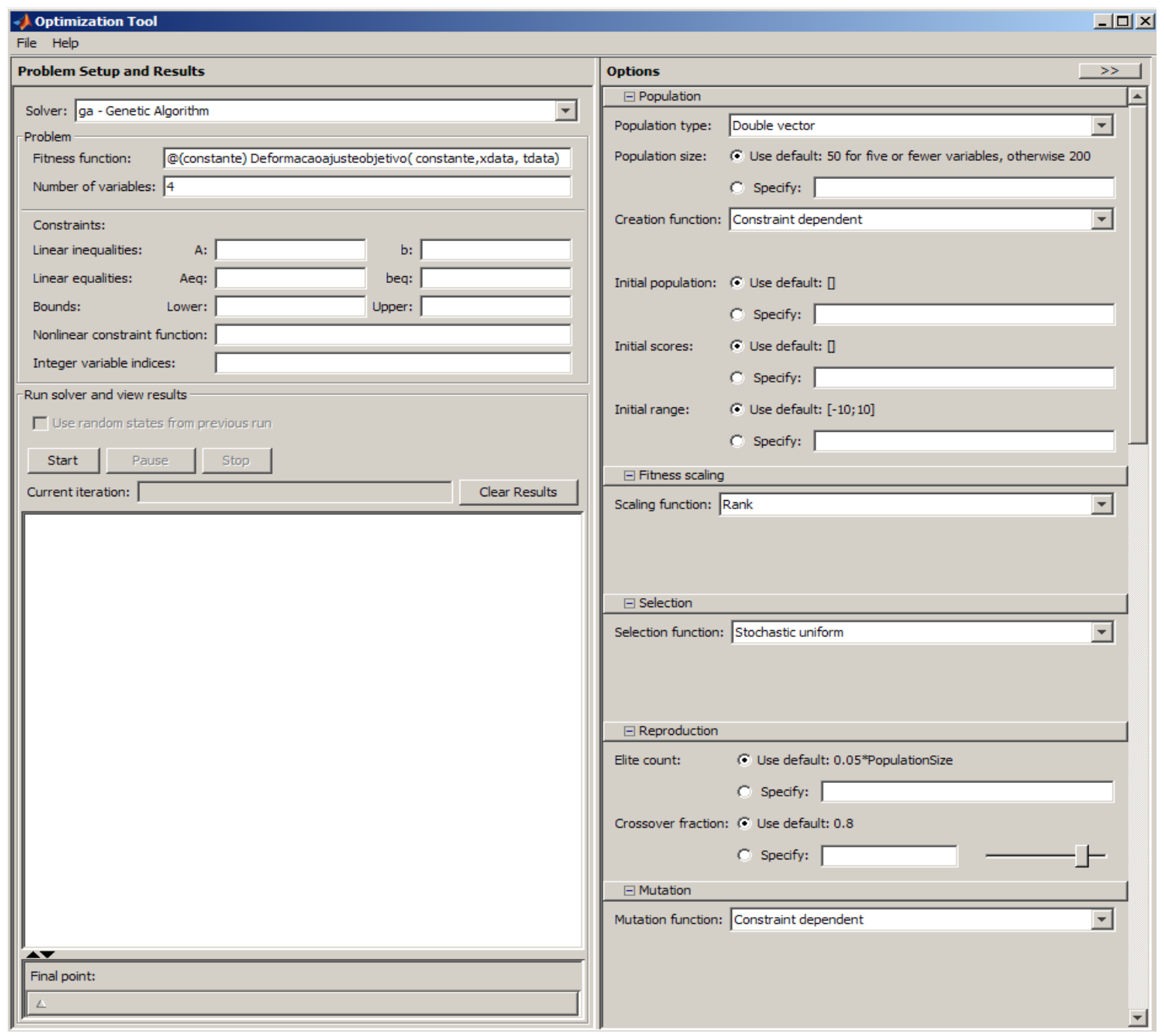

Fonte: Autor 
APÊNDICE C - Sub-rotina da CFE implementada no MSC. Marc ${ }^{\circledR}$ 
subroutine crplaw (eqcp, eqcpnc, s, crpe, t, dt, timinc, cptim, m, nn,

* kc, mat, ndi, nshear)

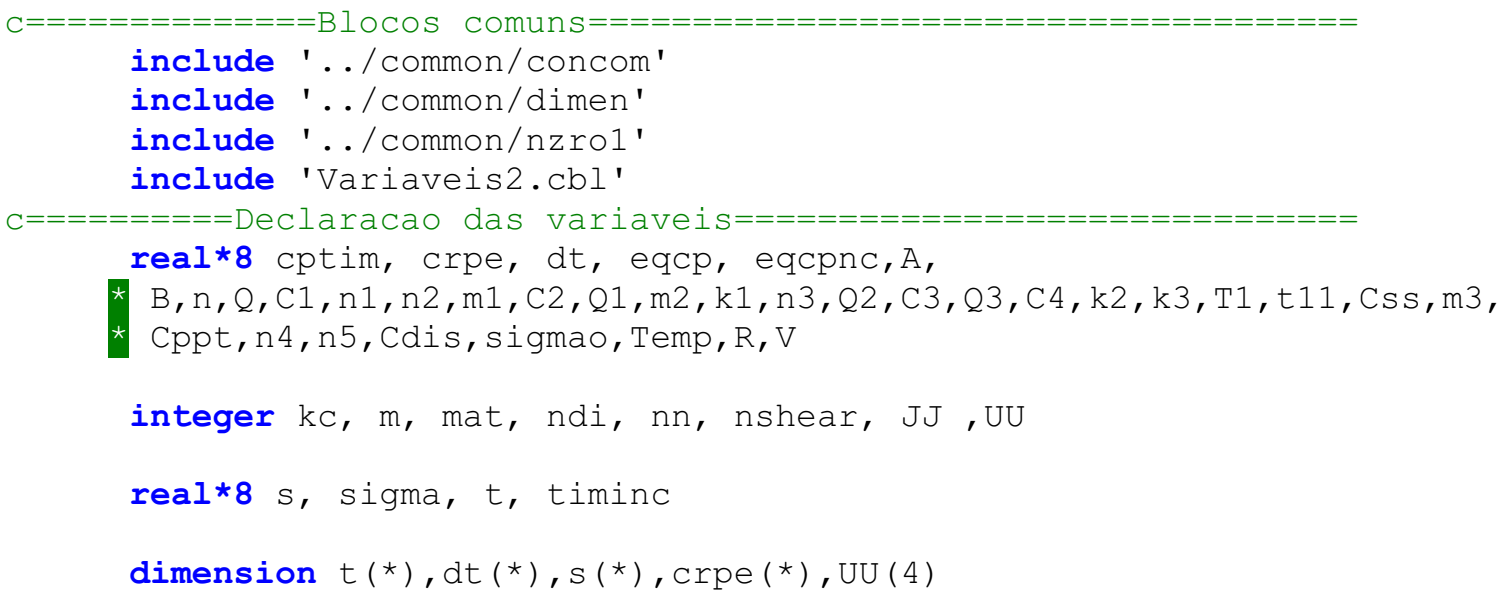




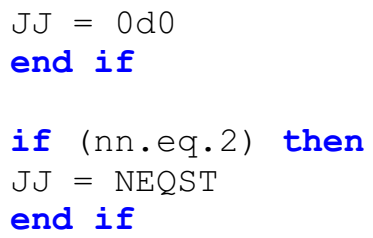

if (inc.GE.2 and. UU(1).eq.inc) then

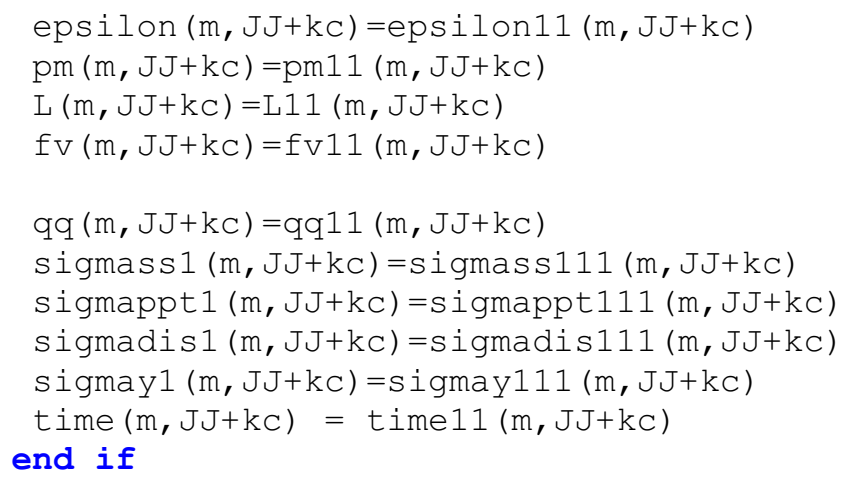


sigmappt2 $(1)=(\operatorname{Cppt} *((((\mathrm{C} 4 /(\exp ((\mathrm{k} 2 *(\mathrm{Temp}-\mathrm{T} 1) * * 2)+$ $*(\mathrm{k} 3 *((\operatorname{cptim}+(\mathrm{h} / 2 \mathrm{~d} 0))-\mathrm{t} 11) * \star 2 \mathrm{~d} 0))))) *(((\mathrm{fv}(\mathrm{m}, \mathrm{JJ}+\mathrm{kc}))+$ $(\mathrm{X}(1)) / 2 \mathrm{~d} 0))) * \star(\mathrm{n} 4)) *((((\mathrm{~L}(\mathrm{~m}, \mathrm{JJ}+\mathrm{kc}))+$

$(\mathrm{Y}(1)) / 2 \mathrm{~d} 0)) * \star \mathrm{n} 5)$ )

sigmadis2 $(1)=\operatorname{Cdis}^{*}((((\mathrm{pm}(\mathrm{m}, \mathrm{J} J+\mathrm{kc}))+$

( ( ( (1) ) / 2d0) )** (1d0/2d0))

sigmay2 $(1)=($ sigmao + sigmass $2(1)+$

*sigmappt2 (1) +sigmadis2 (1))

$\mathrm{K}(2)=\mathrm{h} *(\mathrm{~A} *(\sinh ((\mathrm{B} * \operatorname{sigma}) /(\operatorname{sigmay} 2(1))) * \star \mathrm{n}) *$

$(\exp (-Q /(R * T e m p))))$

$\mathrm{Z}(2)=\mathrm{h} *(\mathrm{C} 3 *(\mathrm{Q} 3-(\mathrm{pm}(\mathrm{m}, \mathrm{JJ}+\mathrm{kc})+((\mathrm{Z}(1)) / 2 \mathrm{~d} 0))) *$

$\left(A^{*}\left(\sinh \left(\left(B^{*} \operatorname{sigma}\right) /(\operatorname{sigmay} 2(1))\right) * * n\right) *\right.$

$(\exp (-Q /(R * T e m p)))))$

$\mathrm{Y}(2)=\mathrm{h} *(\mathrm{C} 2 *((\mathrm{Q} 1-((\mathrm{L}(\mathrm{m}, \mathrm{JJ}+\mathrm{kC}))+$

$*(\mathrm{Y}(1)) / 2 \mathrm{~d} 0)) * *(\mathrm{~m} 2)) *$

$(1 \mathrm{~d} 0+(\mathrm{k} 1 *(((\mathrm{pm}(\mathrm{m}, \mathrm{JJ}+\mathrm{kc}))+(\mathrm{Z}(1)) / 2 \mathrm{~d} 0) * \star \mathrm{n} 3) *((\mathrm{c} 3 *$

$(\mathrm{Q} 3-(\mathrm{pm}(\mathrm{m}, \mathrm{JJ}+\mathrm{kc})+((\mathrm{Z}(1)) / 2 \mathrm{~d} 0))) *\left(\mathrm{~A} *\left(\mathrm{sinh}\left(\left(\mathrm{B}^{*} \mathrm{sigma}\right) /\right.\right.\right.$

$(\operatorname{sigmay2}(1))) * \star n) *(\exp (-Q /(R * T e m p)))))))) *$

$(\exp (-\mathrm{Q} 2 /(\mathrm{R} * \mathrm{Temp}))))$

$\mathrm{X}(2)=\mathrm{h} *((\mathrm{C} 1 *((((\mathrm{~L}(\mathrm{~m}, \mathrm{JJ}+\mathrm{kC}))+$

$(\mathrm{Y}(1)) / 2 \mathrm{~d} 0)) * * \mathrm{n} 1) *$

$((\mathrm{C} 2 *((\mathrm{Q} 1-((\mathrm{L}(\mathrm{m}, \mathrm{JJ}+\mathrm{kC}))+(\mathrm{Y}(1)) / 2 \mathrm{~d} 0)) * \star(\mathrm{m} 2)) *(1 \mathrm{~d} 0+(\mathrm{k} 1 *$

$(((\mathrm{pm}(\mathrm{m}, \mathrm{JJ}+\mathrm{kc}))+(\mathrm{Z}(1)) / 2 \mathrm{~d} 0) * \star \mathrm{n} 3) *$

$((\mathrm{C} 3 *(\mathrm{Q} 3-(\mathrm{pm}(\mathrm{m}, \mathrm{J} \mathrm{J}+\mathrm{kC})+$

$((\mathrm{Z}(1)) / 2 \mathrm{~d} 0))) *\left(\mathrm{~A} *\left(\sinh \left(\left(\mathrm{B}^{*} \operatorname{sigma}\right) /\right.\right.\right.$

$(\operatorname{sigmay} 2(1))) * \star n) *$

$(\exp (-\mathrm{Q} /(\mathrm{R} * \mathrm{Temp})))))))) *(\exp (-\mathrm{Q} 2 /(\mathrm{R} * \mathrm{Temp})))))) /(((\mathrm{C} 4 /$

$(\exp ((\mathrm{k} 2 *(\mathrm{Temp}-\mathrm{T} 1) * * 2 \mathrm{~d} 0)+(\mathrm{k} 3 *((\mathrm{cptim}+(\mathrm{h} / 2 \mathrm{~d} 0))-$

$(11) * \star 2 \mathrm{~d} 0))))) * \star(\mathrm{n} 2))) *((1 \mathrm{~d} 0-((\mathrm{fv}(\mathrm{m}, \mathrm{JJ}+\mathrm{kc}))+$

$(\mathrm{X}(1)) / 2 \mathrm{~d} 0)) * *(\mathrm{~m} 1))$

$\operatorname{sigmass} 2(2)=\mathrm{Css}^{*}(1 \mathrm{~d} 0-((\mathrm{fv}(\mathrm{m}, \mathrm{J} J+\mathrm{kc}))+$

$(\mathrm{X}(2)) / 2 \mathrm{~d} 0)) * \star(\mathrm{m} 3)$

sigmappt2 $(2)=($ Cppt* $((((\mathrm{C} 4 /(\exp ((\mathrm{k} 2 *(\mathrm{Temp}-\mathrm{T} 1) * \star 2 \mathrm{~d} 0)+$ $(\mathrm{k} 3 *((\operatorname{cptim}+(\mathrm{h} / 2 \mathrm{~d} 0))-\mathrm{t} 11) * \star 2 \mathrm{~d} 0))))) *(((\mathrm{fv}(\mathrm{m}, \mathrm{JJ}+\mathrm{kc}))+$

$(\mathrm{X}(2)) / 2 \mathrm{~d} 0))) * \star(\mathrm{n} 4)) *((((\mathrm{~L}(\mathrm{~m}, \mathrm{JJ}+\mathrm{kc}))+$

$(\mathrm{Y}(2)) / 2 \mathrm{~d} 0)) * \star \mathrm{n} 5))$

sigmadis2 $(2)=\operatorname{Cdis} *((((\mathrm{pm}(\mathrm{m}, \mathrm{JJ}+\mathrm{kc}))+$

$*(\mathrm{Z}(2 \mathrm{)}) / 2 \mathrm{~d} 0)) * \star(1 \mathrm{~d} 0 / 2 \mathrm{~d} 0))$

sigmay2 $(2)=($ sigmao+sigmass $2(2)+$

* sigmappt2 (2) +sigmadis2 (2))

$\mathrm{K}(3)=\mathrm{h} *\left(\mathrm{~A} *\left(\sinh \left(\left(\mathrm{B}^{*} \operatorname{sigma}\right) /\right.\right.\right.$

* $(\operatorname{sigmay} 2(2))) * \star n) *(\exp (-Q /(R * T e m p))))$

$\mathrm{Z}(3)=\mathrm{h} *(\mathrm{C} 3 *(\mathrm{Q} 3-(\mathrm{pm}(\mathrm{m}, \mathrm{JJ}+\mathrm{kc})+((\mathrm{Z}(2)) /$

(2d0)) $)$ * $\left(A *\left(\sinh \left(\left(B^{*} \operatorname{sigma}\right) /(\operatorname{sigmay} 2(2))\right) * \star n\right) *\right.$

$(\exp (-Q /(R * T e m p)))))$

$\mathrm{Y}(3)=\mathrm{h} *(\mathrm{C} 2 *((\mathrm{Q} 1-((\mathrm{L}(\mathrm{m}, \mathrm{JJ}+\mathrm{kC}))+$

$(\mathrm{Y}(2)) / 2 \mathrm{~d} 0)) \star \star(\mathrm{m} 2)) *$

$(1 \mathrm{~d} 0+(\mathrm{k} 1 *(((\mathrm{pm}(\mathrm{m}, \mathrm{J} J+\mathrm{kc}))+(\mathrm{Z}(2)) / 2 \mathrm{~d} 0) * * \mathrm{n} 3) *$

$((\mathrm{C} 3 *(\mathrm{Q} 3-(\mathrm{pm}(\mathrm{m}, \mathrm{J} \mathrm{J}+\mathrm{kc})+$

$((\mathrm{Z}(\mathrm{Z})) / 2 \mathrm{~d} 0))) *(\mathrm{~A} *$

$\left(\sinh \left(\left(B^{*} \operatorname{sigma}\right) /(\operatorname{sigmay} 2(2))\right) * * n\right) *$

$(\exp (-\mathrm{Q} /(\mathrm{R} * \mathrm{Temp})))))))) *(\exp (-\mathrm{Q} 2 /(\mathrm{R} * \mathrm{Temp}))))$

$\mathrm{X}(3)=\mathrm{h} *\left(\left(\mathrm{C} 1^{*}((((\mathrm{~L}(\mathrm{~m}, \mathrm{JJ}+\mathrm{kC}))+\right.\right.$

$(\mathrm{Y}(2)) / 2 \mathrm{~d} 0)) \star \star n n 1) *$

$((\mathrm{C} 2 *((\mathrm{Q} 1-((\mathrm{L}(\mathrm{m}, \mathrm{JJ}+\mathrm{kC}))+(\mathrm{Y}(2)) / 2 \mathrm{~d} 0)) * *(\mathrm{~m} 2)) *(1 \mathrm{~d} 0+(\mathrm{k} 1 *$

$(((\mathrm{pm}(\mathrm{m}, \mathrm{JJ}+\mathrm{kc}))+(\mathrm{Z}(2)) / 2 \mathrm{~d} 0) * \star \mathrm{n} 3) *$ 
$((\mathrm{C} 3 *(\mathrm{Q} 3-(\mathrm{pm}(\mathrm{m}, \mathrm{JJ}+\mathrm{kc})+$

$((\mathrm{Z}(2)) / 2 \mathrm{~d} 0))) *\left(\mathrm{~A} *\left(\sinh \left(\left(\mathrm{B}^{*} \operatorname{sigma}\right) /\right.\right.\right.$

$(\operatorname{sigmay} 2(2))) * \star n) *$

$(\exp (-\mathrm{Q} /(\mathrm{R} * \mathrm{Temp})))))))) *(\exp (-\mathrm{Q} 2 /(\mathrm{R} * \mathrm{Temp})))))) /(((\mathrm{C} 4 /(\exp ((\mathrm{k} 2 *$

$($ Temp-T1)**2) $+(\mathrm{k} 3 *((\operatorname{cptim}+(\mathrm{h} / 2 \mathrm{~d} 0))-\mathrm{t} 11) \star \star 2))))) * \star(\mathrm{n} 2))) *$

$((1 \mathrm{~d} 0-((\mathrm{fv}(\mathrm{m}, \mathrm{JJ}+\mathrm{kc}))+(\mathrm{X}(2)) / 2 \mathrm{do})) * \star(\mathrm{m} 1))$

sigmass2 $(3)=\mathrm{Css}^{*}(1 \mathrm{~d} 0-((\mathrm{fv}(\mathrm{m}, \mathrm{JJ}+\mathrm{kc}))+$

(X(3)) )) $* *(\mathrm{~m} 3)$

sigmappt2 $(3)=\left(\operatorname{Cppt}^{*}((((\mathrm{C} 4 /(\exp ((\mathrm{k} 2 *(\mathrm{Temp}-\mathrm{T} 1) * \star 2)+\right.$

$(k 3 *((\operatorname{cptim}+(\mathrm{h}))-t 11) * * 2))))) *(((\mathrm{fv}(\mathrm{m}, \mathrm{JJ}+\mathrm{kc}))+$

$(\mathrm{X}(3 \mathrm{)})))) * \star(\mathrm{n} 4)) *((((\mathrm{~L}(\mathrm{~m}, \mathrm{JJ}+\mathrm{kc}))+$

$(\mathrm{Y}(3)))) * * n 5))$

sigmadis2 $(3)=\operatorname{Cdis}^{*}((((\mathrm{pm}(\mathrm{m}, \mathrm{JJ}+\mathrm{kc}))+$

$(\mathrm{z}(3)))) * \star(1 \mathrm{~d} 0 / 2 \mathrm{~d} 0))$

sigmay2 $(3)=($ sigmao+sigmass $2(3)+$

* sigmappt2 (3) +sigmadis2 (3))

$\mathrm{K}(4)=\mathrm{h} *\left(\mathrm{~A} *\left(\sinh \left(\left(\mathrm{B}^{*} \operatorname{sigma}\right) /\right.\right.\right.$

* $(\operatorname{sigmay} 2(3))) * \star n) *(\exp (-Q /(R * T e m p))))$;

$\mathrm{Z}(4)=\mathrm{h} *(\mathrm{C} 3 *(\mathrm{Q} 3-(\mathrm{pm}(\mathrm{m}, \mathrm{JJ}+\mathrm{kC})+((\mathrm{Z}(3))))) *$

* $\left(A^{*}\left(\sinh \left(\left(B^{*} \operatorname{sigma}\right) /(\operatorname{sigmay} 2(3))\right) * * n\right) *\right.$

$\left.\left.\left(\exp \left(-Q /\left(R^{*} \mathrm{Temp}\right)\right)\right)\right)\right)$

$Y(4)=h *(C 2 *((Q 1-((\mathrm{L}(\mathrm{m}, \mathrm{JJ}+\mathrm{kC}))+$

$(\mathrm{Y}(3)))) * *(\mathrm{~m} 2)) *(1 \mathrm{~d} 0+(\mathrm{k} 1 *(((\mathrm{pm}(\mathrm{m}, \mathrm{JJ}+\mathrm{kc}))+$

$(\mathrm{Z}(3))) * \star \mathrm{n} 3) *((\mathrm{C} 3 *(\mathrm{Q} 3-(\mathrm{pm}(\mathrm{m}, \mathrm{JJ}+\mathrm{kc})+$

$((Z(3))))) *$

$\left(A^{*}\left(\sinh \left(\left(B^{*} \operatorname{sigma}\right) /(\operatorname{sigmay} 2(3))\right) * * n\right) *\right.$

$(\exp (-\mathrm{Q} /(\mathrm{R} * \mathrm{Temp})))))))) *(\exp (-\mathrm{Q} 2 /(\mathrm{R} * \mathrm{Temp}))))$

$\mathrm{X}(4)=\mathrm{h} *((\mathrm{C} 1 *((((\mathrm{~L}(\mathrm{~m}, \mathrm{JJ}+\mathrm{kC}))+(\mathrm{Y}(3)))) * * \mathrm{n} 1) *$

$((\mathrm{C} 2 *((\mathrm{Q} 1-((\mathrm{L}(\mathrm{m}, \mathrm{JJ}+\mathrm{kC}))+(\mathrm{Y}(3)))) * *(\mathrm{~m} 2)) *$

$(1 \mathrm{~d} 0+(\mathrm{k} 1 *(((\mathrm{pm}(\mathrm{m}, \mathrm{JJ}+\mathrm{kc}))+(\mathrm{Z}(3))) * \star \mathrm{n} 3) *$

$\left(\left(\mathrm{C} 3 *(\mathrm{Q} 3-(\mathrm{pm}(\mathrm{m}, \mathrm{JJ}+\mathrm{kC})+((\mathrm{Z}(3))))) *\left(\mathrm{~A}^{*}\left(\mathrm{sinh}\left(\left(\mathrm{B}^{*} \mathrm{sigma}\right)\right)\right.\right.\right.\right.$

$(\operatorname{sigmay} 2(3))) * \star n) *(\exp (-Q /(R * T e m p)))))))) *$

$(\exp (-\mathrm{Q} 2 /(\mathrm{R} * \mathrm{Temp})))))) /(((\mathrm{C} 4 /(\exp ((\mathrm{k} 2 *(\mathrm{Temp}-\mathrm{T} 1) * * 2 \mathrm{~d} 0)+$

$(k 3 *(($ cptim+h $)-t 11) * * 2 d 0))))) * *(n 2))) *((1 d 0-((f v(m, J J+k c))+$

$(\mathrm{X}(3)))) \star \star(\mathrm{m} 1))$

$K(5)=(1 \mathrm{~d} 0 / 6 \mathrm{~d} 0) *((\mathrm{~K}(1))+$

$2 \mathrm{do} *(\mathrm{~K}(2))+2 \mathrm{do} *(\mathrm{~K}(3))+(\mathrm{K}(4)))$

$Z(5)=(1 d 0 / 6 d 0) *((Z(1))+$

* $2 \mathrm{~d} 0 *(\mathrm{Z}(2))+2 \mathrm{~d} 0 *(\mathrm{Z}(3))+(\mathrm{Z}(4)))$

$Y(5)=(1 d 0 / 6 d 0) *((Y(1))+$

$\star 2 \mathrm{~d} 0 *(\mathrm{Y}(2))+2 \mathrm{~d} 0 *(\mathrm{Y}(3))+(\mathrm{Y}(4)))$

$\mathrm{X}(5)=(1 \mathrm{~d} 0 / 6 \mathrm{~d} 0) *((\mathrm{X}(1))+2 \mathrm{~d} 0 *(\mathrm{X}(2))+$

$* 2 \mathrm{~d} 0 *(\mathrm{X}(3))+(\mathrm{X}(4)))$

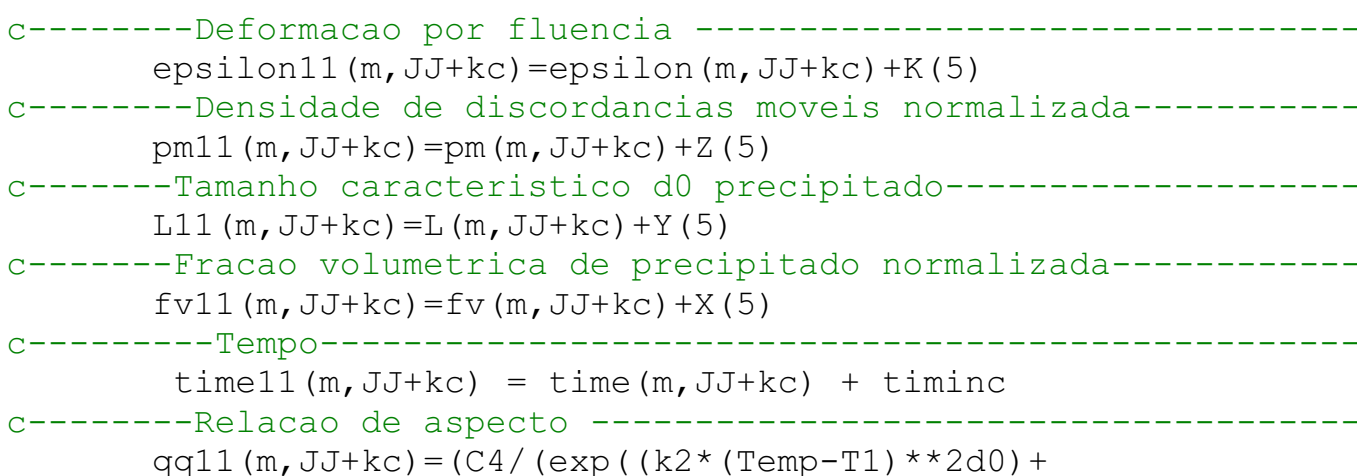




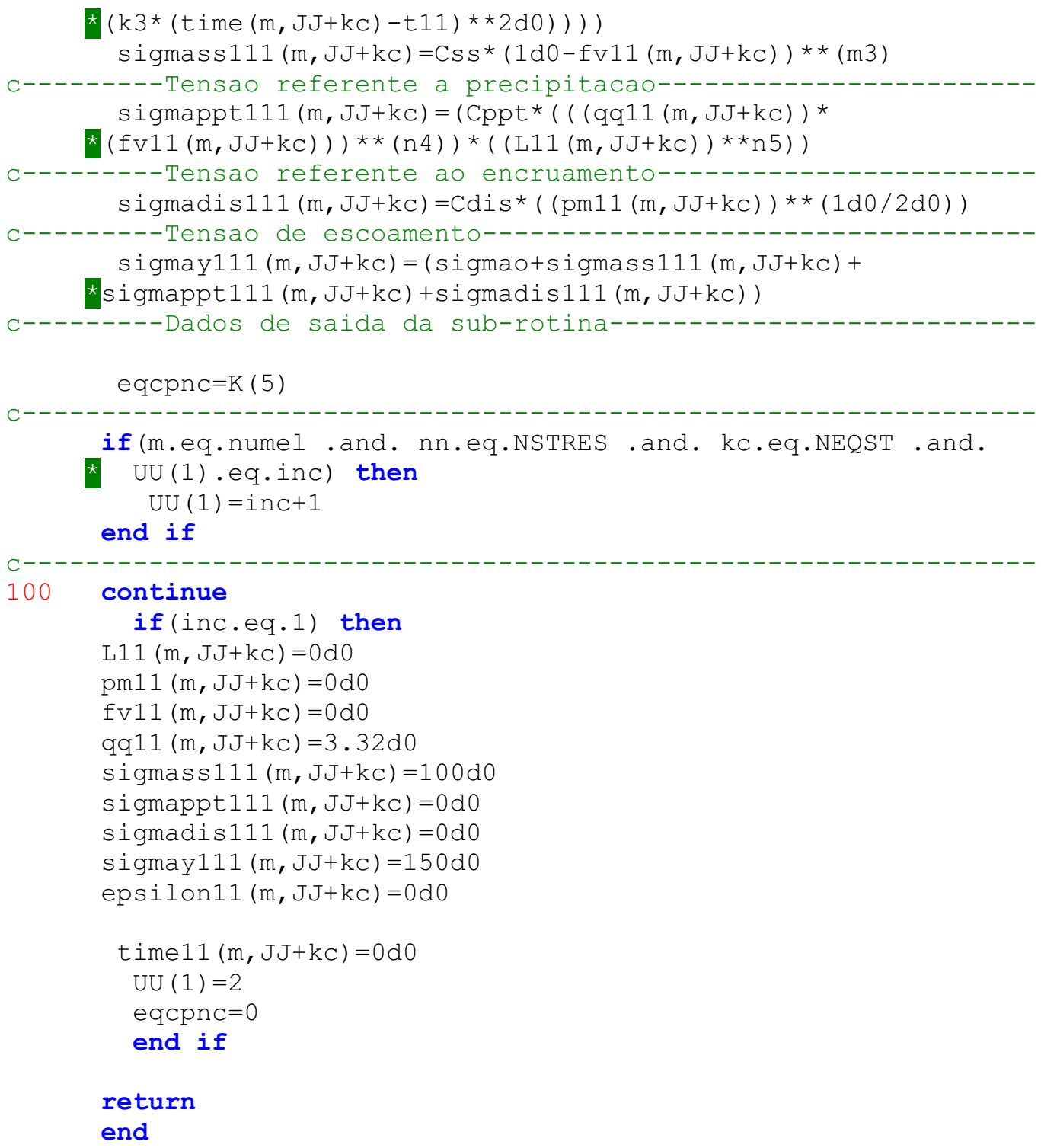

É importante destacar que no incremento de número 1 na sub-rotina o valor do tempo é igual a zero.

O bloco comum 'Variaveis2.cbl' designado na sub-rotina foi criado para armazenar as variáveis, o código é demonstrado a seguir:

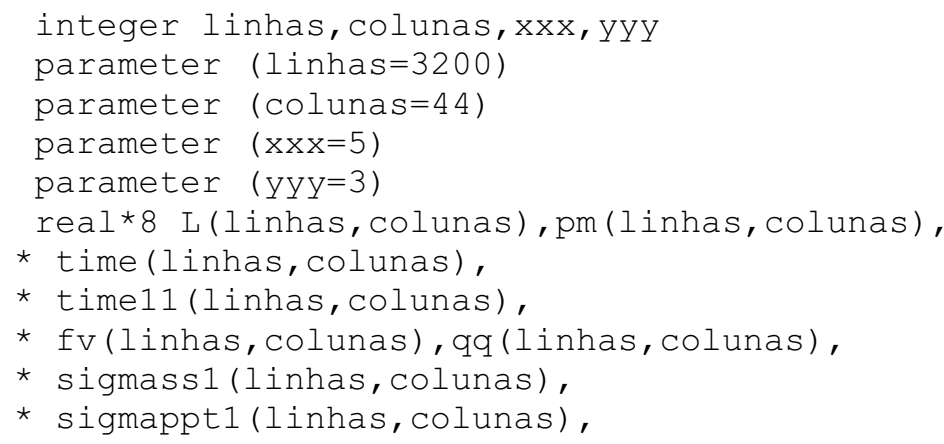


* sigmadis1 (linhas, colunas), sigmayl (linhas, colunas),

* sigmass2 (YYy),

* sigmappt2 (yyy),

* sigmadis2 (ууу), sigmay2 (ууy),

* epsilon(linhas, colunas),DL,Dpm,Dfv, Depsilon,

* $\mathrm{X}(\mathrm{xxx}), \mathrm{Y}(\mathrm{xxx}), \mathrm{Z}(\mathrm{xxx}), \mathrm{K}(\mathrm{xxx})$,

* L11 (linhas, colunas), pm11 (linhas, colunas),

* fv11 (linhas, colunas), qq11 (linhas, colunas),

* sigmassil1 (linhas, colunas),

* sigmappt111 (linhas, colunas),

* sigmadis111 (linhas, colunas), sigmay111(linhas, colunas),

* epsilon11 (linhas, colunas)

common /Variaveis/ L, pm, fv, qq,

* sigmass1, sigmappt1,

* sigmadis1, sigmayl, epsilon, DL, Dpm, Dfv, Depsilon,

* $\mathrm{X}, \mathrm{Y}, \mathrm{Z}, \mathrm{K}, \mathrm{h}$,

* L11, pm11, fv11, qq11,

* sigmass111, sigmappt111,

* sigmadis111, sigmay111, epsilon11

O comando parameter (linhas=3200), o valor dentro dos parênteses deve ser o número de elementos utilizados na análise.

O comando parameter (colunas $=44$ ), o valor dentro dos parênteses deve ser o número de pontos de integração do elemento vezes o número de camadas. 